\title{
ESTUDO DAS VIBRAÇÕES EM PEÇAS DE BAIXA RIGIDEZ NO PROCESSO DE RETIFICAÇÃO CILÍNDRICA EXTERNA DE ALTA VELOCIDADE UTILIZANDO REBOLO DE CBN
}

\author{
THIAGO VALLE FRANÇA
}

Tese apresentada à Escola de Engenharia de São Carlos da Universidade de São Paulo, como parte dos requisitos para obtenção do título de Doutor em Engenharia de Produção.

Orientador: Professor Titular João Fernando Gomes de Oliveira

São Carlos

2009 
AUTORIZO A REPRODUÇÃO E DIVULGAÇÃO TOTAL OU PARCIAL DESTE TRABALHO, POR QUALQUER MEIO CONVENCIONAL OU ELETRÔNICO, PARA FINS DE ESTUDO E PESQUISA, DESDE QUE CITADA A FONTE.

Ficha catalográfica preparada pela Seção de Tratamento da Informação do Serviço de Biblioteca - EESC/USP

França, Thiago Valle

Estudo de vibrações em peças de baixa rigidez no processo de retificação cilíndrica externa de alta velocidade utilizando rebolo de CBN / Thiago Valle França ; orientador João Fernando Gomes de Oliveira. -- São Carlos, 2009 .

Tese (Doutorado-Programa de Pós-Graduação e Área de Concentração em Engenharia de Produção) -- Escola de Engenharia de São Carlos da Universidade de São Paulo, 2009 .

1. Retificação. 2. Vibração. 3. Desgaste. 4. CBN. I. Título. 


\section{FOLHA DE JULGAMENTO}

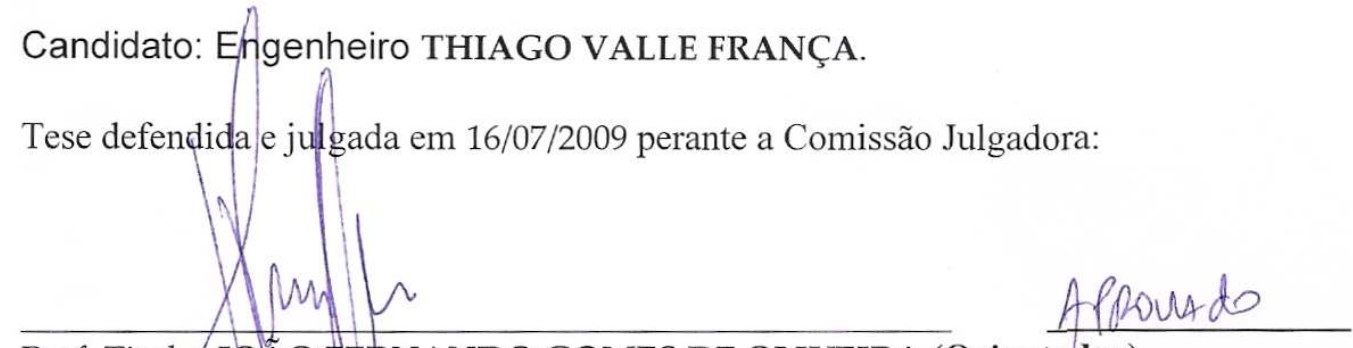

Prof. Titular JOÃO FERNANDO GOMES DE OLIVEIRA (Orientador)

(Escola de Engerharia de São Carlos/USP)

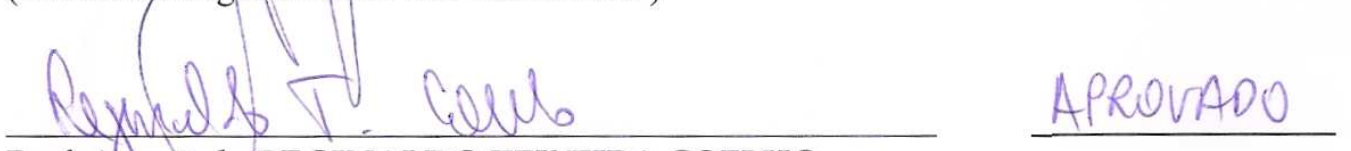

Prof. Asşociado REGINALDO TEIXEIRA COELHO

(Escola de Engenharia, de São Carlos/USP)
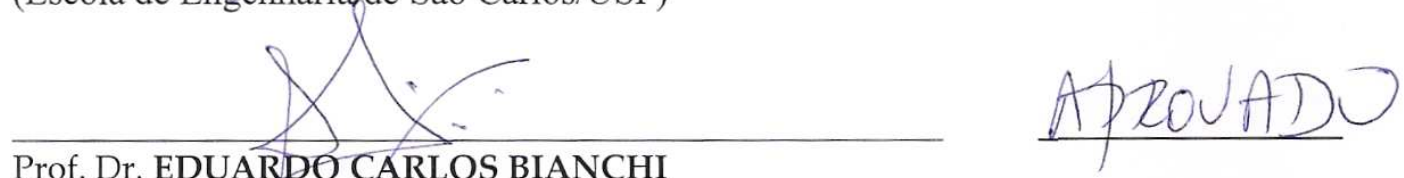

Prof. Dr. EDUARDO CARLOS BIANCHI

(Universidade Estadual Paulista "Julio de Mesquita Filho"/UNESP/Campus de Bauru)

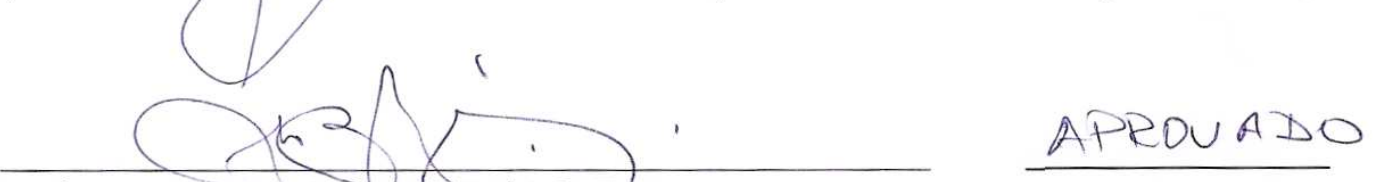

Prof. Dr. PAULO ROBERTO DE AGUIAR

(Universidade Estadual Paulista "Julio de Mesquita Filho"/UNESP/Campus de Bauru)

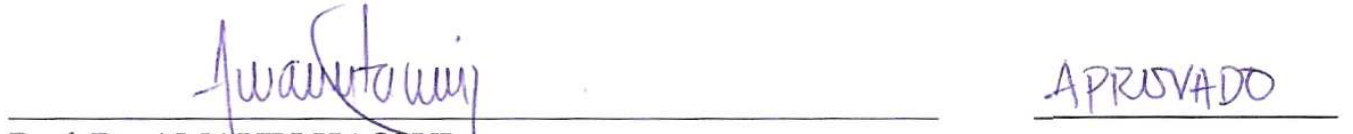

Prof. Dr. AMAURI HASSUI

(Universidade Estadual de Campinas/UNICAMP)

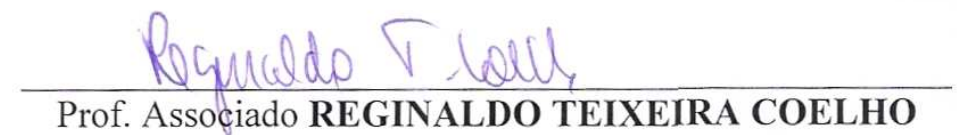

Prof. Associado REGINALDO TEIXEIRA COELHO

Coordenador do Programa de Pós-Graduação em

Engenharia de Produção

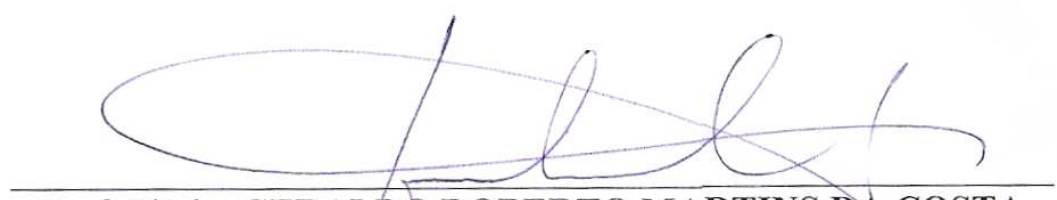

Prof. Titular GERALDO ROBERTO MARTINS DA COSTA Presidente da Comissão da Pós-Graduação da EESC 



\section{DEDICATÓRIA}

Aos meus pais, Carlos Alberto França de Oliveira e Conceição de Maria Valle França, e as minhas queridas irmãs, Carla Valle França e Carolina Valle França. 


\section{AGRADECIMENTOS}

Agradeço primeiramente e especialmente a Deus por ter me concedido saúde, disposição e capacidade para a realização desta pesquisa científica.

Agradeço ao meu orientador, Professor Titular João Fernando Gomes de Oliveira, pelo constante auxílio, amizade e confiança em meu potencial acadêmico, apoiando e me incentivando durante toda a realização deste trabalho.

Ao Professor Associado Reginaldo Teixeira Coelho, pelo apoio constante e pelas diversas discussões que em muito me ajudaram para a conclusão deste trabalho.

Aos docentes do Departamento de Engenharia Mecânica da USP de São Carlos, que de forma direta ou indiretamente contribuíram para esta pesquisa, notoriamente, aos Professores Carlos Alberto Fortulan, Paulo Sérgio Varoto e Zilda de Castro Silveira. Em especial para o Professor Luiz Carlos Felício, pela amizade e auxílio.

À Universidade Estadual de Campinas - UNICAMP, em especial aos professores Anselmo Eduardo Diniz e Amauri Hassui que gentilmente cederam as dependências e recursos do Laboratório de Usinagem, da Faculdade de Engenharia Mecânica, para a conclusão deste trabalho.

À todos os colegas do Laboratório OPF - Otimização de Processos de Fabricação, que proporcionaram um ambiente excepcional de amizade, cooperação e trabalho. Em 
especial aos amigos Adolfo Ferrarin Neto (técnico do laboratório), Alex Camilli Bottene e Gustavo Batista de Lima que ajudaram na execução deste trabalho por diversas vezes.

Agradeço às seguintes empresas: Zema (construção, doação e instalação da retificadora de alta velocidade), GE Fanuc (doação do CNC da retificadora), Saint Gobain (doação de rebolos, sistema de dressagem e disco dressador), Sensis (doação do sistema de mapeamento acústico), Micro Química (doação do fluido de corte) e TRW (doação dos corpos-se-prova)

À FAPESP - Fundação de Amparo à Pesquisa do Estado de São Paulo, pela concessão da Bolsa de Doutorado e Reserva Técnica, essenciais para realização desta pesquisa.

Aos meus companheiros de república Alexandre Tácito Malavolta, Américo Guelere Filho, Ricardo Arai e Federico Martinez Aneiro pelas conversas proveitosas, constante presença e apoio em todos os momentos.

E por fim, agradeço aos companheiros de longa data, sempre concentrados na árdua tarefa de me mostrar o caminho mais correto e justo. 


\section{RESUMO}

O objetivo deste trabalho é estudar as interações dinâmicas entre um rebolo de CBN vitrificado e a peças de baixa rigidez estrutural na retificação de alta velocidade utilizando materiais difíceis de retificar (DTG). Este problema é característico da retificação de válvulas de motores à combustão interna. O banco de testes utilizado foi uma retificadora cilíndrica de altas velocidades de corte junto com um sistema de vibração composto por excitador eletrodinâmico e amplificador. A máquina foi equipada com sensores de emissão acústica, aceleração, potência e proximidade. Além disso, foram utilizados dois sistemas para a aquisição dos sinais, sendo um computador para a aquisição da emissão acústica, rotação do rebolo e potência consumida e o outro para a aquisição dos sinais de aceleração e geração do sinal para o excitador eletrodinâmico. Experimentos foram realizados no intuito de observar a influência das vibrações no desgaste do rebolo. A influência da força tangencial por grão abrasivo foi investigada como uma importante variável de controle na determinação da relação G. As medições dos sinais de emissão acústica, potência e vibração ajudaram na identificação da relação entre as interações dinâmicas (produzidas pela excitação forçada aleatória) e o desgaste da ferramenta. O fenômeno do chatter regenerativo (vibração autoexcitada) foi observado utilizando o método do mapa acústico. Os resultados indicam que existe um valor limite de velocidade de vibração acima do qual ocorre uma mudança do mecanismo predominante de desgaste do rebolo. Outro importante fenômeno observado é a mudança de característica do rebolo quando ocorre excitação forçada no processo, fazendo com que o rebolo atue como uma ferramenta de maior grão abrasivo.

Palavras-chave: retificação, vibração, desgaste, CBN. 


\section{ABSTRACT}

The aim of this work is to study the wheel/workpiece dynamic interactions in high speed grinding using vitrified CBN wheel and low stiffness workpieces made of difficult-to-grind (DTG) materials. This problem is typical in the grinding of engine valve heads. The test bench used is a high speed grinding machine with an excitation system composed of an electrodynamic exciter (shaker) and an amplifier. The machine was equipped with acoustic emission, acceleration, power and proximity sensors. Two different systems were used to perform the acquisition of these signals, with one computer being utilized to acquire the acoustic emission, power and rotary signals and another in charge of acquiring the acceleration signal as well as generating the excitation signal to the shaker. Experiments were carried out to observe the influence of vibrations in the wheel wear. The influence of tangential force per abrasive grain was investigated as an important control variable for the determination of $\mathrm{G}$ ratio. The measurements of acoustic emission, power and vibration signals helped in identifying the correlation between the dynamic interactions (produced by forced random excitation) and the wheel wear. The wheel regenerative chatter phenomenon was observed by using the wheel mapping technique. The results indicate the existence of a vibration velocity limit value above which there is a change in the major wear mechanism of the wheel. Another important observed phenomenon, when the process is dynamically excited, is the modification of the chip formation mechanism which makes the wheel to work as a rougher toll.

Keywords: grinding, chatter, wear, CBN. 


\section{LISTA DE FIGURAS}

Figura 2.1 - Formação do cavaco na retificação (König e Klocke, 1996 apud Kopac e Krajnik, 2006 - Adaptada) 8

Figura 2.2 - Retificação cilíndrica externa de mergulho (Malkin, 1989 - Adaptada) 9

Figura 2.3 - O efeito da velocidade de corte, ou velocidade tangencial do rebolo, na potência consumida pelo motor do rebolo (Werner, 1995 apud Jackson et al., 2001 Adaptada).

Figura 2.4 - Níveis do consumo da $P_{v}, P_{f}$, e $P_{l}$ para retificação com rebolo de ligante galvânico de CBN (Werner, 1995 apud Jackson et al., 2001 - Adaptada).

Figura 2.5 - Retificação de alta velocidade de corte com taxa de remoção de material constante (Klocke et al., 1997 - Adaptada).

Figura 2.6 - Retificação de alta velocidade de corte com espessura do cavaco constante (Klocke et al., 1997 - Adaptada).

Figura 2.7 - Temperatura da superfície da peça versus velocidade periférica de rebolos de CBN e de óxido de alumínio (Tawakoli, 1993 apud Silva, 2004 -

Adaptada).

Figura 2.8 - Principais campos de aplicação da retificação de alta velocidade (Jackson e Mills, 2004 - Adaptada).

Figura 2.9 - Microestrutura de um rebolo de ligante vitrificado. (A) porosidade distribuída; (B) ligante vitrificado; e (C) grão abrasivo. (Jackson e Mills, 2004 Adaptada).

Figura 2.10 - Tipos de ligante versus velocidade tangencial do rebolo $\left(v_{s}\right)$ com a taxa de remoção de material $\left(Q^{\prime}{ }_{w}\right.$ ) (Martin e Yegenoglu, 1992 apud Jackson et al., 2001 Adaptada).

Figura 2.11 - Grãos de CBN (Jackson et al., 2001 - Adaptada).....

Figura 2.12 - Vantagens dos rebolos com grãos de CBN (Inasaki et al., 1993 -

Adaptada).

Figura 2.13 - Curva do desgaste do rebolo versus volume do material removido (Graham e Voutsadopoulos, 1978 - Adaptada). 26 
Figura 2.14 - Mecanismos de desgaste (Malkin, 1989 - Adaptada).................................... 27

Figura 2.15 - Mecanismos de desgaste (Jackson e Mills, 2004 - Adaptada)........................ 27

Figura 2.16 - Fratura frágil em modelo de grão (Graham e Voutsadopoulos, 1978 Adaptada)

Figura 2.17 - Efeitos do passo de dressagem $\left(S_{d}\right)$ na topografia do rebolo (Chen et al., 1998 - Adaptada).

Figura 2.18 - Técnicas de dressagem (Chen et al., 2002 - Adaptada).

Figura 2.19 - Circularidade dos rebolos com diferentes profundidades de dressagem.

(a) $a_{d}$ de $10 \mu \mathrm{m}$ e (b) $a_{d}$ de $3 \mu \mathrm{m}$ (Chen et al., 2002).

Figura 2.20 - Geometria do ângulo de penetração da dressagem $\theta$ (Takagi e Liu, 1996 - Adaptada).

Figura 2.21 - Distribuição de tensões em um rebolo de CBN segmentado (Hitchiner,

2001 apud Silva, 2004 - Adaptada). 40

Figura 2.22 - Projeto otimizado para corpo de rebolo de alta velocidade (Klocke et al., 1997 - Adaptada). 40

Figura 2.23 - Expansão do rebolo versus rotação (Yui e Lee, 1996 - Adaptada).

Figura 2.24 - Segmentos da força normal com presença e ausência de trepidação (Govekar et al., 2002 - Adaptada). 45

Figura 2.25 - NCER (Normalized Coarse-grained Entropy Rate) versus volume específico de material desgastado (Govekar et al., 2002 - Adaptada). 46

Figura 2.26 - Principais fontes de EA no processo de retificação (Hundt et al., 1994 Adaptada). 48

Figura 2.27 - Método de construção do mapa acústico de um rebolo (Oliveira et al., 2001).

Figura 2.28 - Exemplo de mapa acústico obtido na dressagem de um rebolo excêntrico (Oliveira et al., 2001).

Figura 2.29 - Exemplo de mapa acústico obtido no processo de retificação sem e com vibrações (Oliveira et al., 2001)......

Figura 3.1 - Tipos de vibração na retificação (Inasaki et al., 2001 - Adaptada).

Figura 3.2 - Resultado da simulação computacional para a velocidade de vibração do rebolo na fase I e fase II (Oryński e Pawłowski, 1999 - Adaptada).

Figura 3.3 - Resultados dos ensaios experimentais para a razão de amplitudes dos deslocamentos entre fase I (AI) e fase II (AII) (Oryński e Pawtowski, 2004 -

Adaptada).

Figura 3.4 - Erro de forma gerado na superfície do rebolo e peça devido à vibração

(Weck et al., 2001 - Adaptada). 59

Figura 3.5 - Vibrações na retificação (Inasaki et al., 2001 - Adaptada). 60 
Figura 3.6 - Valores de vibração de torção e horizontal da peça (Drew et al., 1999 Adaptada).

Figura 3.7 - Amplitude da variação da força versus variação da velocidade da peça (Drew et al., 2001 - Adaptada).

Figura 3.8 - Resultado da vibração na superfície da peça (Brodtmann et al., 1984;

Forth, 1989 apud Inasaki et al., 2001 - Adaptada).

Figura 3.9 - Influência da razão de rotação rebolo/peça na superfície da peça (Forth, 1989 apud Inasaki et al., 2001 - Adaptada).

Figura 3.10 - Perfil do rebolo após diferentes tempos de retificação (Tellbüscher,

1986 apud Inasaki et al., 2001 - Adaptada).

Figura 3.11 - Balanceador automático de rebolos (Horiouchi e Kojima, 1986 apud Inasaki et al., 2001 - Adaptada).

Figura 3.12 - Efeito de um amortecedor passivo na redução da flexibilidade da estrutura (Hong et al., 1990 apud Inasaki et al., 2001 - Adaptada).

Figura 3.13 - Aplicação de amortecedor ativo na retificação de mergulho (Weck e

Brecher, 2001 - Adaptada).

Figura 3.14 - Amortecedor ativo montado em uma retificadora centerless e resposta em freqüência do sistema máquina-ferramenta-peça (Albizuri et al., 2007 - Adaptada).

Figura 3.15 - Rebolos flexíveis para eliminação da trepidação (Bzymek et al., 1994 -

Adaptada).

Figura 3.16 - Eliminação da trepidação pela variação da velocidade da peça

(Inasaki, 1977 apud Inasaki et al., 2001 - Adaptada).

Figura 3.17 - Eliminação da trepidação pela variação da velocidade do rebolo

(Hoshi et al., 1987 apud Inasaki et al., 2001 - Adaptada).

Figura 4.1 - Configuração 1 da bancada de testes utilizada para os ensaios nãoexcitados.

Figura 4.2 - Fluxograma dos ensaios da Configuração 1.

Figura 4.3 - Vista da fixação dos sensores de emissão acústica e de proximidade na retificadora cilíndrica ZEMA, modelo Compakta G600.

Figura 4.4 - Configuração 2 da bancada de testes utilizada para ensaios dinâmicos com rebolo de CBN.

Figura 4.5 - Mancal de deslizamento utilizado na Configuração 2.

Figura 4.6 - Dimensões em milímetro do corpo-de-prova dos ensaios da Configuração 2 .

Figura 4.7 - Fluxograma dos ensaios da Configuração 2. 88

Figura 4.8 - Conjunto mancal-rolamento utilizado na Configuração 3. 89

Figura 4.9 - Fluxograma dos ensaios da Configuração 3. 
Figura 4.10 - Exemplo de válvula de motores a combustão interna.

Figura 4.11 - Retificação de sede de válvula utilizando mecanismo do amortecedor passivo.

Figura 4.12 - Painel frontal do programa em LabVIEW utilizado nos testes de impacto.

Figura 4.13 - Localização do acelerômetro e do impacto do martelo dos testes. 99

Figura 4.14 - Painel frontal do programa em LabVIEW utilizado na aquisição de EA e potência.

Figura 4.15 - Painel frontal do programa em LabVIEW utilizado na aquisição das acelerações e geração do sinal de excitação para o shaker.

Figura 4.16 - Representação esquemática da medição do desgaste radial e vista do dispositivo. 104

Figura 5.1 - Potência de corte versus taxa específica de remoção de material $\left(Q{ }^{\prime}{ }_{w}\right)$. 105

Figura 5.2 - Erro de circularidade e rugosidade versus taxa específica de remoção de material $\left(Q{ }^{\prime}{ }_{w}\right)$. 106

Figura 5.3 - Relação $G$ versus taxa específica de remoção de material $\left(Q{ }^{\prime}{ }_{w}\right)$. 107

Figura 5.4 - Relação $G$ versus força tangencial em um grão $\left(F_{t 1 g}\right)$. 109

Figura 5.5 - Resposta em freqüência da peça. 110

Figura 5.6 - Espectro na freqüência do impulso e da resposta. 111

Figura 5.7 - Resposta em freqüência do rebolo. 112

Figura 5.8 - Espectro na freqüência do impulso e da resposta. 112

Figura 5.9 - Potência de corte versus aceleração de vibração $\left(a_{v i b}\right)$. 114

Figura 5.10 - Erro de circularidade e rugosidade versus aceleração de vibração $\left(a_{\text {vib }}\right)$....... 115

Figura 5.11 - Relação $G$ versus aceleração de vibração $\left(a_{v i b}\right)$. 116

Figura 5.12 - Espectro da freqüência da aceleração para cada ciclo do ensaio VO. 117

Figura 5.13 - Média do espectro da freqüência da aceleração para o ensaio VO. 118

Figura 5.14 - Espectro da freqüência da aceleração para cada ciclo do ensaio V1. 118

Figura 5.15 - Média do espectro da freqüência da aceleração para o ensaio Vl. 119

Figura 5.16 - Espectro da freqüência da aceleração para cada ciclo do ensaio V2. 119

Figura 5.17 - Média do espectro da freqüência da aceleração para o ensaio V2. 120

Figura 5.18 - Espectro da freqüência da aceleração para cada ciclo do ensaio V3. 120

Figura 5.19 - Média do espectro da freqüência da aceleração para o ensaio V3. 121

Figura 5.20 - Espectro da freqüência da aceleração para cada ciclo do ensaio V4. 121 
Figura 5.21 - Média do espectro da freqüência da aceleração para o ensaio V4.

Figura 5.22 - Espectro da freqüência da aceleração para cada ciclo do ensaio V5.

Figura 5.23 - Média do espectro da freqüência da aceleração para o ensaio V5.

Figura 5.24 - Espectro da freqüência da aceleração para cada ciclo do ensaio V6. 123

Figura 5.25 - Média do espectro da freqüência da aceleração para o ensaio V6. 124

Figura 5.26 - Espectro da freqüência da aceleração para cada ciclo do ensaio V7... 124

Figura 5.27 - Média do espectro da freqüência da aceleração para o ensaio V7. 125

Figura 5.28 - Potência de corte versus velocidade de vibração $\left(v_{v i b}\right)$. 127

Figura 5.29 - Erro de circularidade e rugosidade versus velocidade de vibração $\left(v_{v i b}\right)$.

Figura 5.30 - Relação $G$ versus velocidade de vibração $\left(v_{\text {vib }}\right)$.

Figura 5.31 - Mapa acústico do efeito da vibração na topografia do rebolo e potência de retificação.

Figura 5.32 - Mapa acústico com a presença de trepidação causada pela vibração senoidal......

Figura 5.33 - Mapa acústico do processo de retificação de sede de válvulas com e sem o amortecedor passivo.

Figura 5.34 - Mapa acústico das últimas quatro válvulas antes da operação de dressagem com e sem a utilização do amortecedor passivo.

Figura 5.35 - Erro de circularidade das últimas 30 válvulas antes da operação de dressagem com e sem a utilização do amortecedor passivo. 136

\section{ANEXO}

Figura 1 - Bancada de testes utilizada para a texturização de rebolos. 150

Figura 2 - Mapas acústicos da operação de dressagem com diferentes padrões 151

Figura 3 - Mapas acústicos da operação de dressagem com diferentes padrões 152

Figura 4 - Resultados dos ensaios realizados com o dressador tipo ponta-única. 155

Figura 5 - Resultados dos ensaios realizados com o dressador tipo fliese. 155 


\section{LISTA DE TABELAS}

Tabela 2.1- Comparação entre as propriedades do aço e fibra de carbono (Klocke et al., 1997).

Tabela 4.1 - Composição química dos materiais dos corpos-de-prova dos ensaios da Configuração 1 (\% em peso). 78

Tabela 4.2 - Parâmetros de retificação dos ensaios da Configuração 1 80

Tabela 4.3 - Parâmetros de dressagem dos ensaios da Configuração 1. 80

Tabela 4.4 - Composição química do material do corpo-de-prova dos ensaios da Configuração 2 (\% em peso). 85

Tabela 4.5 - Parâmetros de retificação dos ensaios da Configuração 2 86

Tabela 4.6 - Parâmetros de dressagem dos ensaios da Configuração 2. 87

Tabela 4.7 - Parâmetros de retificação dos ensaios da Configuração 3 90

Tabela 4.8 - Parâmetros de dressagem dos ensaios da Configuração 3. 90

Tabela 4.9 - Parâmetros de retificação dos ensaios adicionais de retificação. 92

Tabela 4.10 - Parâmetros de retificação dos ensaios realizados na empresa TRW. 93

Tabela 4.11 - Parâmetros de dressagem dos ensaios adicionais de retificação. 94

Tabela 4.12 - Parâmetros utilizados no condicionador MSM. 100

Tabela 4.13 - Parâmetros utilizados no condicionador 2525. 102

\section{ANEXO}

Tabela 1 - Parâmetros de dressagem dos ensaios. 154

Tabela 2 - Parâmetros de retificação dos ensaios. 154 


\section{LISTA DE SÍMBOLOS E ABREVIATURAS}

a Profundidade de corte

$a_{d} \quad$ Profundidade da dressagem

$a_{v} \quad$ Aceleração da vibração

$b \quad$ Largura de retificação

$b_{d} \quad$ Largura de atuação do diamante

$C_{r} \quad$ Razão de contração

$C_{\text {stat }}$ Densidade estática de arestas de corte

D Densidade superficial de grãos do rebolo

$d_{e q} \quad$ Diâmetro equivalente

$d_{s} \quad$ Diâmetro do rebolo

$d_{t} \quad$ Diâmetro do disco dressador

$d_{w} \quad$ Diâmetro da peça

E Módulo de elasticidade ou Young

$F_{n} \quad$ Força normal de retificação

$F_{t} \quad$ Força tangencial de retificação

$F_{\text {tig }} \quad$ Força tangencial de retificação por grão

G Relação G $[\mu \mathrm{m}]$

$[\mu \mathrm{m}]$

$\left[\mathrm{m} / \mathrm{s}^{2}\right]$

[mm]

[mm]

$[-]$

[arest. $/ \mathrm{mm}^{3}$ ]

[grãos $/ \mathrm{mm}^{2}$ ]

[mm]

[mm]

[mm]

[mm]

$\left[\mathrm{N} / \mathrm{mm}^{2}\right]$

$[\mathrm{N}]$

$[\mathrm{N}]$

[N]

[-] 


\begin{tabular}{|c|c|c|}
\hline$g$ & Aceleração da gravidade & {$\left[\mathrm{m} / \mathrm{s}^{2}\right]$} \\
\hline$h_{c u}$ & Espessura do cavaco indeformado & {$[\mu \mathrm{m}]$} \\
\hline$h_{m}$ & Espessura máxima do cavaco & {$[\mu \mathrm{m}]$} \\
\hline$K$ & Rigidez de contato entre o martelo de impacto e a peça testada & {$[\mathrm{N} / \mathrm{mm}]$} \\
\hline$l$ & Distância entre a cabeça da válvula e a castanha da placa & {$[\mathrm{mm}]$} \\
\hline$l_{c}$ & Comprimento de contato & {$[\mu \mathrm{m}]$} \\
\hline$M$ & Massa do instrumento de impacto & {$[\mathrm{kg}]$} \\
\hline$n_{s}$ & Rotação do rebolo & [rpm] \\
\hline$n_{t}$ & Rotação do disco dressador & [rpm] \\
\hline$n_{w}$ & Rotação da peça & [rpm] \\
\hline$P_{c}$ & Potência de corte & {$[\mathrm{kW}]$} \\
\hline$P_{d}$ & Potência dissipada & {$[\mathrm{kW}]$} \\
\hline$P_{f}$ & Potência perdida devido ao fluido de corte & {$[\mathrm{kW}]$} \\
\hline$P_{l}$ & Potência perdida devido ao jato do bocal de limpeza do rebolo & {$[\mathrm{kW}]$} \\
\hline$P_{t}$ & Potência total & {$[\mathrm{kW}]$} \\
\hline$P_{v}$ & Potência em vazio & {$[\mathrm{kW}]$} \\
\hline$q$ & Razão de velocidades $\left(v_{s} / v_{w}\right)$ & {$[-]$} \\
\hline$q_{d}$ & Razão de esmagamento $\left(v_{d} / v_{s}\right)$ & {$[-]$} \\
\hline$Q_{w}^{\prime}$ & Taxa de remoção de material & {$\left[\mathrm{mm}^{3} / \mathrm{mm} . \mathrm{s}\right]$} \\
\hline$r$ & Raio do rebolo & {$[\mathrm{mm}]$} \\
\hline$S_{d}$ & Passo de dressagem & {$[\mathrm{mm} /$ volta $]$} \\
\hline$U_{d}$ & Grau de recobrimento & {$[-]$} \\
\hline$u$ & Dilatação do rebolo & {$[\mathrm{mm}]$} \\
\hline$u_{c h}$ & Energia específica de formação de cavaco & {$\left[\mathrm{J} / \mathrm{mm}^{3}\right]$} \\
\hline
\end{tabular}


$v \quad$ Velocidade relativa entre o rebolo e o dressador

$v_{c} \quad$ Velocidade de corte

$v_{d} \quad$ Velocidade do tangencial disco dressador

$v_{f} \quad$ Velocidade de avanço

$[\mathrm{mm} / \mathrm{min}]$

$v_{s} \quad$ Velocidade tangencial do rebolo

$[\mathrm{m} / \mathrm{s}]$

$V_{s} \quad$ Volume específico desgastado do rebolo

$\left[\mathrm{mm}^{3} / \mathrm{mm}\right]$

$v_{v i b} \quad$ Velocidade da vibração

$[\mathrm{mm} / \mathrm{min}]$

$v_{w} \quad$ Velocidade tangencial da peça

$[\mathrm{m} / \mathrm{s}]$

$V^{\prime}{ }_{w} \quad$ Volume específico de material removido

$\left[\mathrm{mm}^{3} / \mathrm{mm}\right]$

\section{Símbolos utilizando o alfabeto grego}

$\alpha \quad$ Coeficiente de expansão linear

$\left[1 /{ }^{\circ} \mathrm{C}\right]$

$\gamma \quad$ Peso específico

$\left[\mathrm{N} / \mathrm{dm}^{3}\right]$

$\theta \quad$ Ângulo de penetração da dressagem

$\left[{ }^{\circ}\right]$

$v \quad$ Coeficiente de Poisson

$[-]$

$\sigma_{y} \quad$ Tensão de tração

$\left[\mathrm{N} / \mathrm{mm}^{2}\right]$

$\tau \quad$ Período do pulso gerado pelo teste de impacto

$[\mathrm{s}]$

$\Omega \quad$ Rotação instantânea da peça

[rpm]

$\Omega_{w} \quad$ Rotação nominal da peça

$[\mathrm{rpm}]$

$\omega \quad$ Velocidade angular

[rad/s] 


\section{Abreviaturas}

$\begin{array}{ll}\mathrm{Al}_{2} \mathrm{O}_{3} & \text { Óxido de Alumínio } \\ \mathrm{B}_{2} \mathrm{O}_{3} & \text { Óxido de Boro } \\ \mathrm{CBN} & \text { Nitreto Cúbico de Boro (Cubic Boron Nitride) } \\ \mathrm{CFRP} & \text { Plástico Reforçado com Fibra de Carbono (Carbon Fiber Reinforced Plastic) } \\ \mathrm{CNC} & \text { Controle Numérico Computadorizado (Computer Numeric Control) } \\ \mathrm{CD} & \text { Dressagem Contínua (Continuous Dressing) } \\ \mathrm{DTG} & \text { Difícil de Retificar (Difficult to Grinding) } \\ \mathrm{EA} & \text { Emissão Acústica } \\ \mathrm{FFT} & \text { Transformada Rápida de Fourier (Fast Fourier Transform) } \\ \mathrm{HSG} & \text { Retificação de Alta Velocidade (High Speed Grinding) } \\ \mathrm{NCER} & \text { Normalized Coarse-Grained Entropy Rate } \\ \mathrm{NCIR} & \text { Normalized Coarse-Grained Information Rate } \\ \mathrm{RMS} & \text { Valor Médio Quadrático (Root Mean Square) } \\ \mathrm{SiC} & \text { Carbeto de Silício } \\ \mathrm{N} & \text { Óxido de Silício } \\ \mathrm{N} & \end{array}$




\section{SUMÁRIO}

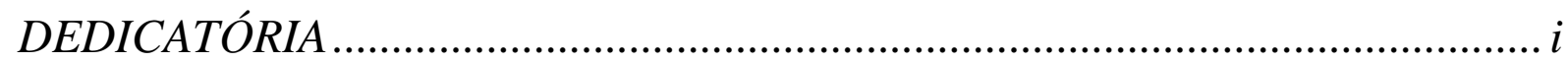

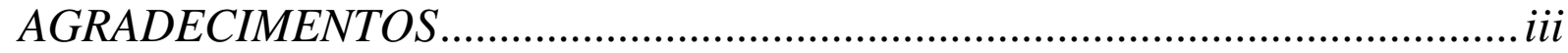

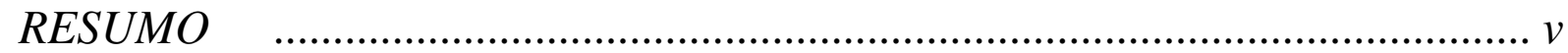

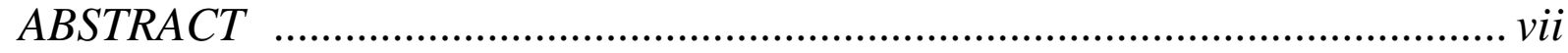

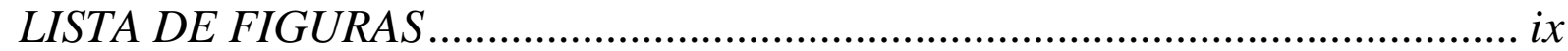

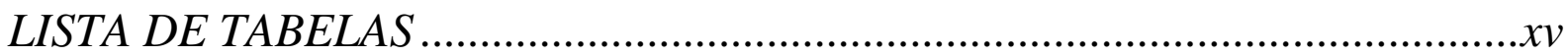

LISTA DE SÍMBOLOS E ABREVIATURAS................................................. xvii

CAPÍtUlo 1:

INTRODUÇÃO

1.1 Estrutura do Trabalho ...................................................................................4

CApítulo 2:

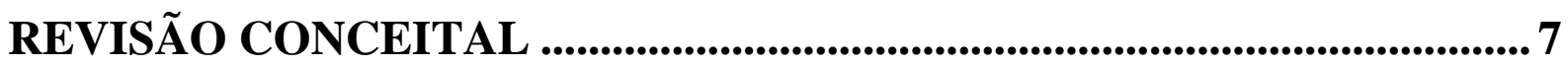

2.1 O Processo de Retificação ...............................................................................................7

2.1.1 Retificação de Alta Velocidade de Corte................................................. 10

2.2 O Rebolo de CBN.................................................................................................19

2.2.1 Características Técnicas .......................................................................21

2.2.2 O Fenômeno de Desgaste do Rebolo de CBN .......................................25

2.2.3 A Operação de Dressagem de Rebolos de CBN.........................................32

2.2.4 O Rebolo de CBN na Retificação de Alta Velocidade...............................39

2.3 Métodos de Monitoramento do Processo....................................................................43

2.3.1 Monitoramento da Vibração ……………………………….................. 44

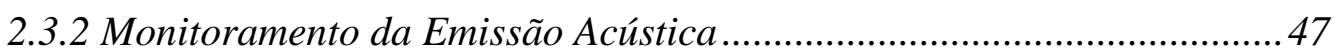

2.3.3 Monitoramento da Potência ………………………………………….......52 


\section{CApítulo 3:}

\section{A VIBRAÇÃO NO PROCESSO DE RETIFICAÇÃO}

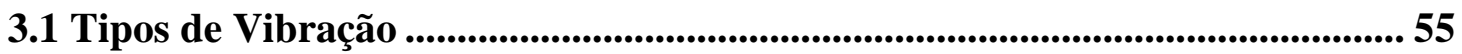

3.1.1 Vibração Forçada ......................................................................... 56

3.1.2 Vibração Auto-excitada ................................................................... 58

3.2 Influência na Qualidade Superficial da Peça ......................................................... 63

3.3 Influência no Desgaste da Ferramenta.................................................................... 65

3.4 Métodos de Eliminação da Vibração na Retificação ......................................... 66

3.4.1 Eliminação da vibração forçada.......................................................... 67

3.4.2 Eliminação da vibração auto-excitada ................................................. 68

\section{Capítulo 4:}

MATERIAIS E MÉTODOS......................................................................75

4.1 Configuração 1 de Retificação ................................................................................. 76

4.1.1 Bancada de Testes - Configuração 1 ……………………………..... 76

4.1.2 Corpos-de-Prova........................................................................... 78

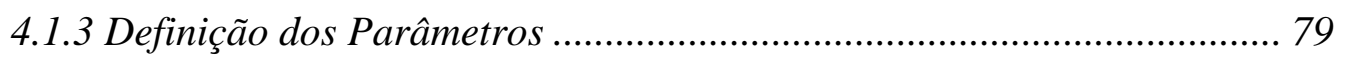

4.2 Configuração 2 de Retificação ............................................................................. 81

4.2.1 Bancada de Testes - Configuração 2 ……………………………..... 81

4.2.2 Corpos-de-Prova....................................................................... 84

4.2.3 Definição dos Parâmetros ……………………………………………. 86

4.3 Configuração 3 de Retificação .............................................................................. 88

4.3.1 Bancada de Testes - Configuração 3 ................................................. 88

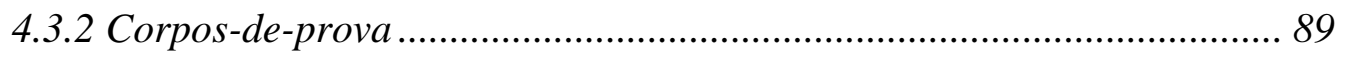

4.3.3 Definição dos Parâmetros ……………………………………........ 89

4.4 Ensaios Adicionais de Retificação ..................................................................... 91

4.4.1 Verificação da Potência de Retificação Durante Vibração Forçada e Formação da Vibração Auto-excitada ................................ 91

4.4.2 Verificação da Influência do Amortecedor Passivo na Retificação de Sede de Válvulas........................................................................... 93

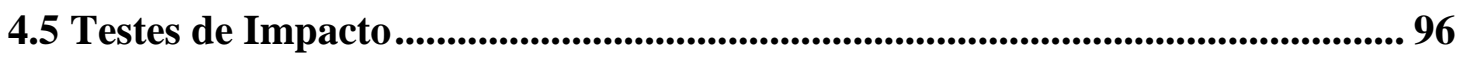

4.6 Geração da Excitação e Medição da Emissão Acústica, Potência e Vibração....................................................................................................... 99

4.6.1 Sistema de Aquisição da Emissão Acústica e Potência ........................... 99

4.6.2 Sistema de Aquisição da Vibração e Geração da Excitação.................. 102

4.7 Medição da Rugosidade, Desgaste Radial do Rebolo e Erro de Circularidade. 


\section{Capítulo 5:}

RESULTADOS E DISCUSSÃO

5.1 Configuração 1 .......................................................................................................105

5.1.1 Potência de Retificação, Rugosidade e Circularidade .......................... 105

5.1.2 Desgaste do Rebolo e Força Tangencial por Grão............................... 107

5.2 Testes de Impacto ................................................................................................................... 110

5.2.1 Resposta em Freqüência da Peça........................................................ 110

5.2.2 Resposta em Freqüência do Rebolo ...................................................... 112

5.3 Configuração 2..............................................................................................................113

5.3.1 Potência de Retificação, Rugosidade e Circularidade ........................... 114

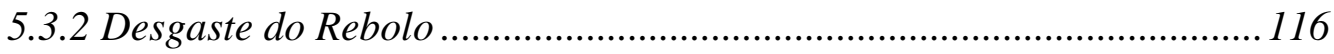

5.3.3 Freqüências Excitadas Durante a Retificação ..................................... 117

5.4 Configuração 3..................................................................................................................... 126

5.4.1 Potência de Retificação, Rugosidade e Circularidade .......................... 127

5.4.2 Desgaste do Rebolo ............................................................................ 129

5.5 Ensaios Adicionais de Retificação .....................................................................130

5.5.1 Potência de Retificação Durante a Vibração Forçada e Formação da Vibração Auto-excitada ................................................ 130

5.5.2 Influência do Amortecedor Passivo na Retificação de Sede de Válvulas

CApítulo 6:

CONCLUSÃO

CAPÍtulo 7:

SUGESTÕES PARA TRABALHOS FUTUROS ........................................ 139

REFERÊNCIAS BIBLIOGRÁFICAS ...................................................... 141

ANEXO:

PESQUISAS ORIGINADAS DESTE TRABALHO

Texturização de Rebolos ..........................................................................................149

Estudo da Dressagem com Vibração Forçada na Rugosidade de Peças

Retificadas ..............................................................................................................153 


\section{Capítulo 1}

\section{INTRODUÇÃO}

A presença de vibração auto-excitada, ou trepidação, também conhecida pelo termo em inglês chatter, no processo de retificação pode levar a conseqüências desagradáveis para a peça que está sendo trabalhada e para o rebolo, tais como: erros geométricos, acabamento superficial indesejável e desgaste excessivo da ferramenta (Inasaki et al., 2001; Malkin, 1989).

Vibrações auto-excitadas são geralmente relacionadas aos modos de vibração natural do sistema mecânico. O efeito regenerativo é a principal causa do seu aparecimento na retificação. Este efeito é criado por distúrbios no processo que acabam por gerar variações na força de corte, e conseqüentemente, excitações dinâmicas do sistema máquina-ferramentapeça, provocando assim, uma variação da profundidade de corte de retificação. Desta forma, o efeito regenerativo causado pela peça ocorre quando são produzidos lóbulos na mesma em suas revoluções subseqüentes (Altintas e Weck, 2004; Alfares e Elsharkawy, 2000).

De maneira similar, o efeito regenerativo da vibração observado no rebolo pode ocorrer devido a um desgaste irregular do mesmo (Weck et al., 2001; Hashimoto et al., 1984). Esta afirmação ainda não é experimentalmente comprovada, já que os dois tipos de vibração auto-excitada, ou chatter, podem acontecer simultaneamente. Além disso, a medição da topografia do rebolo continua sendo uma tarefa difícil de ser realizada. 
A detecção de vibrações no processo de retificação é geralmente realizada por meio de acelerômetros, sensores de emissão acústica (EA) ou dinamômetros. Consideráveis quantidades de trabalhos científicos apresentam diferentes métodos de detecção, como por exemplo, limites estatísticos calculados por meio das flutuações da força normal de retificação e EA (Govekar et al., 2002; GradiŠek et al., 2003). Do mesmo modo, variações na força tangencial também provaram indicar a presença de vibrações torcionais no cabeçote do rebolo e/ou cabeçote porta-peça, influenciando significativamente o aparecimento de trepidação (Mannan et al., 1999; Drew et al., 1999; Mannan et al., 2000; Drew et al., 2001).

Já que a trepidação, ou vibração auto-excitada, é de importância fundamental para a retificação, a estabilização do processo é um dos tópicos mais estudados. Diversos modelos analíticos e numéricos do processo já foram desenvolvidos com o intuito de determinar os efeitos da dinâmica estrutural da máquina, rigidez de contato e flexibilidade do rebolo na eliminação da trepidação (Baylis e Stone, 1989; Baylis e Stone, 1983). Outros estudos demonstram que diferentes tecnologias de fabricação do rebolo e também o controle da variação da rotação do rebolo ou peça pode ajudar na sua eliminação (Mannan et al., 2000; Sexton e Stone, 1981).

Apesar da vibração auto-excitada ter sido profundamente estudada ao longo dos anos, existem poucas informações de como as interações dinâmicas entre o rebolo e a peça podem afetar as variáveis do processo. Do mesmo modo, nenhum estudo parece investigar como vibrações propositalmente induzidas na retificação podem melhorar o seu desempenho.

Um importante exemplo da ocorrência de trepidação é a retificação de válvulas de motor a combustão interna. De acordo com Oliveira et al. (2009), atualmente existe uma tendência de diminuição do peso dos componentes móveis de motores objetivando a redução da energia consumida na sua movimentação. As válvulas, por exemplo, estão sujeitas a altos 2 
níveis de aceleração, portanto, o seu peso tem grande influência na energia requerida para sua movimentação. Além disso, é necessário que estes componentes tenham alta resistência ao desgaste, fazendo com que o material empregado seja de difícil usinabilidade, geralmente denominados materiais de difícil retificação (DTG - Difficult to Grinding).

Esta tendência de diminuição de peso está proporcionando o aparecimento de novos projetos de válvulas onde a haste é formada por um tubo e a cabeça da válvula é feita de uma chapa de metal, sendo que os mesmos são unidos por solda a laser. Isto faz com que as novas válvulas sejam de 35 a $55 \%$ mais leves em comparação com as convencionais do mesmo tamanho. Todas estas mudanças proporcionam grandes desafios para o desenvolvimento de novos processos de retificação, pois há maior chance de ocorrer vibração auto-excitada. Dentre estes, a retificação de peças de baixa rigidez estrutural, baixo peso e de material de difícil retificação (Oliveira et al., 2009).

Este trabalho apresenta uma análise experimental da influência da vibração na retificação de mergulho de alta velocidade de corte utilizando rebolo de CBN vitrificado.

Com o intuito de estabelecer uma referência, foram realizados alguns testes de retificação com e sem excitação externa utilizando diferentes materiais DTG e rebolo de CBN. Deste modo, dois importantes aspectos relacionados à vibração na retificação serão estudados: a influência da vibração no desgaste da ferramenta e os mecanismos de geração da trepidação nas peças de baixa rigidez estrutural.

Esta pesquisa faz parte de uma parceria entre o grupo de Otimização de Processos de Fabricação (OPF - NUMA) da Escola de Engenharia de São Carlos - USP e as empresas Zema Zselics (fabricante de máquinas), Saint Gobain Abrasives (fabricantes de rebolos), Microquímica (fabricante de fluidos de usinagem) e TRW (fabricante de peças e sistemas automotivos) e, portanto, será de grande importância não só para a comunidade científica, 
mas também para a integração universidade-empresa, fortalecendo assim, as articulações entre a pesquisa e o setor produtivo do país. As empresas participantes têm doado equipamentos, materiais, além de ceder suas instalações para treinamentos e testes.

Esta pesquisa tem como objetivo principal o estudo das interações dinâmicas entre o rebolo e a peça na retificação de alta velocidade utilizando rebolo de $\mathrm{CBN}$ vitrificado e materiais DTG (Difficult to Grind).

Para isso, alguns objetivos secundários foram alcançados:

- Entender a influência das forças de retificação no mecanismo de desgaste do rebolo;

- Examinar a influência da amplitude da vibração nas variáveis do processo e no desgaste do rebolo;

- Entender o mecanismo da formação de trepidação; e

- Desenvolver um método de controle passivo da vibração visando reduzir as vibrações.

\subsection{Estrutura do Trabalho}

Com a introdução do trabalho definida, é apresentada a seguir uma breve descrição de cada capítulo.

Capítulo 2: $\quad$ Este capítulo mostra a revisão bibliográfica do trabalho, abrangendo o processo de retificação de alta velocidade de corte, o rebolo de CBN e sua utilização e métodos de monitoramento da retificação.

Capítulo 3: Apresentação dos conceitos relativos à presença de vibrações forçadas ou auto-excitadas no processo de retificação. 
Capítulo 4: Neste capítulo é apresentada a metodologia e os materiais utilizados nos ensaios.

Capítulo 5: Este é o capítulo onde são apresentados os resultados e discussões dos ensaios realizados nesta pesquisa.

Capítulo 6: São apresentadas as conclusões finais baseadas na discussão realizada no capítulo 5 .

Capítulo 7: Este capítulo apresenta duas pesquisas originadas de resultados preliminares desta tese, assim como sugestões para trabalhos futuros. 


\section{Capítulo 2}

\section{REVISÃO CONCEITAL}

\subsection{O Processo de Retificação}

O processo de retificação é considerado um dos mais importantes da manufatura. Quase todos os produtos manufaturados possuem componentes que foram fabricados a partir deste processo ou a partir de máquinas que possuem a sua precisão graças à retificação (Malkin, 1989).

O objetivo da retificação é melhorar o acabamento superficial, precisão dimensional, além de garantir a integridade das peças acabadas (Vieria et al., 1999). Para Kopac e Krajnik (2006), o processo de retificação busca constantemente maximizar a velocidade de fabricação de produtos dentro de especificações de qualidade restritas e, ao mesmo tempo, diminuir os custos de produção.

Trata-se, portanto, de um processo de alta precisão e importância, já que é inaceitável perder uma peça nesta etapa final de fabricação, pois o valor agregado ao material nesta fase já é muito elevado devido aos outros processos que antecederam a retificação (Soares e Oliveira, 2002).

Além disso, a retificação é um processo bastante complexo, pois envolve uma gama de parâmetros e variáveis que o influenciam, tais como: tipos de fluidos de corte, tipos de 
rebolos e parâmetros como velocidades de corte e de avanço etc. Portanto, para se controlar melhor a retificação é necessário analisar o maior número de variáveis possíveis, evitando assim perdas de peças durante o processo.

Este processo de corte é classificado como de "geometria não definida", pois a sua ferramenta possui arestas de corte distribuídas randomicamente na sua superfície. Deste modo, cada grão abrasivo remove um cavaco da superfície da peça gerando assim um acabamento superficial (Kopac e Krajnik, 2006).

No início do corte, segundo König e Klocke (1996) apud (Kopac e Krajnik, 2006), ocorre deformação elástica por parte do material devido à alta força normal $\left(F_{n}\right)$, seguido pelo seu escoamento lateral (deformação plástica). Após isso, inicia-se a formação do cavaco pelo aumento da força tangencial $\left(F_{t}\right)$ que acaba por cisalhar o material (Figura 2.1). As condições de atrito da interface, as propriedades de escoamento do material e a velocidade de corte têm influência significativa na formação do cavaco.

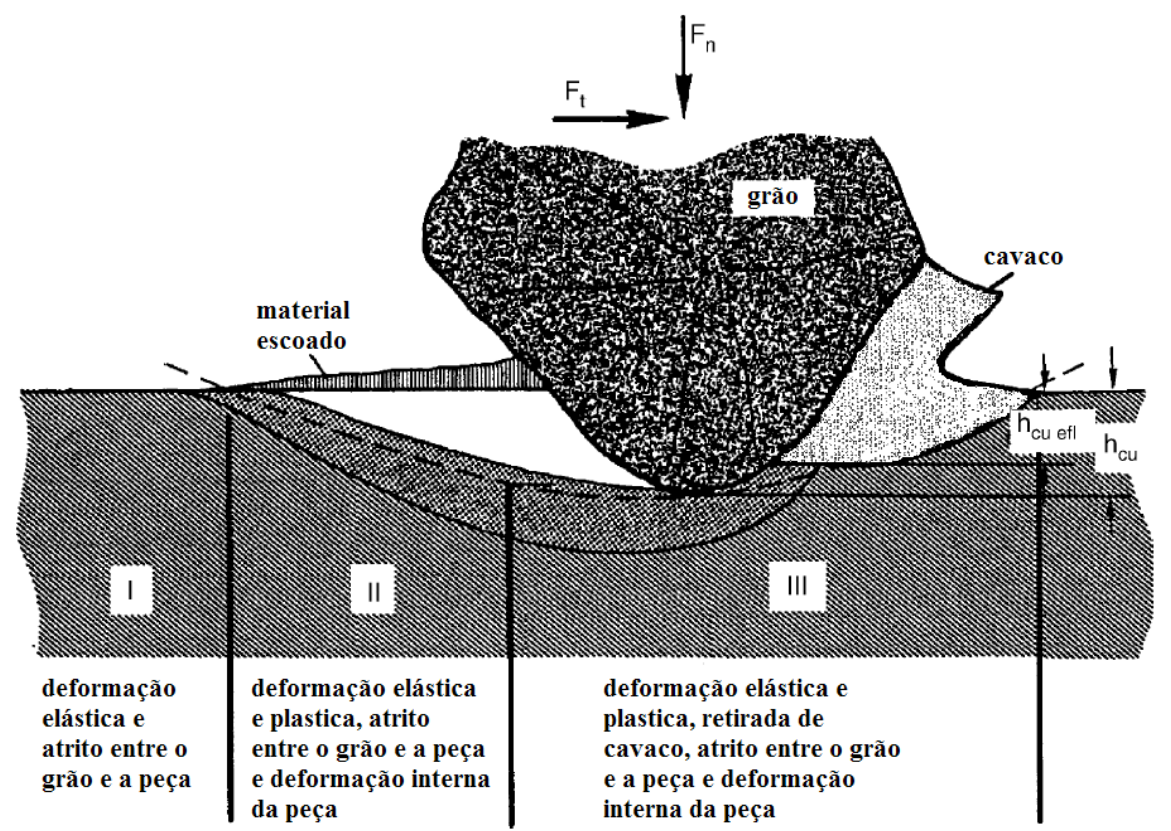

Figura 2.1 - Formação do cavaco na retificação (König e Klocke, 1996 apud Kopac e Krajnik, 2006 - Adaptada). 
De acordo com Hamdi, Dursapt e Zahouani (2003), na formação do cavaco ocorre uma deformação elástica do material da peça, de forma que a altura do grão é maior do que a profundidade da ranhura causada por este grão. O estudo também discute a possível existência de mais de uma aresta de corte em cada grão abrasivo (fator que na maioria das análises feitas por outros autores não é levado em consideração). Este estudo conclui ainda que o escoamento lateral depende da topografia das arestas de corte do grão abrasivo. Nos testes realizados, a aresta de corte mais alta do grão não produziu escoamento lateral, enquanto que as outras arestas produziram em escalas diferentes. A operação de retificação cilíndrica externa de mergulho, utilizada neste trabalho, pode ser visualizada na Figura 2.2.

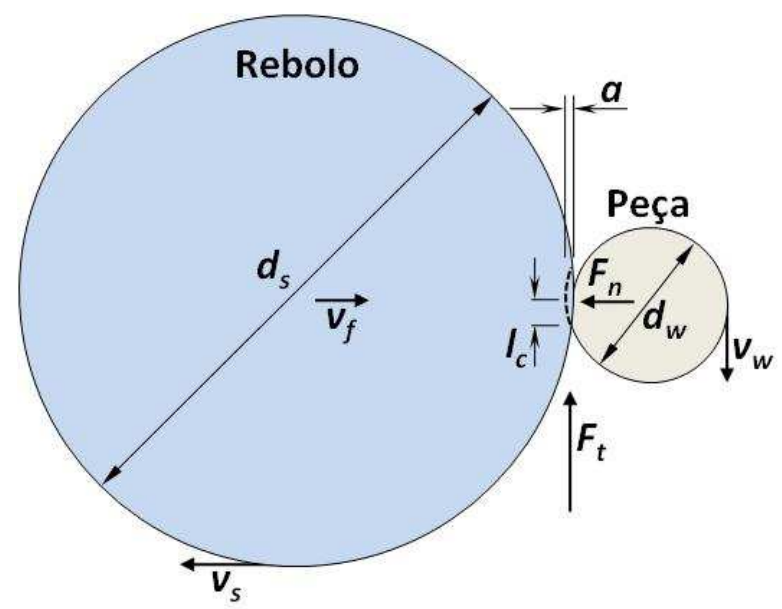

Figura 2.2 - Retificação cilíndrica externa de mergulho (Malkin, 1989 - Adaptada).

De acordo com a Figura 2.2, tem-se que a operação de retificação cilíndrica externa de mergulho consiste, basicamente, da profundidade de corte (a) correspondente ao avanço do rebolo no tempo decorrido de uma volta da peça, velocidade de corte $\left(v_{c}\right)$ ou velocidade tangencial do rebolo $\left(v_{s}\right)$, velocidade de mergulho $\left(v_{f}\right)$ velocidade periférica da peça $\left(v_{w}\right)$, diâmetro do rebolo $\left(d_{s}\right)$, diâmetro da peça $\left(d_{w}\right)$, força tangencial de corte $\left(F_{t}\right)$, comprimento de contato $\left(l_{c}\right)$, e força normal de corte $\left(F_{n}\right)$. A correlação entre estes parâmetros caracteriza a operação de retificação cilíndrica externa de mergulho. 
A necessidade de aumentar a produtividade dos processos convencionais de acabamento levou ao desenvolvimento da retificação de alta velocidade de corte (Klocke et al., 1997). Desde a sua implementação, esta nova tecnologia expandiu o campo de aplicação da retificação, indo do clássico processo de acabamento para a usinagem de alto desempenho (Jackson et al., 2001).

\subsubsection{Retificação de Alta Velocidade de Corte}

Tem-se estudado muito a retificação de alta velocidade uma vez que aumentando a velocidade periférica do rebolo é possível melhorar algumas características do processo, assim como as tolerâncias finais da peça. No entanto, o projeto, a construção e a implementação de retificadoras de alta velocidade (com velocidades de corte acima de 100 $\mathrm{m} / \mathrm{s}$ ) estão intimamente ligadas ao desenvolvimento de rebolos superabrasivos (Oliveira et al., 2002).

Para Klocke et al. (1997), os desenvolvimentos de rebolos de alto desempenho e de retificadoras mais eficientes criaram condições para diminuir o tempo de retificação e o número de operações de usinagem necessárias. A utilização da técnica de retificação de alta velocidade em conjunto com operações preliminares de forjamento e conformação de alta precisão permite a configuração de novas seqüências de processamento de alto desempenho.

Além disso, estas máquinas devem possuir alguns requisitos básicos (Werner e Tawakoli, 1988):

- Eixo devidamente dimensionado para motor de alta potência;

- Mancais e suportes rígidos;

- Comando CNC;

- Mesas e guias com alta rigidez;

- Sistema de refrigeração otimizado; 
- Sistema de balanceamento de rebolo integrado; e

- Sistema de dressagem com alta rigidez.

Para que se consiga obter bons resultados na retificação com velocidades de corte desta magnitude, o cabeçote porta-rebolo da máquina deve operar com rotações próximas a $20.000 \mathrm{rpm}$. O sistema motor-eixo-rebolo deve trabalhar com extrema precisão e baixíssimas amplitudes de vibração para minimizar o nível das forças dinâmicas do processo. Também é necessária uma elevada rigidez estrutural da máquina-ferramenta. Um importante aspecto a ser levado em consideração é o sistema de balanceamento do rebolo na máquina que deve ser dinâmico (Jackson et al., 2001).

De acordo com Klocke et al. (1997), o cabeçote porta-rebolo de uma retificadora de alta velocidade é o seu elemento principal. Este componente deve possuir tecnologias especiais, tais como: rolamentos hidrostáticos ou hidrodinâmicos de alto desempenho e sistema de resfriamento do fluido hidráulico para assegurar temperatura constante durante uma operação contínua.

Outra consideração importante no projeto de retificadoras de alta velocidade é a potência necessária para o funcionamento da máquina ou potência consumida pelo motor do rebolo (Jackson et al., 2001). Pode-se considerar esta potência total $\left(P_{\text {total }}\right)$ como sendo a somatória da potência de corte $\left(P_{c}\right)$ e da potência dissipada $\left(P_{d}\right)$ (Equação 2.1).

$$
P_{\text {total }}=P_{c}+P_{d}
$$

A potência de corte é o produto da força tangencial e velocidade tangencial do rebolo (Equação 2.2).

$$
P_{c}=F_{t} v_{s}
$$


Já a potência dissipada é a soma da potência em vazio $\left(P_{v}\right)$, potência perdida devido ao fluido de corte $\left(P_{f}\right)$ e potência perdida devido ao jato atomizado do bocal de limpeza do rebolo $\left(P_{v}\right)$ (Equação 2.3).

$$
P_{d}=P_{v}+P_{f}+P_{l}
$$

De acordo com a Figura 2.3, nota-se que o aumento da velocidade de corte faz com que a potência total consumida pelo motor do rebolo também aumente.

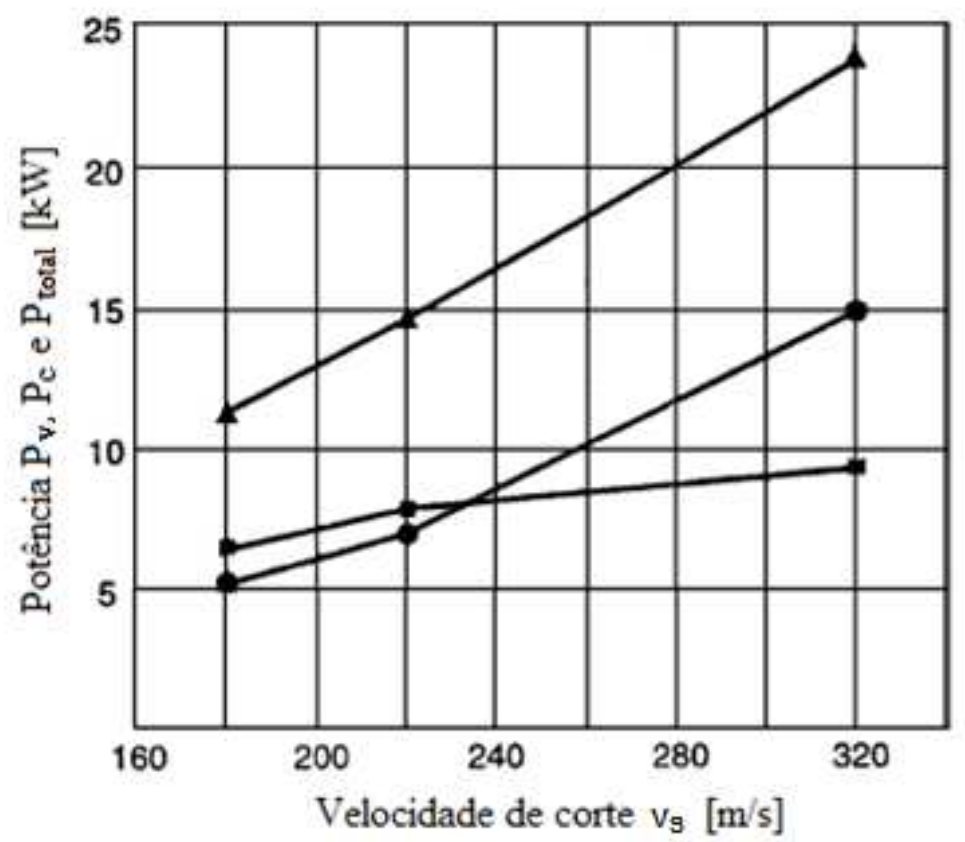

\section{-Rebolo: \\ CBN B252 GSS}

- Profundidade de corte:

$a_{p}=2,5 \mathrm{~mm}$

- Material da peça:

$16 \mathrm{MnCr} 5$

- Razào de remoçào de mat. espec. $Q_{w}^{*}=100 \mathrm{~mm} / \mathrm{mms}$

Potência total $P_{\text {total }}$

Potência em vazio $P_{v}$

Potência de corte $P_{c}$

Figura 2.3 - O efeito da velocidade de corte, ou velocidade tangencial do rebolo, na potência consumida pelo motor do rebolo (Werner, 1995 apud Jackson et al., 2001 - Adaptada).

No entanto, este acréscimo no valor da potência total é influenciado principalmente pela potência em vazio e muito pouco pela potência de corte. Portanto, é indispensável o estudo de soluções eficazes para a diminuição do consumo de energia do cabeçote porta- 
rebolo, já que a potência em vazio está diretamente ligada aos seus componentes (Jackson et al., 2001).

As quantidades e pressões dos fluidos de corte no processo de retificação são um dos principais focos de atenção no projeto de retificadoras. As perdas relacionadas com o aumento da velocidade de corte são complementares as perdas relacionadas com a lubri-refrigeração do processo e o sistema de limpeza do rebolo (Figura 2.4). Estas perdas dependem dos parâmetros do processo e, portanto, devem ser otimizadas para a retificação de alta velocidade de corte (Jackson et al., 2001).

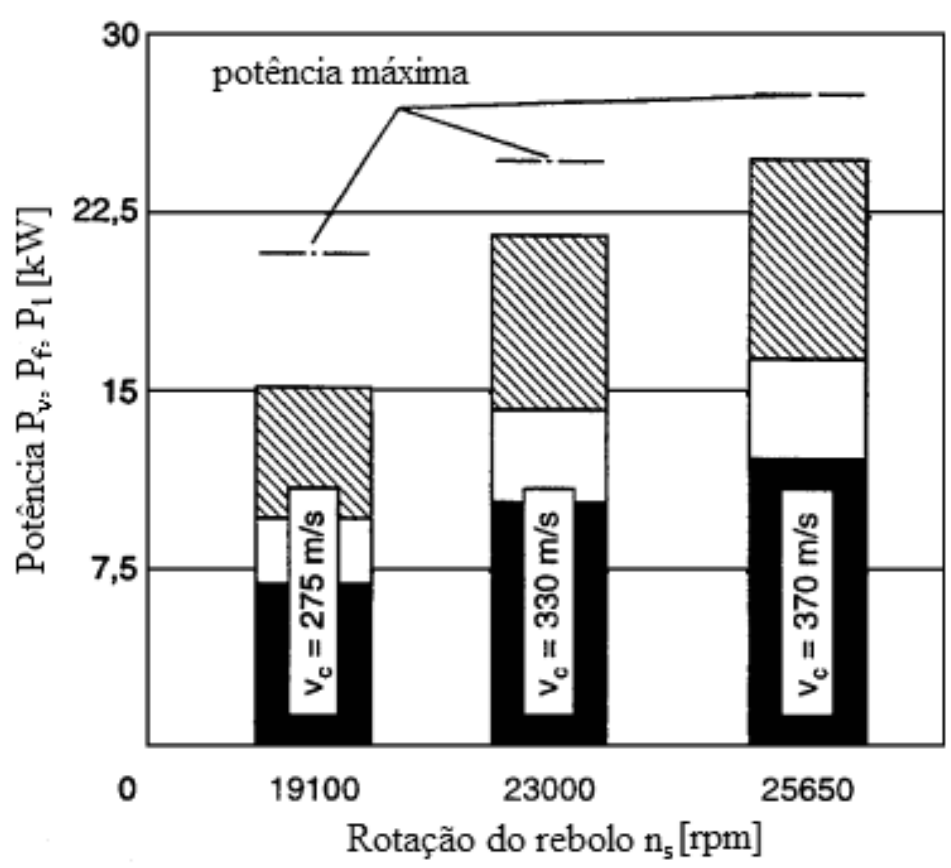

rebolo: CBN B252 GSS

diâmetro do rebolo: $\mathrm{d}_{\mathrm{S}}=275 \mathrm{~mm}$ sist. de lubri-refrigeração: $300 \mathrm{~V} / \mathrm{min}, 2 \mathrm{MPa}$ sist. de limpeza do rebolo: $20 \mathrm{l} / \mathrm{min}, 1,5 \mathrm{MPa}$

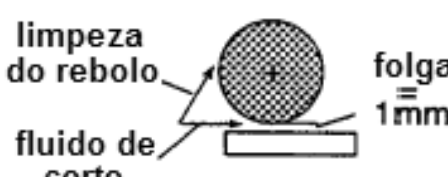
corte

Potência dissipada pelo sist. de limpeza $\left(P_{1}\right)$

Potência dissipada pelo fluido de corte $\left(P_{\mathrm{f}}\right)$

Potência em vazio $\left(P_{v}\right)$

Figura 2.4 - Níveis do consumo da $P_{v}, P_{f}$, e $P_{l}$ para retificação com rebolo de ligante galvânico de CBN (Werner, 1995 apud Jackson et al., 2001 - Adaptada).

Em seu estudo, Klocke et al. (1997) afirma que o aumento das perdas provocadas pelo fluido de corte e sistema de limpeza do rebolo (fluido de corte aplicado a alta pressão) é devido ao crescente atrito gerado entre o fluido e o rebolo e a necessidade de acelerar o fluido de corte de forma proporcional ao aumento da velocidade tangencial do rebolo. 
As consequiências positivas da retificação de alta velocidade, ou HSG (High Speed Grinding), têm origem na diminuição da espessura do cavaco indeformado $\left(h_{c u}\right)$. Também chamada de profundidade de corte de cada grão abrasivo, a espessura do cavaco indeformado expressa a máxima profundidade de corte alcançada por um único grão abrasivo dentro da zona de contato rebolo-peça (Malkin, 1989). Essa diminuição gera uma redução das forças normal e tangencial de retificação (Yui e Lee, 1996). Pode-se citar ainda a redução do desgaste do rebolo e o aumento da qualidade superficial da peça (Jackson et al., 2001). Além disso, existe também a possibilidade de aumentar a velocidade de avanço do rebolo $\left(v_{f}\right)$, possibilitando assim, a redução do tempo de retificação para o mesmo volume de material.

Os efeitos da HSG podem ser igualmente interpretados por qualquer um dos modelos básicos de espessura de cavaco. A espessura do cavaco indeformado $\left(h_{c u}\right)$ é dependente da densidade estática das arestas de corte $\left(C_{\text {stat }}\right)$, e de outras variáveis geométricas e cinemáticas, de acordo com a Equação 2.4 (König e Klocke, 1996 apud Kopac e Krajnik, 2006).

$$
h_{c u} \approx k\left[\frac{1}{C_{s t a t}}\right]^{\alpha}\left[\frac{v_{w}}{v_{s}}\right]^{\beta}\left[\frac{a_{e}}{d_{e q}}\right]^{\gamma}
$$

Onde, $a_{e}$ (ou $a$ ) é a profundidade de corte; $d_{e q}$ é o diâmetro equivalente do rebolo; $\alpha$, $\beta$ e $\gamma$ são expoentes positivos.

O segundo modelo é referente à espessura máxima do cavaco $\left(h_{m}\right)$ :

$$
h_{m} \approx c_{g w}\left[\frac{v_{w}}{v_{s}}\right]^{e}\left[\frac{a_{e}}{d_{e q}}\right]^{\frac{e}{2}}
$$

Onde, $c_{g w}$ é uma constante de topografia do rebolo; e o expoente $e$ é positivo (Klocke et al., 1997). 
Pelas equações 2.4 e 2.5 pode-se estabelecer que o aumento na velocidade de corte, com todas as outras variáveis constantes, resulta na diminuição da espessura do cavaco, e conseqüentemente nas forças de retificação. Isto pode ser utilizado para melhorar a qualidade da peça ou aumentar a taxa de remoção de material.

Pela Figura 2.5, pode-se observar as conseqüências do aumento da velocidade de corte mantendo-se a taxa de remoção de material constante. A redução da espessura do cavaco melhora a rugosidade e reduz as forças de corte, diminuindo assim o desgaste do rebolo. Isto é particularmente atraente para melhorar a precisão de forma e dimensão do componente retificado quando a rigidez da estrutura mecânica é baixa (Klocke et al., 1997).

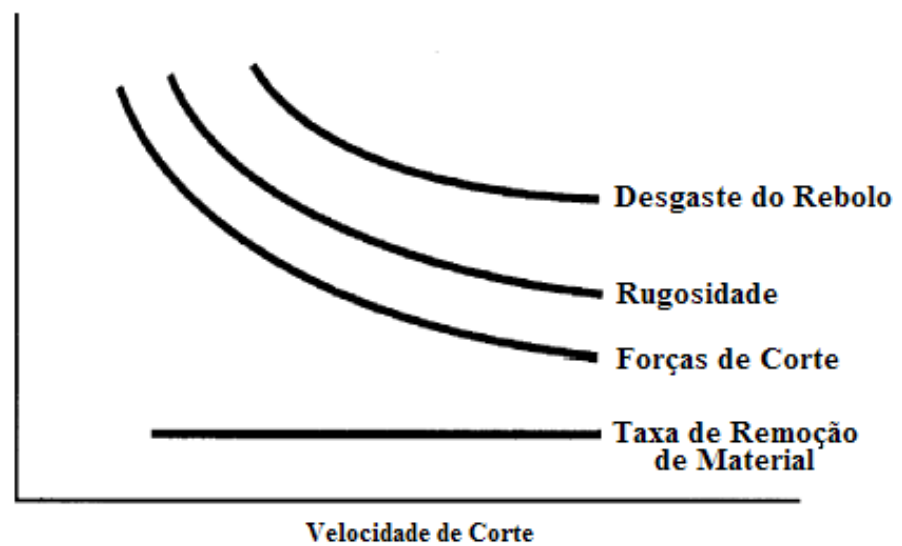

Figura 2.5 - Retificação de alta velocidade de corte com taxa de remoção de material constante (Klocke et al., 1997 - Adaptada).

Já a Figura 2.6 mostra o efeito do aumento da velocidade de corte e taxa de remoção de material, mantendo-se a espessura do cavaco constante. Desta forma, a velocidade da peça aumenta na mesma proporção da velocidade de corte. Este caso é interessante quando se deseja aumentar a taxa de remoção de material sem aumentar as forças de corte do processo (Klocke et al., 1997). 


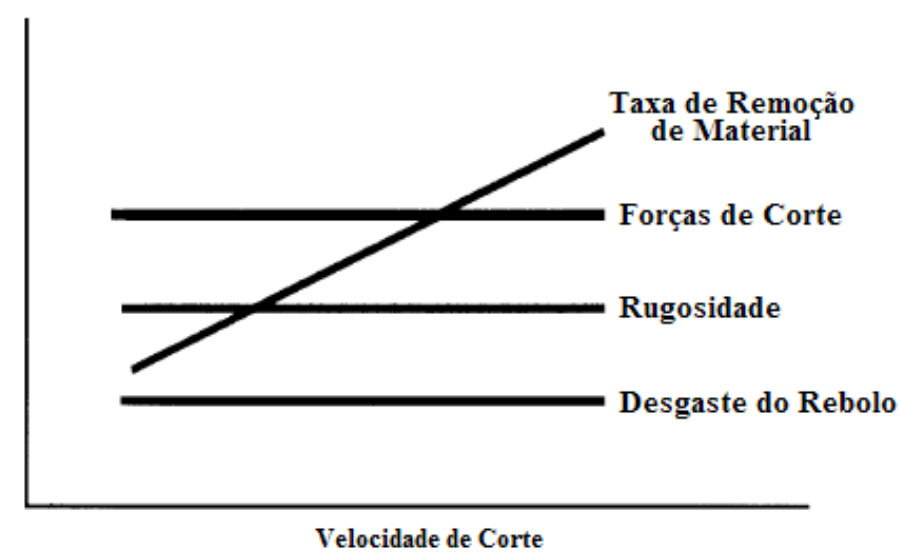

Figura 2.6 - Retificação de alta velocidade de corte com espessura do cavaco constante (Klocke et al., 1997 - Adaptada).

De acordo com Kopac e Krajnik (2006), a Figura 2.5 representa um processo HSG de alta qualidade, enquanto que a Figura 2.6 apresenta um processo HSG de alta produtividade.

O aumento da velocidade periférica do rebolo $\left(v_{s}\right)$, ou velocidade de corte, proporciona também uma redução da temperatura da zona de contato rebolo-peça (Tawakoli, 1990; Tawakoli, 1993 apud Silva, 2004) (Figura 2.7.).

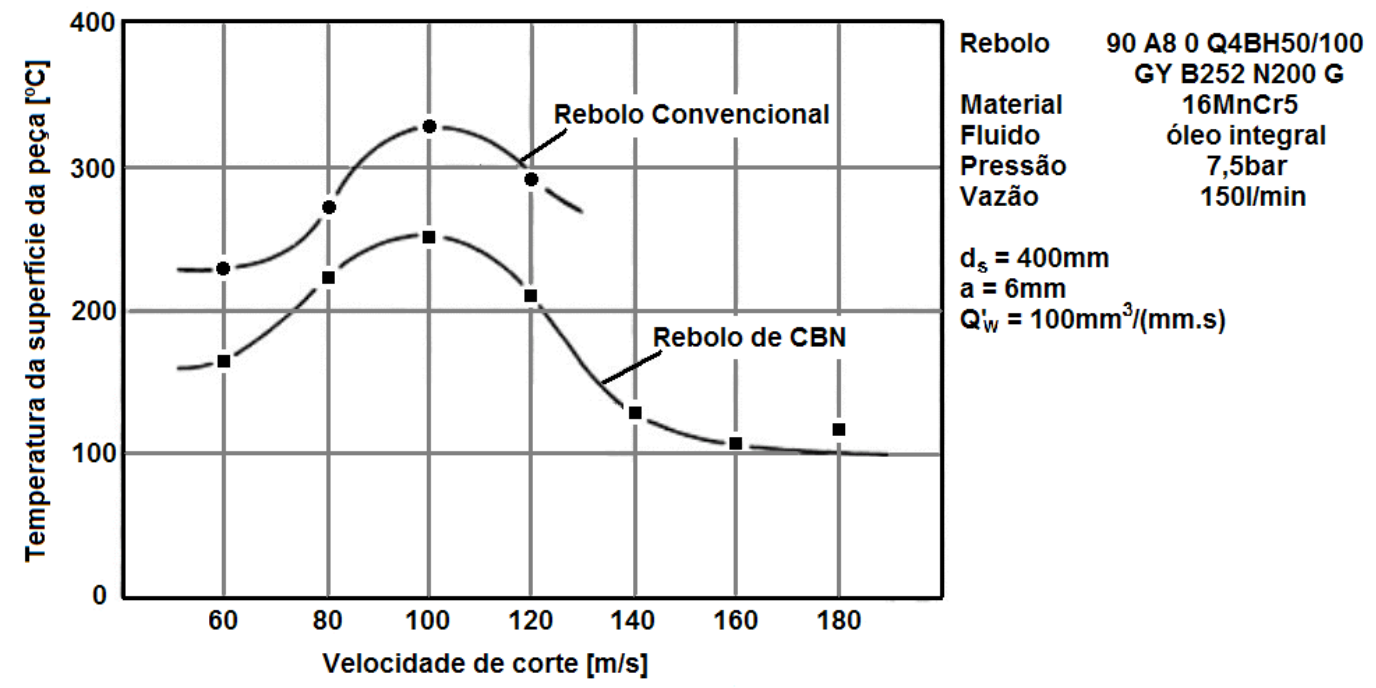

Figura 2.7 - Temperatura da superfície da peça versus velocidade periférica de rebolos de CBN e de óxido de alumínio (Tawakoli, 1993 apud Silva, 2004 - Adaptada). 
De acordo com Klocke et al. (1997), o aumento de $v_{s}$ normalmente não é acompanhado pela redução proporcional da força tangencial de retificação, resultando no aumento do calor gerado. Isto pode ser visto na Figura 2.7 para as velocidades de corte de 60 a $100 \mathrm{~m} / \mathrm{s}$.

No entanto, para velocidades maiores do que $100 \mathrm{~m} / \mathrm{s}$, apesar do processo de retificação gerar ainda mais calor, a temperatura no contato rebolo-peça diminui.

Este fenômeno ocorre, pois em altas velocidades o tempo de contato dos grãos abrasivos é tão pequeno que o processo térmico se torna adiabático, já que o calor gerado pela interação entre a ferramenta de corte e a peça não tem tempo suficiente para se propagar em direção à peça antes de ser removido pelo grão abrasivo posterior (Hitchiner, 1999). Neste caso, a maior parte do calor gerado no processo é dissipada pelos grãos abrasivos do rebolo que se desprendem e pelos cavacos da peça (Tawakoli, 1993 apud Silva, 2004).

Outro aspecto importante no processo de retificação é o custo. Um estudo realizado por Rowe et al. (2004) que levou em consideração diversos componentes de custeio, tais como: custos de diferentes tipos de rebolos, de mão-de-obra e relativos à máquina; concluiu que o processo de retificação de alta velocidade de corte com rebolos de CBN possui custos menores, mesmo com uma máquina mais cara. De acordo com o estudo, o processo de retificação convencional com rebolo de CBN também obteve bons resultados devido a grande quantidade de peças feitas entre as operações de dressagem.

Com o aumento da velocidade de corte do rebolo, algumas desvantagens podem ocorrer. Inicialmente, pode-se citar o encarecimento dos rebolos de corte, já que os mesmos são submetidos a altas rotações e por isso são considerados "especiais". Estes rebolos devem, por exemplo, ser capazes de suportar a elevada força centrífuga e minimizar a expansão 
dimensional por ela produzida, o que poderia ocasionar erro na dimensão final da peça (Yui e Lee, 1996).

Existem três campos principais de estudo e aplicação da retificação de alta velocidade (Jackson et al., 2001). Estes são:

- Retificação de alta velocidade com rebolos de CBN;

- Retificação de alta velocidade com rebolos de óxido de alumínio; e

- Retificação de alta velocidade com rebolos de óxido de alumínio em conjunto com técnicas de dressagem contínua (CD - Continuous Dressing).

A Figura 2.8, mostra a taxa de remoção de material versus a velocidade de corte para estes três principais campos (Jackson e Mills, 2004).

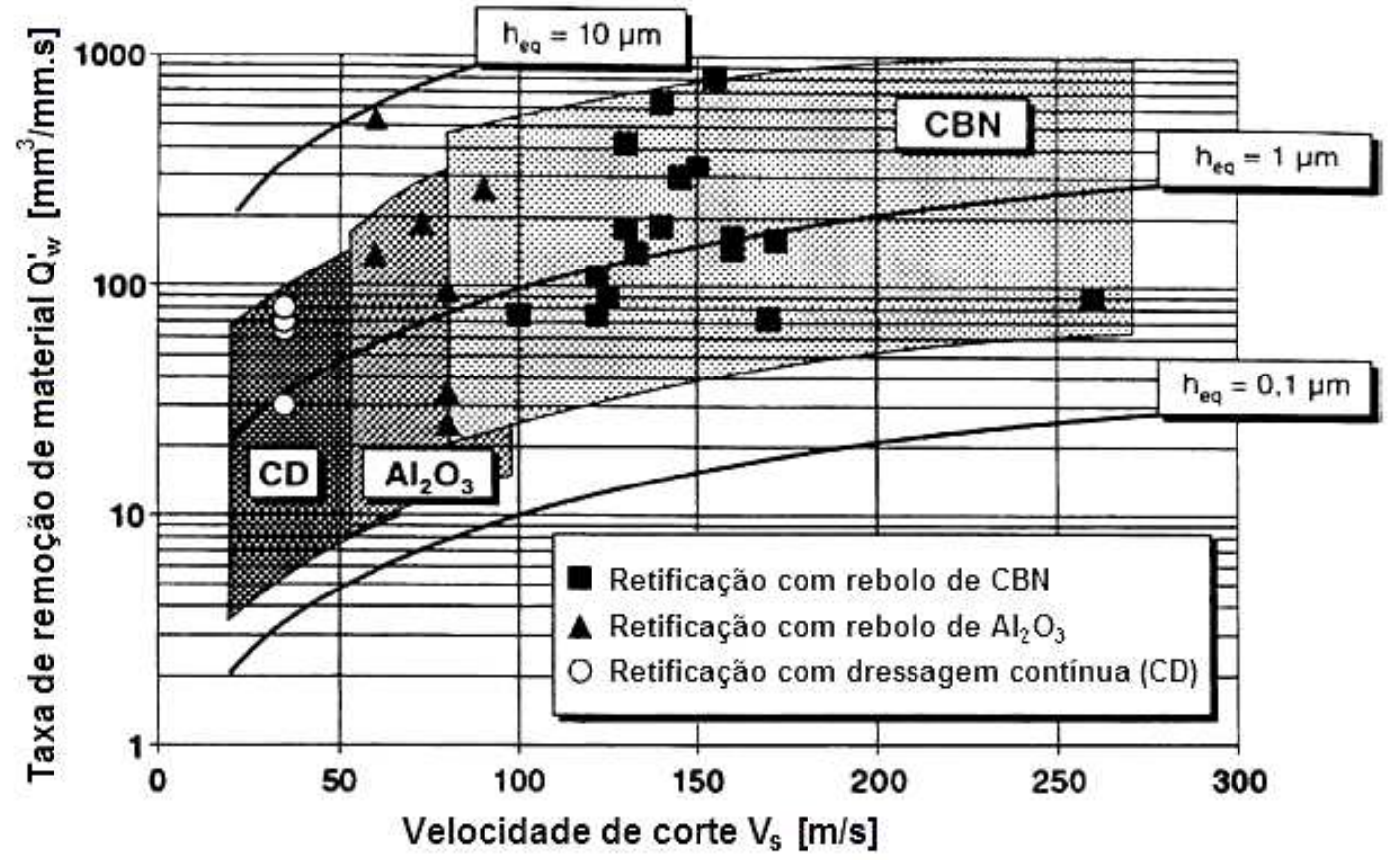

Figura 2.8 - Principais campos de aplicação da retificação de alta velocidade (Jackson e Mills, 2004 - Adaptada). 


\subsection{O Rebolo de CBN}

Existe uma grande tendência de utilização de rebolos de CBN (Nitreto Cúbico de Boro) no mercado. Abrangendo indústrias tais como: automobilísticas; aeroespaciais; de componentes de motores etc. Embora o rebolo de CBN tenha um elevado custo inicial, comparado com rebolos de óxido de alumínio, sua aplicação é compensada desde que o custo operacional total seja reduzido (Oliveira et al, 2002).

De acordo com Chen et al. (2002), a retificação com rebolos de CBN está sujeita ao uso de técnicas especiais, tais como: rebolos com alta porosidade para a usinagem de materiais de difícil corte, alta velocidade de corte, técnicas especiais de dressagem, sistema de refrigeração eficiente, dentre outras. As vantagens do rebolo de CBN só podem ser alcançadas quando todos os fatores importantes do processo forem controlados.

Diversos estudos já mostraram a maior vida do rebolo de CBN em relação aos rebolos convencionais, deste modo, sabe-se que a utilização do mesmo gera uma maior economia no processo como um todo (Hitchiner, 1999).

Os danos térmicos provocados pela retificação com rebolos superabrasivos de CBN são, na maioria das vezes, de grandeza menor do que os que ocorrem na retificação com rebolos convencionais (Malkin, 1985). Fazendo-se uso dos rebolos de CBN, a queima da peça raramente ocorre e as tensões residuais são predominantemente de compressão (Tönshoff e Grabner, 1984; Vansevenat, 1989). Podendo-se concluir que são geradas menores temperaturas de retificação na região de corte. Isto pode ser parcialmente atribuído à menor energia gasta para a retificação com rebolos de $\mathrm{CBN}$, devido à maior dureza de seus grãos (Kohli et al., 1995). Além disso, sabe-se que a condutividade térmica do CBN é maior que a 
dos materiais abrasivos utilizados nos rebolos convencionais. Desta forma, a capacidade de corte do rebolo de CBN se mantém durante tempos maiores, diminuindo assim o seu desgaste.

Outra explicação para a geração de menores temperaturas nos processos de retificação com rebolos de $\mathrm{CBN}$ deve-se ao fato da maior condutividade térmica de seus grãos abrasivos, quando confrontada com a do óxido de alumínio. Desta forma, uma quantidade muito maior de calor gerado pelo processo é transportada para fora da zona de retificação pela ferramenta abrasiva, ao invés do mesmo fluir para a peça. (Lavine et al., 1989). Assim, a menor partição de energia permite uma diminuição das temperaturas na região de contato e também, uma menor tendência de ocorrência de danos térmicos à peça.

Além disso, a utilização do rebolo de CBN também gera, na maioria dos casos, tensões residuais de compressão na superfície e subsuperfície de peças retificadas, aumentando assim, a resistência à fadiga e conseqüentemente a vida útil do componente (Oliveira et al., 2002).

O rebolo de $\mathrm{CBN}$ normalmente consiste de um corpo cilíndrico de alta rigidez estrutural e uma fina camada externa de abrasivo (grãos de CBN) misturado com um tipo de ligante, sendo esta mistura presa ao corpo por meio de um adesivo (Jackson et al., 2001).

De acordo com Hitchiner (1990), o corpo cilíndrico, geralmente feito em aço, alumínio ou baquelita (resina polimérica sintética), confere alta precisão dimensional ao rebolo, além de evitar problemas com o desbalanceamento devido à retenção de fluido de corte - fato este que ocorre nos rebolos convencionais pela porosidade do seu corpo. 


\subsubsection{Características Técnicas}

A estrutura de um rebolo é composta basicamente de um corpo cilíndrico e de segmentos abrasivos distribuídos na sua periferia. Esta região abrasiva tem sua estrutura formada por grãos abrasivos, ligantes e poros (Figura 2.9).

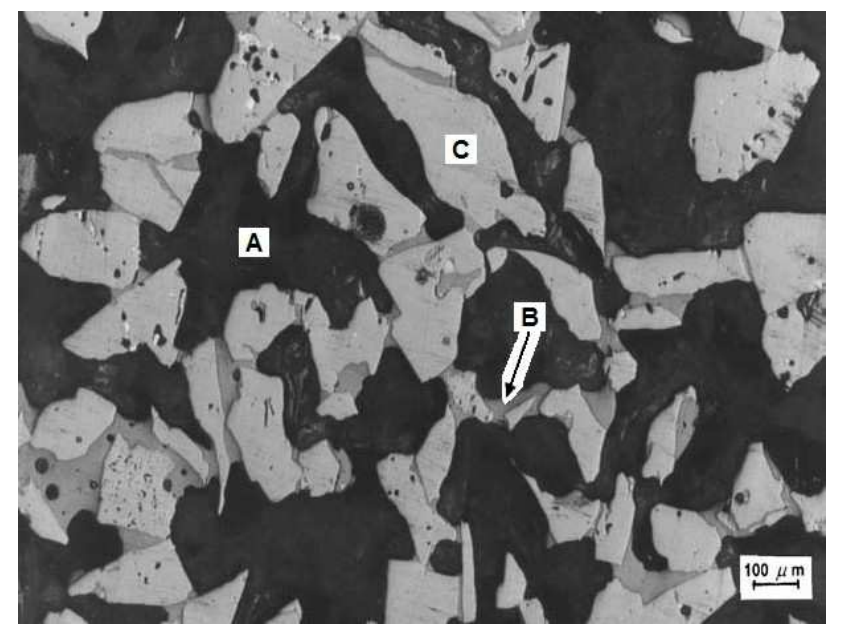

Figura 2.9 - Microestrutura de um rebolo de ligante vitrificado. (A) porosidade distribuída;

(B) ligante vitrificado; e (C) grão abrasivo. (Jackson e Mills, 2004 - Adaptada).

\section{Tipos de Ligante}

Existem vários tipos de ligantes para rebolos de CBN. Podem-se classificar estes tipos em ligante de camada única de abrasivo e de múltiplas camadas.

O rebolo de ligante de camada única possui uma única camada de abrasivos de CBN. Neste caso, quem fixa os grãos ao corpo do rebolo é um ligante metálico eletro-depositado (ou galvânico). O níquel é um exemplo de ligante galvânico que possui ótimas características de ancoragem dos grãos abrasivos. Geralmente a vida-útil do rebolo termina com o desgaste destes grãos (Jackson et al., 2001). Para Kopac e Krajnik (2006), este tipo de ligante permite as maiores taxas de remoção de material no processo de retificação.

De acordo com Weingaertner e Severiano (2006), a espessura da camada do ligante galvânico varia de 30 a 70\% da altura do grão, dependendo da aplicação e características do 
processo. Já os ligantes de múltiplas camadas para rebolos de CBN podem ser: metálico, resinóide e vitrificado (Kopac e Krajnik, 2006).

- Ligante resinóide: resinas fenólicas e de poliamida são utilizadas na maioria destes rebolos produzidos. São capazes de altas taxas de remoção de material, mas possuem baixa capacidade de manter a sua forma e vida-útil;

- Ligante metálico: são os materiais mais resistentes usados como ligantes de rebolos. Estes rebolos oferecem grande precisão para a peça e altas taxas de remoção de material; e

- Ligantes vitrificados: a flexibilidade de uso deste tipo de ligante permite que o rebolo ofereça ao processo uma grande faixa de taxas de remoção de material e acabamentos superficiais. Como resultado, o ligante vitrificado está se tornando muito importante nas diversas aplicações de retificação.

A Figura 2.10 mostra os tipos de ligantes e suas respectivas faixas de velocidade tangencial do rebolo $\left(v_{s}\right)$ e taxa de remoção de material $\left(Q^{\prime}{ }_{w}\right)$ (Jackson et al., 2001).

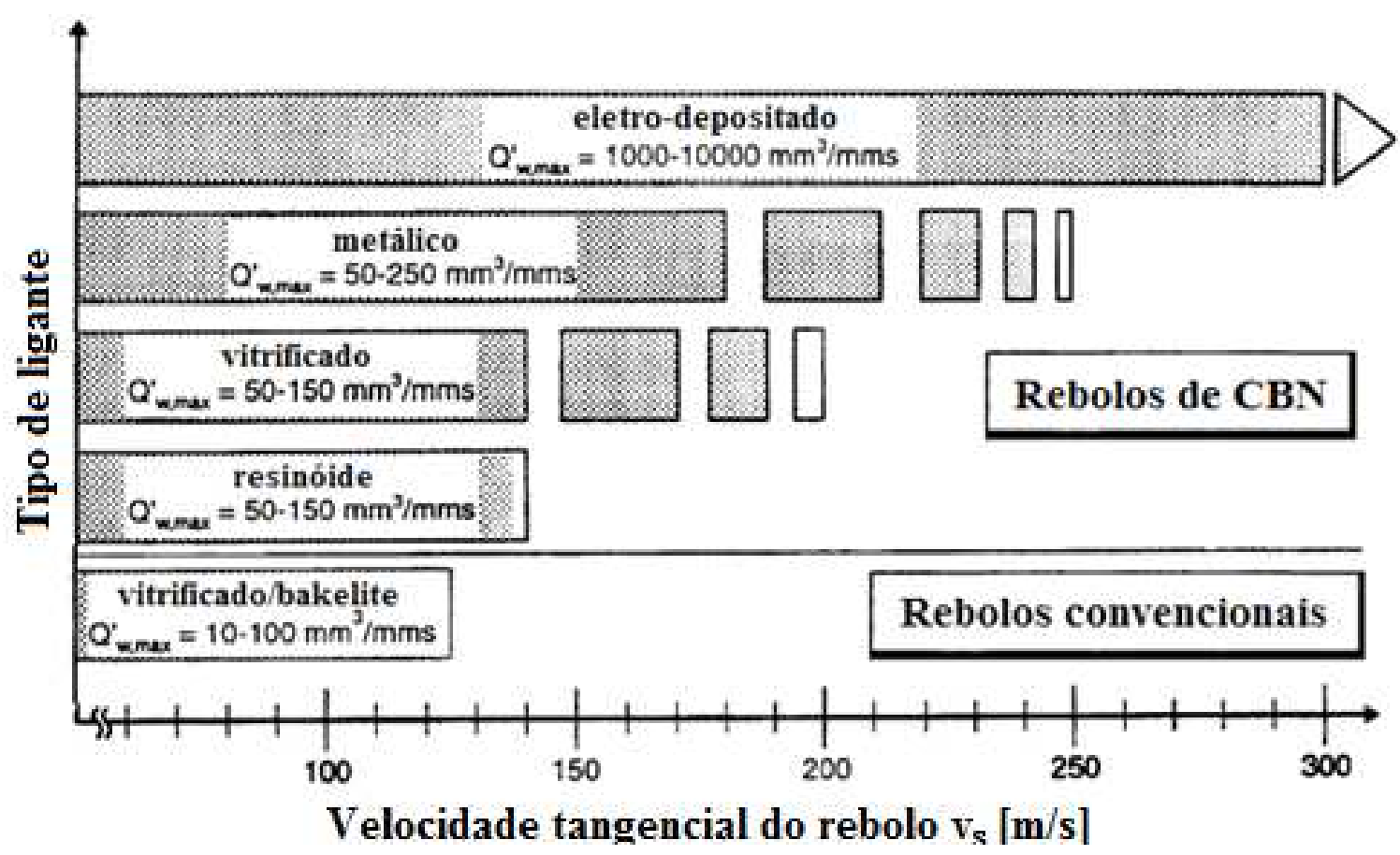

Figura 2.10 - Tipos de ligante versus velocidade tangencial do rebolo $\left(v_{s}\right)$ com a taxa de remoção de material $\left(Q^{\prime}{ }_{w}\right)$ (Martin e Yegenoglu, 1992 apud Jackson et al., 2001 - Adaptada). 
A faixa de tipos de ligantes vitrificados é muito ampla, no entanto, apenas os tipos silicato alcalino de alumínio e borossilicato de alumínio são utilizados pela indústria de rebolos abrasivos. A prática usual é ajustar as proporções de $\mathrm{Al}_{2} \mathrm{O}_{3}, \mathrm{~B}_{2} \mathrm{O}_{3}, \mathrm{SiO}_{2}$ e óxidos alcalinos para atingir as propriedades desejadas, tais como: molhabilidade, viscosidade, adesão etc. Outras propriedades físicas e químicas podem ser alcançadas pela adição dos óxidos alcalino-terrosos. O ligante vitrificado é composto da mistura de quartzo, feldspato, argila, minerais boratos e outras matérias-primas do vidro (Jackson e Mills, 2004).

O ligante vitrificado utilizado para rebolos de $\mathrm{CBN}$ geralmente possui maior resistência mecânica do que os ligantes vitrificados empregados nos rebolos convencionais, para o mesmo tamanho de grão. Pois se deve evitar a perda de grão pela fratura do ligante já que o grão de CBN possui menor taxa de desgaste (maior dureza) (Chen et al., 2002).

O potencial para a aplicação prática do ligante vitrificado na retificação de alta velocidade ainda deve ser mais profundamente explorado. O conjunto de corpos de rebolos especialmente projetados e novos ligantes vitrificados permite velocidades de corte de até 200 m/s. Em comparação com outros tipos de ligantes, o vitrificado permite uma dressagem fácil apesar de sua alta resistência ao desgaste abrasivo. Ao contrário dos densos ligantes resinóides e metálicos, a porosidade do ligante vitrificado na estrutura do rebolo pode ser ajustada em uma ampla faixa por variações na sua fórmula e processo produtivo (Jackson et al., 2001; Klocke et al., 1997).

De acordo com Chen et al. (2002), a utilização de rebolos de alta porosidade ajuda o fluido de corte a atingir a zona de contato mais facilmente, além de fornecer mais espaço para acomodar os cavacos produzidos no processo. Este tipo de rebolo é muito eficaz na retificação de materiais de difícil usinagem, como o inconel 718. No seu estudo, foram comparados dois tipos de rebolos de $\mathrm{CBN}$ de granulação fina na retificação interna: rebolo com alta 
porosidade; e rebolo de estrutura convencional. Os resultados mostraram que o rebolo de estrutura de alta porosidade obteve maiores valores de relação $G$ e menor rugosidade média para velocidade de corte de $50 \mathrm{~m} / \mathrm{s}$. Os resultados foram ainda mais expressivos quando a velocidade de corte utilizada foi de $60 \mathrm{~m} / \mathrm{s}$. A relação $G$ do rebolo de alta porosidade dobrou com o aumento da velocidade e a rugosidade diminuiu ainda mais.

\section{O Grão de $C B N$}

O Nitreto Cúbico de Boro ( $\mathrm{CBN})$, junto com o diamante, são denominados de superabrasivos devido a algumas de suas características, tais como: alta dureza, alta resistência ao desgaste e prolongada vida-útil (Kopac e Krajnik, 2006).

Devido à sua alta dureza, resistência térmica e química, o CBN é perfeitamente apropriado para retificação de aços difíceis de usinar, como aços ligados e com durezas superiores a 55 HRc. Um grão de $\mathrm{CBN}$, como mostra a Figura 2.11, além de ser extremamente duro, possui alta condutividade térmica e, portanto, uma vida-útil centenas de vezes maior do que um grão convencional (Kopac e Krajnik, 2006).
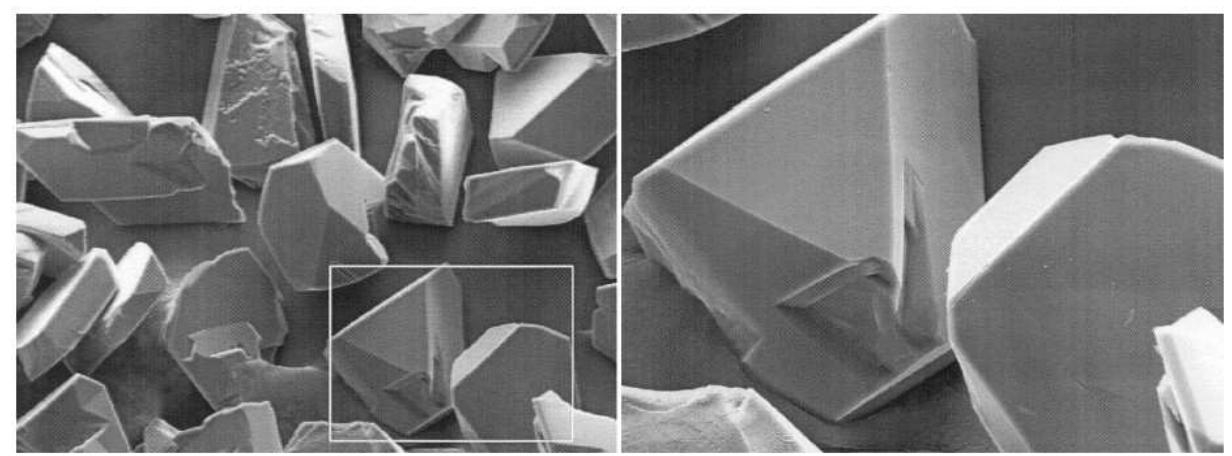

Figura 2.11 - Grãos de CBN (Jackson et al., 2001 - Adaptada).

De acordo com, Inasaki et al. (1993), os grãos de CBN possuem uma alta capacidade de gerar novas arestas de corte quando fraturados (grãos friáveis), promovendo, desta forma, a auto-afiação do rebolo. Estas características fazem com que o grão de CBN seja muito 
utilizado na fabricação de rebolos para o processo de retificação. A Figura 2.12 mostra algumas das vantagens no uso dos rebolos de CBN.

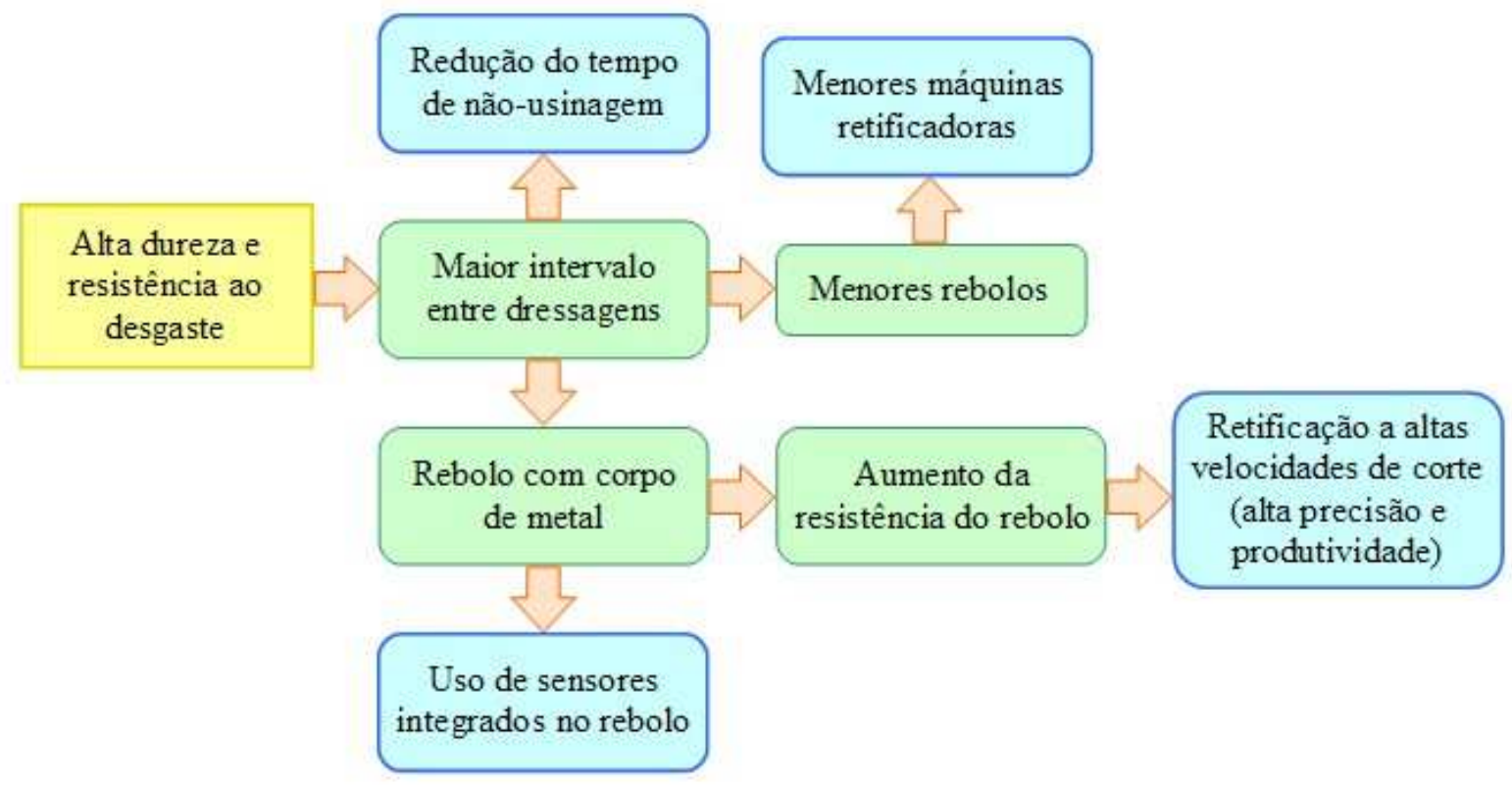

Figura 2.12 - Vantagens dos rebolos com grãos de CBN (Inasaki et al., 1993 - Adaptada).

\subsubsection{O Fenômeno de Desgaste do Rebolo de CBN}

A retificação é acompanhada pelo contínuo desgaste do rebolo abrasivo e a taxa deste desgaste define uma importante regra para determinar a eficiência do processo e a qualidade da peça (Jackson e Mills, 2004).

O critério para a escolha de um rebolo é normalmente baseado no comportamento ao desgaste do mesmo para a operação em questão. Este desgaste é de natureza física e química. A influência de cada tipo de desgaste dependerá das condições de usinagem e da combinação rebolo-peça. (Stetiu e Lal, 1974).

De acordo com Graham e Voutsadopoulos (1978), a curva de desgaste do rebolo, Figura 2.13, possui três regiões distintas. 


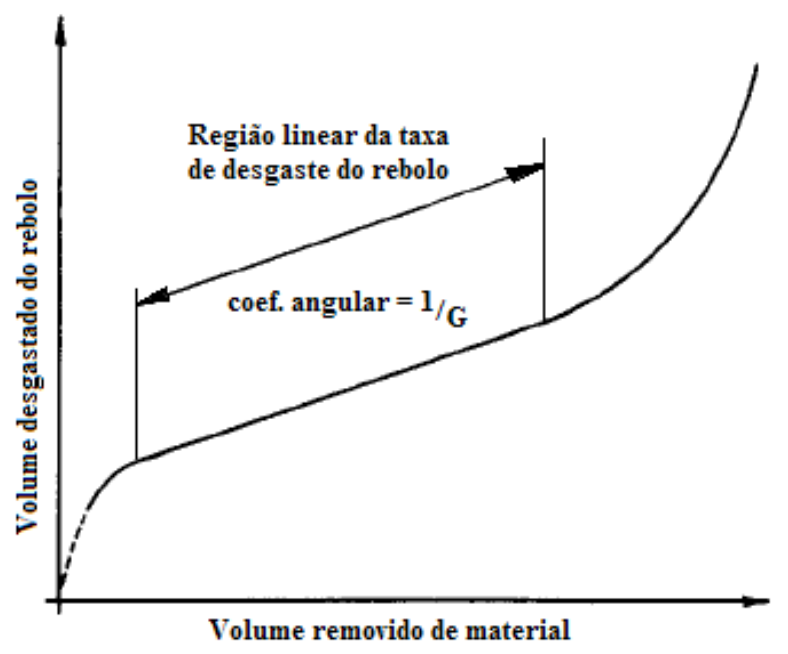

Figura 2.13 - Curva do desgaste do rebolo versus volume do material removido (Graham e Voutsadopoulos, 1978 - Adaptada).

A primeira região se caracteriza por um desgaste muito acentuado do rebolo caracterizado pela fácil remoção de grãos abrasivos (em pedaços ou inteiros). A causa deste fenômeno é o desalojamento e/ou enfraquecimento do grão devido ao processo de dressagem do rebolo. Esta fase inicial é considerada quase que instantânea para grande parte dos casos.

Depois disso, a taxa de desgaste do rebolo torna-se constante e com os valores mais baixos da curva inteira. O coeficiente angular da reta nesta região é igual ao inverso da relação $G$, que é a razão entre o volume de material usinado pelo volume desgastado do rebolo. Na terceira região a taxa de desgaste do rebolo aumenta drasticamente e o processo de retificação de forma geral se torna barulhento e insatisfatório. Comumente, a dressagem é feita antes desta região ou no momento de mudança da inclinação da curva. É importante salientar que nem todos os rebolos possuem o comportamento de desgaste explicitado na Figura 2.13, com três regiões distintas. Características do rebolo como o tipo e a dureza do ligante ou a sua porosidade podem provocar curvas distintas de desgaste.

De acordo com Malkin (1989), existem três tipos de mecanismos de desgaste (Figura 2.14): desgaste por atrito (A); fratura do grão (B); e fratura do ligante (C). 


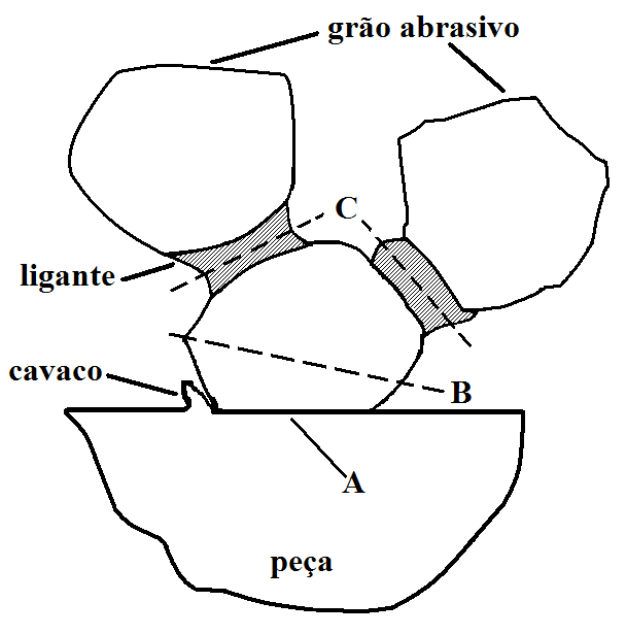

Figura 2.14 - Mecanismos de desgaste (Malkin, 1989 - Adaptada).

Outros autores, como Jackson e Mills (2004), ainda classificam um quarto mecanismo de desgaste chamado de fratura da interface grão-ligante (Figura 2.15). Onde: I mostra um grão abrasivo de superfície desgastada (A); II - apresenta uma fratura de ligante com grão abrasivo (A), interface grão-ligante (B) e ligante (C); III - apresenta um grão fraturado (A); e IV - exibe uma fratura da interface grão-ligante.
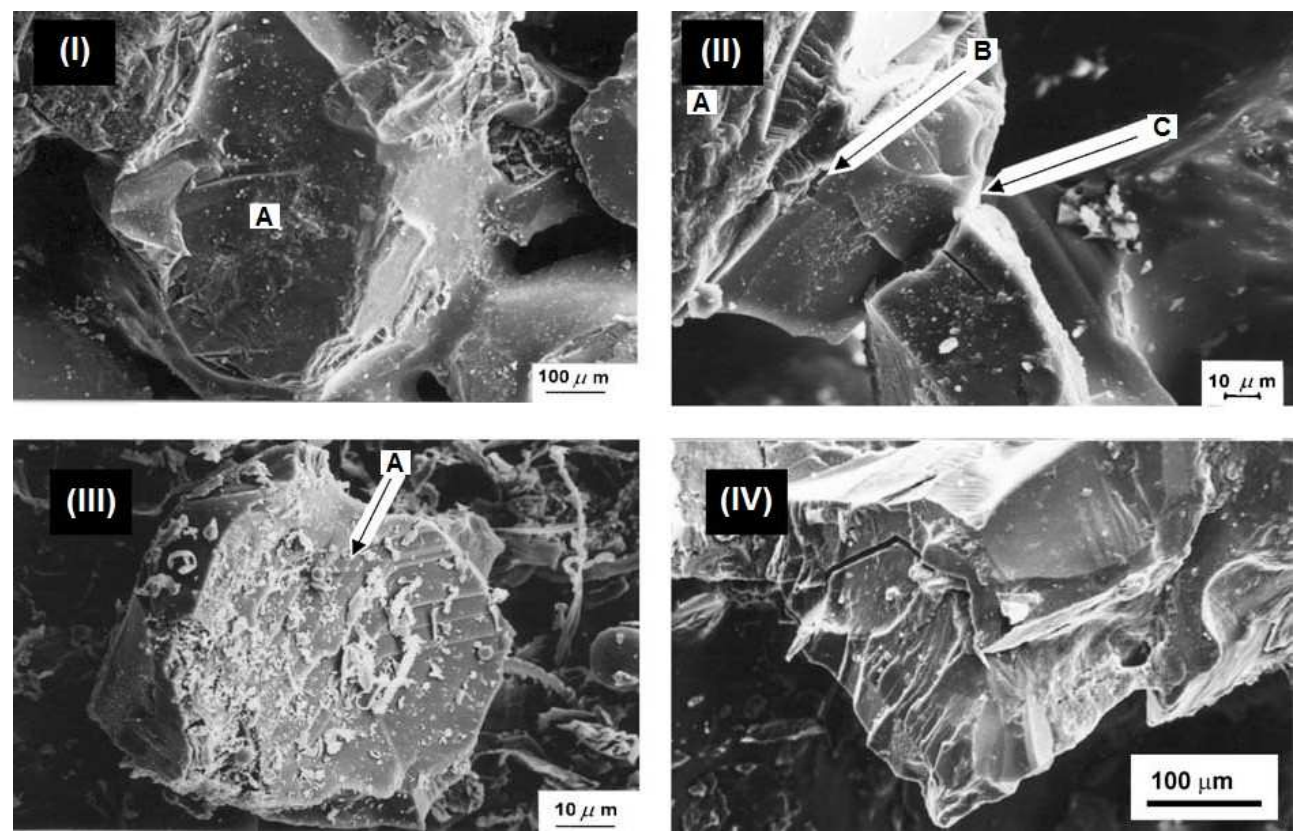

Figura 2.15 - Mecanismos de desgaste (Jackson e Mills, 2004 - Adaptada). 


\section{$\underline{\text { Desgaste por Atrito }}$}

O desgaste por atrito gera o arredondamento das arestas de corte do grão abrasivo. De acordo com Graham e Voutsadopoulos (1978), este arredondamento é gradual e resulta na perda da agressividade inicial do grão.

Este tipo de desgaste tem a menor contribuição para redução do volume do rebolo, no entanto, é o fenômeno mais importante para a definição do fim de sua vida. O seu aumento causa uma elevação das forças de retificação e da temperatura, o que leva a uma diminuição da qualidade e integridade superficial da peça usinada (Hassui et al., 1998).

De acordo com Jackson e Mills (2004), as causas deste desgaste são:

- Desgaste devido ao atrito entre o material da peça e o grão abrasivo;

- Escoamento plástico do grão abrasivo devido às altas pressões e temperaturas de contato;

- Fragmentação do grão pela difusão térmica e micro-impacto mecânico; e

- Reação química entre o material da peça e grão abrasivo em condições de altas temperaturas e na presença de fluido de corte.

Grãos desgastados geram um aumento da área de contato e do atrito entre a peça e o grão. Neste ponto de desgaste do grão abrasivo, altas temperaturas se tornam inerentes ao processo, o que provoca uma forte adesão, e também, reações químicas entre as duas superfícies. Se a fratura do grão ou ligante não ocorrer neste momento, a superfície plana do grão torna-se mais larga e a taxa de desgaste aumenta. Se a fratura persistir em não ocorrer, característica dos rebolos de alta dureza, a faixa do rebolo em contato com a peça se torna de aparência vitrificada e a peça sofre danos térmicos (Jackson e Mills, 2004). 
De acordo com Hitchiner e Wilks (1987), o desgaste por atrito provoca um aumento da força normal de retificação e conseqüente aumento das tensões no ligante e grãos abrasivos, causando assim, fraturas nos mesmos.

\section{Desgaste por Fratura do Grão}

A fratura do grão ocorre quando as tensões induzidas no mesmo são muito altas, causando deste modo, a fratura do grão em pedaços livres que escapam do rebolo. Estas tensões são oriundas do próprio carregamento mecânico, ou ainda, induzidas termicamente. Este tipo de fratura, quando é da mesma ordem de grandeza da espessura do cavaco indeformado, é considerado benéfico para o processo, pois gera novas arestas de corte fazendo com que o processo continue de maneira satisfatória (Graham e Voutsadopoulos, 1978).

Em um trabalho realizado por Graham e Voutsadopoulos (1978), foi estudada a relação entre o desgaste do rebolo e a natureza das tensões aplicadas em seus grãos ativos provenientes das forças de retificação. Valores de força de retificação foram extraídos de trabalhos publicados anteriormente e aplicados no que seria a região de contato rebolo-peça em um modelo ideal de grão abrasivo. Assim, foi realizada uma investigação destas tensões no grão por meio de técnicas de elementos finitos.

Neste mesmo trabalho, a natureza frágil dos grãos abrasivos em geral foi levada em consideração. Esta característica é muito importante quando se analisam as tensões aplicadas no grão. Sabe-se que materiais frágeis, como os abrasivos cerâmicos óxido de alumínio $\mathrm{Al}_{2} \mathrm{O}_{3}$ e carbeto de silício - $\mathrm{SiC}$, possuem baixa resistência à tração e alta resistência à compressão (Van Vlack, 1984). 
Os resultados obtidos mostraram que existem duas regiões onde o início da fratura do grão é mais provável (Figura 2.16).

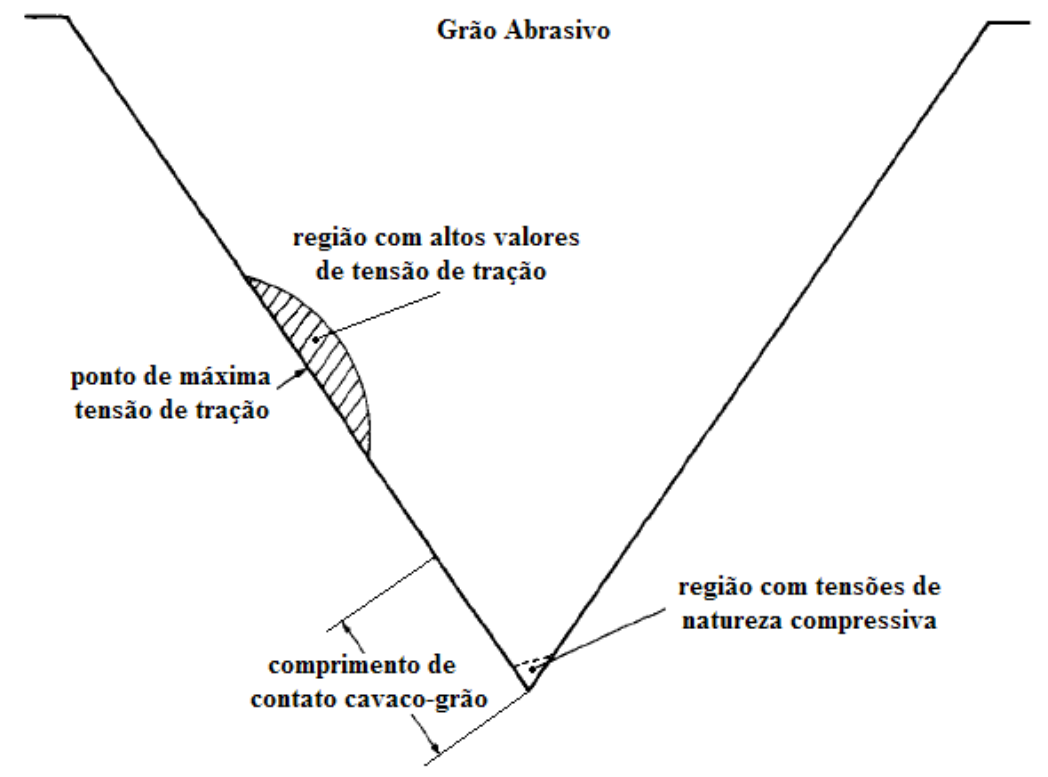

Figura 2.16 - Fratura frágil em modelo de grão (Graham e Voutsadopoulos, 1978 Adaptada).

A primeira é localizada na região ao redor do ponto onde existe o maior valor de tensão de tração. A falha gerada nesta região, localizada na face de saída do grão abrasivo, surge a uma distância da aresta de corte de duas a três vezes o comprimento de contato cavaco-grão. Esta fratura é da mesma ordem de grandeza da espessura do cavaco e pode ser relacionada com o aparecimento de novas arestas de corte.

A segunda região por sua vez, é muito menor que a primeira e quando de fato existe, está localizada nas proximidades da aresta de corte. De natureza compressiva, a falha é originada por um esmagamento de pequenas proporções e pode ser relacionada com a perda de agressividade do grão.

Desta forma, este trabalho concluiu que a perda de material abrasivo no processo de retificação é amplamente causada pelas fraturas do grão e do ligante. Estas fraturas são 
originadas principalmente por tensões de tração no grão e no ligante (Graham e Voutsadopoulos, 1978).

\section{Desgaste por Fratura do Ligante}

De acordo com Hassui et al. (1998), este tipo de desgaste, que ocorre principalmente em rebolos com ligante vitrificado, é o que mais influencia na perda de volume do rebolo.

Geralmente a fratura do ligante é mais propensa a ocorrer em rebolos de baixa dureza ou quando condições severas de retificação são empregadas (Graham e Voutsadopoulos, 1978).

O estudo realizado por Jackson e Mills (2004) afirma que para ligantes vitrificados, a fratura do ligante é de mesma natureza da fratura do grão, ou seja, frágil. Portanto a teoria de fratura frágil pode ser aplicada para ambos os mecanismos. Os carregamentos mecânicos e térmicos, geralmente sob condições cíclicas, causam a introdução e posterior desenvolvimento de trincas que ocasionam a fratura e o surgimento de novas superfícies irregulares.

De acordo com Stetiu e Lal (1974), a dureza do rebolo é a propriedade que mais influencia no fenômeno de desgaste. Para rebolos de baixa dureza, os mecanismos predominantes de desgaste são os de fratura do grão e ligante. Já para rebolos de alta dureza, o mecanismo de desgaste é o atrito.

Já para Jackson e Mills (2004), é muito difícil quantificar a parte de cada mecanismo de desgaste. Os autores afirmam que os rebolos de baixa dureza apresentam uma grande parcela do seu desgaste causada pela fratura do ligante e os rebolos de alta dureza pela fratura do grão. Afirmam também que existe a presença do desgaste por atrito em ambos os rebolos. 


\subsubsection{A Operação de Dressagem de Rebolos de CBN}

Para Oliveira et al. (1992), existem dois conceitos distintos de desgaste do rebolo. O primeiro está relacionado com o desgaste volumétrico do rebolo e o segundo com a perda da sua capacidade de corte. A retificação, sendo um processo de precisão, necessita de tolerâncias dimensionais estreitas no componente usinado e, portanto, o desgaste volumétrico deve ser evitado com a utilização de rebolos com maior capacidade de retenção dos grãos abrasivos. Desta forma, a dressagem se torna parte integrante da operação de precisão, pois, com o passar do tempo, o rebolo perde a sua agressividade. Ainda de acordo com o autor, a dressagem deve ser feita mais próxima possível deste ponto, pois se:

- A dressagem for feita após o ponto de reafiação, peças poderão ser produzidas com danos térmicos, trincas, rugosidade alta etc.; e

- A dressagem for feita antes do ponto de reafiação, haverá perda de tempo de produção e rebolo, já que a ferramenta ainda é capaz de produzir peças dentro das especificações.

A forma do grão e a distribuição das suas arestas de corte podem sofrer grande variação dependendo das condições de dressagem utilizadas. Desta forma, o efeito da dressagem influencia fortemente no processo de desgaste primário da ferramenta, podendo-se afirmar que o desempenho da retificação varia fortemente no ciclo imediatamente após a dressagem (Chen et al., 1998).

Os seguintes termos podem ser aplicados nas operações de preparação inicial de rebolos superabrasivos, cada um com seu significado específico (Hitchiner, 1999):

- Perfilamento (Truing): permite criar um rebolo com periferia geometricamente corrigida e concêntrica ao seu eixo de rotação, gerando, se necessário, um perfil especial na face do rebolo; 
- Avivamento (Conditioning): remoção preferencial do ligante para a exposição dos grãos abrasivos; e

- Dressagem (Dressing): operação simultânea de perfilamento do rebolo e avivamento de sua superfície, conferindo ao rebolo a agressividade necessária.

De acordo com Chen et al. (1998), não importam quais as condições de dressagem, os valores da potência de retificação e rugosidade da peça tendem a convergir para valores similares quando as mesmas condições de usinagem são utilizadas. As diferenças restantes podem ser explicadas pelo efeito da dressagem na densidade dos grãos da superfície do rebolo. Contudo, diferenças significativas podem ocorrer no número de ciclos entre as operações de dressagem.

A Figura 2.17 exibe a diferença entre dois tipos de dressagem: a dressagem grosseira e a fina. Esta diferença está baseada no passo de dressagem $\left(S_{d}\right)$ e na profundidade de dressagem $\left(a_{d}\right)$. Quando o valor de $S_{d}$ e $a_{d}$ são altos, a dressagem é considerada grosseira e a densidade de arestas de corte é baixa. Esta topografia de rebolo gera baixos valores de potência de corte e alta rugosidade no início da operação. Já a dressagem fina possui valores de passo e profundidade de dressagem menores e gera uma topografia com alta densidade de arestas de corte. Neste caso, o valor da potência de corte no início da operação é alto e este tipo de dressagem gera superfícies com baixos valores de rugosidade (Chen et al., 1998). Além disso, Xue et al. (2002) afirmam que as forças de retificação e a temperatura na zona de contato também aumentam para a mesma situação. 


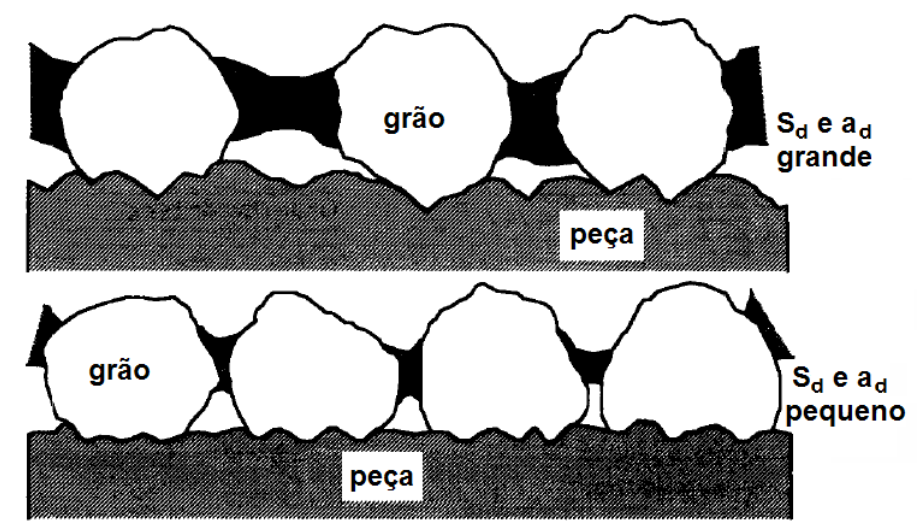

Figura 2.17 - Efeitos do passo de dressagem $\left(S_{d}\right)$ na topografia do rebolo (Chen et al., 1998 Adaptada).

Para Ramesh et al. (2005), as técnicas usuais de dressagem de rebolos de CBN com ligantes vitrificados oferecem relações de desgaste de dressagem (razão entre o volume do rebolo consumido e o volume desgastado do dressador) baixas. No seu trabalho, foi estudada a influência da técnica de dressagem com velocidades reversas na preparação de um rebolo de CBN com ligante vitrificado, utilizando um dressador de copo vertical. Esta técnica se baseia na sucessiva mudança do sentido de rotação do dressador de forma a variar abruptamente a velocidade relativa entre o rebolo e o dressador. Esta mudança rápida na velocidade relativa faz com que os grãos abrasivos e o ligante fiquem sujeitos a constantes tensões cíclicas que acabam por introduzir micro-fraturas nos mesmos, melhorando a topografia do rebolo. Desta forma, os grãos abrasivos ficam mais expostos e o rebolo com baixo erro de forma. Além disso, o experimento mostrou que esta técnica é capaz aumentar de duas a três vezes a relação de desgaste de dressagem.

De acordo com Chen et al. (2002), na operação de dressagem de rebolos de CBN, as forças geradas são altas devido à alta dureza do grão, o que acaba por arrancar grãos abrasivos superficiais e expor o ligante na superfície do rebolo. Isto faz com que o valor da potência de corte seja alto no início da retificação. Este valor diminui gradualmente com o tempo até se 
tornar constante. Sendo assim, o ligante que antes estava no contato peça-ferramenta se desgasta e as arestas de corte dos grãos de CBN são expostas gradativamente na superfície do rebolo.

Este fenômeno se agrava se for utilizada a mesma técnica de dressagem para rebolos convencionais. Neste caso, a profundidade de dressagem é muito alta o que contribui para a expulsão de grãos inteiros e exposição do ligante. Os autores citam o uso de uma técnica chamada de dressagem de contato (touch dressing), ou dressagem de toque, onde a profundidade de dressagem $\left(a_{d}\right)$ é tão pequena (geralmente menor que $5 \mu \mathrm{m}$ ) que não ocasiona a expulsão do grão (Figura 2.18). Desta forma, o perfil do rebolo é restaurado sem perda da capacidade de corte.

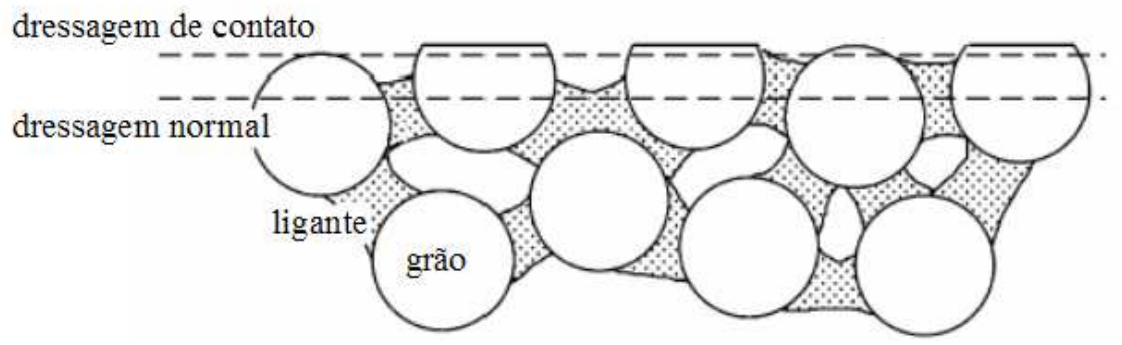

Figura 2.18 - Técnicas de dressagem (Chen et al., 2002 - Adaptada).

Um aspecto que deve ser levado em consideração é a utilização de algum método para a detecção do contato entre o dressador e o rebolo, já que se deve saber exatamente onde ocorre o contato para não desgastar mais material do que é necessário (Chen et al., 2002). Inasaki et al. (1993), mencionaram a utilização do sinal de emissão acústica para este fim.

Existe também o problema relacionado com as deformações térmicas da máquina sofridas ao longo de um dia, já que a operação de dressagem para rebolos de CBN não é tão freqüente, podendo ocorrer em turnos diferentes (Chen et al., 2002; Hitchiner, 1990). 
Com o uso da técnica de touch dressing, a variação da potência de corte durante o processo diminui e faz com que o desempenho da retificação seja mais estável. A variação do valor de rugosidade também diminui durante os ciclos entre uma dressagem e outra. Além disso, esta técnica consome menos rebolo (geralmente um terço a menos do que a técnica convencional), o que reduz os custos do processo (Chen et al., 2002).

Outra diferença entre os dois tipos de dressagem pode ser vista na Figura 2.19. A dressagem de contato garante mais grãos na superfície de contato.

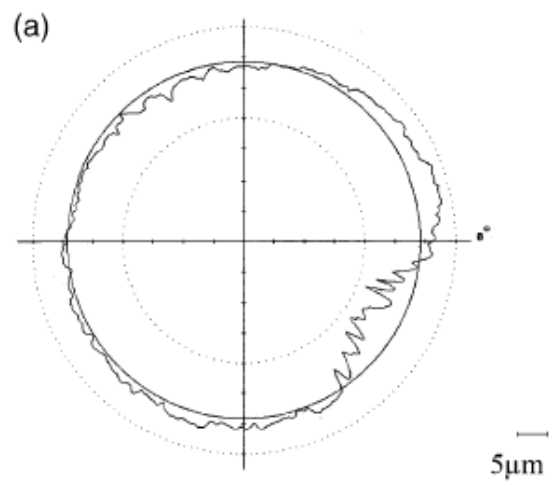

(b)

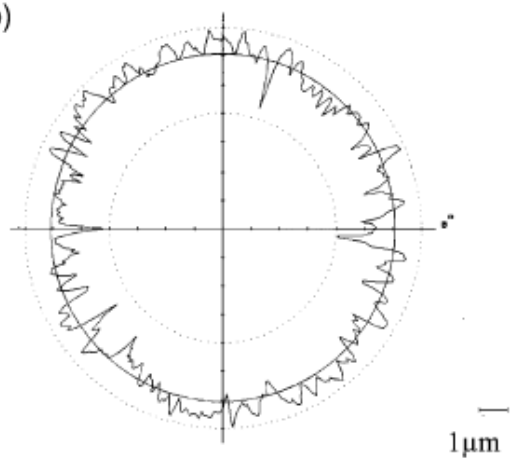

Figura 2.19 - Circularidade dos rebolos com diferentes profundidades de dressagem. (a) $a_{d}$ de $10 \mu \mathrm{m}$ e (b) $a_{d}$ de $3 \mu \mathrm{m}$ (Chen et al., 2002).

De acordo com Hitchiner (1990), a dressagem de rebolos de CBN com dressador de ponta única, ou de diamantes múltiplos, deve ser evitada, pois a alta dureza dos grãos de CBN irá acarretar em um desgaste excessivo do dressador já que a quantidade de grãos abrasivos por grão de diamante é muito alta. Para este tipo de rebolo, é recomendado o uso de dressadores rotativos com grande quantidade de grãos de diamante para o desgaste no mesmo ser mínimo.

Para Takagi e Liu (1996), a dressagem de rebolos de CBN com discos rotativos é geralmente utilizada para se obter alta eficiência na operação e alta precisão dimensional do rebolo. No seu estudo foi avaliado o efeito da dressagem com disco rotativo na fratura das 
arestas de corte de um rebolo de CBN. O trabalho sugere que o mecanismo de formação de arestas de corte em grãos de CBN é fortemente afetado pela razão de esmagamento $\left(q_{d}\right)$ que pode ser positiva (concordante) ou negativa (discordante) (Equação 2.6):

$$
q_{d}=\frac{v_{d}}{v_{s}}
$$

Onde, $v_{d}$ é a velocidade periférica do disco dressador.

De forma a construir uma relação entre a força normal de dressagem e a razão de esmagamento $\left(q_{d}\right)$, um novo parâmetro, chamado de ângulo de penetração da dressagem $\theta$, foi estudado. A representação deste ângulo pode ser vista na Figura 2.20. Onde: $d_{t}$ é o diâmetro do dressador, $n_{t}$ a rotação do disco dressador, $n_{s}$ a rotação do rebolo e $v$ a velocidade relativa entre o rebolo e o dressador

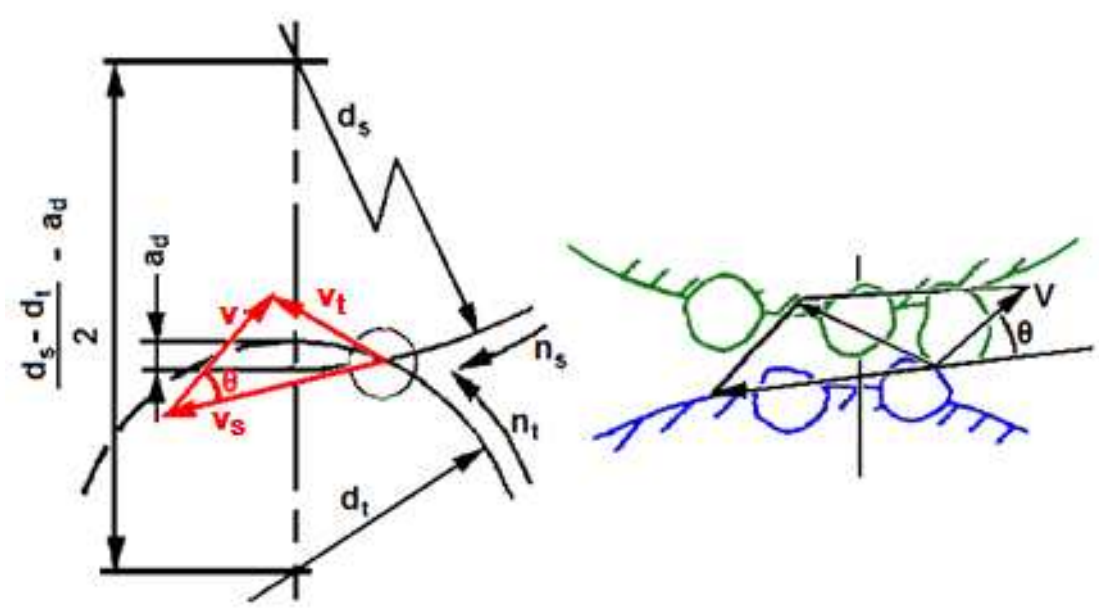

Figura 2.20 - Geometria do ângulo de penetração da dressagem $\theta$ (Takagi e Liu, 1996 Adaptada).

Concluiu-se que quando a razão de esmagamento $\left(q_{d}\right)$ é concordante e pequena, o ângulo de penetração da dressagem $(\theta)$ é baixo (para $q_{d}=+0,5: \theta=1^{\circ}$ ). Portanto, as colisões ocorrem na direção tangencial dos grãos de $\mathrm{CBN}$, induzindo forças de cisalhamento nos mesmos. 
De acordo com Ishikawa e Kumar (1991), esta condição provoca micro-fraturas no grão, gerando uma elevada densidade de arestas de corte e conseqüentemente, uma maior vida do rebolo, porém causando também maiores forças de retificação.

Já quando $q_{d}$ é igual a $+0,8, \theta$ aumenta $\left(4,3^{\circ}\right)$, fazendo com que a força aumente na direção radial do grão abrasivo. Então uma força de compressão age no grão e o seu esmagamento ocorre. Conseqüentemente a força normal de dressagem aumenta e o rebolo se torna mais agressivo (Takagi e Liu, 1996).

Para Ishikawa e Kumar (1991), esta condição gera macro-fratura do grão e baixa densidade de arestas de corte na superfície do rebolo, leva a uma menor vida do rebolo, porém gera menores forças de retificação. Isto pode causar também perda de ligante.

Para $q_{d}$ igual a $+1, \theta$ é igual a $89,5^{\circ}$, fazendo com que ocorra apenas compressão entre os grãos e surge o problema do puro esmagamento, onde as forças são tão altas que geram as macro-fraturas dos grãos e a possível fratura da camada superabrasiva.

Para Chen et al. (2002), o material retificado possui uma forte tendência de aderir na superfície de corte causando uma situação chamada de empastamento do rebolo. Este material se acumula na periferia do rebolo, preenchendo o espaço entre os grãos. Mesmo com pouco empastamento a rugosidade da peça aumenta consideravelmente. Com o empastamento excessivo, a capacidade de corte do rebolo rapidamente se deteriora, causando um aumento nas forças de corte e na temperatura, o que pode ocasionar a queima da peça. Desta forma, alguns cuidados devem ser tomados para se evitar o empastamento.

Uma vez que o rebolo se encontra empastado, este deve ser dressado novamente. No entanto, esta é uma opção de custo elevado, já que a dressagem de rebolos de CBN deve ser evitada ao máximo devido ao alto valor do grão abrasivo. Além disso, o material aderido na superfície do rebolo pode estar a uma profundidade de até $10 \mu \mathrm{m}$, portanto devem-se realizar 38 
muitas operações de dressagem até "limpar" por completo o rebolo, desperdiçando grão abrasivo e tempo.

Como forma de se evitar o empastamento pode-se fazer uso de duas soluções: a utilização de um sistema de limpeza do rebolo e o emprego de um rebolo poroso.

O sistema de limpeza nada mais é do que um bocal de alta pressão e baixa vazão de fluido de corte que é direcionado para a superfície do rebolo de forma que o fluido, ao colidir com o rebolo, remove o material preso nos poros do mesmo.

\subsubsection{O Rebolo de CBN na Retificação de Alta Velocidade}

A utilização do rebolo de CBN atrelado à retificação de alta velocidade pode gerar importantes benefícios tanto para a peça quanto para a produção como um todo (Tso, 1995).

Os rebolos de CBN utilizados no processo de retificação de alta velocidade de corte estão sujeitos a especificações especiais, tais como boa resistência à fratura e baixo desgaste. Boas características de amortecimento, alta rigidez estrutural e boa condutividade térmica também são desejáveis. A eficácia do Nitreto Cúbico de Boro, como material abrasivo na usinagem com alta velocidade de corte de materiais ferrosos, é atribuída à sua extrema dureza e estabilidade térmica e química (Jackson et al., 2001; Klocke et al., 1997).

No que diz respeito à estrutura do rebolo, diversas pesquisas estão sendo realizadas tendo como objetivo o projeto de novos corpos de rebolos para resistirem às altas velocidades (Hitchiner, 2001 apud Silva, 2004). De acordo com Weingaertner e Severiano (2006), a geometria de rebolos convencionais, de seção retangular e com um furo no centro, geralmente causa danos à camada abrasiva pelas altas deformações sofridas.

A Figura 2.21 mostra a distribuição de tensões em um rebolo segmentado de CBN. 

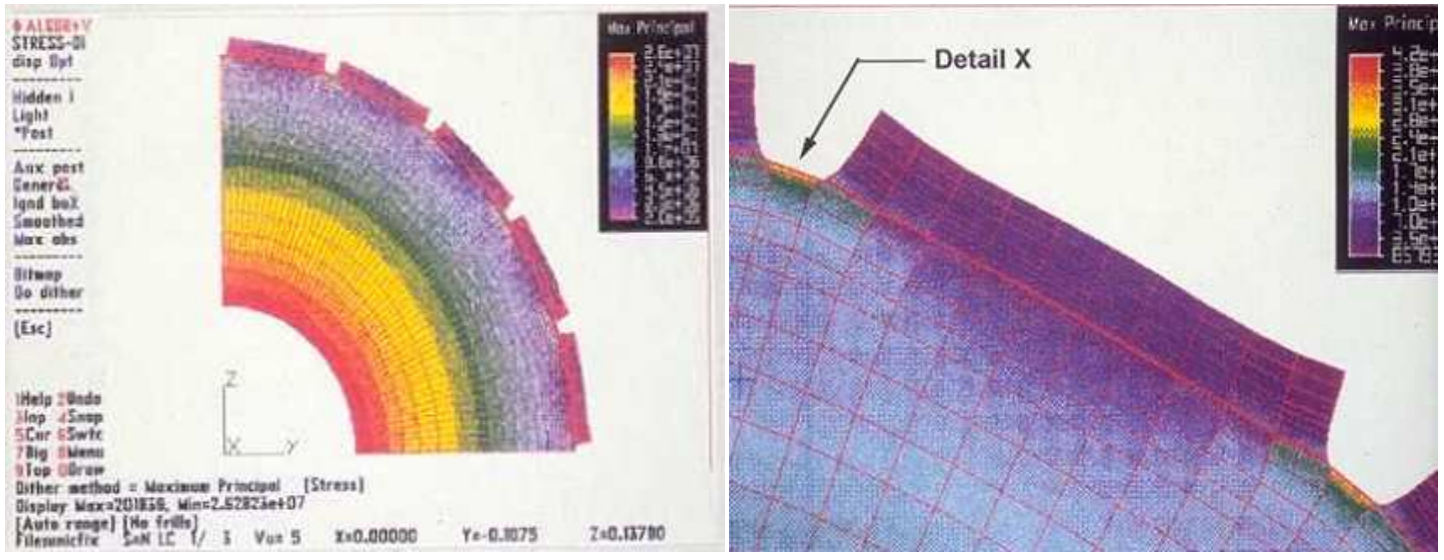

Figura 2.21 - Distribuição de tensões em um rebolo de CBN segmentado (Hitchiner, 2001 apud Silva, 2004 - Adaptada).

Para Klocke et al. (1997), quando as tensões radiais e tangenciais do corpo do rebolo são calculadas, percebe-se que os maiores níveis de tensão ocorrem na direção tangencial no diâmetro interno (furo) do corpo. Portanto, este valor não pode ser maior que o limite de resistência do material do corpo do rebolo.

Deste modo, a eliminação do furo central e a otimização da forma do rebolo pela diminuição de sua espessura com o aumento do raio são muito importantes para a retificação de alta velocidade (Figura 2.22). Esta configuração reduz drasticamente as tensões máximas e resulta em um nível de tensão constante (Klocke et al., 1997).

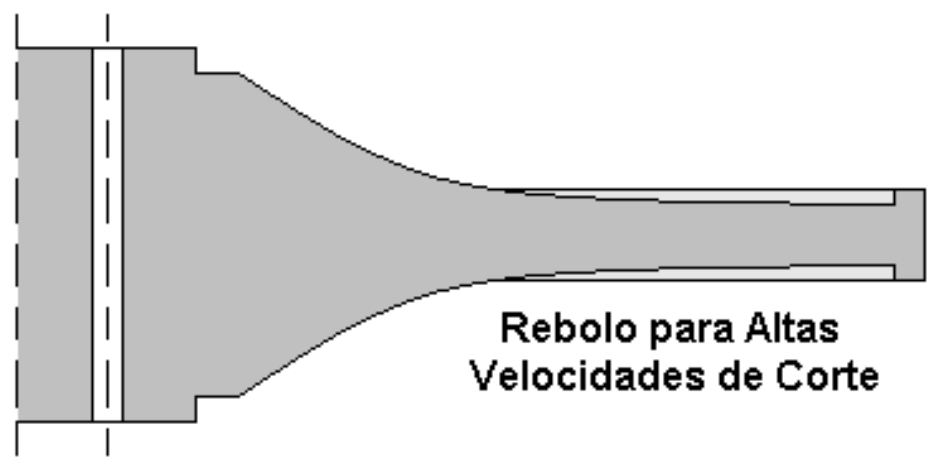

Figura 2.22 - Projeto otimizado para corpo de rebolo de alta velocidade (Klocke et al., 1997 Adaptada). 
Para eliminar a possibilidade de falha, a escolha do material e o dimensionamento do corpo devem levar em consideração a diminuição da força centrífuga e também o deslocamento das faixas de freqüência natural para rotações mais elevadas (Jackson et al., 2001).

Apesar da grande maioria dos rebolos superabrasivos apresentarem corpo de aço ou alumínio, a aplicação de outros tipos de materiais como, por exemplo, a fibra de carbono (CFRP) é admissível. A comparação entre algumas das propriedades do aço e da fibra de carbono CFRP pode ser feita pela Tabela 2.1. (Klocke et al., 1997).

Tabela 2.1- Comparação entre as propriedades do aço e fibra de carbono (Klocke et al., 1997).

\begin{tabular}{|c|c|c|}
\hline Propriedades & $\begin{array}{c}\text { Aço } \\
(\text { S45C) }\end{array}$ & CFRP \\
\hline $\begin{array}{c}\text { Peso específico } \\
\gamma\left[\mathrm{N} / \mathrm{dm}^{3}\right]\end{array}$ & 78,4 & 15,8 \\
\hline $\begin{array}{c}\text { Módulo de elasticidade } \\
E\left[10^{3} \times \mathrm{N} / \mathrm{mm}^{2}\right]\end{array}$ & 200 & 70 \\
\hline \begin{tabular}{c}
$E / \gamma\left[\mathrm{x} 10^{6} \mathrm{~m}\right]$ \\
\hline $\begin{array}{c}\text { Tensão de tração } \\
\sigma_{y}\left[\mathrm{~N} / \mathrm{mm}^{2}\right]\end{array}$
\end{tabular} & 2,66 & 4,43 \\
\hline $\begin{array}{c}\text { Coeficiente de expansão } \\
\text { linear } \\
\alpha\left[10^{-6} / \mathrm{K}\right]\end{array}$ & 12 & 1 \\
\hline
\end{tabular}

Apesar do módulo de elasticidade do CFRP ser menor do que o do aço, o seu peso específico extremamente baixo faz com que a relação $E / \gamma$ seja alta, o que é vantajoso para o processo de retificação. De fato, a expansão provocada pelas altas velocidades tangenciais pode ser suprimida pelo uso de materiais no corpo do rebolo com altos valores da relação $E / \gamma$. 
Outra vantagem no uso da fibra de carbono é o baixo valor do coeficiente de expansão linear (Klocke et al., 1997).

Um trabalho realizado por Yui e Lee (1996), analisou a influência da velocidade de corte na dilatação (expansão dimensional) do rebolo de CBN. Verificou-se que o rebolo se expande de forma exponencial com o aumento da velocidade de corte (Figura 2.23).

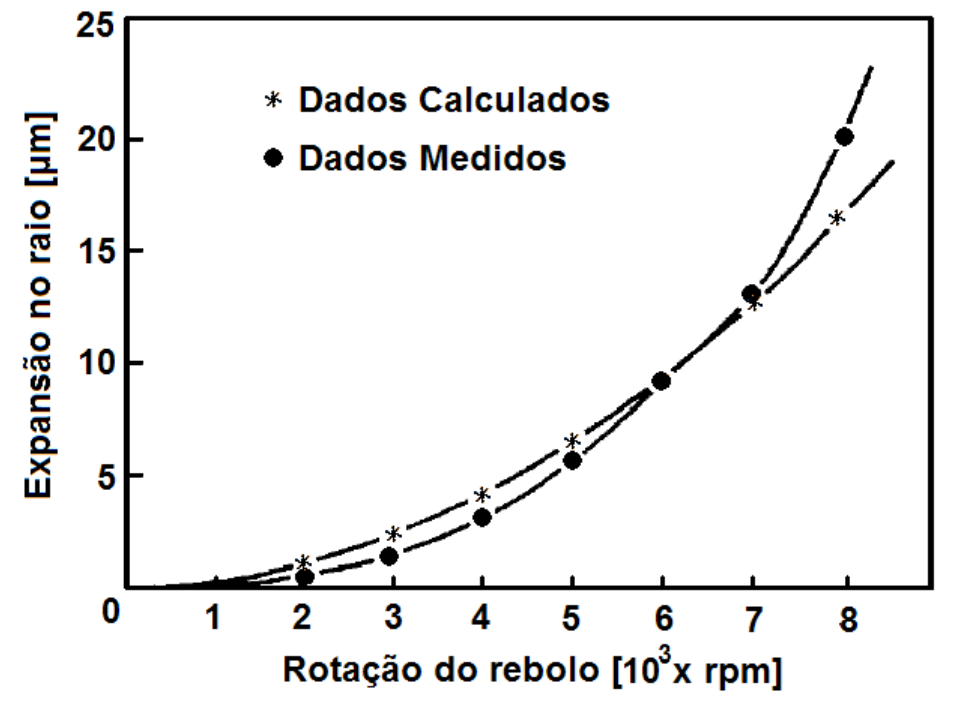

Figura 2.23 - Expansão do rebolo versus rotação (Yui e Lee, 1996 - Adaptada).

Os autores afirmam que o cálculo teórico da dilatação pode ser feito pela fórmula da Equação 2.7, obtendo-se grande precisão.

$$
u=\frac{\gamma \omega^{2}}{4 E g}(1-v) r^{3}
$$

Onde, $u$ é a dilatação do rebolo; $\gamma$ o peso específico do material do corpo de rebolo; $E$ o módulo de Young (ou elasticidade) do material do corpo; $\omega$ a velocidade angular; $g$ a aceleração da gravidade; $v$ o coeficiente de Poisson e $r$ o raio do rebolo. 
Esta expansão gera erros na dimensão final da peça retificada. O estudo concluiu que a correção feita na profundidade de corte utilizando o valor teórico da dilatação do rebolo pode ser feita para garantir a precisão dimensional da peça (Yui e Lee, 1996).

\subsection{Métodos de Monitoramento do Processo}

Pesquisas recentes afirmam que o processo de retificação possui três características principais:

- Altamente complexo;

- Dependente de um alto número de parâmetros de entrada; e

- Não-estacionário (mecanismos inerentes ao processo mudam com o tempo).

Portanto, o monitoramento do processo é de fundamental importância para que ocorra a garantia de uma melhor qualidade final da peça usinada (Tönshoff et al., 2002).

O comportamento de qualquer processo abrasivo está intimamente ligado ao desempenho da ferramenta. O rebolo deve ser devidamente selecionado e condicionado para satisfazer os requerimentos da peça. Além disso, o seu desempenho pode mudar de modo significante durante o processo, o que torna difícil a previsão do comportamento do processo. O rebolo deve ser condicionado antes do início do processo e também no fim da sua vida para restaurar as suas características iniciais. Este processo periférico ao processo de retificação em si deve ser monitorado para minimizar o tempo gasto, garantir a topografia da ferramenta desejada e manter uma quantidade mínima de abrasivos arrancados.

Os sistemas de monitoramento na retificação devem ser capazes de detectar com alta confiabilidade qualquer mau funcionamento inesperado do processo. Os maiores problemas do processo de retificação são: vibração, queima da peça e deterioração da sua rugosidade. 
Estes problemas devem ser identificados para manter a qualidade desejada da peça (Tönshoff e Inasaki, 2001).

Geralmente, na retificação, os sistemas de monitoramento em processo utilizam grandezas físicas, tais como a emissão acústica, forças, potência, posição etc., que podem ser captadas durante o processo propriamente dito ou na dressagem do rebolo (Biffi, 2003).

\subsubsection{Monitoramento da Vibração}

O monitoramento da vibração do processo de retificação é usado principalmente para dois propósitos (Tönshoff et al., 2002):

- Medir vibrações forçadas para identificar desbalanceamento ou fontes externas de vibração; e

- Detectar vibrações auto-excitadas, isto é, trepidação ou chatter.

A vibração forçada é facilmente detectada, pois sua freqüência pode ser mensurada e comparada com os elementos rotativos da própria máquina ou de equipamentos adjacentes a esta. Já a vibração auto-excitada possui frequiências mais altas, próximas da freqüência de ressonância da máquina e sua importância no processo de retificação é maior uma vez que a sua origem é mais difícil de ser determinada.

Diversos trabalhos foram realizados com o intuito de utilizar os sinais provenientes da retificação para o monitoramento e/ou diagnóstico do processo.

Hassui et al. (1998) utilizou o sinal de vibração para a avaliação do processo de retificação. O sinal de vibração do processo foi utilizado com sucesso na determinação indireta do melhor momento para a dressagem do rebolo. Foi verificado ainda que a vibração é capaz de indicar com clareza as três fases da retificação cilíndrica externa de mergulho: deformação elástica inicial, remoção de material e spark-out. 
Em um estudo David e Warnecke (1996) apud Hassui et al. (1998) relacionaram o sinal de vibração com as forças dinâmicas da retificação. A pesquisa mostrou que estas forças fazem o sistema (máquina-rebolo-peça) vibrar e que é possível captar o aumento de amplitude da vibração em algumas freqüências à medida que o rebolo perde a afiação.

Métodos de detecção on-line da trepidação dependem em sua maioria de medições da emissão acústica, aceleração e forças de retificação. Estas vibrações são geralmente identificadas pelo espectro da freqüência destes sinais.

Em um estudo realizado por Govekar et al. (2002), foi utilizado um parâmetro estatístico não-linear chamado NCER (Normalized Coarse-Grained Entropy Rate) para a detecção on-line de vibrações auto-excitadas na retificação. De acordo com os autores, a presença de trepidação no processo altera de maneira significativa a dinâmica de retificação, e conseqüentemente a dinâmica das flutuações da força normal. Isto é ilustrado na Figura 2.24 que mostra segmentos da força normal obtidos de testes com a presença e ausência de chatter.
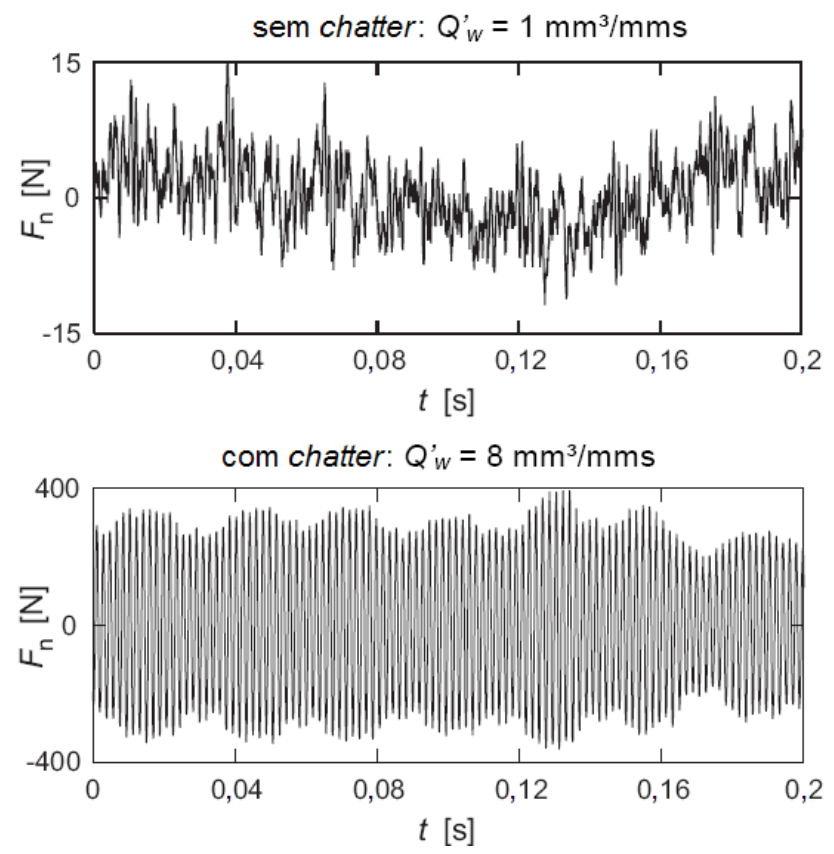

Figura 2.24 - Segmentos da força normal com presença e ausência de trepidação (Govekar et al., 2002 - Adaptada). 
Pela comparação feita dos dois segmentos apresentados na Figura 2.24, os autores concluíram que vibrações irregulares de pequenas amplitudes são típicas do processo sem a ocorrência de trepidação, já quando ocorrem, as vibrações auto-excitadas são praticamente harmônicas e de altas amplitudes.

Desta forma, valores de NCER (que pode ser entendido como uma medida da previsibilidade do processo) próximos de zero são obtidos quando a variável medida (força normal) possui característica periódica, já valores próximos de um quando possui característica randômica. A Figura 2.25 exibe os resultados obtidos para as duas condições testadas.

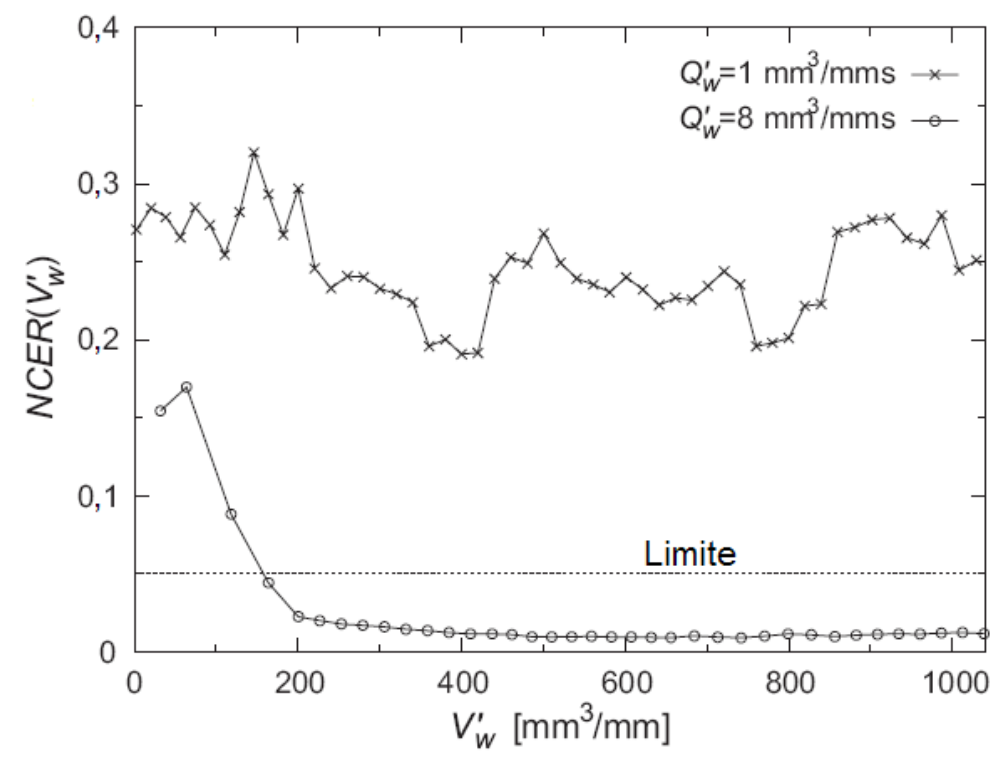

Figura 2.25 - NCER (Normalized Coarse-grained Entropy Rate) versus volume específico de material desgastado (Govekar et al., 2002 - Adaptada).

De acordo com o a Figura 2.25, concluiu-se que este parâmetro é capaz de detectar o aparecimento da trepidação no processo com a adoção de um valor limite adequado.

Em estudo complementar, GradiŠek et al. (2003) utilizou o parâmetro NCIR (Normalized Coarse-Grained Information Rate), semelhante ao NCER, e também a entropia 
normalizada como método indicativo de trepidação. O parâmetro NCIR foi calculado para os valores de emissão acústica (RMS - Root Mean Square) e força normal, enquanto que a entropia normalizada foi calculada utilizando o espectro de freqüência dos sinais de emissão (RMS) acústica e força normal.

Os resultados indicam que a entropia e o parâmetro NCIR conseguem indicar satisfatoriamente a presença de vibração. Os valores calculados com o sinal da força normal conseguem detectar a vibração no seu estágio inicial, antes da peça sofrer danos superficiais. Já os mesmos parâmetros (NCIR e entropia) calculados com o sinal RMS da emissão acústica indicaram a presença de vibração em estágios mais avançados.

A transformada de Wavelet foi utilizada para detectar a trepidação em um trabalho realizado por Gonzalez-Brambila et al. (2006). As marcas superficiais da peça ocasionadas pela vibração no processo foram medidas com um medidor de perfil de ponta de diamante e em seguida a transformada Wavelet foi calculada. De acordo com os autores, o método foi capaz de medir adequadamente a amplitude, extensão e informar a localização das marcas de trepidação na superfície analisada.

\subsubsection{Monitoramento da Emissão Acústica}

A emissão acústica pode ser definida como sendo ondas de tensão elástica geradas pelo resultado da liberação rápida de energia de deformação dentro de um material submetido a um estímulo externo, devido ao rearranjo de sua estrutura. Estas ondas de tensão produzem deslocamentos na superfície do material que pode ser detectados por um sensor piezoelétrico que transforma estes deslocamentos em sinais elétricos (Diniz et al., 1991).

Sua faixa de freqüência gira em torno de $50 \mathrm{kHz}$ a $1.000 \mathrm{kHz}$, que está acima da faixa de muitos ruídos vindo de fontes externas ao próprio processo de retificação. Sendo 
assim, é um método sensível e adequado para monitorar o processo de retificação (Kluft, 1994).

Webster et al. (1994) afirma que a medida do sinal de emissão acústica é significativamente mais sensível às variações das condições de retificação do que as medidas de força e potência e oferece um método mais promissor para o monitoramento on-line do processo.

As origens da emissão acústica no processo são decorrentes principalmente da fratura do grão e do ligante, atrito entre o grão abrasivo e a peça-obra, formação de trincas, deformação elástica do material. Todos diretamente ligados ao processo de formação de cavaco e desgaste do rebolo (Biffi, 2003), como pode ser visto na Figura 2.26.

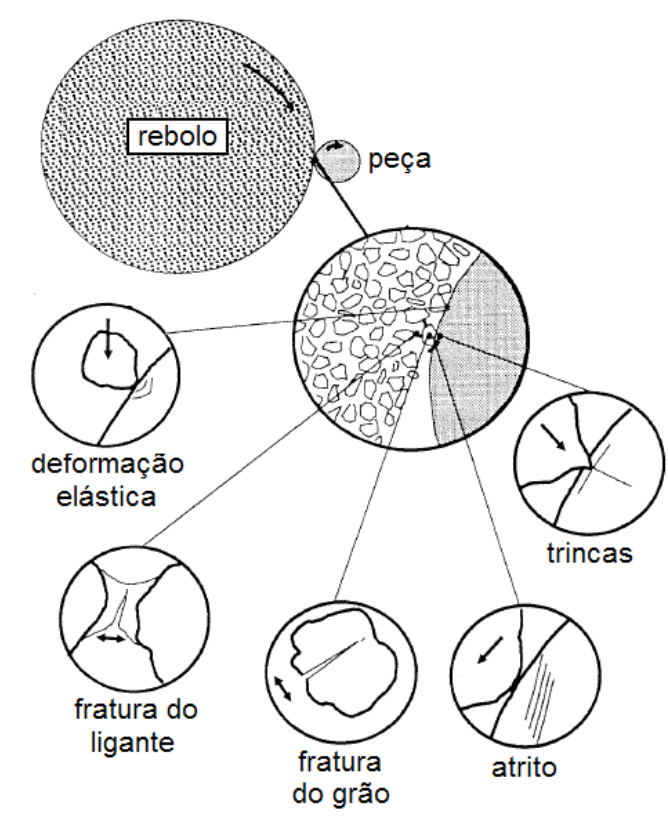

Figura 2.26 - Principais fontes de EA no processo de retificação (Hundt et al., 1994 Adaptada).

Nos primeiros trabalhos referentes à utilização da emissão acústica para a monitoração da retificação, a técnica era utilizada basicamente para detectar a ocorrência do contato entre a peça e o rebolo (Inasaki e Okamura, 1985; Dornfeld e Cai, 1984). Já a 48 
dressagem também era monitorada e o sinal de emissão acústica servia para verificar a uniformidade da passada, indicando assim, o final da dressagem.

Após isto, a aplicação da emissão acústica teve um grande salto e surgiram diversos estudos que tentaram relacionar sinais de emissão acústica a aspectos relativamente complicados do processo de retificação, incluindo a detecção de quebra, queima, trincas e a transição do modo dúctil/frágil (Bifano e Yi, 1992).

O parâmetro predominantemente estudado em pesquisas utilizando emissão acústica vem sendo o valor médio quadrático (RMS) do sinal de EA filtrado $\left(\mathrm{EA}_{\mathrm{RMS}}\right)$ sobre uma banda de freqüência cuidadosamente selecionada. Este sinal tem sido um parâmetro razoável de estudo, pois o processo de retificação é muito rico em ondas sonoras, contendo portanto, muita informação acústica disponível.

O sinal bruto de emissão acústica também está sendo explorado no monitoramento do processo de retificação. Estudos (Wang et al., 2001; Jemielniak, 1997) mostram que a utilização de ferramentas de processamento de sinais, juntamente com as redes neurais artificiais, são eficientes no monitoramento da retificação.

\section{$\underline{\text { Mapa acústico }}$}

Um novo método na análise do processo de retificação utilizando o sinal de emissão acústica foi proposto por Oliveira e Dornfeld (2001). Este se baseia na análise do sinal RMS da emissão acústica em intervalos de tempo bastante curtos.

Os dados da amostragem adquiridos pela placa de aquisição de dados são agrupados de forma que cada vetor corresponde aos valores do sinal de emissão acústica (valor RMS filtrado) referente a uma volta completa do rebolo. Este agrupamento é comandado pelo sinal de um sensor de aproximação que envia um pulso a cada nova volta da ferramenta. 
A imagem produzida é formada pela seqüência de vetores devidamente ajustados em um gráfico tridimensional com escala de cor de forma que cada linha vertical (coluna) equivale a um vetor, ou seja, aos valores amostrados em uma rotação do rebolo. Cada ponto desta linha representa o nível do sinal de EA de cada amostra adquirida.

O método é chamado de mapeamento acústico e pode ser feito basicamente para três situações (Vieira e Oliveira, 2002):

- Avaliação da dressagem;

- Mapeamento topográfico; e

- Avaliação da retificação.

Durante a operação de dressagem a interação entre o dressador e o rebolo pode ser mapeada acusticamente (Figura 2.27). A ausência de contato é representada como áreas escuras no mapa e a dressagem deve continuar até que toda a área do mapa esteja com o mesmo nível de intensidade.

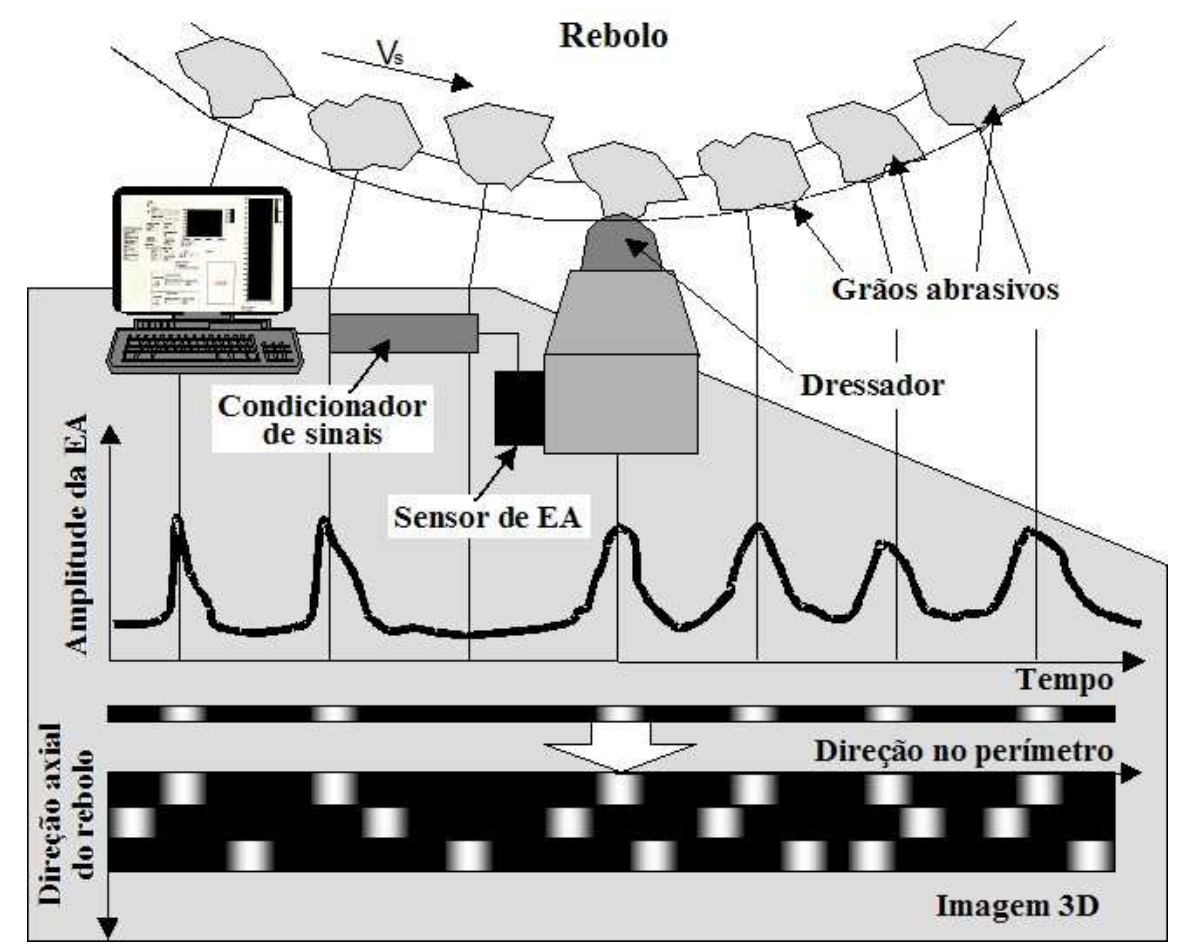

Figura 2.27 - Método de construção do mapa acústico de um rebolo (Oliveira et al., 2001). 
Para o mapeamento topográfico do rebolo, o mapa é similar ao obtido na dressagem, no entanto, a profundidade de corte utilizada é próxima de zero. Assim, o mapa mostra a superfície ativa do rebolo, ou seja, a superfície que entrará em contato com a peça no decorrer do processo (Figura 2.28).

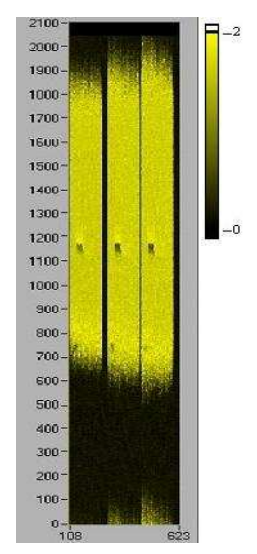

Figura 2.28 - Exemplo de mapa acústico obtido na dressagem de um rebolo excêntrico (Oliveira et al., 2001).

Pode-se observar na Figura 2.28 que o mapa mostra os três passos iniciais de dressagem de um rebolo excêntrico com avanço de $2 \mu \mathrm{m}$ por passo, sendo o da esquerda o primeiro. Fica evidente que a região mais clara (indicando maior contato) aumenta com o número de passos.

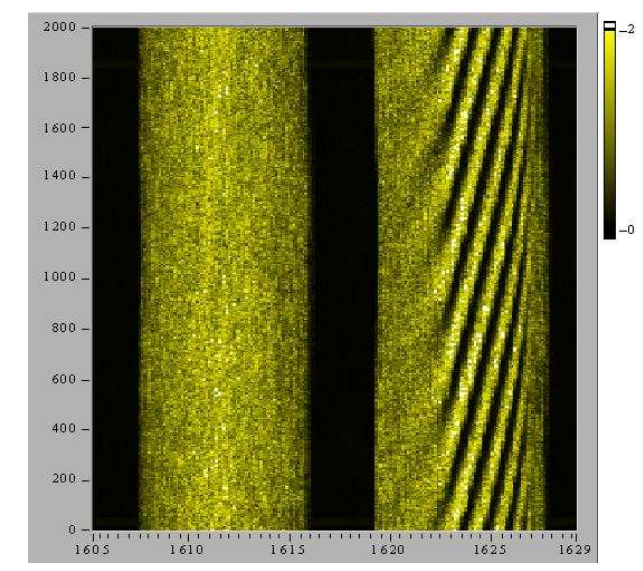

Figura 2.29 - Exemplo de mapa acústico obtido no processo de retificação sem e com vibrações (Oliveira et al., 2001). 
Já a Figura 2.29 exibe dois mapas de dressagem, um com energia bem distribuída (mapa da esquerda) e o outro com algumas linhas diagonais. Estas linhas diagonais indicam vibração no processo, uma vez que a profundidade de dressagem varia mais de uma vez por volta do rebolo e de forma não sincronizada.

$\mathrm{Na}$ operação de retificação, a interação ferramenta-peça também pode ser avaliada. Neste caso, o mapa acústico é diferente, pois, um eixo é o tempo de retificação e o outro a energia acústica média do processo em toda a largura de retificação.

\subsubsection{Monitoramento da Potência}

O monitoramento da potência é comumente utilizado na retificação. A principal razão para isto é a fácil instalação sem influência na área de trabalho da retificadora e também o baixo custo. Dependendo do tipo utilizado, corrente, voltagem ou mudança de fase podem ser medidas (Tönshoff e Inasaki, 2001).

No entanto, diferentes investigações mostram claramente que a resposta dinâmica deste sensor de potência do motor do rebolo é limitada. A potência utilizada para a remoção da material é apenas uma fração da potência total consumida pelo motor (Tönshoff e Inasaki, 2001). De forma geral, estas perdas que ocorrem na transmissão do movimento atuam como um filtro passa-baixa, retardando a resposta do sistema às ocorrências repentinas. Além disso, a potência efetiva do eixo-árvore é proporcional à força tangencial de retificação, um parâmetro com baixa sensibilidade ao desgaste do rebolo (Gomes, 2001).

Apesar disso, é muito utilizada no meio industrial para detecção de colisão e prevenção da sobrecarga da máquina (Tönshoff e Inasaki, 2001).

O sinal de potência pode ser utilizado na diminuição do tempo de aproximação da ferramenta na peça, conhecido como “air grinding”. Quando existem variações consideráveis 
na dimensão das peças, como por exemplo, no valor do diâmetro externo, o sinal de potência pode ser utilizado para a detecção do contato. Deste modo, pode-se trabalhar com grandes valores de velocidade de avanço e assim que o contato ocorrer, o avanço é alterado para o valor especificado para a operação. Desta forma, o tempo perdido pela aproximação do rebolo pode ser diminuído consideravelmente. No entanto, estes valores de velocidade de avanço utilizados na aproximação rápida devem ser dependentes do tempo de resposta do sistema (Tönshoff et al., 2002). 


\section{Capítulo 3}

\section{A VIBRAÇÃO NO PROCESSO DE RETIFICAÇÃO}

\subsection{Tipos de Vibração}

No processo de retificação ocorre tanto a vibração auto-excitada, ou trepidação, quanto a vibração forçada. Vibrações forçadas são geradas por distúrbios periódicos externos ao processo. Podem ter origem em eixos ou rebolos desbalanceados, motores elétricos, rolamentos, atuadores hidráulicos, ou até mesmo por outras máquinas nas adjacências (Malkin, 1989). A principal dificuldade deste tipo de vibração é sua eliminação, já que a identificação da fonte de vibração é relativamente simples, por meio de medições das freqüências (Inasaki et al., 2001).

Já as causas da vibração auto-excitada são muito mais complexas, pois estão associadas à vibração natural da estrutura máquina-ferramenta. A instabilidade da retificação é atribuída a aspectos relacionados ao rebolo e à peça (Altintas e Weck, 2004).

Qualquer irregularidade no processo gera variações na força de corte, que por sua vez pode excitar dinamicamente a estrutura máquina-ferramenta (Malkin, 1989). A Figura 3.1 apresenta os diversos tipos de vibração no processo de retificação, entre elas: a vibração forçada interna, vibração forçada externa e a vibração auto-excitada. 


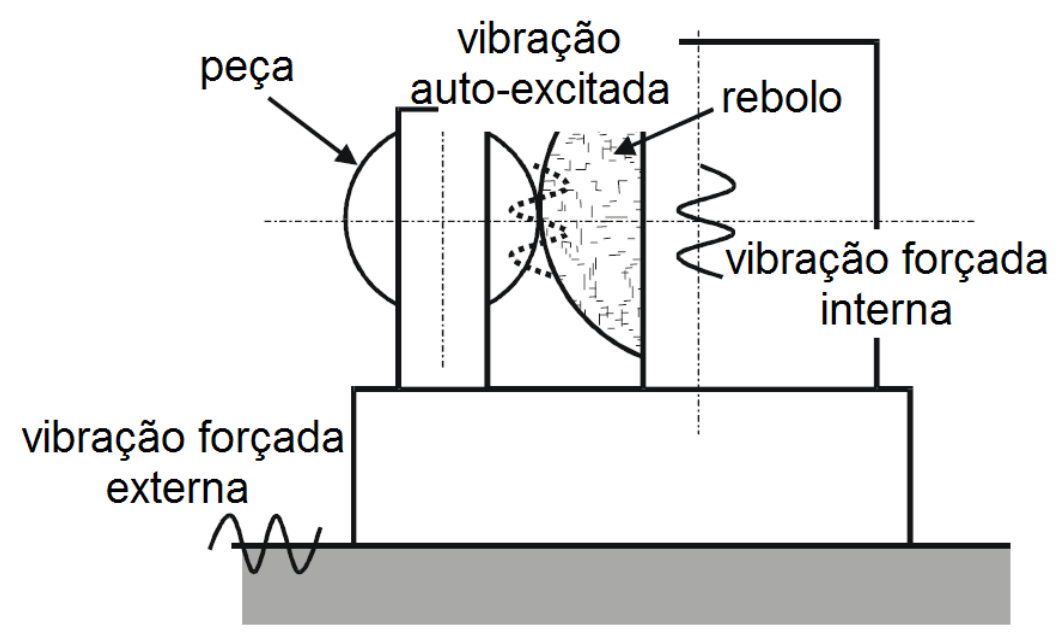

Figura 3.1 - Tipos de vibração na retificação (Inasaki et al., 2001 - Adaptada).

\subsubsection{Vibração Forçada}

As fontes de vibração forçada podem ser localizadas pela análise da freqüência. Por exemplo, se a vibração for causada pelo desbalanceamento ou excentricidade do rebolo, a frequiência medida deve ser equivalente à rotação do rebolo. (Inasaki et al., 2001).

Em um estudo teórico realizado por Oryński e Pawłowski (1999), analisou-se a influência do processo de retificação no amortecimento da vibração forçada. O modelo matemático levou em consideração uma máquina retificadora equipada com mancais hidrostáticos, guias hidrostáticas e força de excitação harmônica atuando no cabeçote do rebolo. A Figura 3.2 exibe o resultado qualitativo da simulação. 


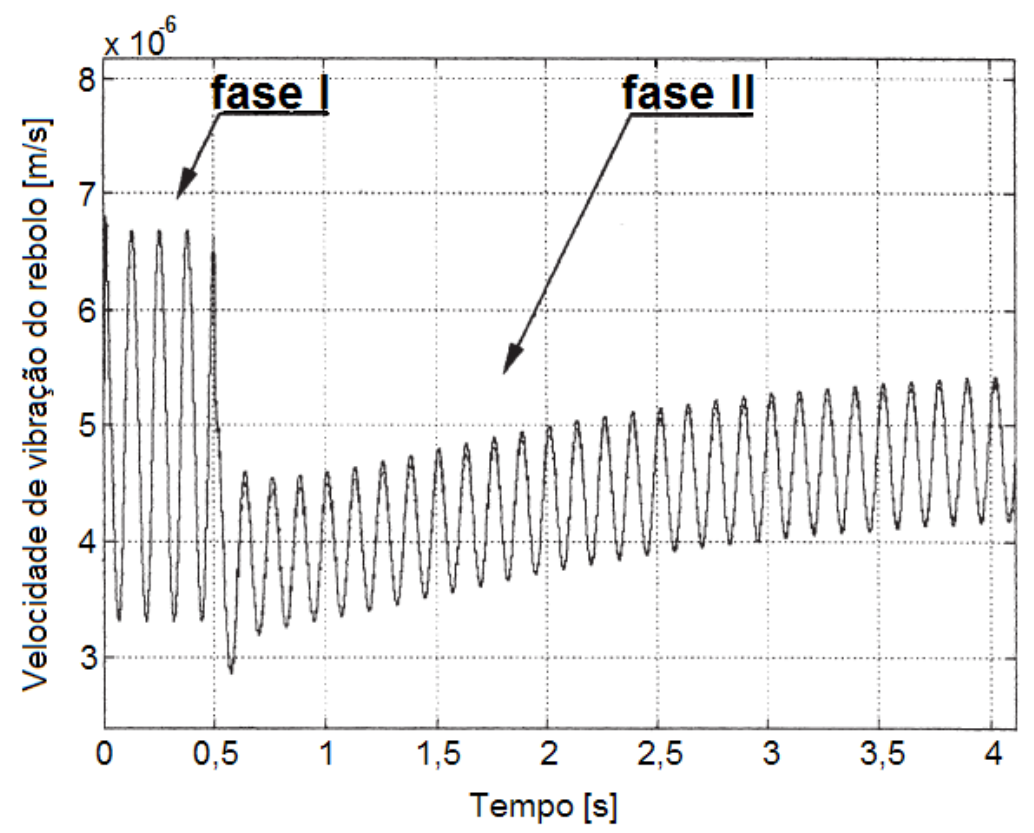

Figura 3.2 - Resultado da simulação computacional para a velocidade de vibração do rebolo na fase I e fase II (Oryński e Pawłowski, 1999 - Adaptada).

Pelo gráfico da Figura 3.2 fica explícita a diminuição da velocidade de vibração quando o rebolo entra em contato com a peça (fase II) em relação ao período em que o rebolo apenas se aproxima da peça (fase I). De acordo com os autores, a força normal possui um efeito de amortização da vibração forçada.

Em um estudo complementar, Oryński e Pawłowski (2004) utilizaram um modelo matemático e físico de uma máquina retificadora ligeiramente diferente do anterior. Este modelo, descrito em um trabalho anterior (Oryński e Pawłowski, 2002), levou em consideração mancais hidrostáticos e guias hidrostáticas do cabeçote do rebolo e da mesa. Foram realizadas simulações para verificar o efeito de amortização da força normal de retificação, assim como testes experimentais para a validação dos resultados. Os resultados dos ensaios experimentais são exibidos em função da razão de amplitudes dos deslocamentos entre fase de aproximação $\left(\mathrm{A}_{I}\right.$ - fase $\left.\mathrm{I}\right)$ e a fase de retificação $\left(\mathrm{A}_{I I}\right.$ - fase II) (Figura 3.3). 
Os resultados validam a afirmação de que o processo de retificação amortece as vibrações forçadas. Foi verificado ainda que a intensidade deste amortecimento depende dos parâmetros de retificação e da freqüência de excitação.
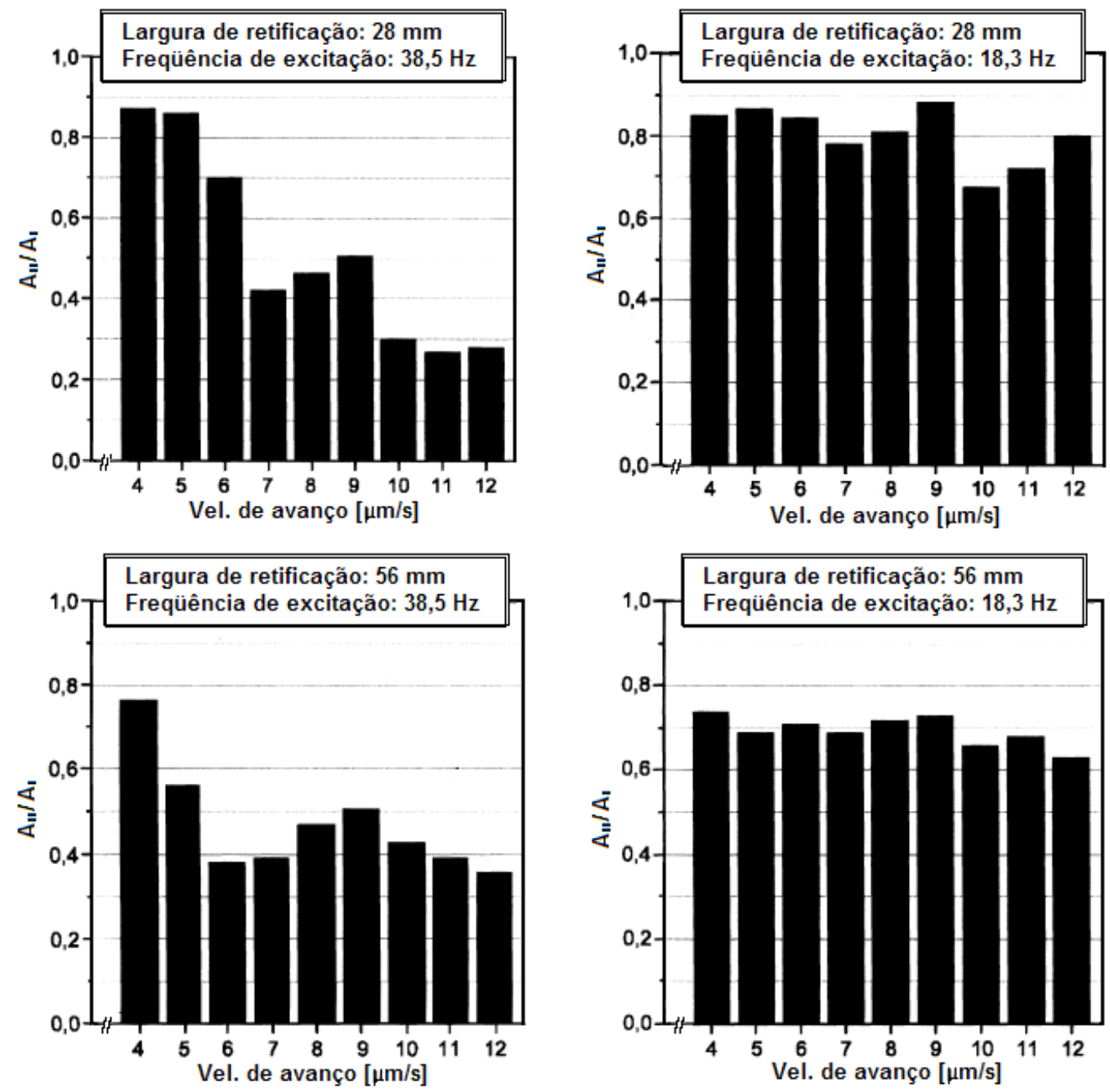

Figura 3.3 - Resultados dos ensaios experimentais para a razão de amplitudes dos deslocamentos entre fase I $\left(\mathrm{A}_{\mathrm{I}}\right)$ e fase II ( $\left.\mathrm{A}_{\text {II }}\right)$ (Oryński e Pawłowski, 2004 - Adaptada).

\subsubsection{Vibração Auto-excitada}

Dentre as várias razões concebíveis de instabilidade no processo, o efeito regenerativo é considerado a maior causa de vibrações auto-excitadas na retificação. Devido ao movimento rotacional da peça durante a remoção de material, as ondulações geradas na sua 
superfície criadas pela vibração relativa entre esta e o rebolo, resultam na variação da profundidade de corte após uma revolução da peça. Nas revoluções subseqüentes, a diferença de fase entre as ondulações da superfície da peça e a vibração relativa deixa o processo instável quando uma determinada condição é atingida. Isto é o que faz a vibração autoexcitada na retificação ser tão complexa.

Devido a este efeito regenerativo, as amplitudes das ondulações geradas na superfície da peça aumentam rapidamente. Este tipo de vibração é um dos fatores limitantes na escolha dos parâmetros de usinagem. Por outro lado, as ondulações geradas na superfície do rebolo aumentam lentamente devido à sua maior resistência ao desgaste (Figuras 3.4 e 3.5). Estas ondulações estão diretamente ligadas à vida do rebolo, já que se adquirirem uma dada amplitude crítica, o rebolo deve ser dressado para a completa remoção das mesmas (Inasaki et al., 2001; Weck et al., 2001).

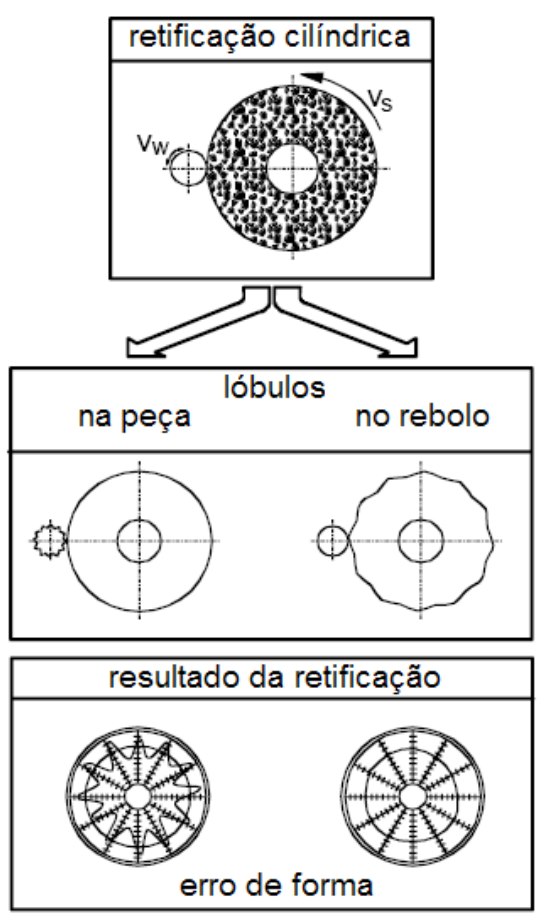

Figura 3.4 - Erro de forma gerado na superfície do rebolo e peça devido à vibração (Weck et al., 2001 - Adaptada). 


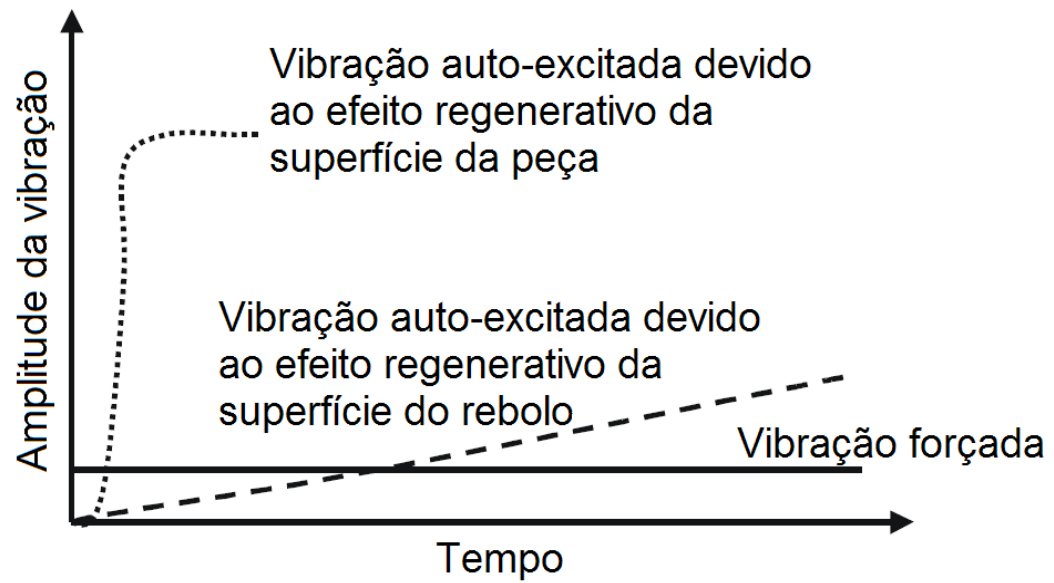

Figura 3.5 - Vibrações na retificação (Inasaki et al., 2001 - Adaptada).

De acordo com Sweeney et al. (1970), o empastamento do rebolo também pode ocasionar vibração auto-excitada. Durante um processo convencional de retificação, o rebolo se torna empastado pelo alojamento de cavacos nas suas porosidades, ou espaçamento entre os grãos. Quando ocorre uma variação dinâmica no processo a taxa com que o rebolo é empastado também sofre variação. Deste modo, pequenas ondulações de metal retificado podem ser formadas na periferia do rebolo, provocando na volta subseqüente variação nas forças de retificação.

Estudos teóricos realizados por Mannan et al. (1999) e Mannan et al. (2000) indicam que o efeito gerado pela torção do cabeçote do rebolo e da peça durante o processo de corte pode alterar a dinâmica de vibração da retificação. De acordo com o modelo de força descrito por Chiu e Malkin (1993) (Equação 3.8) e levando em consideração a variação da força tangencial no tempo, obtém-se a equação diferencial (Equação 3.9):

$$
F_{t}=\frac{u_{c h} \cdot b \cdot a \cdot v_{w}}{v_{s}} \text { e } \quad F_{n}=k \cdot F_{t}
$$




$$
\frac{d F_{t}}{d t}=u_{c h} \cdot b\left(\frac{v_{w}}{v_{s}} \cdot \frac{d a}{d t}+\frac{a}{v_{s}} \cdot \frac{d v_{w}}{d t}-\frac{a \cdot v_{w}}{v_{s}{ }^{2}} \cdot \frac{d v_{s}}{d t}\right)
$$

Onde, $k$ é uma constante e $u_{c h}$ é a energia específica de formação de cavaco. É importante observar que esta equação só leva em consideração a formação de cavaco no cálculo da força.

Pela análise da Equação 3.9, pode-se afirmar que existem outros termos que influenciam na variação da força tangencial de retificação $\left(a, v_{w}\right.$ e $\left.v_{s}\right)$. Sendo que $v_{s}$ e $v_{w}$ estão relacionados com as características de torção do cabeçote do rebolo e da peça, respectivamente.

Desta forma, Mannan et al. (2000) afirmam que o modelo utilizado por eles foi capaz de confirmar que os efeitos provocados pela torção podem melhorar ou piorar a ocorrência da trepidação, dependendo das condições do processo.

Uma tentativa de medir a profundidade instantânea de corte foi realizada por Drew et al. (1999). Entretanto, a investigação inicial indicou que esta medição é extremamente complexa e propensa a erros já que a trepidação está presente no sistema. Apesar do objetivo principal do trabalho não ter sido alcançado, esta pesquisa apresenta uma afirmação muito interessante a respeito da freqüência da vibração auto-excitada. Os autores afirmam que a freqüência de trepidação está relacionada com a freqüência natural fundamental transversal da peça e do rebolo.

Deste modo, se a largura de retificação não for muito maior que a largura limite para uma retificação estável, a frequiência de trepidação é a próxima harmônica inteira da freqüência do rebolo acima da freqüência natural transversal da peça. 
A faixa da frequiência natural transversal da peça, medida pelo teste do martelo, foi de 146 148 Hz, já a rotação do rebolo utilizada foi de $1710 \mathrm{rpm}(28,5 \mathrm{~Hz})$. Portanto, de acordo com a afirmação anterior, a freqüência de trepidação do processo deve ser igual a sexta harmônica do rebolo $(6$ x 28,5 Hz), ou seja, $171 \mathrm{~Hz}$. Isto é confirmado pelos resultados obtidos (Figura 3.6).

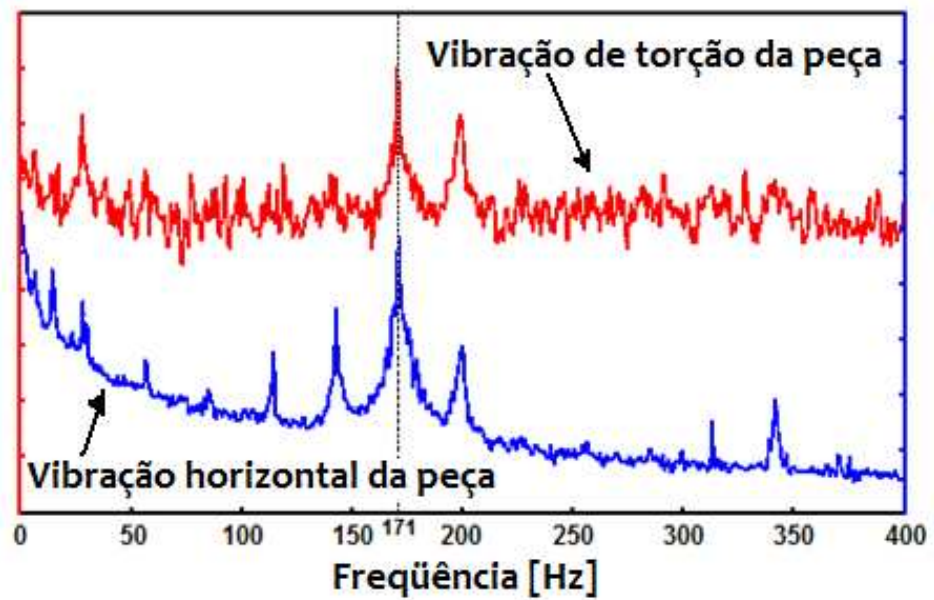

Figura 3.6 - Valores de vibração de torção e horizontal da peça (Drew et al., 1999 Adaptada).

Devido à dificuldade de medição da profundidade de corte $(a)$, os mesmos autores realizaram outro estudo onde foi verificada a influência da variação de velocidade tangencial da peça $\left(v_{w}\right)$ na variação da força de retificação (Drew et al., 2001).

Os testes foram realizados de forma que a rotação instantânea da peça fosse representada pela equação:

$$
\Omega=\Omega_{w}+\operatorname{A.sen}(\omega . t)
$$

Onde, $\Omega_{w}$ é a rotação nominal da peça; $\omega$ é a velocidade angular de variação da velocidade da peça; e $A$ é a amplitude desta variação. A Figura 3.7 exibe os resultados obtidos. 


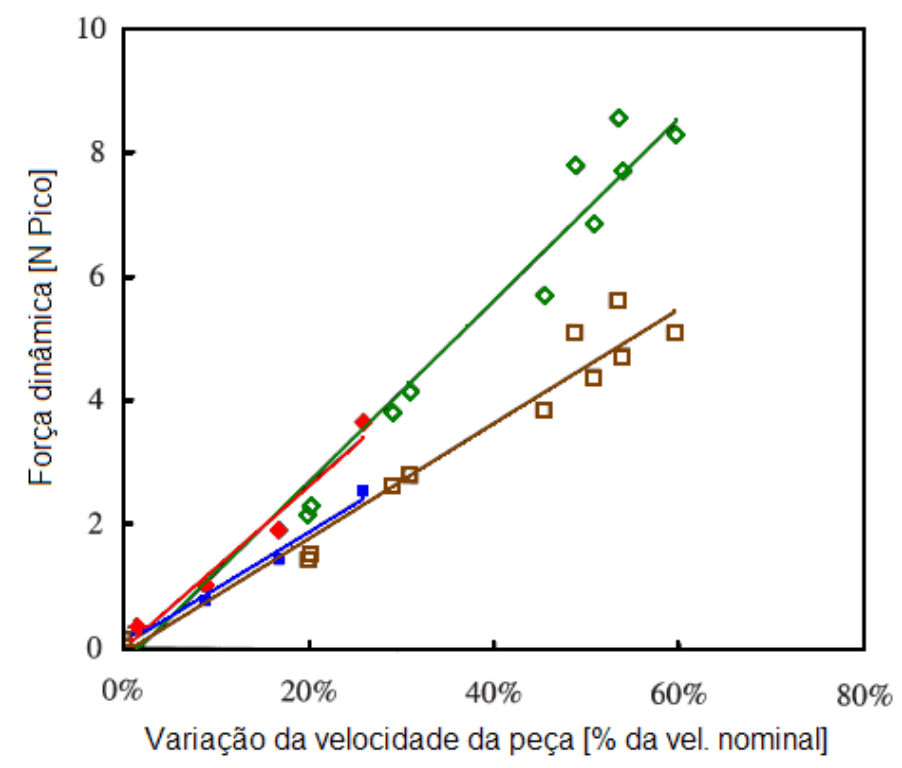

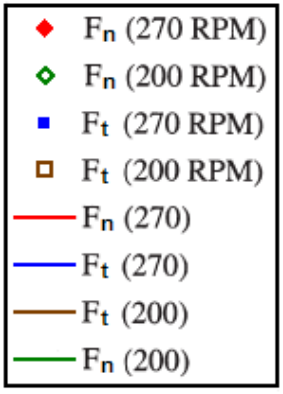

Figura 3.7 - Amplitude da variação da força versus variação da velocidade da peça (Drew et al., 2001 - Adaptada).

A Figura 3.7 mostra a amplitude da oscilação da força de retificação com a variação da velocidade da peça. $\mathrm{O}$ estudo ainda afirma que existe a possibilidade de usar a variação da velocidade da peça a altas freqüências como forma de redução da trepidação.

\subsection{Influência na Qualidade Superficial da Peça}

A ocorrência da vibração auto-excitada tem uma grande influência na geometria do rebolo e da peça. Na peça, as consequiências mais óbvias são as marcas visíveis a olho nu da superfície facetada (Oryński e Pawłowski, 1999).

Embora esta deterioração visível deva ser considerada uma perda de qualidade, é extremamente difícil quantificar estas marcas usando qualquer técnica de medição. Os desvios angulares entre as faces vizinhas são muito pequenos e difíceis de serem medidos por medidores de contato. Por esta razão, a técnica mais apropriada para a avaliação destas marcas é a medição por sensores ópticos (Inasaki et al., 2001). 
A Figura 3.8 mostra uma medição das marcas de um virabrequim retificado com um sensor óptico e também marcas visíveis a olho nu de um corpo-de-prova.

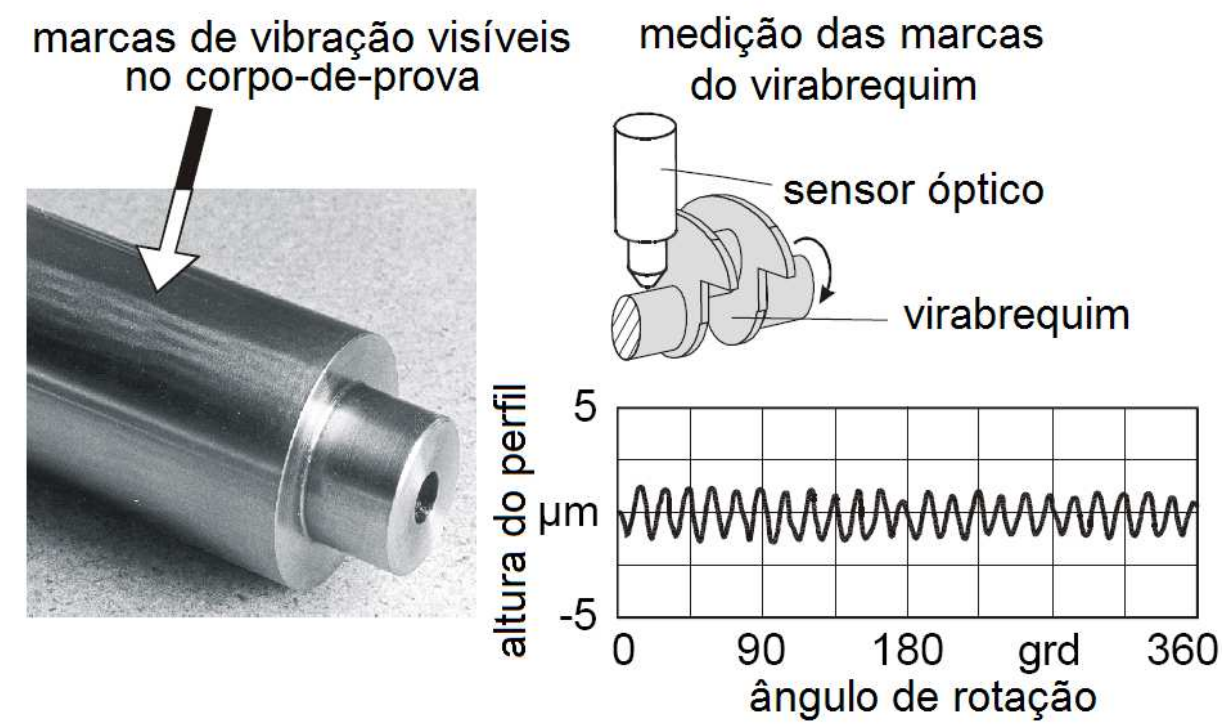

Figura 3.8 - Resultado da vibração na superfície da peça (Brodtmann et al., 1984; Forth, 1989 apud Inasaki et al., 2001 - Adaptada).

A Figura 3.9 mostra um aspecto interessante no perfil medido de peças retificadas que também deve ser levado em consideração. Foram realizados testes de retificação cilíndrica externa de mergulho com um rebolo desbalanceado, o que significa que o processo sofreu vibração forçada interna. Se a razão de rotação rebolo/peça é um número inteiro, então o resultado alcançado é uma superfície ondulada com distância pico-vale de $4 \mu \mathrm{m}$. Até um tempo de spark-out (tempo de centelhamento) de 5 segundos não melhora este resultado. $\mathrm{O}$ número de oscilações ao longo da circunferência é o valor da razão de rotação, neste caso, este valor é 12.

Já se a razão de rotação for alterada para 12,3 ajustando a rotação da peça, uma melhora notável é alcançada na sua superfície. Deste modo, embora o rebolo continue desbalanceado, nenhuma oscilação é percebida na superfície da peça (Inasaki et al., 2001). 


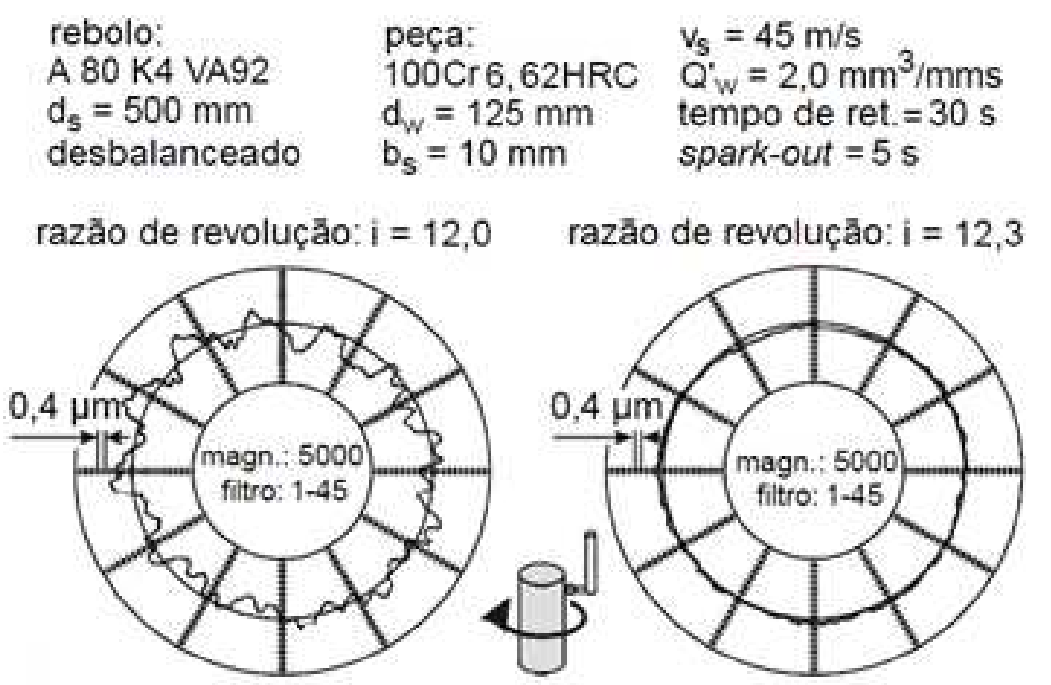

Figura 3.9 - Influência da razão de rotação rebolo/peça na superfície da peça (Forth, 1989 apud Inasaki et al., 2001 - Adaptada).

Influências macro-geométricas, como esta da Figura 3.9, são os principais resultados obtidos em peças retificadas com a presença de vibração. Não existem resultados suficientes na literatura que indiquem com maior clareza a influência destas vibrações na rugosidade da peça. Tudo que se pode afirmar é que com a presença de vibração no processo, o rebolo tende a se desgastar, o que acaba por aumentar a rugosidade e aumentar também a tendência de geração de vibração auto-excitada regenerativa (Inasaki et al., 2001).

\subsection{Influência no Desgaste da Ferramenta}

Inicialmente, a topografia do rebolo é gerada pela operação de dressagem e as mudanças ocorrem ao longo da retificação. A Figura 3.10 exemplifica estas mudanças no perfil de um rebolo de corundum em diferentes tempos de retificação. 


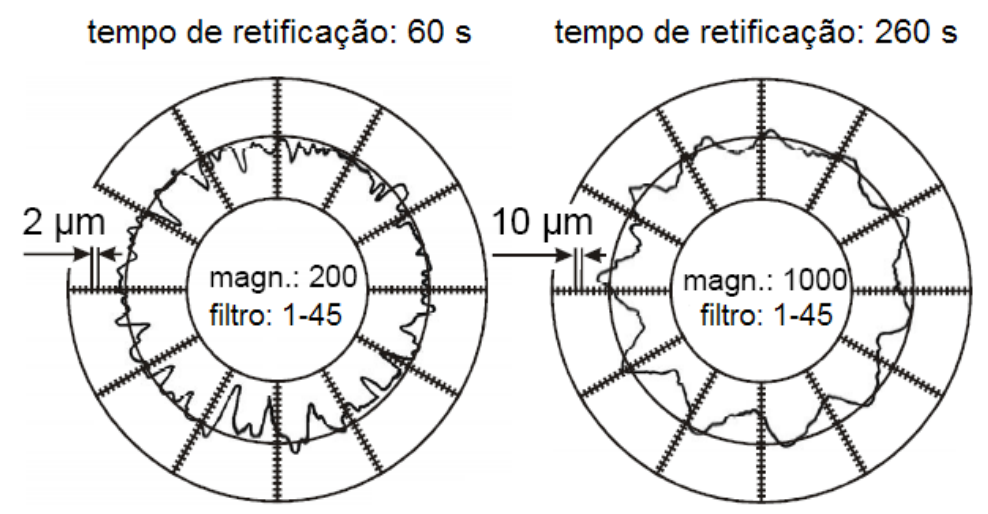

Figura 3.10 - Perfil do rebolo após diferentes tempos de retificação (Tellbüscher, 1986 apud Inasaki et al., 2001 - Adaptada).

A medição do erro de circularidade do rebolo revela uma mudança significativa no seu perfil de 60 para 260 segundos na operação de retificação cilíndrica externa. No exemplo exibido na Figura 3.10, a freqüência de vibração dominante medida foi de $253 \mathrm{~Hz}$, que corresponde a um múltiplo da frequiência de rotação do rebolo $(23 \mathrm{~Hz})$. Pela contagem das ondulações do perfil do rebolo após 260 segundos, chega-se ao número 11.

O desgaste de rebolos pode ser muito influenciado pelos níveis de vibração existentes no processo. Apesar de esta influência ser importante, ainda há poucos estudos sobre esse assunto na literatura. Sendo este problema agravado no caso de peças com baixa rigidez, o seu estudo no âmbito deste trabalho será enfatizado.

\subsection{Métodos de Eliminação da Vibração na Retificação}

Para eliminar a vibração na retificação é necessário antes de tudo determinar o tipo de vibração que está ocorrendo no processo. Se a vibração é detectada sem que o rebolo esteja atuando na peça, é vibração forçada. A vibração de freqüência mais alta que a rotação do rebolo é na maioria dos casos, vibração auto-excitada regenerativa. Destas, o tipo observado no início do corte, logo após a dressagem, é vibração auto-excitada devido ao efeito 
regenerativo da peça. Já a vibração auto-excitada devido ao efeito regenerativo do rebolo aparece no processo após um tempo considerável devido à maior resistência ao desgaste da ferramenta (Inasaki et al., 2001).

\subsubsection{Eliminação da vibração forçada}

Das várias fontes de vibração forçada na retificação, o desbalanceamento do rebolo é a mais significativa. Para a eliminação desta vibração, o desbalanceamento do rebolo deve ser medido por algum transdutor de vibração, geralmente um acelerômetro. A Figura 3.11 mostra uma técnica de balanceamento do rebolo por meio do enchimento de câmaras localizadas no flange da ferramenta. Para tal tarefa, utilizam-se líquidos diversos ou o próprio fluído de corte da máquina.

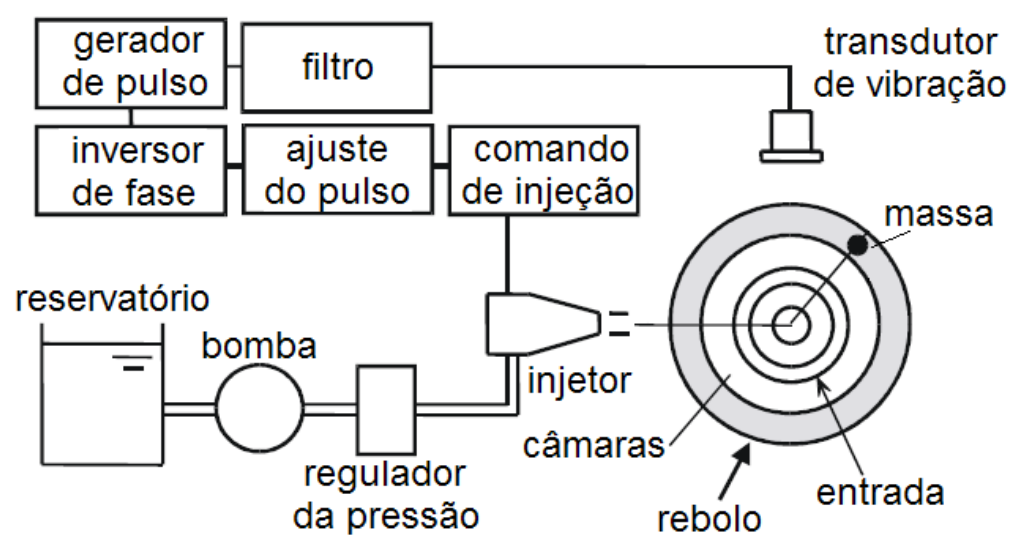

Figura 3.11 - Balanceador automático de rebolos (Horiouchi e Kojima, 1986 apud Inasaki et al., 2001 - Adaptada).

Outros métodos de balanceamento também são utilizados, como o balanceamento automático por deslocamento de massas no flange do rebolo.

A excentricidade do rebolo é outra forte fonte de vibração forçada do sistema e pode ser eliminada pela operação de dressagem do rebolo. No entanto, se o rebolo estiver mal ajustado no flange, a dressagem pode aumentar o desbalanceamento da ferramenta, sendo 
assim, o balanceamento e a dressagem devem ser realizados repetidas vezes e de forma alternada para a correção do problema (Inasaki et al., 2001).

\subsubsection{Eliminação da vibração auto-excitada}

O último objetivo da investigação do chamado chatter (trepidação) é o desenvolvimento de meios práticos para a eliminação destas vibrações. Baseado no entendimento dos princípios da vibração auto-excitada, alguns métodos são propostos.

Uma estratégia para melhorar o desempenho do sistema mecânico é de aumentar o amortecimento. Isto pode ser feito adicionando algum tipo de elemento que armazena ou remove energia do sistema. Este tipo de abordagem na diminuição da vibração é classificado como amortecimento passivo (Albizuri et al., 2007).

A Figura 3.12 mostra um exemplo de aplicação de um amortecedor passivo fixado no cabeçote do rebolo.

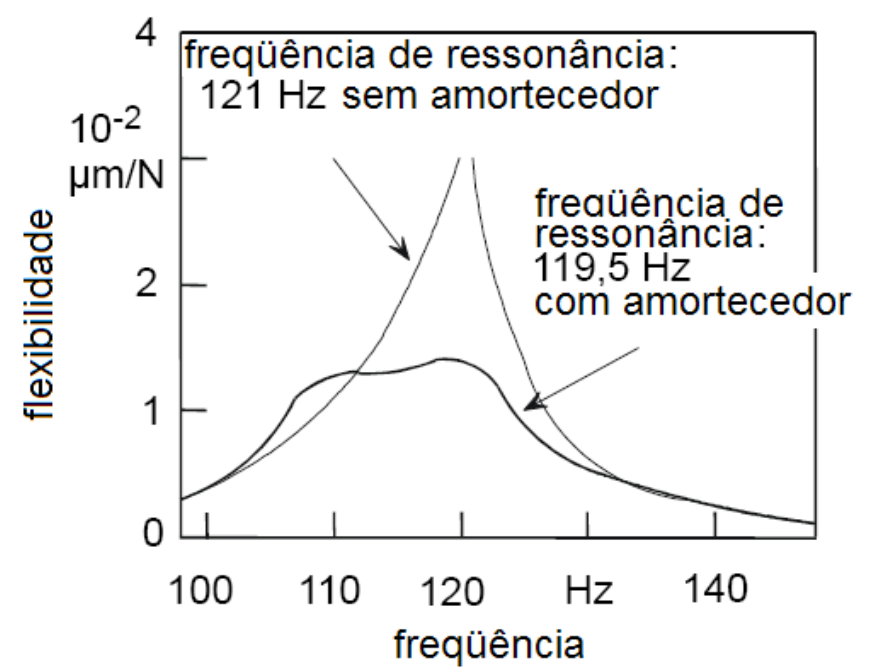

Figura 3.12 - Efeito de um amortecedor passivo na redução da flexibilidade da estrutura (Hong et al., 1990 apud Inasaki et al., 2001 - Adaptada). 
Estes amortecedores são efetivos apenas se perfeitamente ajustados ao sistema mecânico principal e se as características de vibração deste sistema não sofrerem mudanças significativas durante a operação.

Já a utilização de amortecedores ativos é, ao contrário, mais flexível e eficiente mesmo quando as características de vibração do sistema sofrem mudanças significativas. $\mathrm{O}$ objetivo deste método é reduzir os picos ressonantes da função transferência do sistema (Albizuri et al., 2007). As Figuras 3.13 e 3.14 mostram exemplos da aplicação de um amortecedor ativo.

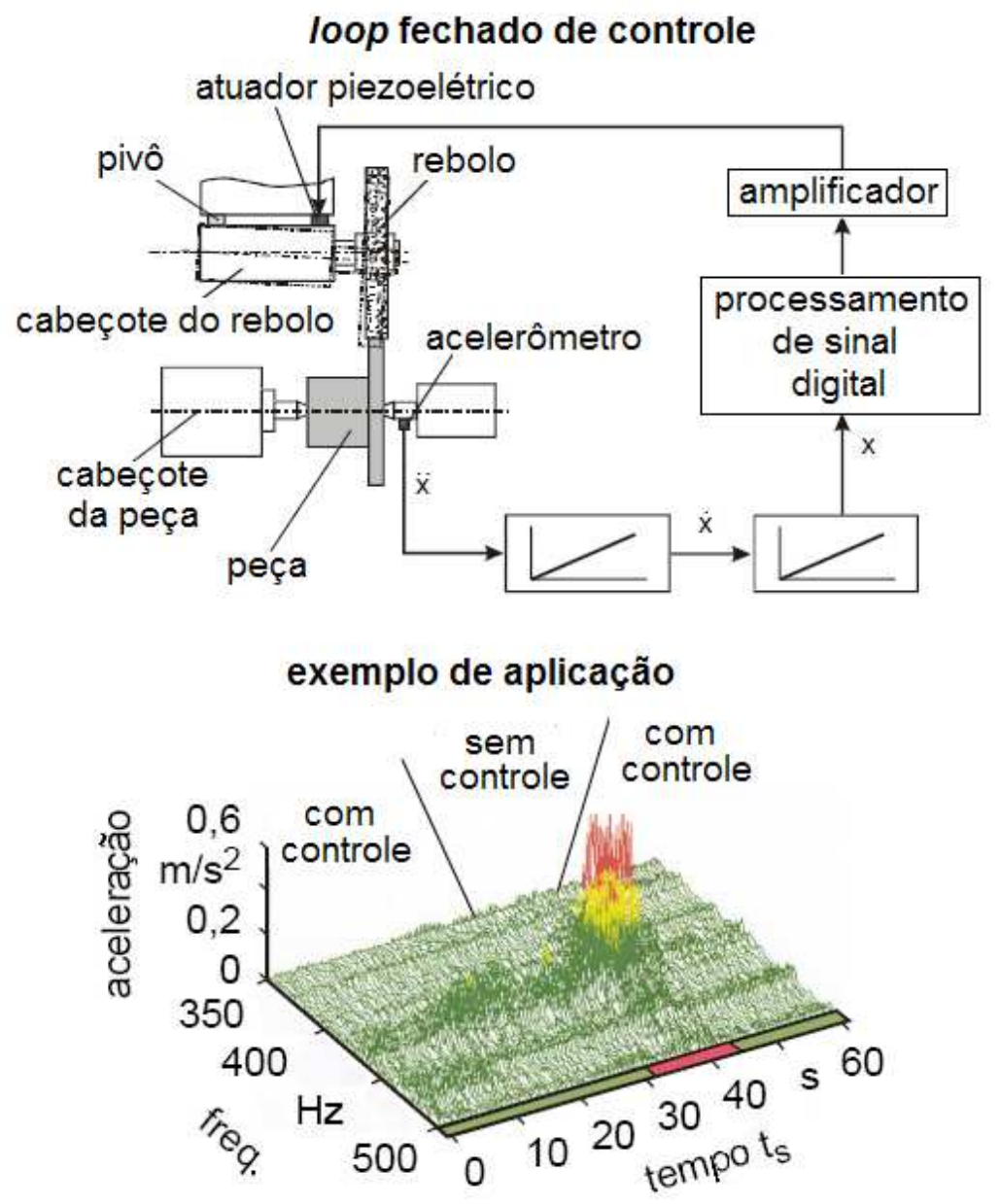

Figura 3.13 - Aplicação de amortecedor ativo na retificação de mergulho (Weck e Brecher, 2001 - Adaptada). 

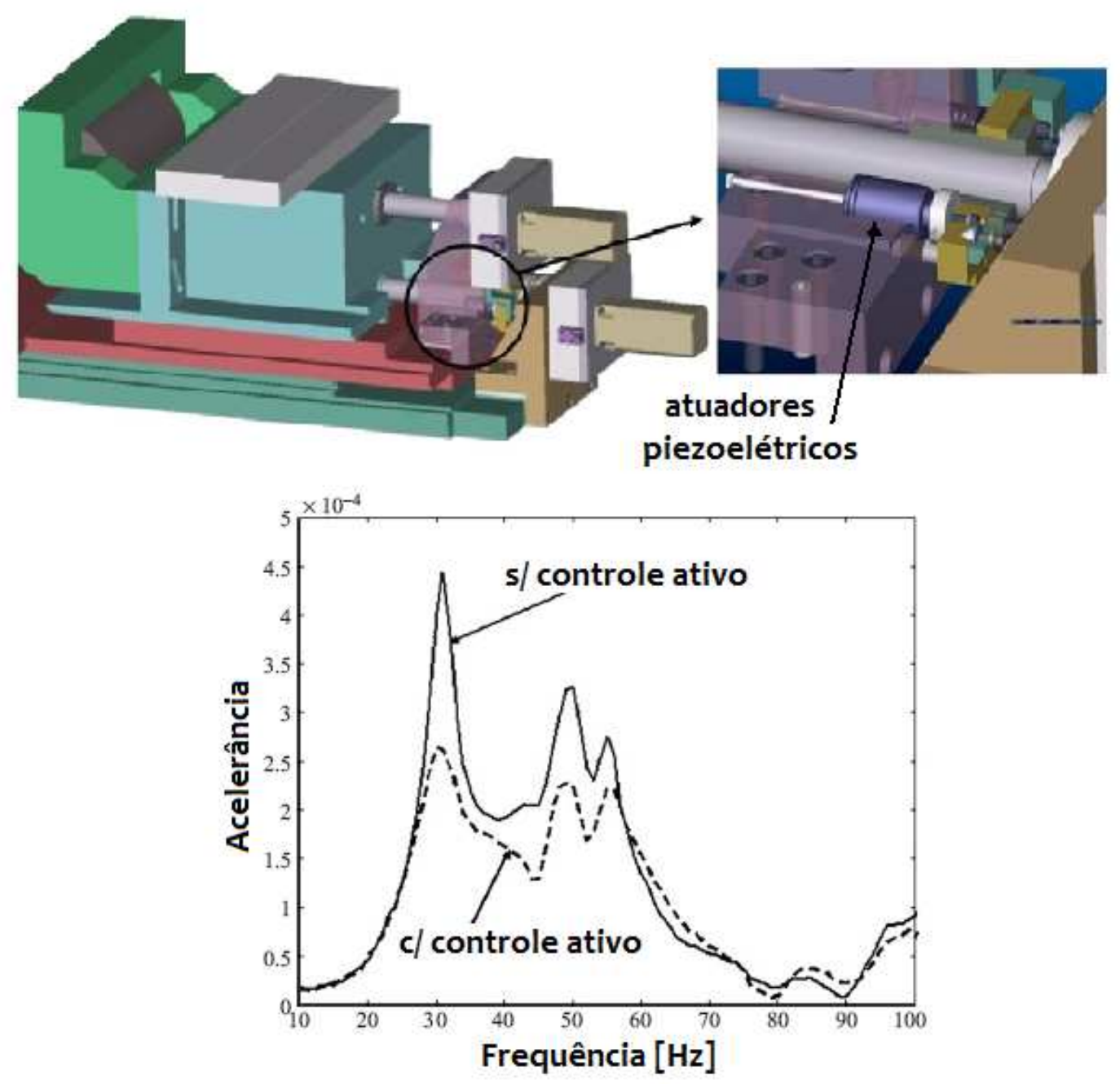

Figura 3.14 - Amortecedor ativo montado em uma retificadora centerless e resposta em frequiência do sistema máquina-ferramenta-peça (Albizuri et al., 2007 - Adaptada).

Durante o mergulho do processo de retificação o sensor de aceleração fixado na contra-ponta da retificadora capta os sinais de aceleração que são convertidos para valores de deslocamento para serem utilizados em um loop de controle que comanda um atuador piezoelétrico conectado ao cabeçote da ferramenta. Este atuador movimenta o cabeçote de modo a compensar a vibração do sistema (Figura 3.13). Da mesma maneira, a Figura 3.14 exibe uma máquina retificadora centerless onde foram montados dois atuadores piezoelétricos que operam no sentido de avanço do rebolo. Os resultados mostram que o método de controle 
ativo foi capaz de alterar as características dinâmicas da máquina, diminuir a amplitude da resposta em freqüência do sistema, reduzindo assim os erros geométricos na peças retificadas.

Outra possibilidade de diminuir a vibração do sistema é a adição de um elemento de mola entre o rebolo e a peça, ou seja, diminuir a rigidez de contato do rebolo. A Figura 3.15 mostra alguns rebolos com modificações baseadas nesta idéia (Bzymek et al., 1994 e McFarland et al. 1999).

Bzymek et al. (1994) realizaram análises utilizando o método dos elementos finitos para desenvolver uma geometria de rebolo capaz de eliminar ou diminuir a vibração autoexcitada. Foram realizadas análises de rigidez e resposta em freqüência para rebolos com furos ou rasgos no seu corpo com o intuito de aumentar a sua flexibilidade. A Figura 3.15 mostra as estruturas analisadas, de corpo do rebolo com: a) rasgos inclinados; b) furos; c) rasgos circulares; e d) sem furos.
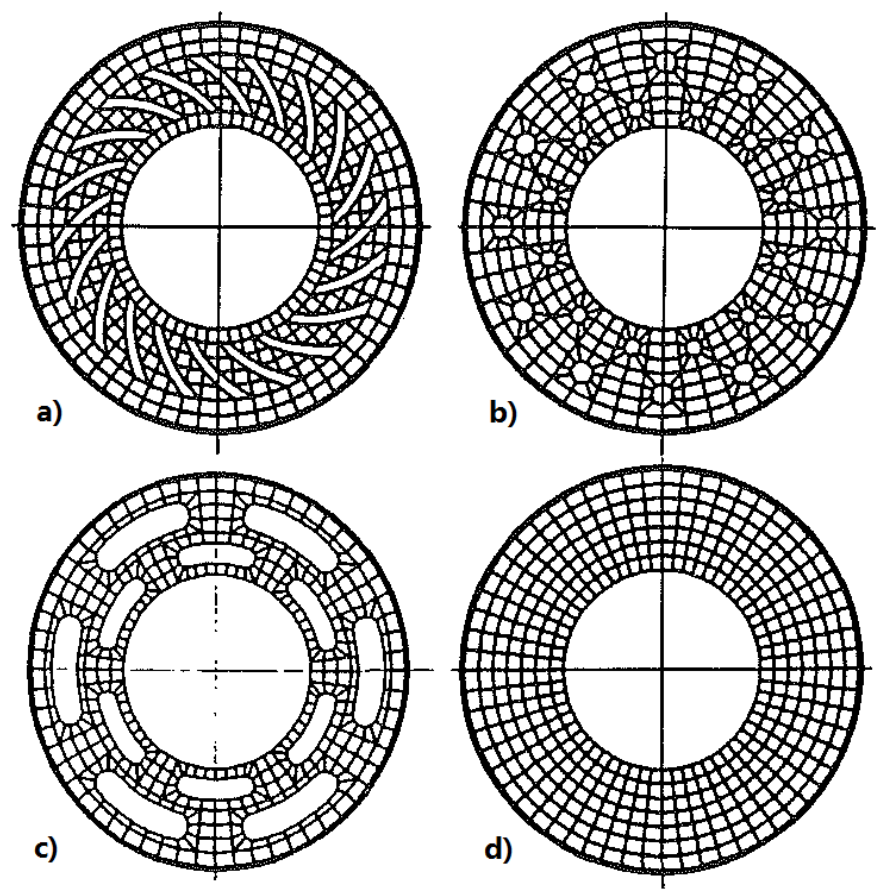

Figura 3.15 - Rebolos flexíveis para eliminação da trepidação (Bzymek et al., 1994 Adaptada). 
Os resultados mostraram que os furos e rasgos fazem com que as deformações ocorridas na circunferência dos rebolos se comportem de maneira ondulatória. Embora este comportamento possa ser minimizado utilizando diferentes formas e tamanhos de rasgos, a falta de simetria axial pode induzir vibrações indesejadas no processo.

Desta forma, os autores desenvolveram um rebolo com espessura de corpo variável e concluíram que: o corpo com espessura variável aumenta a flexibilidade do rebolo, mas mantém a simetria axial do mesmo; a geometria pode ser utilizada em uma grande variedade de condições de usinagem; a estrutura é simples e fácil de fabricar; e as dimensões deste novo rebolo são equivalentes aos rebolos usuais e, desta forma, podem ser utilizados em qualquer máquina retificadora comercial.

Como já citado anteriormente, a variação da velocidade da peça e do rebolo também pode influenciar na eliminação da trepidação (Mannan et al., 2000). As Figuras 3.16 e 3.17 mostram exemplos de trabalhos que realizaram testes variando estas velocidades.

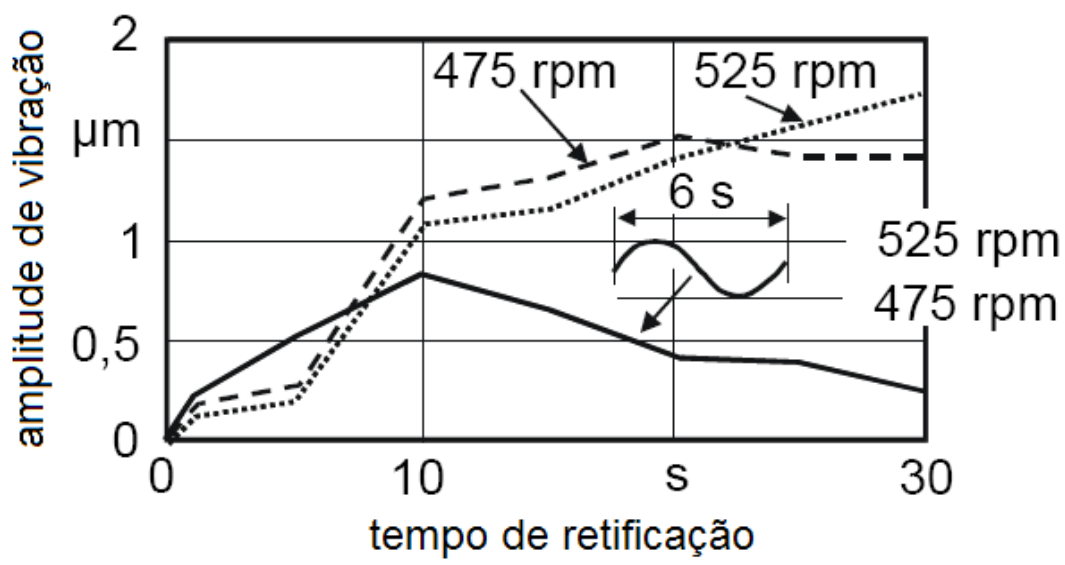

Figura 3.16 - Eliminação da trepidação pela variação da velocidade da peça (Inasaki, 1977 apud Inasaki et al., 2001 - Adaptada). 


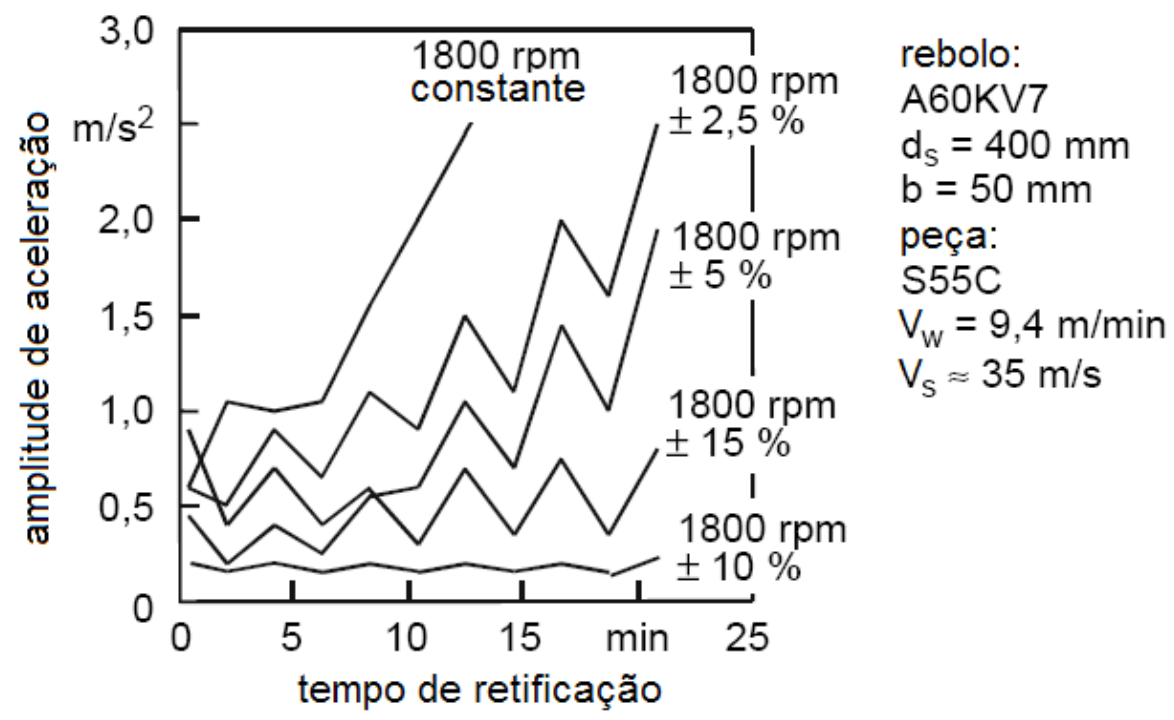

Figura 3.17 - Eliminação da trepidação pela variação da velocidade do rebolo (Hoshi et al., 1987 apud Inasaki et al., 2001 - Adaptada).

As Figuras 3.16 e 3.17 mostram que uma variação na rotação da peça ou rebolo diminui sensivelmente a amplitude de vibração do processo. Os testes foram realizados variando-se a rotação da peça entre 525 e $475 \mathrm{rpm}$, a uma freqüência de aproximadamente 0,17 Hz (Figura 3.16). Já os testes realizados variando-se a rotação do rebolo (Figura 3.17), mostram melhores resultados, isto é menores amplitudes de vibração, quando a variação na rotação é de $10 \%$, ou seja, entre 1980 e 1620 rpm. 


\section{Capítulo 4}

\section{MATERIAIS E MÉTODOS}

Foram realizados ensaios de retificação utilizando três diferentes bancadas de testes que são categorizados de acordo com a classificação a seguir:

- Configuração 1 - ensaios de retificação sem vibração externa utilizando alta velocidade de corte e rebolo de CBN (Item 4.1);

- Configuração 2 - ensaios de retificação convencional com vibração externa utilizando rebolo de CBN (Item 4.2);

- Configuração 3 - ensaios de retificação com vibração externa utilizando alta velocidade de corte e rebolo de CBN (Item 4.3).

Três ensaios adicionais de retificação foram realizados para a observação da ocorrência da trepidação, comportamento da potência na presença de vibração externa e diminuição da vibração com o emprego de um amortecedor passivo (Item 4.4). Este último, realizado na planta da TRW em Santo André sob a supervisão do Professor João Fernando Gomes de Oliveira e do engenheiro da TRW Marcelo Biffi.

Além destes ensaios, foram realizadas análises de resposta em freqüência da peça (fixada no cabeçote porta-peça) e do rebolo (fixado no cabeçote porta-rebolo) por meio de testes de impacto, ou teste do martelo (Item 4.5). 
Os sistemas de aquisição de dados utilizados nestes testes serão detalhados no item 4.6. Já o item 4.7 detalha os procedimentos e equipamentos utilizados nas medições da rugosidade, erro de circularidade e desgaste radial do rebolo.

\subsection{Configuração 1 de Retificação}

A “Configuração 1" foi utilizada para a realização de testes "estáticos" ou "nãoexcitados" de retificação, ou seja, não houve a introdução de excitação externa ao processo. Estes testes foram realizados em conjunto com o aluno Jen Po Wang e fazem parte da sua dissertação de mestrado apresentada ao Departamento de Engenharia Mecânica da Escola de Engenharia de São Carlos - USP (Wang, 2008).

O objetivo principal destes ensaios foi estudar a influência das variáveis do processo no desgaste do rebolo. Para isto foram utilizados materiais de difícil retificação (DTG Difficult to Grind), rebolo de CBN e alta velocidade de corte.

\subsubsection{Bancada de Testes - Configuração 1}

A bancada de testes utilizada foi uma retificadora cilíndrica de altas velocidades de corte da marca ZEMA, modelo Numérica G800, localizada nas dependências do Laboratório de Otimização de Processos de Fabricação da Escola de Engenharia de São Carlos - USP. A máquina é equipada com sensores de emissão acústica e de proximidade para o cálculo da rotação do rebolo. Este sensor de proximidade funciona gerando um pulso elétrico a cada passagem de um parafuso alojado no flange do rebolo pelo mesmo, desta forma pode-se calcular a rotação da ferramenta. Além disso, utilizou-se a saída do inversor de freqüências do motor do rebolo para o cálculo da potência de retificação, pois este sinal é proporcional à corrente elétrica do motor. Os dados técnicos da retificadora cilíndrica são: 
- Máxima velocidade de corte: $100 \mathrm{~m} / \mathrm{s}$;

- Máxima potência disponível: $11 \mathrm{~kW}$;

- Mancal hidrostático no eixo porta-rebolo;

- Bocais de sapata e especial (Webster, 1995);

- Sistema de filtragem por elemento filtrante com vazão máxima de 10000 1/h;

- Sistema de alta pressão para limpeza do rebolo;

- Disco diamantado com acionamento por unidade elétrica;

- Sistema de mapeamento acústico integrado a um CNC de arquitetura aberta;

- Sistema de resfriamento de óleo hidráulico e do fluido de corte;

- Sistema anti-chamas e exaustor de névoa; e

- Medidor de vazão do fluido de corte.

A bancada de testes da Configuração 1 pode ser visualizada na Figura 4.1.

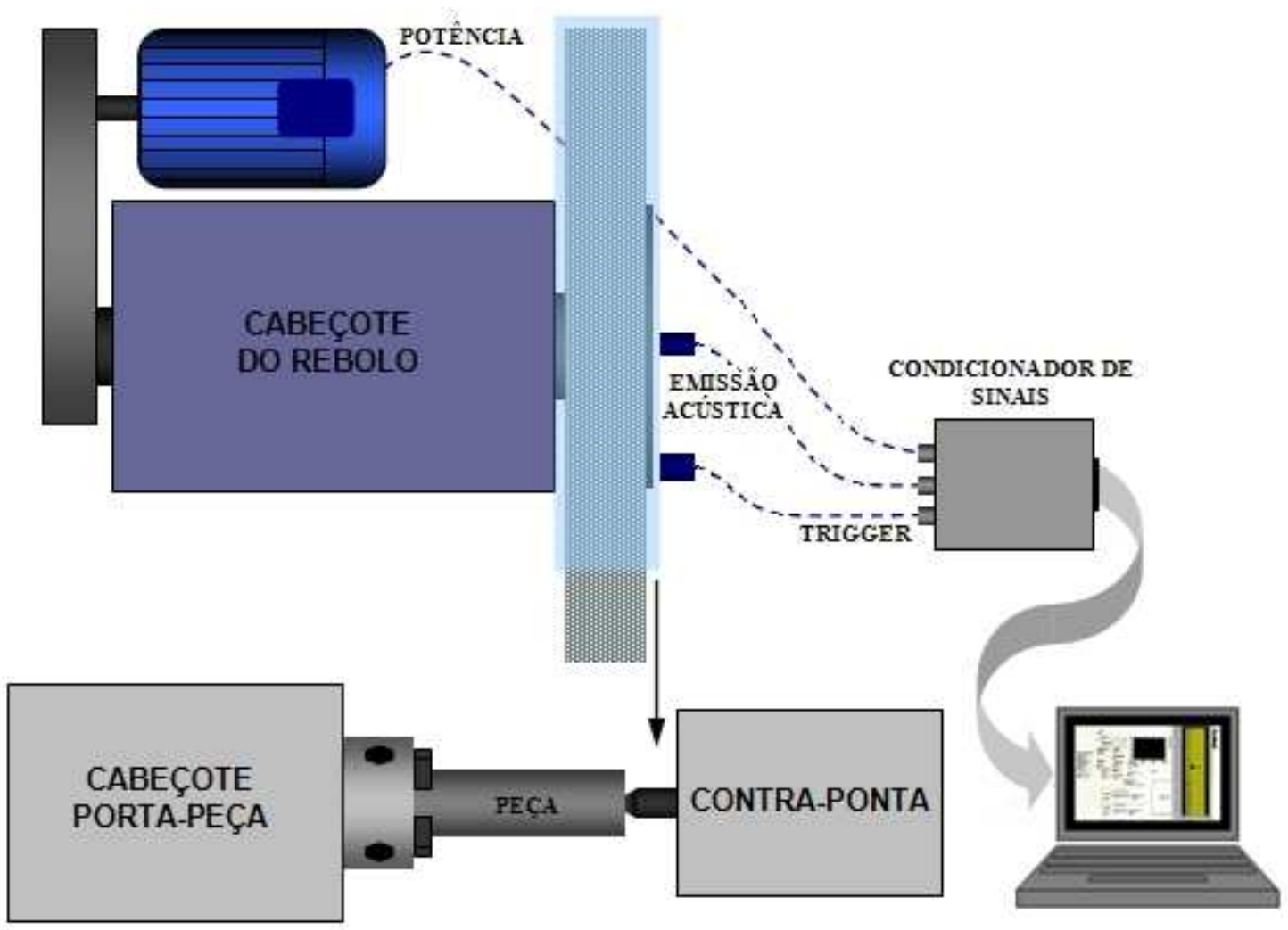

Figura 4.1 - Configuração 1 da bancada de testes utilizada para os ensaios não-excitados. 
Um computador é utilizado para a aquisição dos dados provenientes da máquina. $\mathrm{O}$ programa exibe e grava o mapa acústico e a potência de retificação.

\subsubsection{Corpos-de-Prova}

Para o corpo-de-prova foram utilizados três materiais de diferentes usinabilidades: inconel (751), silcrome 1 (VV45) e 21-2N (VV56). A composição química destes materiais é exibida na Tabela 4.1. Estes materiais não possuem tratamento térmico.

Tabela 4.1 - Composição química dos materiais dos corpos-de-prova dos ensaios da Configuração 1 (\% em peso).

\begin{tabular}{|c|c|c|c|}
\hline Elemento Químico & Inconel (751) & Silcrome 1 (VV45) & 21-2N (VV56) \\
\hline $\mathrm{C}$ & 0,10 Máx. & $0,40 / 0,50$ & $0,50 / 0,60$ \\
\hline $\mathrm{Mn}$ & 1,00 Máx. & 0,60 Máx. & $7,00 / 10,00$ \\
\hline $\mathrm{Si}$ & 0,50 Máx. & $2,70 / 3,30$ & 0,25 Máx. \\
\hline $\mathrm{Cr}$ & $14,00 / 17,00$ & $8,00 / 10,00$ & $19,50 / 22,00$ \\
\hline $\mathrm{Ni}$ & 70,00 Mín. & 0,30 Máx. & $1,50 / 2,75$ \\
\hline $\mathrm{S}$ & 0,01 Máx. & 0,030 Máx. & 0,030 Máx. \\
\hline $\mathrm{Fe}$ & $5,00 / 9,00$ & Restante & Restante \\
\hline $\mathrm{Al}$ & $0,90 / 1,50$ & & \\
\hline $\mathrm{Ti}$ & $2,00 / 2,60$ & & 0,040 Máx. \\
\hline $\mathrm{Cu}$ & 0,50 Máx. & & 0,85 Mín. \\
\hline $\mathrm{Nb}+\mathrm{T}$ & $0,70 / 1,20$ & & \\
\hline $\mathrm{P}$ & & 0,040 Máx. & \\
\hline $\mathrm{C}+\mathrm{N}$ & & & \\
\hline $\mathrm{N}$ & & & \\
\hline
\end{tabular}

De acordo com Diniz et al. (2001), a usinabilidade pode ser entendida como o grau de dificuldade de se usinar um determinado material e depende do seu estado metalúrgico, 
propriedades mecânicas do material, composição química, processos de transformação anteriores e eventual encruamento, além das condições de usinagem utilizadas.

O inconel é uma superliga austenítica a base de níquel e possui a pior usinabilidade dos três materiais ensaiados. Já o silcrome é um material martensítico e o que possui a melhor usinabilidade dentre os três. Finalmente o $21-2 \mathrm{~N}$ é um aço inoxidável austenítico possuindo um grau de usinabilidade entre o inconel e o silcrome.

Os corpos-de-prova possuem as seguintes dimensões: comprimento de $150 \mathrm{~mm}$, inconel tem diâmetro de 28,5 mm, silcrome e 21-2N têm diâmetro de 25,5 mm.

\subsubsection{Definição dos Parâmetros}

O objetivo destes testes é observar a influência das variáveis do processo no desgaste do rebolo. Para isto, alguns parâmetros foram selecionados.

Cada ensaio teve exatamente a mesma quantidade de material removido da peça, deste modo, o volume específico de material removido por ensaio $\left(V^{\prime}{ }_{w}\right)$ foi fixado em 8.000 $\mathrm{mm}^{3} / \mathrm{mm}$. O rebolo de CBN foi dressado com um disco diamantado rotativo e parâmetros constantes. O número de passes de dressagem foi definido de acordo com o ensaio anterior, isto é, apenas o suficiente para limpar a área do rebolo desgastada. Isto foi verificado por meio do mapeamento acústico do processo de dressagem.

Os ensaios consistem na retificação de duas peças para cada uma das condições. Foram realizados 16 mergulhos em cada peça com um degrau de $0,03 \mathrm{~mm}$ entre os mergulhos. O volume específico de material removido em cada mergulho foi de 250 $\mathrm{mm}^{3} / \mathrm{mm}$.

As Tabelas 4.2 e 4.3 apresentam os parâmetros utilizados de retificação e de dressagem, respectivamente. 
Tabela 4.2 - Parâmetros de retificação dos ensaios da Configuração 1.

\begin{tabular}{|c|c|}
\hline \multicolumn{2}{|c|}{ Parâmetros de Retificação } \\
\hline Rebolo de CBN & B181 VSS Q V 320-400x28x10 \\
\hline Corpos-de-prova & Inconel (751), Silcrome 1 (VV45) e 21-2N (VV56). \\
\hline Velocidades de avanço $\left(v_{f}\right)$ & 0,$6 ; 1,2 ; 2,4$ e $5 \mathrm{~mm} / \mathrm{min}$ \\
\hline Velocidade de corte $\left(v_{c}\right)$ & $100 \mathrm{~m} / \mathrm{s}$ \\
\hline Rotação da peça $\left(n_{w}\right)$ & $200 \mathrm{rpm}$ \\
\hline Largura de retificação $(b)$ & $5 \mathrm{~mm}$ \\
\hline Número de ciclos por peça & $16 \mathrm{ciclos}$ \\
\hline $\begin{array}{c}\text { Volume específico de material } \\
\text { removido por ensaio }\left(V^{\prime}{ }_{w}\right)\end{array}$ & $8000 \mathrm{~mm}{ }^{3} / \mathrm{mm}$ \\
\hline Tempo de centelhamento $($ spark-out $)$ & $0,5 \mathrm{~s}$ \\
\hline Fluido de corte & Óleo integral \\
\hline
\end{tabular}

Tabela 4.3 - Parâmetros de dressagem dos ensaios da Configuração 1.

\begin{tabular}{|c|c|}
\hline \multicolumn{2}{|c|}{ Parâmetros de Dressagem } \\
\hline Profundidade de dressagem $\left(a_{d}\right)$ & $2 \mu \mathrm{m}$ \\
\hline Velocidade do dressador $\left(v_{r}\right)$ & $32 \mathrm{~m} / \mathrm{s}$ \\
\hline Velocidade do rebolo $\left(v_{s}\right)$ & $80 \mathrm{~m} / \mathrm{s}$ \\
\hline Grau de recobrimento $\left(U_{d}\right)$ & 4 \\
\hline
\end{tabular}

Foram realizados onze ensaios de desgaste para rebolo de CBN de liga vitrificada, onde se variou o material e a velocidade de avanço na retificação. As condições de dressagem (concordante), a velocidade de corte e a rotação da peça foram mantidas constantes.

Em todos os ensaios, variou-se apenas a velocidade de avanço $\left(v_{f}\right)$ e o material da peça. A Figura 4.2 mostra o fluxograma dos ensaios realizados. 


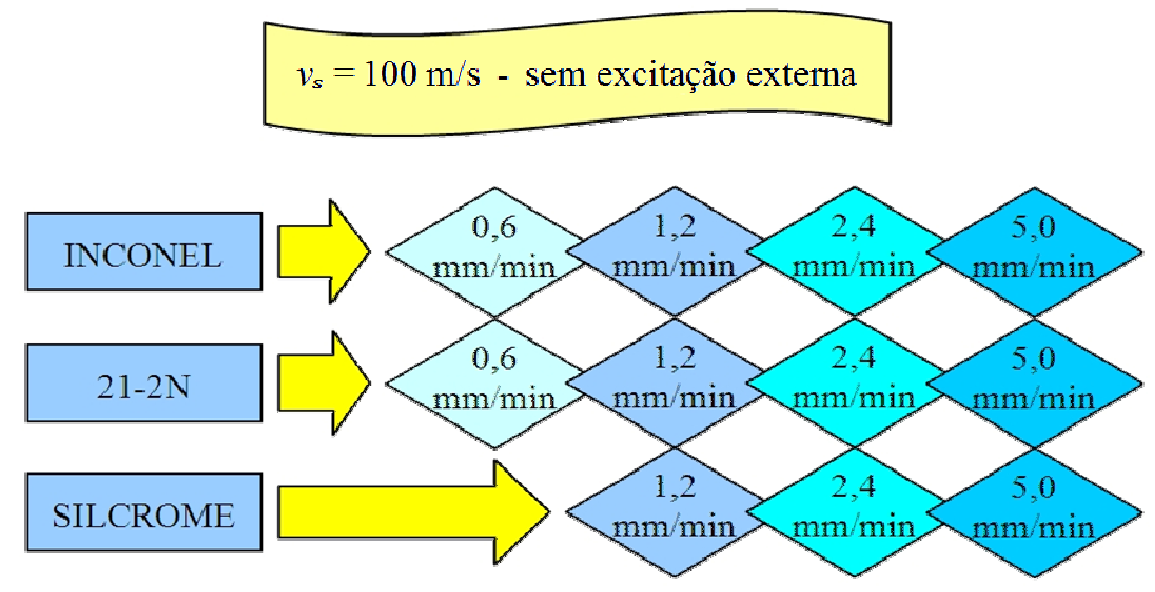

Figura 4.2 - Fluxograma dos ensaios da Configuração 1.

O ensaio realizado com o material silcrome e velocidade de avanço $\left(v_{f}\right)$ igual a 0,6 mm/min não será apresentado nos resultados, pois o rebolo de CBN não apresentou valores mensuráveis de desgaste.

\subsection{Configuração 2 de Retificação}

A Configuração 2 foi utilizada para a realização de testes de retificação convencional com excitação externa. Estes testes foram realizados nas dependências do Laboratório de Usinagem da Faculdade de Engenharia Mecânica - UNICAMP, sob a direção do professor Anselmo Eduardo Diniz.

\subsubsection{Bancada de Testes - Configuração 2}

A bancada de testes utilizada é formada por uma máquina retificadora cilíndrica ZEMA, modelo Compakta G600. Os dados técnicos da retificadora são: comando numérico GE/Fanuc, série 18-T; sistema hidrostático na guia transversal e longitudinal; mancal hidrostático no eixo porta-rebolo; dressador estático do tipo conglomerado; velocidade máxima de corte $\left(v_{s}\right)$ de $45 \mathrm{~m} / \mathrm{s}$ e potência do motor do rebolo igual a $5,5 \mathrm{~kW}$. 
A máquina é equipada com sensores de emissão acústica e de proximidade para o cálculo da rotação do rebolo. O sensor de proximidade funciona gerando um pulso elétrico a cada passagem de um parafuso alojado no flange do rebolo pelo mesmo, desta forma pode-se calcular a rotação da ferramenta. Além disso, utilizou-se a saída do inversor de freqüências do motor do rebolo para o cálculo da potência de retificação, pois este sinal é proporcional à corrente elétrica do motor.

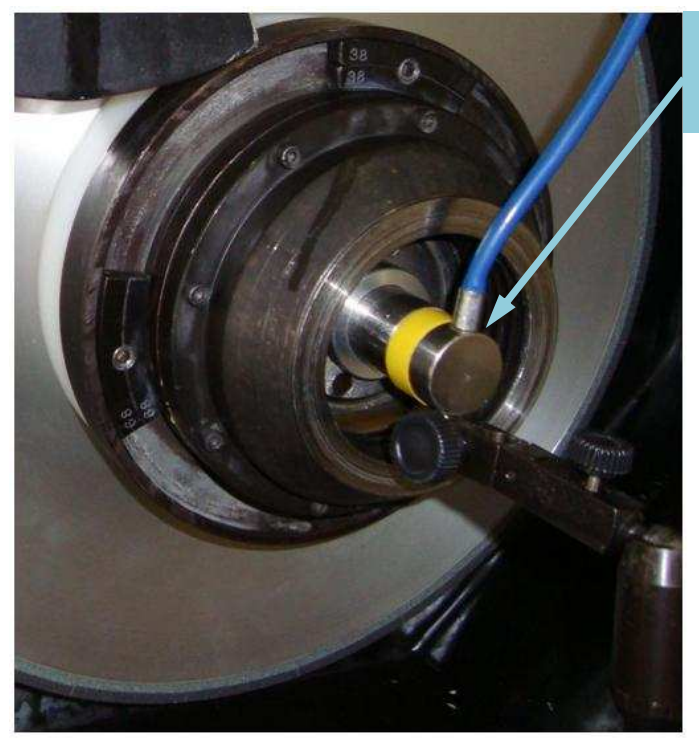

\section{Sensor de emissão acústica sem contato}

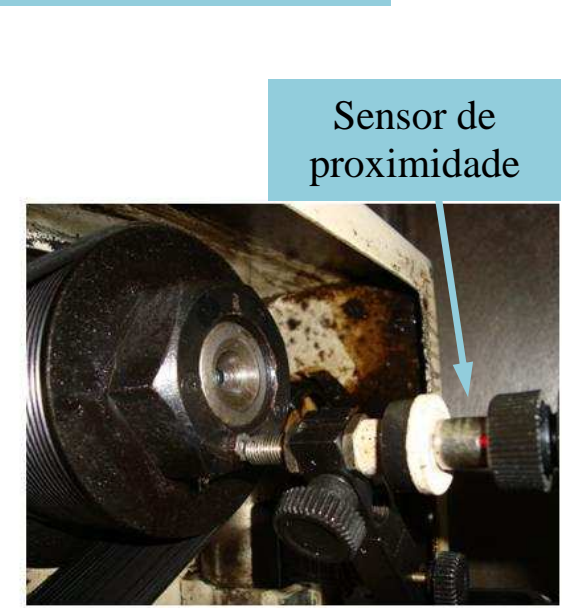

Figura 4.3 - Vista da fixação dos sensores de emissão acústica e de proximidade na retificadora cilíndrica ZEMA, modelo Compakta G600.

O sensor de emissão acústica utilizado foi do tipo sem contato, formado por um emissor que fica preso na ponta do eixo do cabeçote porta-rebolo e um receptor fixado a aproximadamente $2 \mathrm{~mm}$ de distância do emissor com a ajuda de uma base magnética. $\mathrm{O}$ sensor de proximidade, também fixado por uma base magnética, utilizado para a geração do mapa acústico foi fixado próximo à correia do cabeçote porta-peça e o mesmo gera pulsos no sinal por meio da passagem de um pequeno pedaço de metal (parafuso) fixado na polia do eixo (Figura 4.3). Os sinais foram enviados a um computador portátil utilizado exclusivamente para a geração do mapa acústico e gráfico da potência de retificação. 
A máquina foi ainda equipada com um sistema de excitação formado por um excitador eletrodinâmico, amplificador, acelerômetros, haste, mancal de deslizamento e computador portátil. A excitação randômica foi aplicada diretamente na peça por meio do mancal de deslizamento. A peça é fixada a uma distância constante $(l)$ das castanhas da portapeça de $40 \mathrm{~mm}$. A bancada de testes da Configuração 2 pode ser visualizada na Figura 4.4.

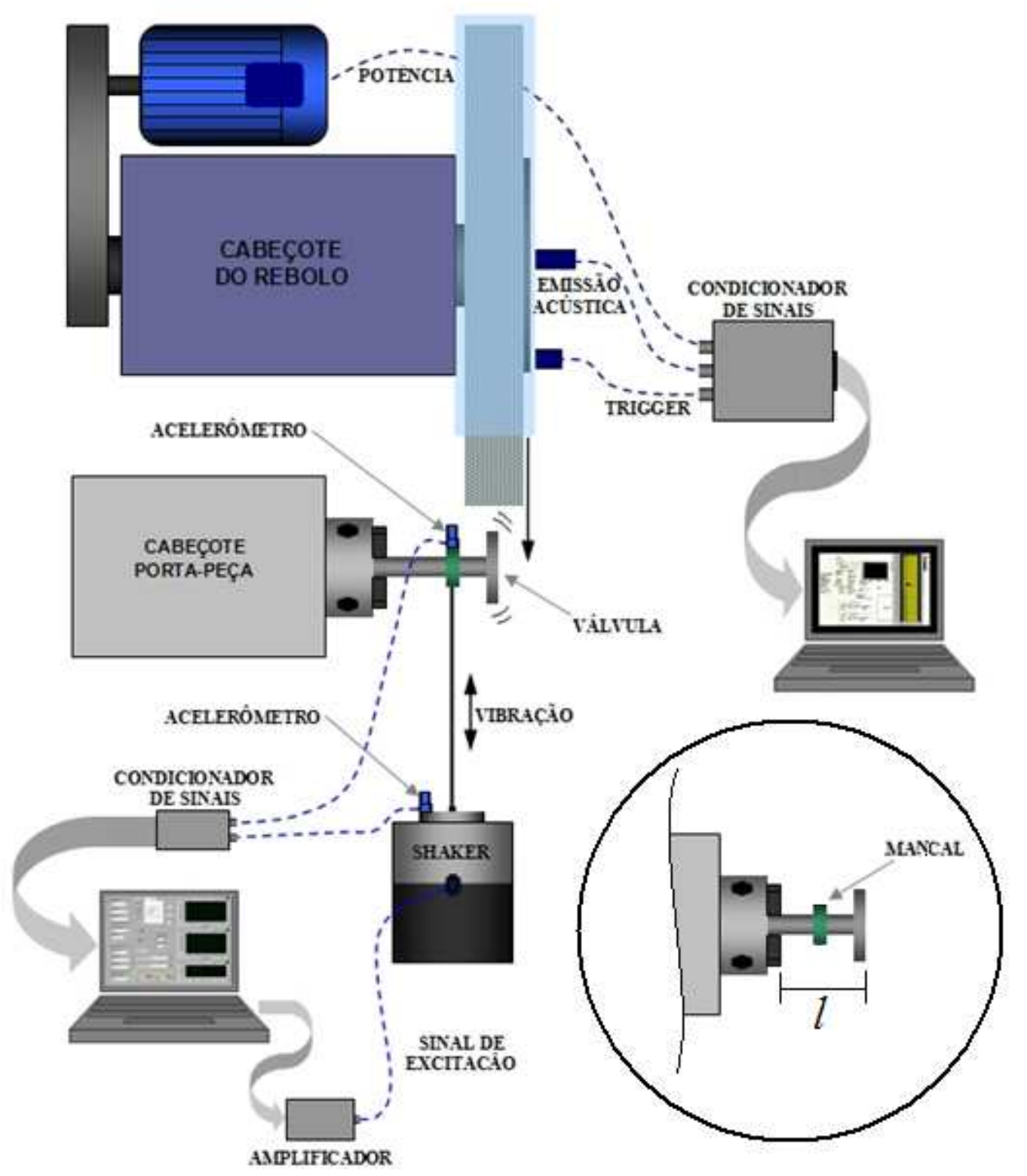

Figura 4.4 - Configuração 2 da bancada de testes utilizada para ensaios dinâmicos com rebolo de CBN. 
Foi utilizada uma haste conectando o shaker ao mancal de deslizamento (Figura 4.5). Desta forma, a haste proveniente do excitador eletrodinâmico pôde ser presa no mancal permitindo a transmissão de vibração sem afetar o movimento rotacional da peça. O mancal possui um parafuso de constrição que é utilizado para eliminar qualquer folga existente e uma bucha grafitada para diminuição do atrito. Além disso, para cada teste o sistema foi montado com aplicação de graxa entre a bucha e a haste da válvula.

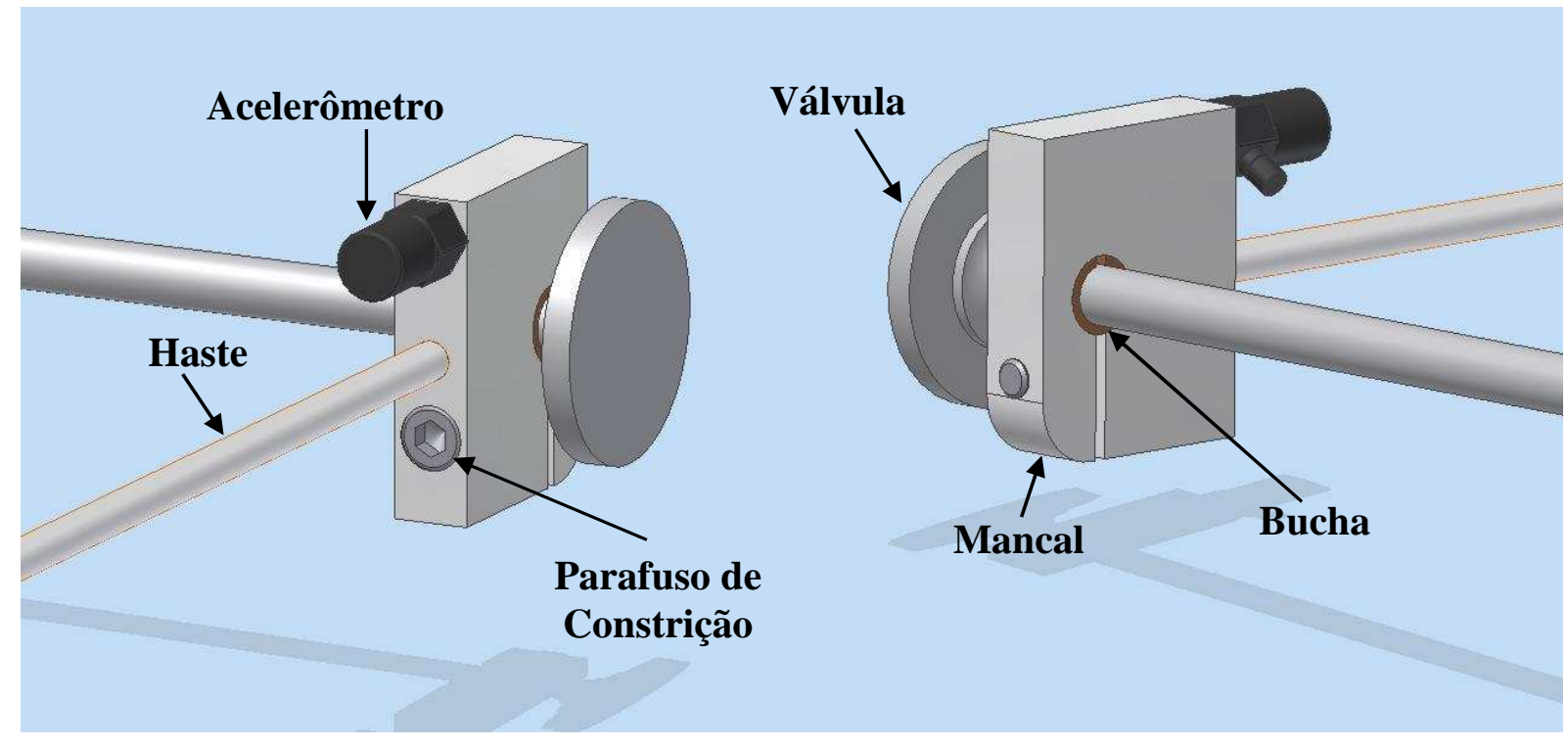

Figura 4.5 - Mancal de deslizamento utilizado na Configuração 2.

\subsubsection{Corpos-de-Prova}

O corpo-de-prova utilizado nestes ensaios é uma válvula de motor de combustão interna fabricada pela TRW. Esta válvula foi devidamente usinada para se adequar aos outros equipamentos utilizados e ao tipo de teste conduzido. A Figura 4.6 exibe as suas dimensões. 

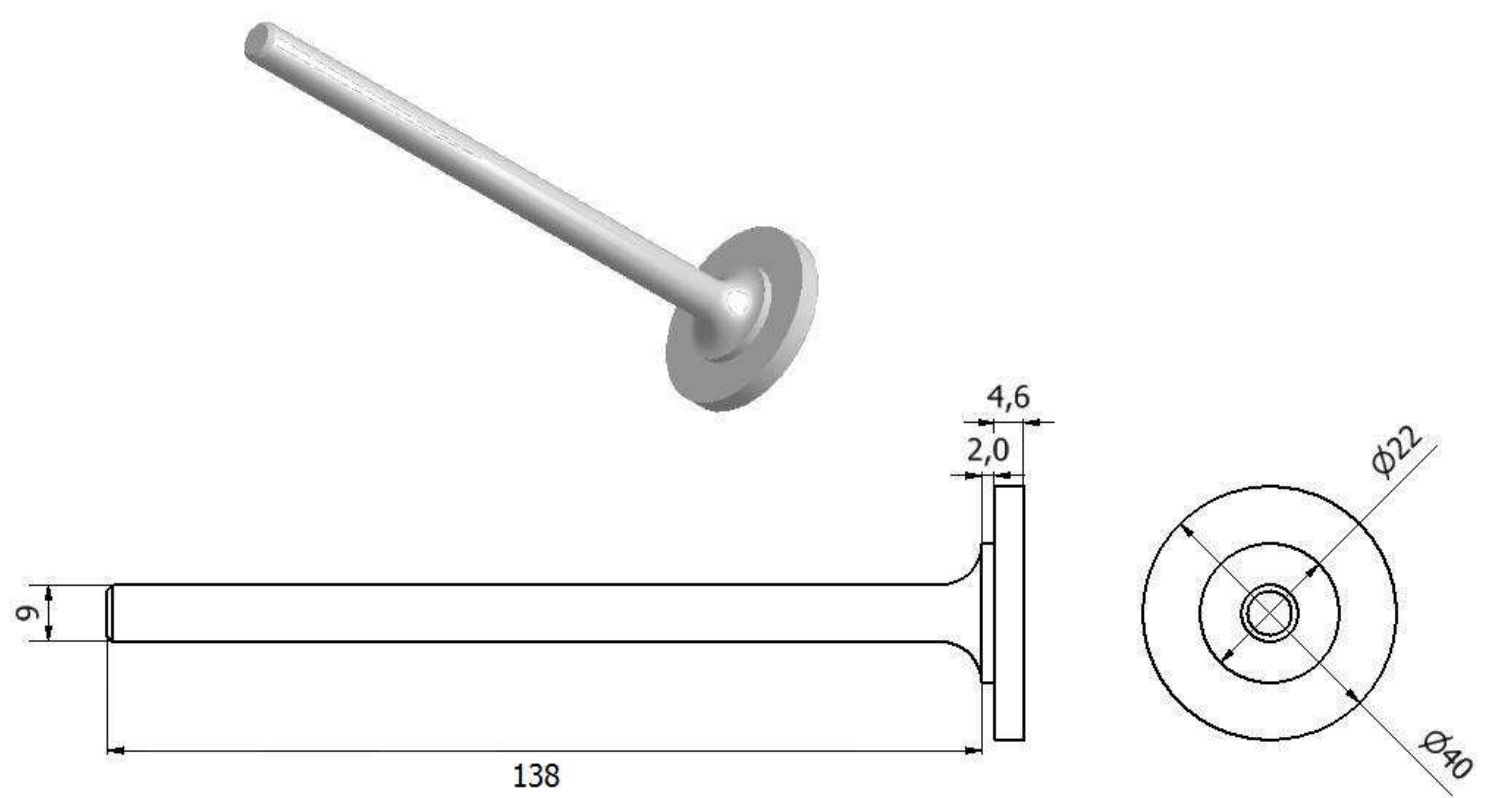

Figura 4.6 - Dimensões em milímetro do corpo-de-prova dos ensaios da Configuração 2.

O material que compõe estes corpos-de-prova é o 23-8N, inoxidável austenítico, com excelente resistência às altas temperaturas, além de excelente resistência à corrosão. É utilizado em larga escala para a manufatura de válvulas de motores de combustão interna. A sua composição química é exibida na Tabela 4.4. Este material não possui tratamento térmico.

Tabela 4.4 - Composição química do material do corpo-de-prova dos ensaios da Configuração 2 (\% em peso).

\begin{tabular}{|c|c|}
\hline Elemento Químico & $\mathbf{2 3 - 8 N}$ \\
\hline $\mathrm{C}$ & $0,30 / 0,35$ \\
\hline $\mathrm{Cr}$ & $22,00 / 24,00$ \\
\hline $\mathrm{Ni}$ & $7,00 / 9,00$ \\
\hline $\mathrm{Mn}$ & $3,00 / 4,00$ \\
\hline $\mathrm{N}$ & $0,30 / 0,34$ \\
\hline $\mathrm{Si}$ & $0,60 / 0,90$ \\
\hline $\mathrm{Fe}$ & Restante \\
\hline $\mathrm{C}+\mathrm{N}$ & 0,625 \\
\hline
\end{tabular}




\subsubsection{Definição dos Parâmetros}

Para entender a influência das interações dinâmicas nas variáveis do processo, foram realizados testes com várias amplitudes de vibração e condições de corte constantes.

De acordo com Felício (2007), idealmente o sinal do tipo ruído branco, ou white noise, é um sinal aleatório de Densidade Espectral Média Quadrada (ou Power Spectral Density) plana. Isto quer dizer que o sinal possui a mesma amplitude em todas as freqüências. Este tipo de sinal foi utilizado como o sinal de excitação nos testes, pois é o que mais se assemelha ao tipo de ruído produzido pelo processo de retificação, onde existe o contato aleatório dos grãos abrasivos (randomicamente distribuído na superfície do rebolo) com a peça retificada. A Tabela 4.5 mostra as condições de corte utilizadas.

Tabela 4.5 - Parâmetros de retificação dos ensaios da Configuração 2.

\begin{tabular}{|c|c|}
\hline \multicolumn{2}{|c|}{ Parâmetros de Retificação } \\
\hline Rebolo de CBN vitrificado & CBN $88691205-355,6 \times 25 \times 127$ \\
\hline Corpos-de-prova & $23-8 \mathrm{~N}$ \\
\hline Distância de fixação da peça $(l)$ & $40 \mathrm{~mm}$ \\
\hline Velocidade de avanço $\left(v_{f}\right)$ & $0,4 \mathrm{~mm} / \mathrm{min}$ \\
\hline Velocidade de corte $\left(v_{c}\right)$ & $45 \mathrm{~m} / \mathrm{s}$ \\
\hline Rotação da peça $\left(n_{w}\right)$ & $100 \mathrm{rpm}$ \\
\hline Largura de retificação $(b)$ & $4,6 \mathrm{~mm}$ \\
\hline Número de ciclos por ensaio & $15 \mathrm{ciclos}$ \\
\hline $\begin{array}{c}\text { Volume específico de material } \\
\text { removido por ensaio }\left(V^{\prime}{ }_{w}\right)\end{array}$ & $427 \mathrm{~mm}{ }^{3} / \mathrm{mm}$ \\
\hline $\begin{array}{c}\text { Tempo de centelhamento }(\text { spark-out }) \\
\text { Fluido de corte }\end{array}$ & $6 \mathrm{~s}(10$ voltas da peça $)$ \\
\hline
\end{tabular}

Foi utilizado um corpo-de-prova para cada ensaio, sendo o mesmo formado por 15 ciclos de retificação de mergulho. O sobremetal retificado de cada ciclo foi fixado em $0,5 \mathrm{~mm}$ 
no diâmetro de forma que o volume específico de remoção de material $\left(V^{\prime}{ }_{w}\right)$ calculado é de $427 \mathrm{~mm}^{3} / \mathrm{mm}$ para cada ensaio.

O rebolo de $\mathrm{CBN}$ foi dressado com um dressador estático do tipo conglomerado de diamantes e parâmetros constantes. O número de passes de dressagem foi definido de acordo com o ensaio anterior, isto é, apenas o suficiente para limpar a área do rebolo desgastada. Isto foi verificado por meio do mapeamento acústico do processo de dressagem. A Tabela 4.6 exibe os parâmetros utilizados.

Tabela 4.6 - Parâmetros de dressagem dos ensaios da Configuração 2.

\begin{tabular}{|c|c|}
\hline \multicolumn{2}{|c|}{ Parâmetros de Dressagem } \\
\hline Profundidade de dressagem $\left(a_{d}\right)$ & $2 \mu \mathrm{m}$ \\
\hline Velocidade do rebolo $\left(v_{s}\right)$ & $45 \mathrm{~m} / \mathrm{s}$ \\
\hline Grau de recobrimento $\left(U_{d}\right)$ & 2 \\
\hline
\end{tabular}

Foram utilizados sete níveis de amplitude de vibração diferentes, além de um ensaio totalmente livre de excitação. Portanto, no total foram realizados oito ensaios com condições de corte e de dressagem do rebolo constantes e diferentes amplitudes de vibração introduzida no sistema.

A intensidade de vibração é controlada pelo programa de geração de sinal de vibração. Este programa pode gerar sinais de até 10 Volts (limitado pela placa de geração e aquisição de sinais), no entanto, utilizar o valor máximo não é recomendado, pois pode gerar uma corrente elétrica muito alta no amplificador do shaker e causar a sua queima.

Desta forma, foram escolhidos os seguintes valores de amplitude $(A)$ de sinal para a realização dos ensaios: 0, 1, 2, 3, 4, 5, 6 e 7 Volts. A Figura 4.7 mostra o fluxograma dos ensaios realizados. A amplitude de 0 Volt representa o ensaio sem excitação externa. 
$v_{s}=45 \mathrm{~m} / \mathrm{s}-$ com excitação externa

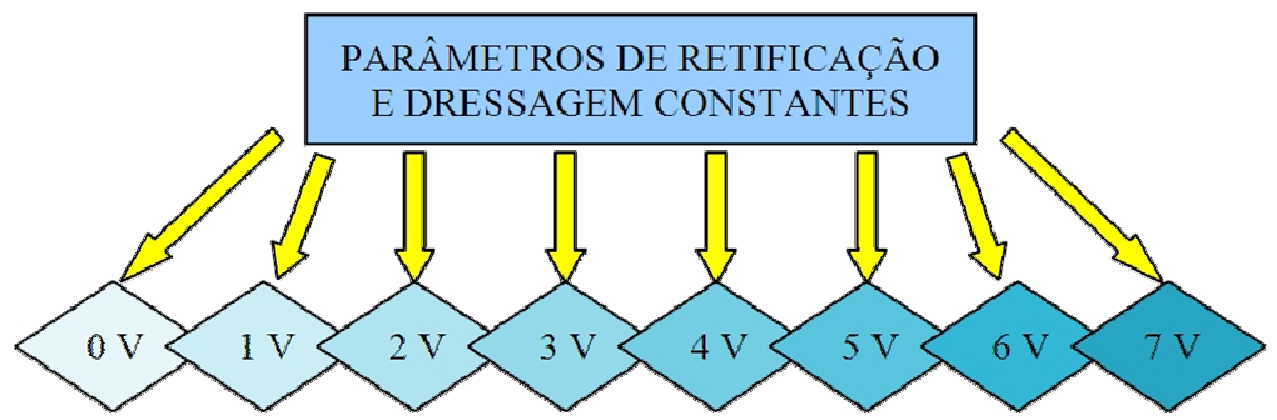

Figura 4.7 - Fluxograma dos ensaios da Configuração 2.

\subsection{Configuração 3 de Retificação}

Esta bancada de testes foi utilizada para a realização de ensaios de retificação de alta velocidade de corte com excitação externa. A máquina retificadora utilizada nesta configuração é a mesma da Configuração 1, ou seja, a retificadora cilíndrica de altas velocidades de corte ZEMA, modelo Numérica G800 (Item 4.1.1).

\subsubsection{Bancada de Testes - Configuração 3}

A não ser pela máquina utilizada, a bancada de testes é muito similar à empregada na Configuração 2 (Figura 4.4). Portanto, a máquina foi instrumentada com todos os equipamentos utilizados na Configuração 2, ou seja, sensor de emissão acústica, de proximidade, acelerômetros, sistema de excitação e dois computadores portáteis - um exclusivo para o sistema de vibração e outro para a geração do mapa acústico e gráficos de potência.

O mancal utilizado nesta configuração (3) é ligeiramente diferente do mancal de deslizamento da Configuração 2 (Figura 4.5). Neste caso, foi utilizado um conjunto mancal- 
rolamento auto-compensador. O conjunto mancal-rolamento pode ser visualizado em detalhe pela Figura 4.8.

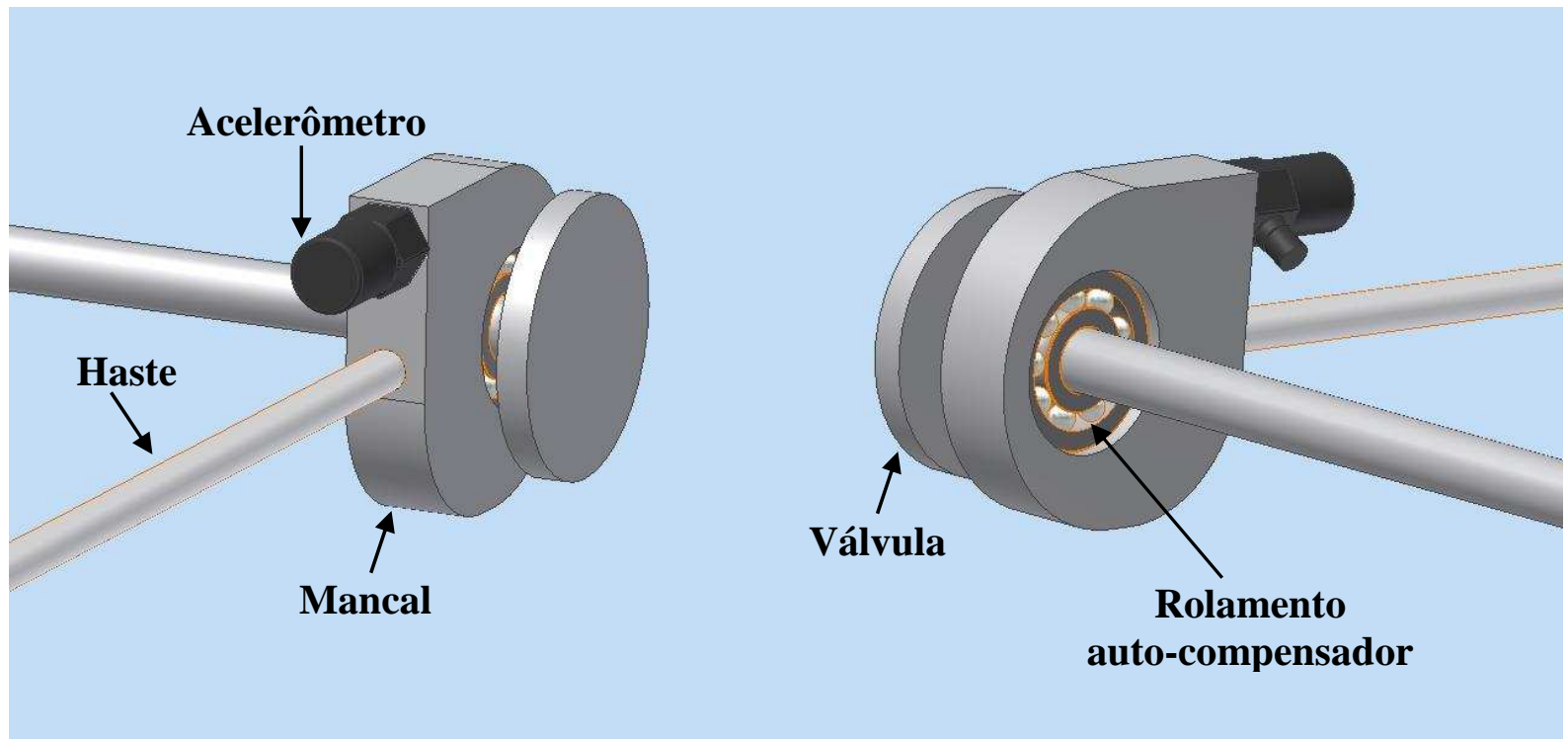

Figura 4.8 - Conjunto mancal-rolamento utilizado na Configuração 3.

\subsubsection{Corpos-de-prova}

O corpo-de-prova utilizado é o mesmo da Configuração 2, apresentado no item 4.2.2, ou seja: uma válvula com dimensões modificadas de material $23-8 \mathrm{~N}$.

\subsubsection{Definição dos Parâmetros}

Os parâmetros de excitação e retificação foram os mesmos utilizados na Configuração 2, salvo a velocidade de corte e especificação do rebolo de CBN vitrificado (Tabela 4.7). 
Tabela 4.7 - Parâmetros de retificação dos ensaios da Configuração 3.

\begin{tabular}{|c|c|}
\hline \multicolumn{2}{|c|}{ Parâmetros de Retificação } \\
\hline Rebolo de CBN vitrificado & B181 VSS Q V 320-400x28x10 \\
\hline Corpos-de-prova & $23-8 \mathrm{~N}$ \\
\hline Distância de fixação da peça $(l)$ & $40 \mathrm{~mm}$ \\
\hline Velocidade de avanço $\left(v_{f}\right)$ & $0,4 \mathrm{~mm} / \mathrm{min}$ \\
\hline Velocidade de corte $\left(v_{c}\right)$ & $100 \mathrm{~m} / \mathrm{s}$ \\
\hline Rotação da peça $\left(n_{w}\right)$ & $100 \mathrm{rpm}$ \\
\hline Largura de retificação $(b)$ & $4,6 \mathrm{~mm}$ \\
\hline Número de ciclos por ensaio & $15 \mathrm{ciclos}$ \\
\hline $\begin{array}{c}\text { Volume específico de material } \\
\text { removido por ensaio }\left(V^{\prime}{ }_{w}\right)\end{array}$ & $427 \mathrm{~mm}{ }^{3} / \mathrm{mm}$ \\
\hline Tempo de centelhamento $($ spark-out $)$ & $6 \mathrm{~s}(10$ voltas da peça $)$ \\
\hline Fluido de corte & Fluido de corte semi-sintético $(5 \%)$ \\
\hline
\end{tabular}

O rebolo de CBN foi dressado na direção concordante com disco diamantado e parâmetros constantes. O número de passes de dressagem foi definido de acordo com o ensaio anterior, isto é, apenas o suficiente para limpar a área do rebolo desgastada. Isto foi verificado por meio do mapeamento acústico do processo de dressagem A Tabela 4.8 exibe os parâmetros utilizados.

Tabela 4.8 - Parâmetros de dressagem dos ensaios da Configuração 3.

\begin{tabular}{|c|c|}
\hline \multicolumn{2}{|c|}{ Parâmetros de Dressagem } \\
\hline Profundidade de dressagem $\left(a_{d}\right)$ & $2 \mu \mathrm{m}$ \\
\hline Velocidade do dressador $\left(v_{r}\right)$ & $32 \mathrm{~m} / \mathrm{s}$ \\
\hline Velocidade do rebolo $\left(v_{s}\right)$ & $100 \mathrm{~m} / \mathrm{s}$ \\
\hline Grau de recobrimento $\left(U_{d}\right)$ & 2 \\
\hline
\end{tabular}


Como nos testes da Configuração 2, foram realizados oito ensaios com condições de corte e de dressagem do rebolo constantes e diferentes amplitudes de vibração introduzida no sistema. Assim, foram utilizados os seguintes valores de amplitude $(A)$ de sinal para a geração do programa: 0, 1, 2, 3, 4, 5, 6 e 7 Volts. A Figura 4.9 mostra o fluxograma dos ensaios realizados.

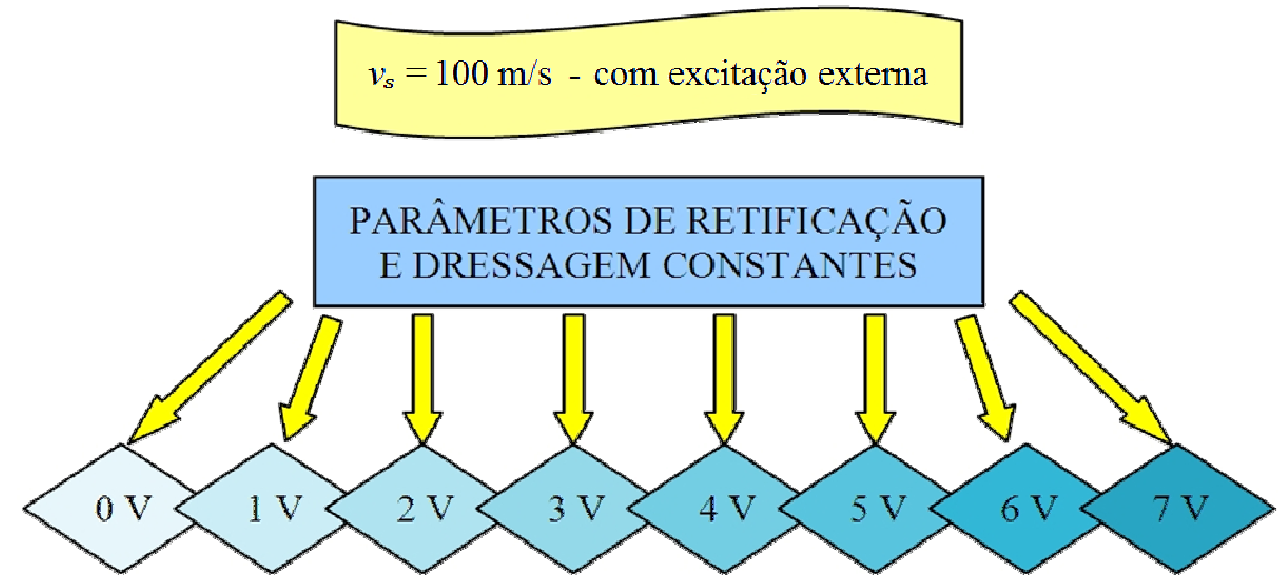

Figura 4.9 - Fluxograma dos ensaios da Configuração 3.

\subsection{Ensaios Adicionais de Retificação}

\subsubsection{Verificação da Potência de Retificação Durante Vibração Forçada e Formação da Vibração Auto-excitada}

Foram realizados outros dois ensaios de retificação no Laboratório de Otimização de Processos de Fabricação (OPF) para analisar o aparecimento da trepidação no processo e a influência da vibração randômica na potência de retificação. Estes testes possuem a mesma configuração básica da Configuração 3 de retificação descrita no item 4.3, com exceção para a velocidade de avanço $\left(v_{f}\right)$, velocidade de corte $\left(v_{c}\right)$, sobremetal, tipo de excitação e número de ciclos. 
O ensaio para a observação do aparecimento da trepidação foi realizado com excitação externa do tipo senoidal, sendo a freqüência desta excitação de valor igual à de rotação do rebolo (aproximadamente $24,5 \mathrm{~Hz}$, equivalente a $30 \mathrm{~m} / \mathrm{s}$ de velocidade tangencial do rebolo). Já o teste para observar a influência da vibração na potência de retificação foi realizado com velocidade de corte $\left(v_{c}\right)$ de $100 \mathrm{~m} / \mathrm{s}$ e excitação randômica, sendo que esta vibração é introduzida no sistema apenas no meio do ciclo de mergulho, ou seja, com o rebolo já retificando a peça. A mesma é desligada aproximadamente 15 segundos depois (antes do final do mergulho). Os parâmetros utilizados nos ensaios são exibidos na Tabela 4.9.

Tabela 4.9 - Parâmetros de retificação dos ensaios adicionais de retificação.

\begin{tabular}{|c|c|}
\hline \multicolumn{2}{|c|}{ Parâmetros de Retificação } \\
\hline Rebolo de CBN vitrificado & B181 VSS Q V 320 - 400x28x10 \\
\hline Corpos-de-prova & $23-8 \mathrm{~N}$ \\
\hline Distância de fixação da peça $(l)$ & $40 \mathrm{~mm}$ \\
\hline Velocidade de avanço $\left(v_{f}\right)$ & $1,5 \mathrm{~mm} / \mathrm{min}$ \\
\hline Velocidade de corte $\left(v_{c}\right)$ & $\begin{array}{c}\text { m/s (trepidação da peça) e } 100 \mathrm{~m} / \mathrm{s} \\
\text { (influência da vibração) }\end{array}$ \\
\hline Rotação da peça $\left(n_{w}\right)$ & $100 \mathrm{rpm}$ \\
\hline Largura de retificação $(b)$ & $4,6 \mathrm{~mm}$ \\
\hline Número de ciclos por ensaio & $1,5 \mathrm{~mm}$ (no diâmetro) \\
\hline Sobremetal removido no ensaio & $6 \mathrm{~s}(10$ voltas da peça) \\
\hline Tempo de centelhamento $($ spark-out $)$ & Fluido de corte semi-sintético $(5 \%)$ \\
\hline Fluido de corte &
\end{tabular}

A utilização de $30 \mathrm{~m} / \mathrm{s}$ como velocidade de corte no teste de trepidação da peça se dá por motivo de segurança, já que este teste propicia a ocorrência de fratura do rebolo.

Os parâmetros de dressagem são os mesmos utilizados nos ensaios da Configuração 3 (Tabela 4.8), descritos no item 4.3.3. 


\subsubsection{Verificação da Influência do Amortecedor Passivo na Retificação de Sede de Válvulas}

Um último teste foi realizado nas dependências da empresa TRW em Santo André, SP, para observar a influência da utilização de um amortecedor passivo na diminuição do erro de circularidade na sede de válvulas retificadas. Este teste foi realizado em uma máquina da marca E-Tech, modelo VSG, com parâmetros de retificação detalhados na Tabela 4.10.

Tabela 4.10 - Parâmetros de retificação dos ensaios realizados na empresa TRW.

\begin{tabular}{|c|c|}
\hline \multicolumn{2}{|c|}{ Parâmetros de Retificação } \\
\hline Rebolo vitrificado & 19A $100 \mathrm{R}$ VHB \\
\hline Corpos-de-prova & $21-2 \mathrm{~N}$ \\
\hline Fluido de corte & Integral \\
\hline Velocidade de corte $\left(v_{c}\right)$ & $53 \mathrm{~m} / \mathrm{s}$ \\
\hline Tempo de ciclo total & $5,5 \mathrm{~s}$ \\
\hline \multicolumn{2}{|c|}{ Ciclo de aproximação } \\
\hline Aproximação rápida & $2,5 \mathrm{~mm}$ \\
\hline Velocidade de avanço $\left(v_{f}\right)$ & $3.000 \mathrm{~mm} / \mathrm{min}$ \\
\hline Aproximação lenta & $0,3 \mathrm{~mm}$ \\
\hline Velocidade de avanço $\left(v_{f}\right)$ & $300 \mathrm{~mm} / \mathrm{min}$ \\
\hline Rotação da peça $\left(n_{w}\right)$ & $390 \mathrm{rpm}$ \\
\hline \multicolumn{2}{|c|}{ Ciclo de desbaste } \\
\hline Sobremetal & $0,18 \mathrm{~mm}$ \\
\hline Velocidade de avanço $\left(v_{f}\right)$ & $13,2 \mathrm{~mm} / \mathrm{min}$ \\
\hline Tempo de centelhamento & $0 \mathrm{~s}$ \\
\hline Rotação da peça $\left(n_{w}\right)$ & $380 \mathrm{rpm}$ \\
\hline \multicolumn{2}{|c|}{ Ciclo de semi-acabamento } \\
\hline Sobremetal & $0,09 \mathrm{~mm}$ \\
\hline Velocidade de avanço $\left(v_{f}\right)$ & $12 \mathrm{~mm} / \mathrm{min}$ \\
\hline Tempo de centelhamento & $0 \mathrm{~s}$ \\
\hline Rotação da peça $\left(n_{w}\right)$ & $380 \mathrm{rpm}$ \\
\hline
\end{tabular}




\begin{tabular}{|c|c|}
\hline \multicolumn{2}{|c|}{ Ciclo de acabamento (cont. da tabela 4.10) } \\
\hline Sobremetal & $0,01 \mathrm{~mm}$ \\
\hline Velocidade de avanço $\left(v_{f}\right)$ & $1,8 \mathrm{~mm} / \mathrm{min}$ \\
\hline Tempo de centelhamento & $1,6 \mathrm{~s}$ \\
\hline Rotação da peça $\left(n_{w}\right)$ & $450 \mathrm{rpm}$ \\
\hline
\end{tabular}

$\mathrm{O}$ ciclo de retificação é escalonado com diferentes avanços e rotação da peça. $\mathrm{O}$ material utilizado para entrar em contato com a sede da válvula foi a madeira.

Os parâmetros de dressagem podem ser observados na Tabela 4.11.

Tabela 4.11 - Parâmetros de dressagem dos ensaios adicionais de retificação.

\begin{tabular}{|c|c|}
\hline \multicolumn{2}{|c|}{ Parâmetros de Dressagem } \\
\hline Dressador Estático & Tipo Fliese \\
\hline Velocidade do rebolo $\left(v_{s}\right)$ & $53 \mathrm{~m} / \mathrm{s}$ \\
\hline Peças por dressagem & 70 \\
\hline Tempo total de dressagem & $38 \mathrm{~s}$ \\
\hline \multicolumn{2}{|c|}{ Primeiro passo de dressagem } \\
\hline Profundidade de dressagem $\left(a_{d}\right)$ & $0,02 \mathrm{~mm}$ \\
\hline Velocidade de dressagem $\left(v_{t}\right)$ & $120 \mathrm{~mm} / \mathrm{min}$ \\
\hline \multicolumn{2}{|c|}{ Segundo passo de dressagem } \\
\hline Profundidade de dressagem $\left(a_{d}\right)$ & $0,015 \mathrm{~mm}$ \\
\hline Velocidade de dressagem $\left(v_{t}\right)$ & $90 \mathrm{~mm} / \mathrm{min}$ \\
\hline
\end{tabular}

A sede de válvulas de motores a combustão interna é a região que entra em contato com o cabeçote do motor. Geralmente esta é a última região a ser retificada. A Figura 4.10 mostra o desenho de uma válvula e sua área da sede. 


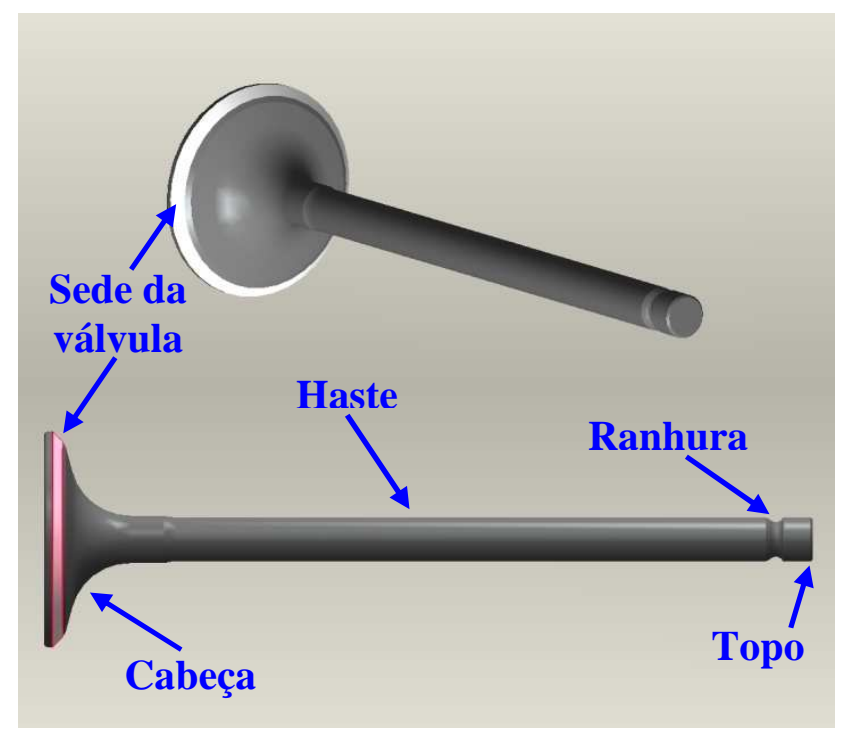

Figura 4.10 - Exemplo de válvula de motores a combustão interna.

Devido às apertadas tolerâncias de circularidade e concentricidade entre a sede e a haste da válvula, é importante que a retificação seja feita com fixação por pinça com a cabeça da válvula em balanço. Esta condição se caracteriza como sendo de baixa rigidez e limita as velocidades de avanços usadas no processo. Desta forma, foi projetado um amortecedor passivo controlado pelo $\mathrm{CNC}$ da máquina por meio de atuador pneumático para apoiar a cabeça da válvula durante o processo de retificação da sua sede. $\mathrm{O}$ amortecedor entra em contato com a sede da válvula antes do mergulho do rebolo (Figura 4.11) e recua após o fim da retificação para que o mecanismo de alimentação possa fixar outra válvula para ser retificada.

O mecanismo ficou em funcionamento durante vários dias e foram feitos mapas acústicos assim como medições de erros de circularidade da sede de válvula (uma das principais variáveis analisadas para a validação da válvula). 


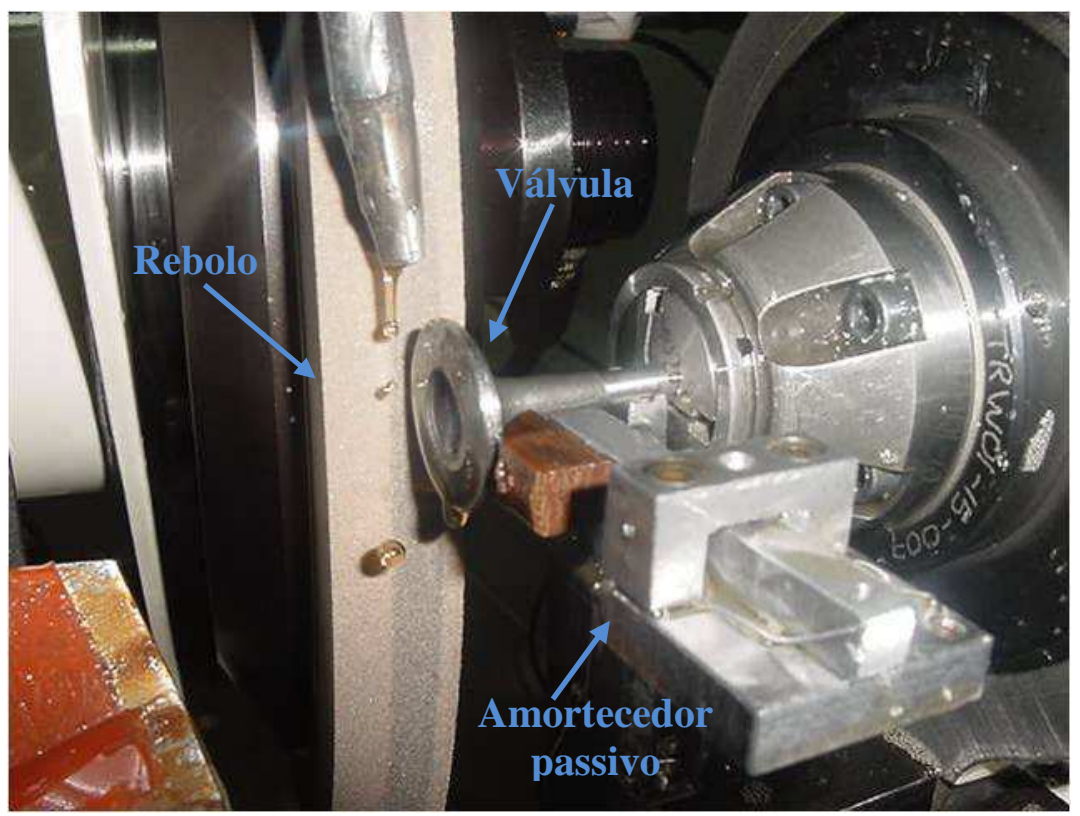

Figura 4.11 - Retificação de sede de válvula utilizando mecanismo do amortecedor passivo.

\subsection{Testes de Impacto}

As vibrações auto-excitadas de máquinas-ferramenta são resultados da instabilidade dinâmica da própria máquina ou do processo de corte. As possíveis fontes de vibração podem ser componentes estruturais fracos (base, colunas, guias etc.), rolamentos, sistema de fixação da ferramenta e da peça, cabeçote porta-rebolo e até mesmo a peça (Buzdugan et al., 1986).

Sendo assim, é importante uma investigação das freqüências de ressonância da peça devidamente fixada na porta-peça e do rebolo a fim de analisar a influência destas no processo. Nesta pesquisa, foram realizados testes do martelo, ou testes de impacto, no rebolo e na peça da Configuração 2 para a determinação da resposta em freqüência dos mesmos.

De acordo com McConnell (1995) e Altintas (2000), o teste do martelo, ou teste de impacto, é uma técnica onde a estrutura sendo testada é excitada por meio do choque contra um martelo de impacto ou outro instrumento. A magnitude do impacto é determinada pela massa do martelo e sua velocidade no instante do choque. A faixa de freqüência efetivamente 
excitada neste método é influenciada pela relação $\sqrt{K / M}$, onde: $K$ é a rigidez de contato e $M$ é a massa do instrumento de impacto (Ewins, 1988).

O testes foram conduzidos utilizando um programa feito em LabVIEW que realiza a aquisição do sinal de aceleração e força. Este programa calcula a resposta em freqüência de um determinado teste ou a média de vários testes. Para isto, os sinais são tratados de acordo com as orientações sugeridas por McConnell (1995), ou seja, o programa faz o uso de janelamento nos dois sinais. A Figura 4.12 exibe o painel frontal deste programa.

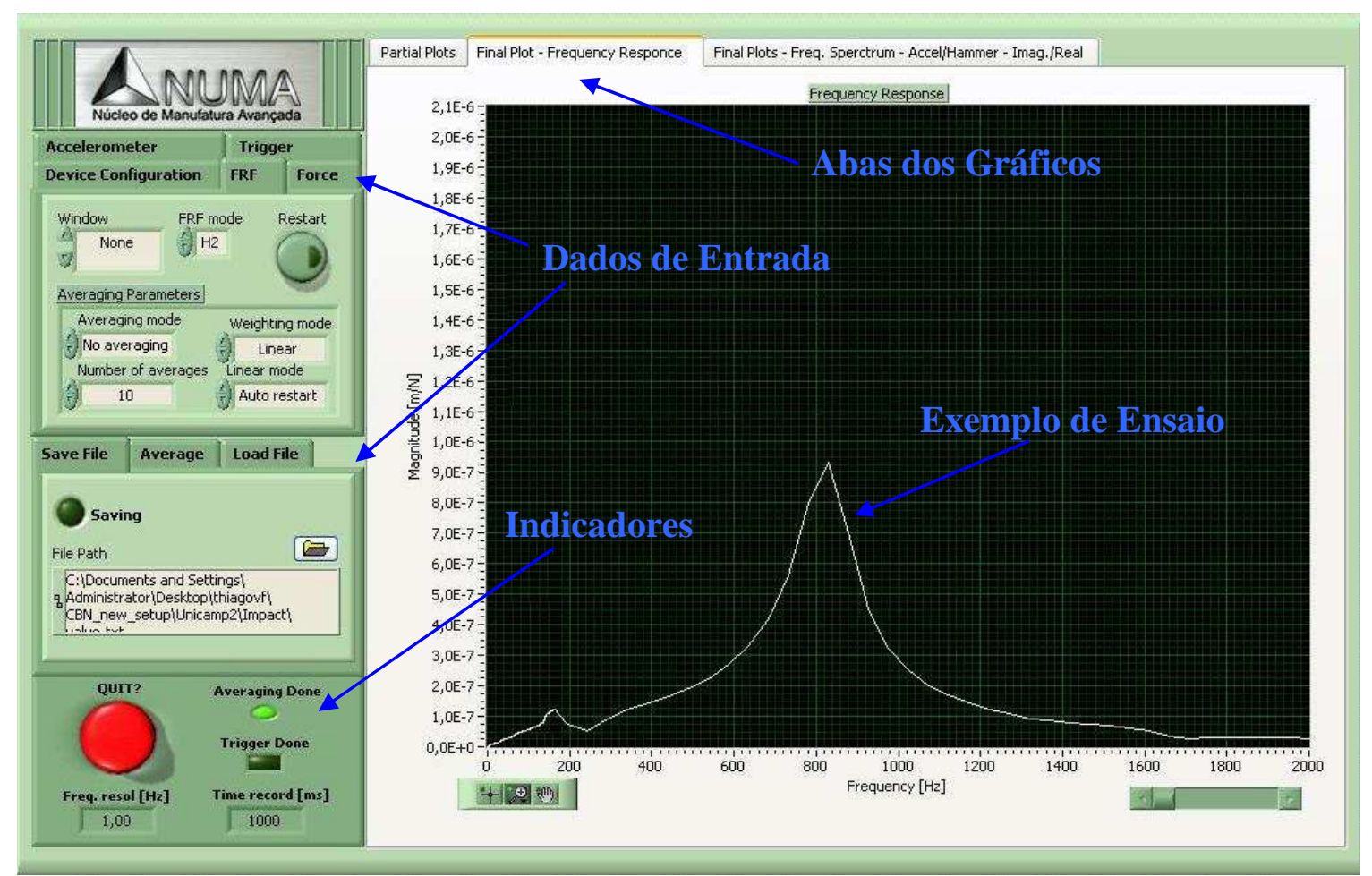

Figura 4.12 - Painel frontal do programa em LabVIEW utilizado nos testes de impacto.

O sinal de aceleração é convertido para deslocamento por meio de uma dupla integração com a ajuda de um janelamento exponencial para diminuir o problema de leakage durante a transformada de Fourier. O leakage é um erro de processamento digital de sinais que ocorre devido ao fato do sinal ter sido medido, ou gravado, por um período finito de 
tempo. A transformada de Fourier, utilizada para análise do sinal no espectro da frequiência, gera este erro devido à falta de periodicidade do sinal. Este erro gera um "vazamento" da energia de freqüências de alta amplitude para freqüências adjacentes de menores amplitudes, degradando assim, a relação sinal/ruído (Arrillaga e Watson, 2003; Lyons, 1997).

No caso do teste do martelo, o erro de leakage ocorre quando a vibração de uma estrutura causada por um impacto tende a persistir durante um tempo maior que o tempo total de aquisição do sinal (estrutura com baixo amortecimento). Com o sinal truncado, a sua transformada de Fourier pode gerar amplitude em frequiências adjacentes às originais da estrutura, causando assim uma distorção do sinal no espectro da frequiência (McConnell, 1995).

Idealmente, o sinal de força de impacto deve ser composto na sua grande maioria de valores iguais a zero, já que o período do pulso $(\tau)$ gerado pelo impacto (basicamente $1 / 2$ ciclo de uma senóide) é geralmente muito pequeno em relação ao tempo total do sinal. Na prática, porém, o sinal de força pode conter ruído oriundo da instrumentação utilizada. Desta forma, utiliza-se uma função janela retangular para garantir que não haja variações no espectro da freqüência (McConnell, 1995).

O sistema utilizado nos testes é um kit da marca $P C B$ Electronics constituído de martelo de impacto com transdutor de força embutido modelo PCB-086C03, acelerômetro modelo 353B16 e cabos coaxiais blindados. Além disso, foi utilizado um módulo de aquisição de sinais dinâmicos de quatro canais da National Instruments, modelo USB-9233. Os testes foram realizados na direção de retificação (horizontal) (Figura 4.13). 

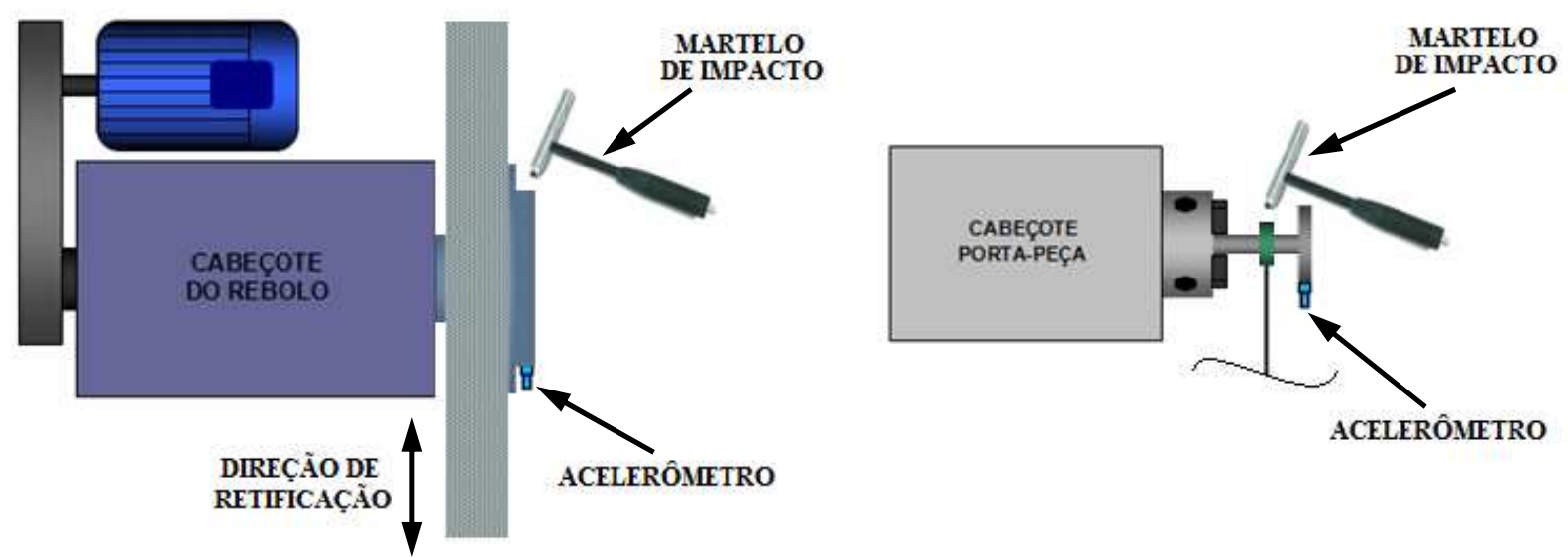

Figura 4.13 - Localização do acelerômetro e do impacto do martelo dos testes.

O teste realizado no rebolo foi feito fixando o acelerômetro no flange do rebolo e martelando o lado oposto do mesmo na direção de retificação. De maneira semelhante, o acelerômetro foi fixado na cabeça da válvula e a martelada se deu no lado oposto, na direção de retificação. A taxa de amostragem utilizada foi de 6.000 amostras por segundo para ambos os testes. Os testes foram realizados na máquina retificadora referente à Configuração 2.

\subsection{Geração da Excitação e Medição da Emissão Acústica, Potência e Vibração}

Foram utilizados dois programas feitos em LabVIEW para a aquisição destes sinais sendo que um computador realiza a aquisição da emissão acústica e dos pulsos do sensor de proximidade para gerar o mapa acústico do processo, além da potência consumida pelo motor do rebolo. O outro programa, executado em um computador distinto, é responsável pela aquisição dos dois sinais de aceleração e geração do sinal de excitação para o shaker.

\subsubsection{Sistema de Aquisição da Emissão Acústica e Potência}

A emissão acústica (EA) foi medida por um sensor conectado a uma unidade de tratamento de sinais da marca SENSIS, modelo MSM, que é um condicionador de sinais com 
filtragem e amplificação. Os parâmetros utilizados neste condicionador podem ser observados na Tabela 4.12.

Tabela 4.12 - Parâmetros utilizados no condicionador MSM.

\begin{tabular}{|c|c|}
\hline \multicolumn{2}{|c|}{ Parâmetros - Condicionador MSM } \\
\hline Filtro passa-alta & $150 \mathrm{kHz}$ \\
\hline Constante de tempo & $0,05 \mathrm{~ms}$ \\
\hline Ganho de entrada & 03 \\
\hline Ganho de sinal & 65 \\
\hline Redução de ruído & 0 \\
\hline
\end{tabular}

Esta unidade de tratamento calcula o valor RMS (sigla em inglês de Root Mean Square) do sinal de EA em Volts e o envia para a placa de aquisição de dados (National Instruments, modelo DAQCard-6062E - PCMCIA), junto com o sinal de potência e do trigger (sinal proveniente do sensor de proximidade).

O programa de aquisição de dados sincroniza a aquisição do sinal de EA com o pulso do sinal do sensor de proximidade (trigger) para um determinado número de pontos por volta do rebolo. Neste trabalho, foram utilizados 450 pontos por volta do rebolo para a confecção do mapa acústico. O programa então calcula a taxa de aquisição de acordo com este valor e a rotação do rebolo. O programa exibe o mapa acústico durante o processo no painel frontal e grava os valores.

O sinal da potência de retificação é oriundo de uma saída analógica dos inversores de frequiência das máquinas retificadoras utilizadas neste trabalho. Este sinal é proporcional à potência de retificação permitindo assim obter o valor da potência de retificação. A aquisição da potência foi realizada em Volts e depois calibrada para $\mathrm{kW}$ para a confecção dos gráficos (10 Volts equivalem a $100 \%$ da potência do motor do rebolo). Desta forma, o valor médio do 
sinal da potência por volta do rebolo é calculado e exibido no painel frontal, depois é calibrado, subtraído do valor de potência em vazio (com rebolo e fluido de corte ligado) e gravado no computador. A Figura 4.14 mostra o painel frontal do programa utilizado na aquisição destes sinais, desenvolvido em LabVIEW.

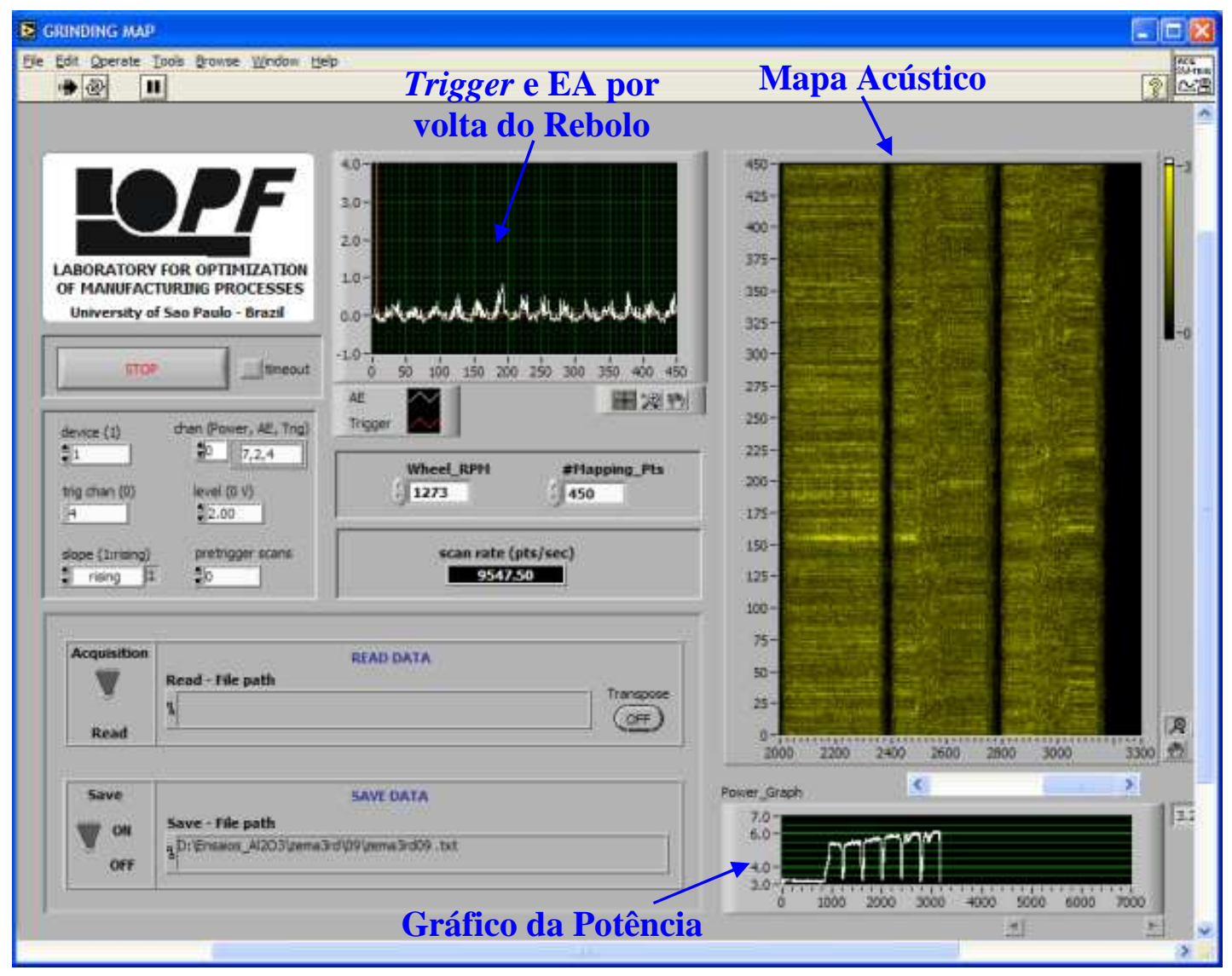

Figura 4.14 - Painel frontal do programa em LabVIEW utilizado na aquisição de EA e potência.

O painel frontal exibe gráficos do mapa acústico do processo, da potência de retificação e do sinal do sensor de proximidade que é utilizado como trigger da aquisição das variáveis. 


\subsubsection{Sistema de Aquisição da Vibração e Geração da Excitação}

Da mesma forma, a aquisição da aceleração foi realizada em Volts e logo depois calibrada para valores de aceleração $\left(\mathrm{m} / \mathrm{s}^{2}\right)$ de acordo com a sensibilidade de cada acelerômetro (10 mV/g ou $100 \mathrm{mV} / \mathrm{g})$. O sinal de aceleração do sensor localizado no mancal passa por um condicionador de sinais da marca $B \& K$, modelo 2525 , que o amplifica e filtra. A Tabela 4.13 mostra os parâmetros utilizados no condicionador de sinal 2525.

Tabela 4.13 - Parâmetros utilizados no condicionador 2525.

\begin{tabular}{|c|c|}
\hline \multicolumn{2}{|c|}{ Parâmetros - Condicionador 2525 } \\
\hline Filtro passa-alta & $30 \mathrm{~Hz}$ \\
\hline Filtro passa-baixa & $3 \mathrm{kHz}$ \\
\hline
\end{tabular}

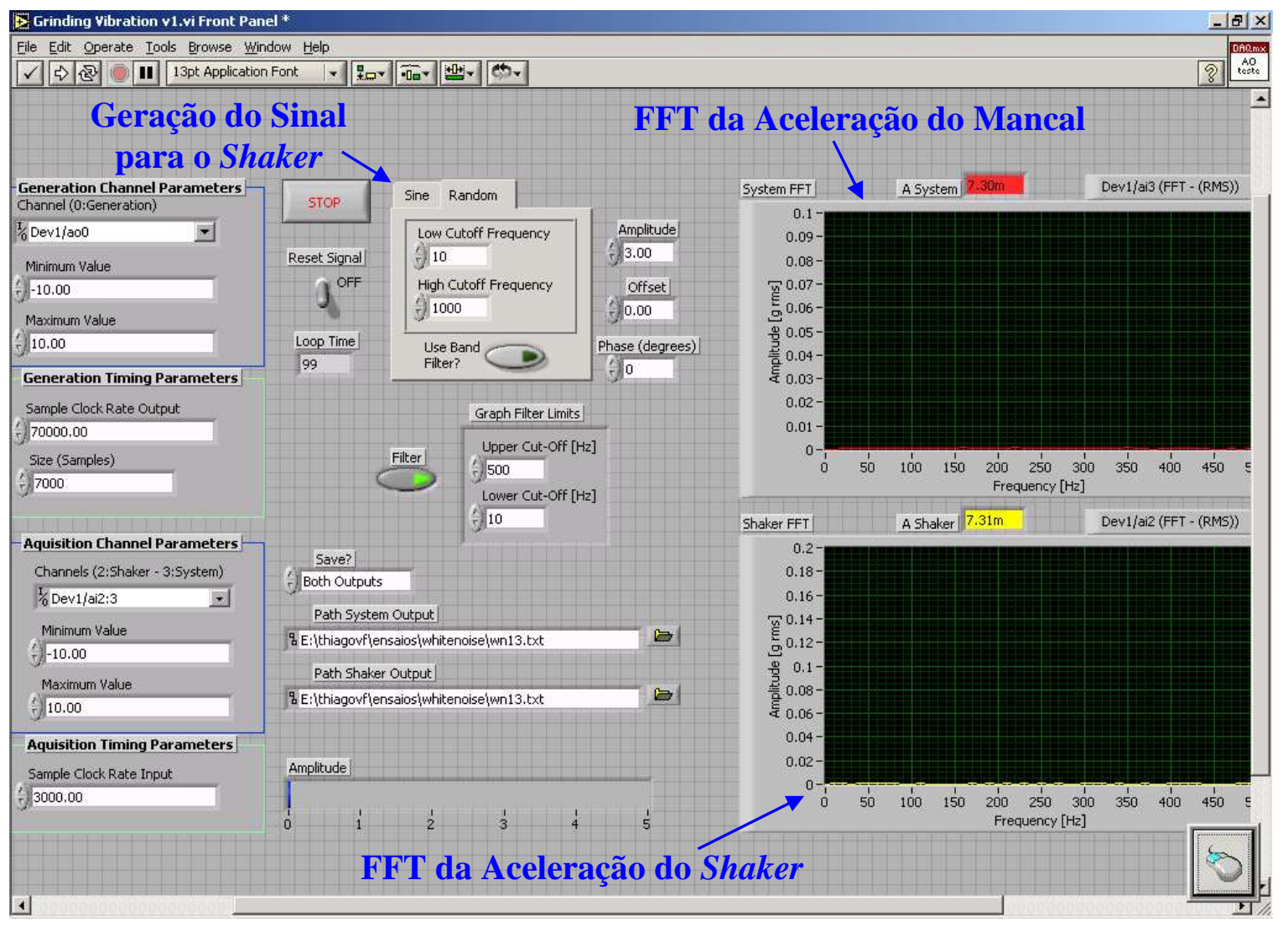

Figura 4.15 - Painel frontal do programa em LabVIEW utilizado na aquisição das acelerações e geração do sinal de excitação para o shaker. 
O acelerômetro localizado na mesa do shaker envia o sinal para outro condicionador (marca ICP, modelo 482B11) que o amplifica. Este sinal não será utilizado nos resultados e foi empregado apenas para o monitoramento da amplitude da excitação introduzida pelo shaker. Dos condicionadores, os sinais seguem para o bloco de conectores da National Instruments, modelo BNC-2120, e deste para a placa de aquisição de dados (National Instruments, modelo DAQCard-6062E - PCMCIA) ligada ao computador. A taxa de amostragem utilizada para os sinais de aceleração foi de 6.000 amostras por segundo.

O sinal de excitação, do tipo ruído branco, enviado por meio de um canal de saída da placa de aquisição de dados (DAQCard-6062E - PCMCIA), segue para o amplificador do shaker (Labworks, modelo PA-138-1) e deste para o próprio shaker. Este tipo de sinal foi utilizado como sinal de excitação nos testes, pois é o que mais se assemelha ao tipo de ruído produzido pelo processo de retificação, onde existe o contato aleatório dos grãos abrasivos com a peça retificada. A taxa de geração do sinal de excitação utilizada foi de 50.000 amostras por segundo.

\subsection{Medição da Rugosidade, Desgaste Radial do Rebolo e Erro de Circularidade}

A rugosidade foi medida com um rugosímetro/perfilômetro modelo FormTalysurf 50, da marca TAYLOR HOBSON, ajustado para um comprimento de amostragem (cut-off) de $0,8 \mathrm{~mm}$ e com filtro do tipo Gauss.

Os valores de rugosidade foram medidos utilizando o parâmetro $\mathrm{R}_{\mathrm{a}}$ (rugosidade média aritmética). Cada peça teve a rugosidade medida em três posições distintas e aproximadamente eqüidistantes. Ao final das medições, foram obtidos os valores médios de cada peça. 
O desgaste radial do rebolo foi analisado pelo método da impressão do perfil desgastado. Neste método, um dispositivo instalado na máquina permite a retificação de uma chapa de aço SAE 1020 após cada ensaio. Desta forma, o perfil do rebolo é "impresso" na chapa metálica, permitindo assim a medição do seu desgaste radial (Figura 4.16). Este perfil foi então medido em três posições diferentes com o rugosímetro/perfilômetro modelo FormTalysurf 50.

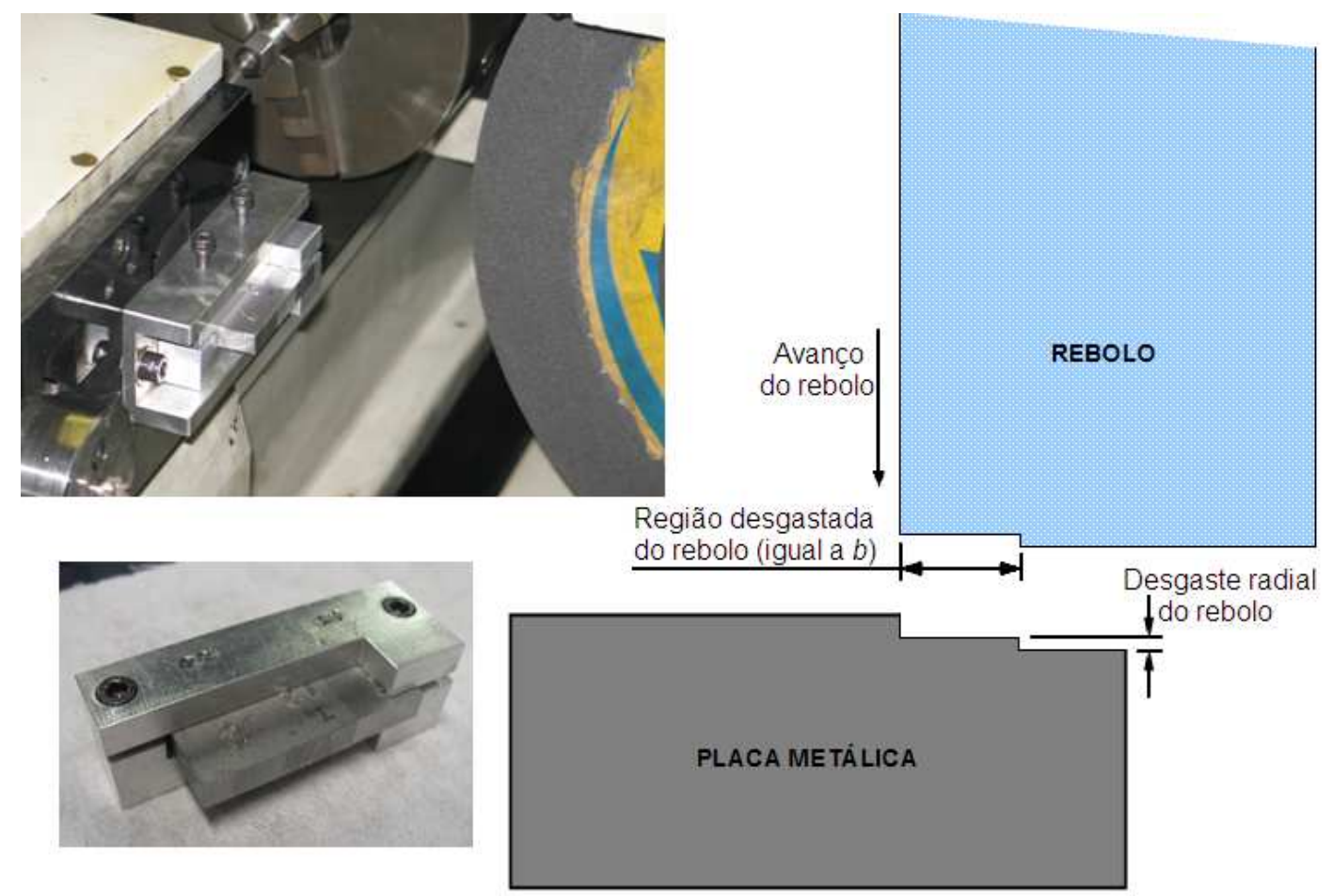

Figura 4.16 - Representação esquemática da medição do desgaste radial e vista do dispositivo.

Para a medição da circularidade, utilizou-se o equipamento Talyrond 131, do fabricante TAYLOR HOBSON. O filtro utilizado para todas as medições é de 1 a 50 upr. A peça foi colocada na placa do equipamento e devidamente centrada. Foram executadas três medições em cada corpo-de-prova em posições distintas da largura retificada e eqüidistantes. Ao final das medições, foram obtidos os valores médios de cada ensaio. 


\section{Capítulo 5}

\section{RESULTADOS E DISCUSSÃO}

Os resultados obtidos para cada teste realizado são apresentados nos itens a seguir. Desta forma, foi também realizada uma discussão acerca dos resultados obtidos.

\subsection{Configuração 1}

\subsubsection{Potência de Retificação, Rugosidade e Circularidade}

A Figura 5.1 mostra os resultados obtidos da potência média de retificação em relação à taxa específica de remoção de material.

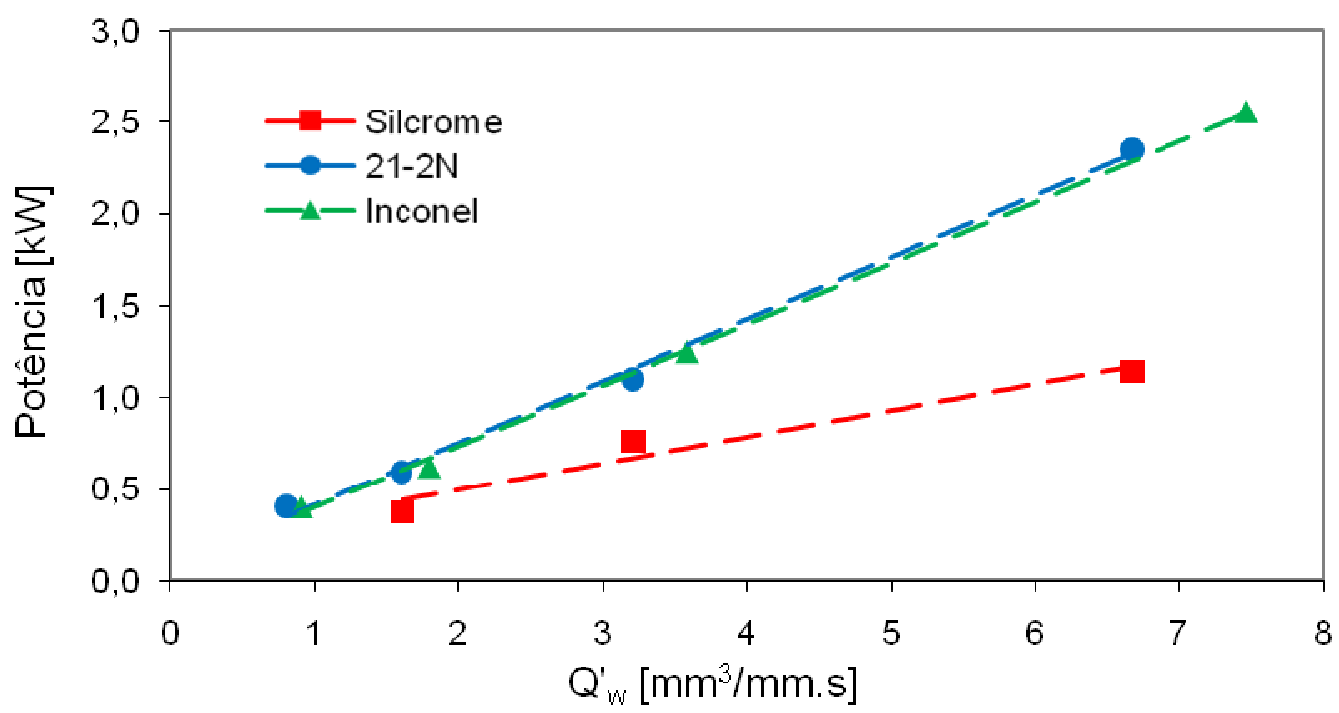

Figura 5.1 - Potência de corte versus taxa específica de remoção de material $\left(Q^{\prime}{ }_{w}\right)$. 
Pode-se perceber pela Figura 5.1 que quanto maior a velocidade de avanço, e conseqüentemente a taxa específica de remoção de material, maior é a potência consumida pelo processo de retificação. A taxa com que ocorre este aumento de potência pode ser considerada igual para o inconel e $21-2 \mathrm{~N}$ e menor para o silcrome.

De acordo com a Equação 2.2, a potência de retificação é igual ao produto $F_{t} v_{s}$. Deste modo, observando a Figura 5.1, pode-se concluir que com o aumento de $Q^{\prime}{ }_{w}$ a força tangencial de retificação aumenta com uma taxa menor para o material silcrome. Isto pode ser explicado pela usinabilidade do material que é melhor em relação aos outros materiais testados gerando assim menores forças de corte.

A Figura 5.2 exibe os valores médios da rugosidade (parâmetro $\mathrm{R}_{\mathrm{a}}$ ) e erro de circularidade em função da taxa específica de remoção de material.

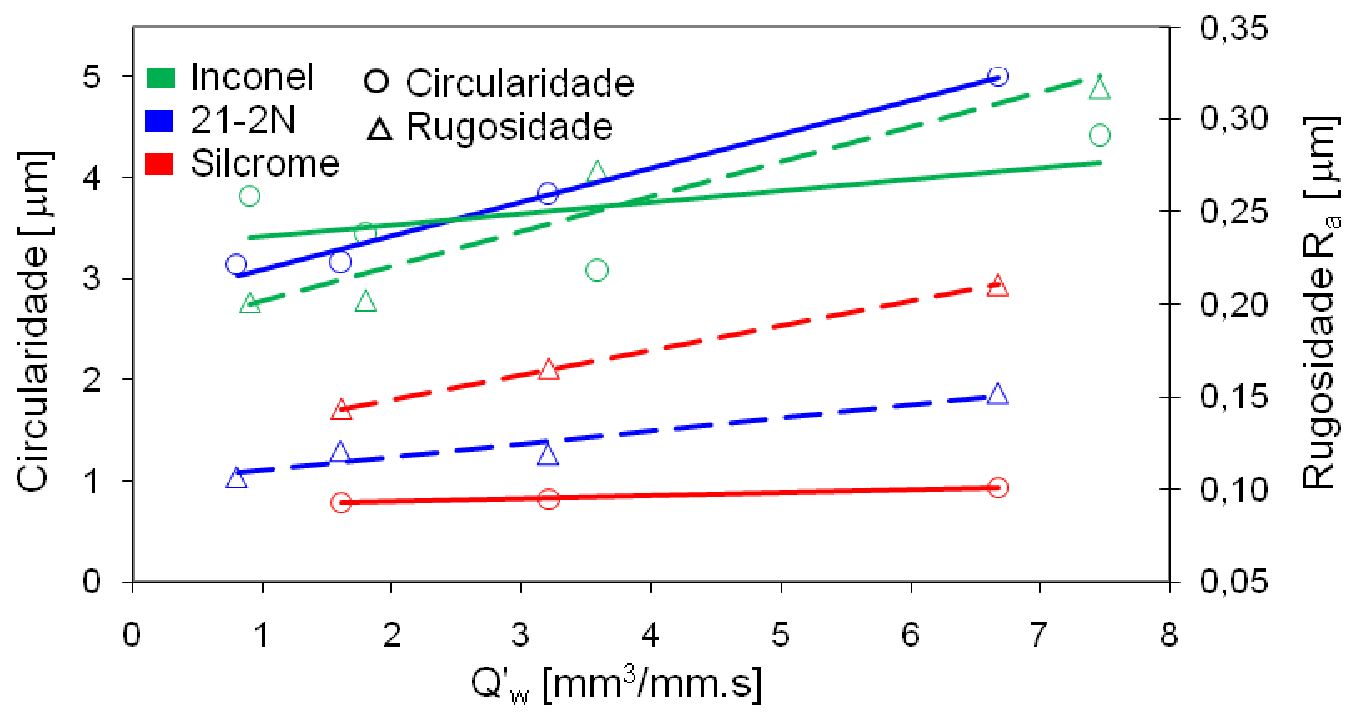

Figura 5.2 - Erro de circularidade e rugosidade versus taxa específica de remoção de material $\left(Q^{\prime}{ }_{w}\right)$.

Pode-se afirmar que tanto a circularidade quanto a rugosidade tendem a aumentar com o aumento da taxa específica de remoção de material. Isto ocorre em taxas diferentes 
para todos os materiais, com exceção para os valores de circularidade do silcrome que se mantiveram praticamente constantes para todos os ensaios.

Analisando separadamente a circularidade, observa-se que o silcrome possui os melhores valores, seguido do inconel e 21-2N, sendo que estes dois últimos materiais possuem valores próximos. Já os melhores valores de rugosidade pertencem aos ensaios com o 21-2N, seguido do silcrome e inconel, respectivamente. Apesar dos valores de rugosidade do silcrome serem maiores do que os valores do material $21-2 \mathrm{~N}$, estes são bem próximos e pode-se dizer que os valores de rugosidade e circularidade do silcrome têm relação direta com a potência consumida nos testes.

\subsubsection{Desgaste do Rebolo e Força Tangencial por Grão}

A Figura 5.3 apresenta os valores de relação $G$ em função da taxa específica de remoção de material.

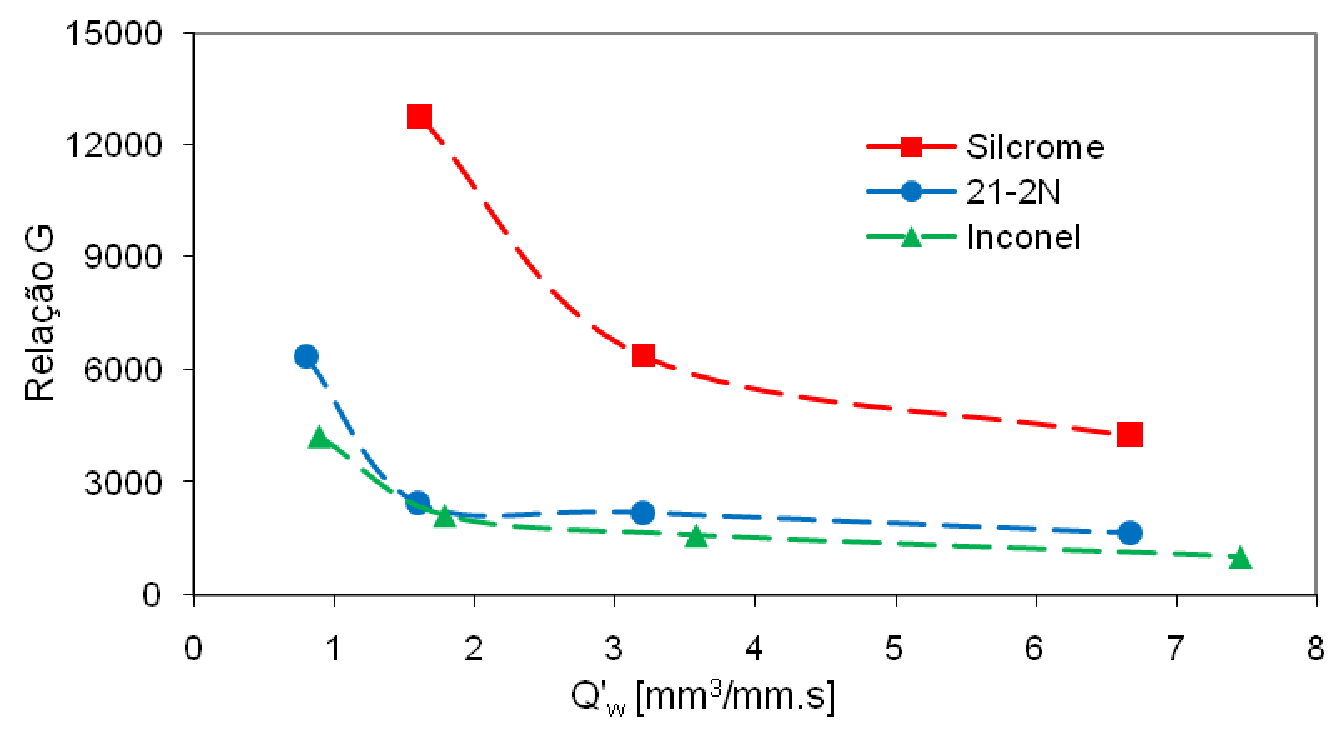

Figura 5.3 - Relação $G$ versus taxa específica de remoção de material $\left(Q^{\prime}{ }_{w}\right)$. 
A Figura 5.3 mostra claramente a diferença de usinabilidade entre os materiais. Outra característica observada é a redução abrupta da relação $G$ com o aumento da taxa específica de remoção de material. Isto indica uma mudança no modo predominante de desgaste do rebolo: fratura do grão para valores pequenos da taxa específica de remoção de material e fratura do ligante para altos valores de $Q^{\prime}{ }_{w}$.

Para um julgamento mais detalhado do fenômeno, deve-se tentar observar o grão abrasivo separadamente. Um bom parâmetro para esta análise é a força tangencial por grão $\left(F_{t l g}\right)$. A força tangencial por grão pode ser calculada pela potência de retificação, e conseqüentemente pela força tangencial. A Equação 5.1 exibe esta fórmula (Bianchi, 1992).

$$
F_{t 1 g}=\frac{F_{t}}{b l_{C} D}
$$

Onde, $F_{t l g}$ é a força tangencial por grão; $F_{t}$ é a força tangencial; $b$ é a largura de retificação; $l_{c}$ é o comprimento de contato; e $D$ é a densidade superficial de grãos do rebolo.

O valor da densidade superficial de grãos do rebolo de CBN foi medido com a ajuda de um microscópio e chegou-se ao valor de 21,42 grãos $/ \mathrm{mm}^{2}$.

A influência da força tangencial por grão para todos os materiais testados pode ser observada na Figura 5.4. Os valores de $F_{t}$ foram calculados pela potência de retificação, ou potência de corte $\left(P_{c}\right)$, e velocidade de avanço $\left(v_{f}\right)$ de cada ensaio realizado (Equação 2.2). 


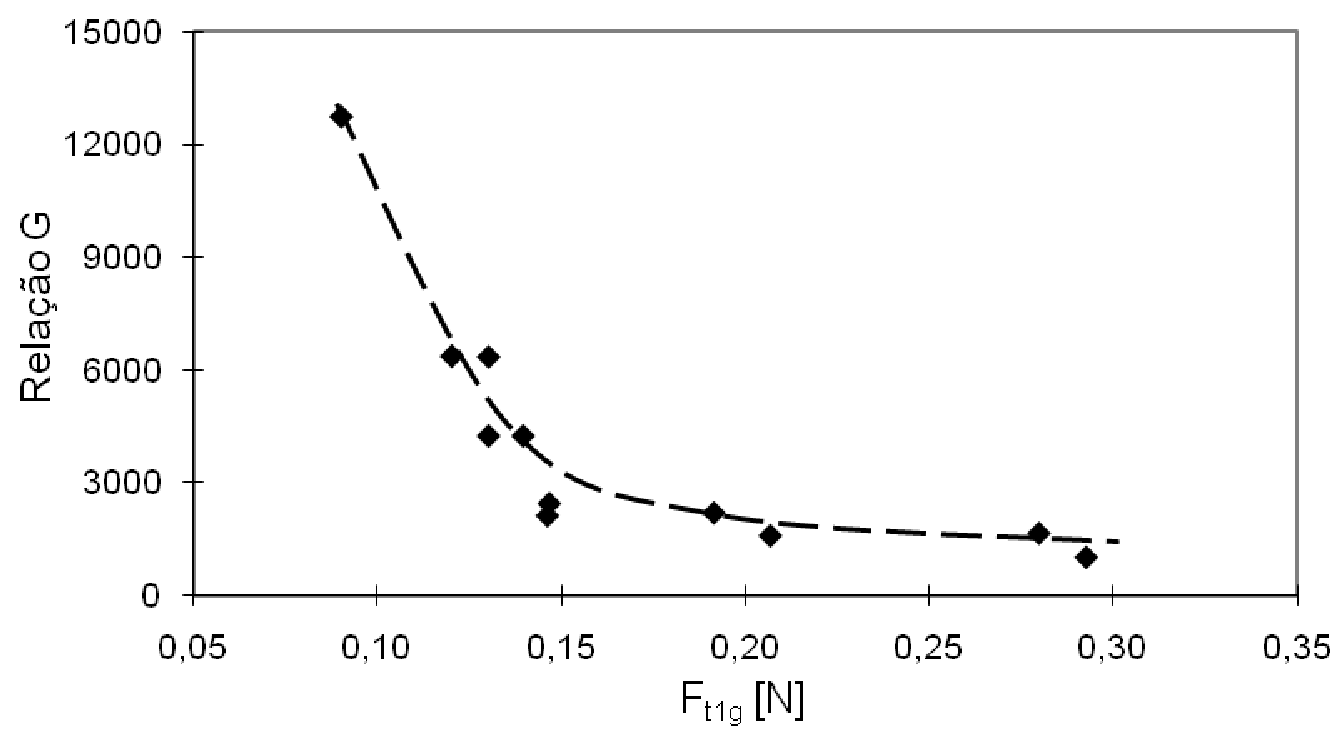

Figura 5.4 - Relação $G$ versus força tangencial em um grão $\left(F_{t l g}\right)$.

Um importante aspecto observado é o fato de que todos os pontos contidos na Figura 5.3 se ajustam em uma mesma curva (Figura 5.4) independente do tipo de material. Isto confirma a hipótese de que o mecanismo de desgaste do rebolo associado com a força de retificação é mais relevante quando comparado com outros tipos de mecanismo relacionados com a composição do material, como por exemplo, a difusão química gerada pelo atrito ferramenta-peça. Pode-se notar ainda que existe um valor limite de força tangencial por grão de aproximadamente $0,1 \mathrm{~N}$, acima do qual, o valor da relação $G$ diminui drasticamente.

A hipótese aqui defendida é de que as forças envolvidas no processo determinam o tipo de desgaste do rebolo (para as condições de corte e tipo do rebolo empregado), logo esta variável é a causa de maior relevância no tipo de desgaste sofrido pelo rebolo.

A Figura 5.4 é de fundamental importância para observar o comportamento de desgaste do rebolo em diversas condições de retificação. No entanto, testes adicionais serão mostrados a seguir para determinar o comportamento do desgaste do rebolo em condições de excitação externa, simulando a vibração no processo. 


\subsection{Testes de Impacto}

Antes de exibir os resultados obtidos da Configuração 2, serão apresentados os resultados dos testes de martelo realizados na peça fixada no cabeçote porta-peça e no rebolo fixado no cabeçote porta-rebolo (Figura 4.13). Isto será feito, pois estes testes foram realizados na máquina retificadora referente à Configuração 2 (como já explicado anteriormente) e os resultados servirão para explicações de alguns resultados desta configuração.

São apresentados três gráficos diferentes dos resultados do teste de impacto tanto para a peça quanto para o rebolo. Estes gráficos são: resposta em freqüência (Figura 5.5) e espectro na freqüência do impulso (entrada) e da resposta (saída) (Figura 5.6).

\subsubsection{Resposta em Freqüência da Peça}

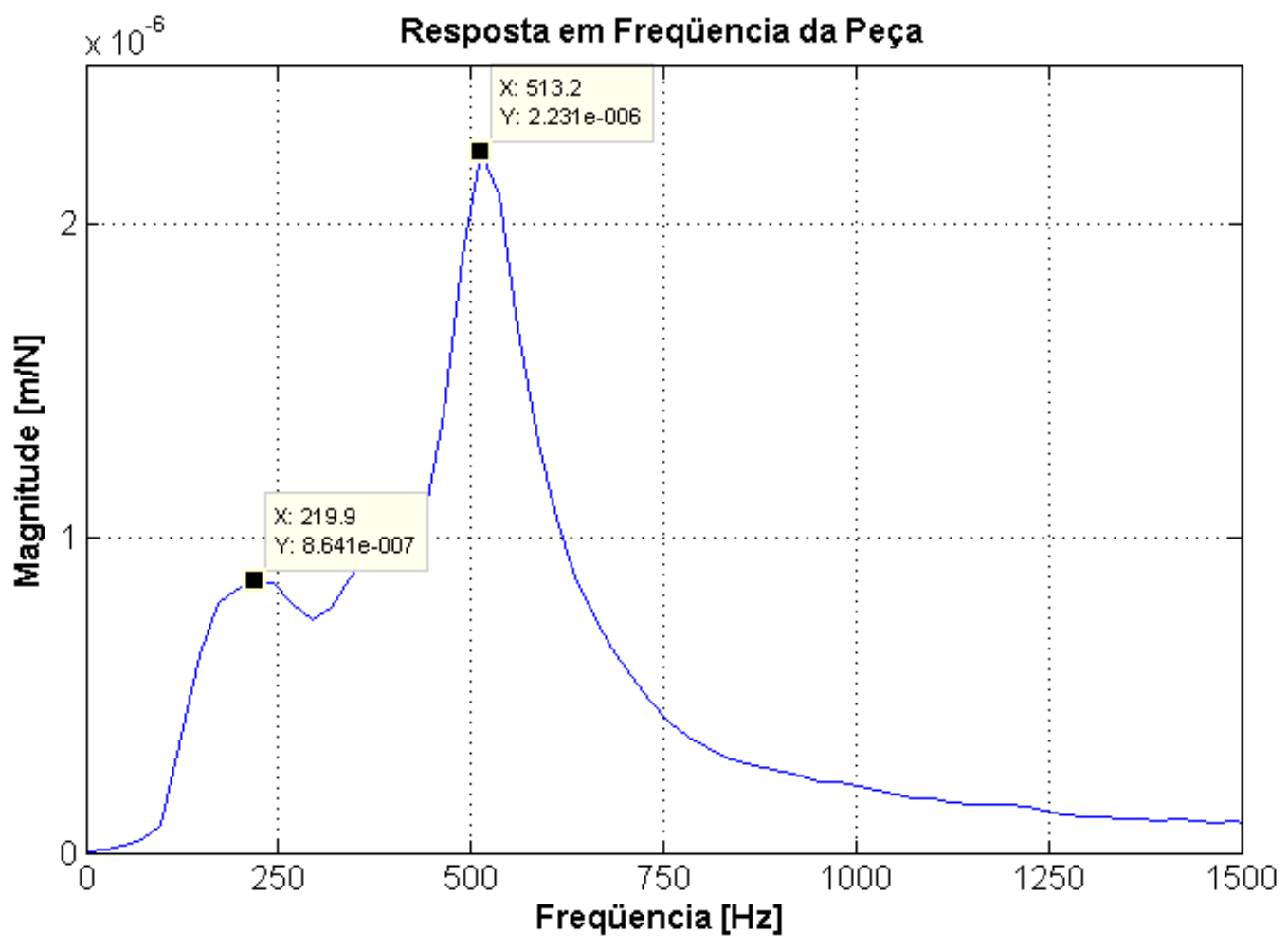

Figura 5.5 - Resposta em freqüência da peça. 

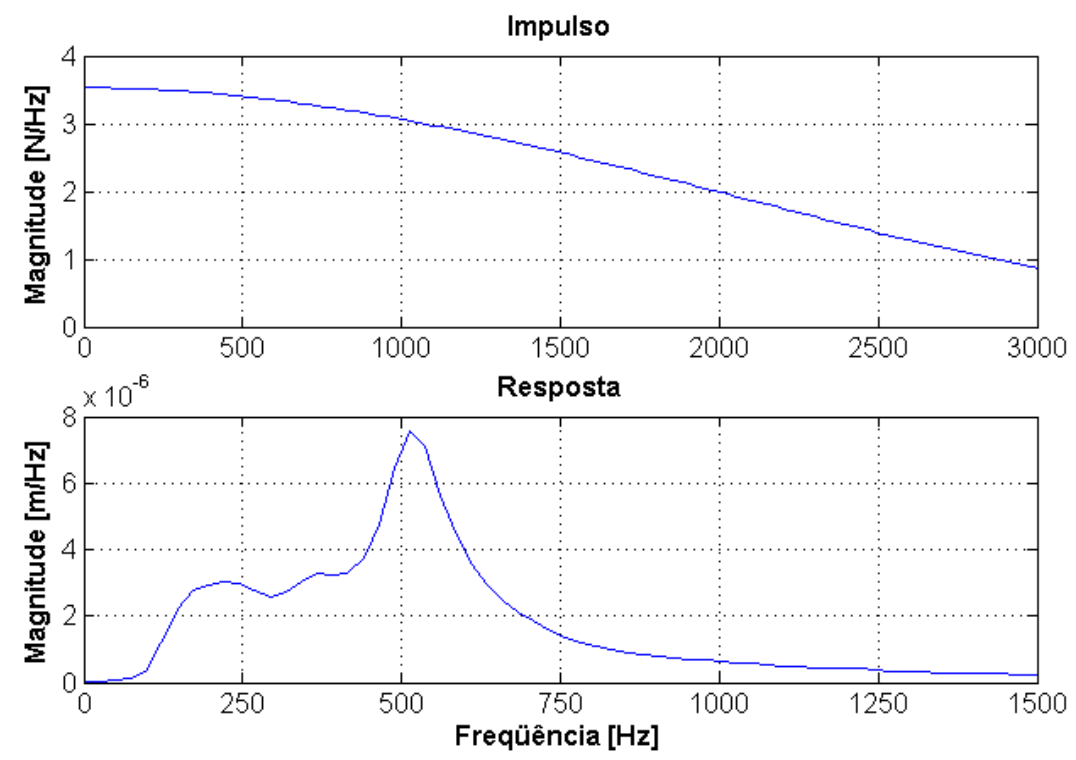

Figura 5.6 - Espectro na freqüência do impulso e da resposta.

Os resultados do teste do martelo realizado na peça mostram duas frequiências naturais da peça: 220 e 513 Hz. Cada valor de freqüência está relacionado com um modo de vibrar. Isto quer dizer que a válvula tenderá a vibrar nestas duas freqüências. A peça possui outros modos de vibrar, no entanto, a energia gerada pelo impacto não foi capaz de excitar estes modos.

Em todos os testes de impacto realizados nesta pesquisa, o semi-seno do impulso teve duração média de $0,44 \mathrm{~ms}$, desta forma a análise do espectro da freqüência tem validade até pouco mais de $2200 \mathrm{~Hz}$. Ou seja, a energia produzida pelo impacto não foi suficiente para excitar os modos de vibração que podem existir acima de $2200 \mathrm{~Hz}$. 


\subsubsection{Resposta em Freqüência do Rebolo}

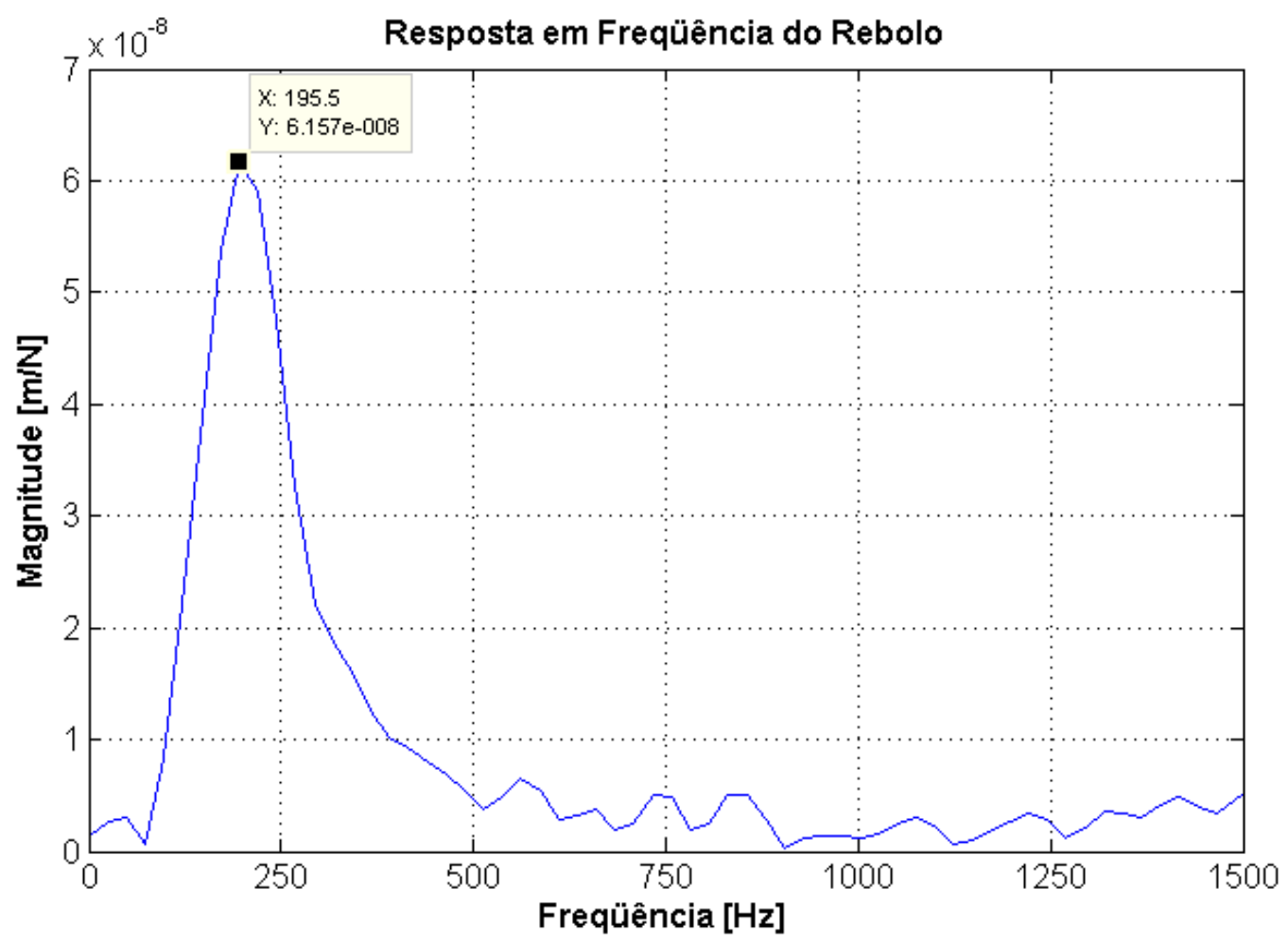

Figura 5.7 - Resposta em freqüência do rebolo.
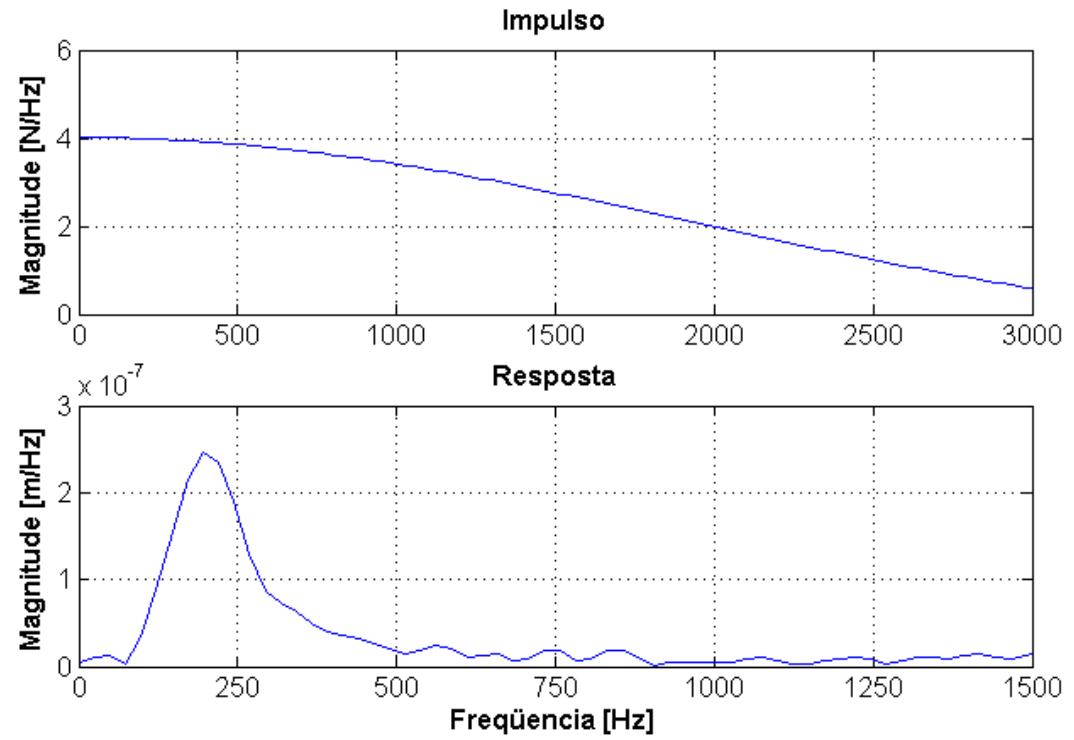

Figura 5.8 - Espectro na freqüência do impulso e da resposta. 
As Figuras 5.7 e 5.8 mostram a freqüência natural do rebolo montado no cabeçote de 195 Hz. Desta forma, o rebolo poderá entrar em ressonância nesta freqüência. O teste realizado não foi capaz de indicar outros modos de vibração para o rebolo até a frequiência de $2200 \mathrm{~Hz}$. No entanto, espera-se que as frequiências encontradas durante os testes de retificação sejam próximas às freqüências naturais da peça devido à sua menor rigidez comparada com a do rebolo.

\subsection{Configuração 2}

Considerando que a aplicação de rebolos de CBN vitrificados na retificação de materiais DTG resulta em uma ampla faixa de valores de relação $G$, a questão sobre a real influência das vibrações no desgaste da ferramenta e em outras variáveis do processo é especialmente importante.

Um bom exemplo disto é a retificação de peças com baixa rigidez estrutural, ou peças com valor da relação diâmetro/comprimento muito pequeno, como as válvulas de motores a combustão interna, onde pode ocorrer a presença de trepidação durante a fase de retificação de desbaste.

Isto é um problema industrial relevante, já que a retificação deste tipo de componente é relativamente difícil e a aplicação do rebolo de $\mathrm{CBN}$ nestes casos ainda não é inteiramente consistente.

Neste sentido, experimentos foram conduzidos para estudar as interações dinâmicas entre o rebolo de $\mathrm{CBN}$ e a peça. $\mathrm{O}$ objetivo principal é entender a influência destas interações na relação $G$ e na qualidade da peça retificada. 


\subsubsection{Potência de Retificação, Rugosidade e Circularidade}

A Figura 5.9 mostra o resultado da potência de retificação de cada teste em função da potência introduzida no sistema. O valor da potência é o valor médio de todos os 15 ciclos de retificação para cada ensaio.

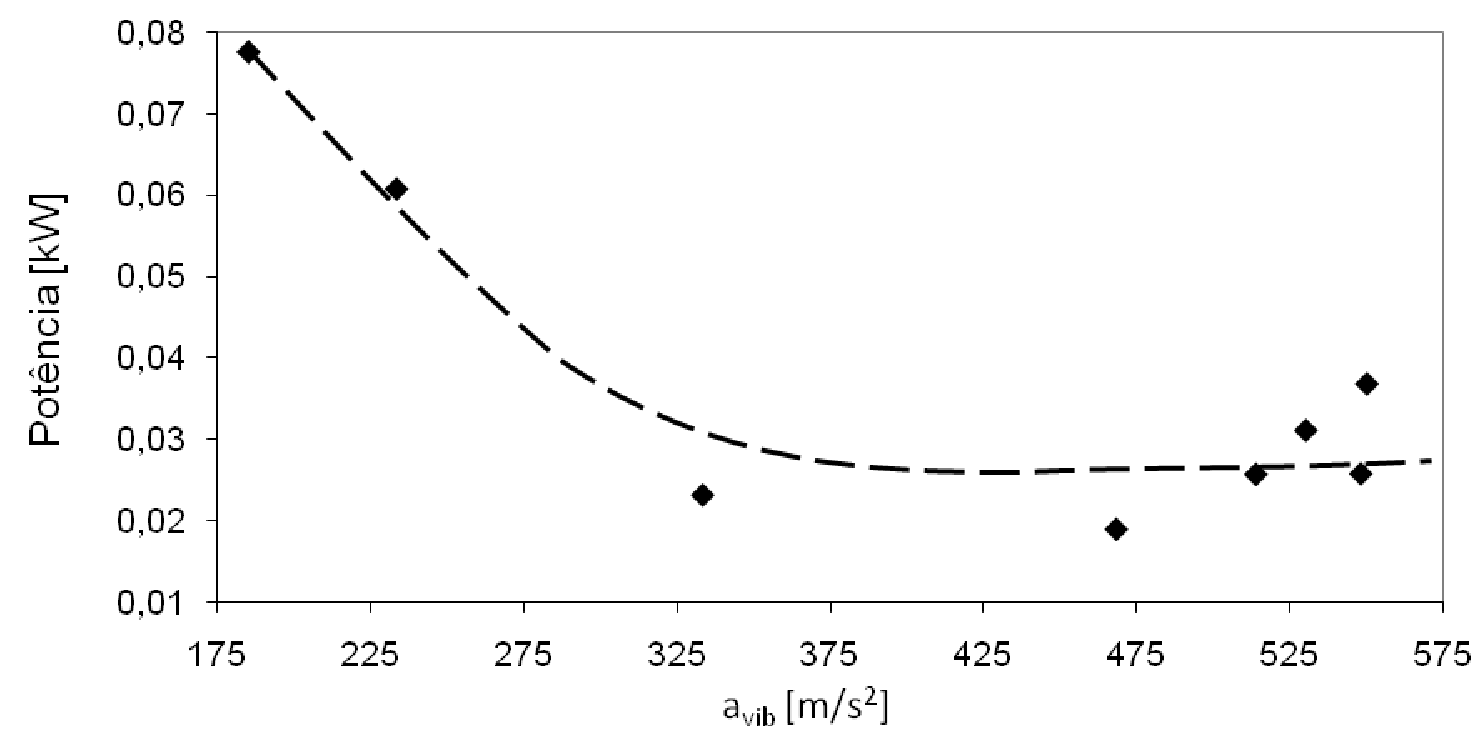

Figura 5.9 - Potência de corte versus aceleração de vibração $\left(a_{v i b}\right)$.

O gráfico acima mostra uma tendência de diminuição da potência com o aumento da vibração introduzida no sistema. Entende-se por sistema aqui o conjunto formado pela peça, cabeçote da peça, rebolo e cabeçote do rebolo.

Este fenômeno é muito interessante, pois pode indicar a existência de um comportamento diferente de remoção de cavaco quando o sistema é excitado. Em uma situação normal de retificação, a remoção de cavaco se dá pela interação entre o grão abrasivo e a peça de acordo com a Figura 2.1. O gráfico de potência acima indica que a interação grão/peça se torna muito mais rápida com o aumento da amplitude de vibração, diminuindo assim as forças de retificação. 
A Figura 5.10 mostra os valores médios de rugosidade e do erro de circularidade para cada ensaio realizado.

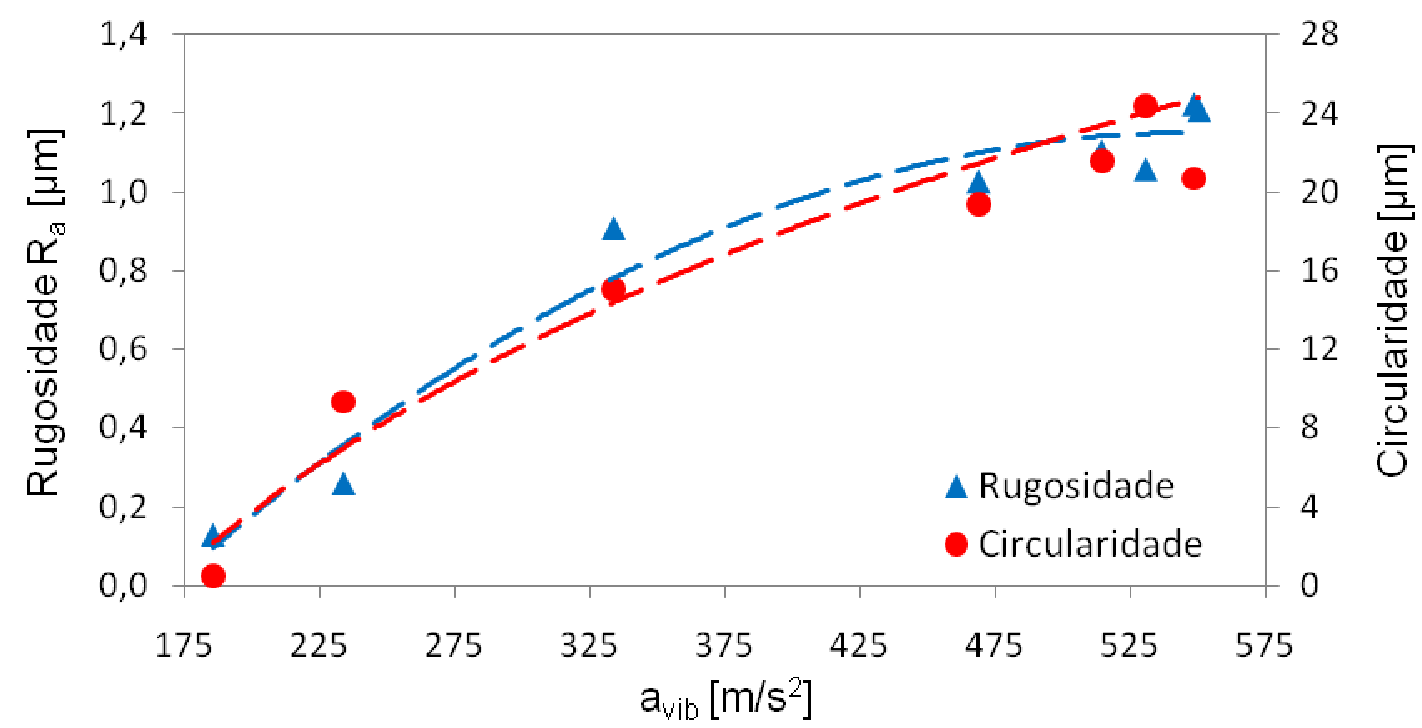

Figura 5.10 - Erro de circularidade e rugosidade versus aceleração de vibração $\left(a_{v i b}\right)$.

Os valores de rugosidade e erro de circularidade mostram uma tendência de crescimento com o aumento da excitação no sistema. A rugosidade e o erro de circularidade estão diretamente relacionados à estabilidade do processo de retificação. As máquinas de baixa rigidez produzem peças com maiores erros de circularidade e pior acabamento superficial. Isto é um agravante no caso de peças de baixa rigidez estrutural.

A análise em conjunto dos gráficos das Figuras 5.9 e 5.10 indica que a ferramenta pode se comportar como um rebolo mais agressivo com o aumento da excitação forçada, lembrando que a excitação utilizada em todos os testes foi randômica, pois esta é similar às vibrações inerentes do processo de retificação. 


\subsubsection{Desgaste do Rebolo}

A Figura 5.11 mostra o comportamento da relação $G$ com o aumento da amplitude da vibração forçada.

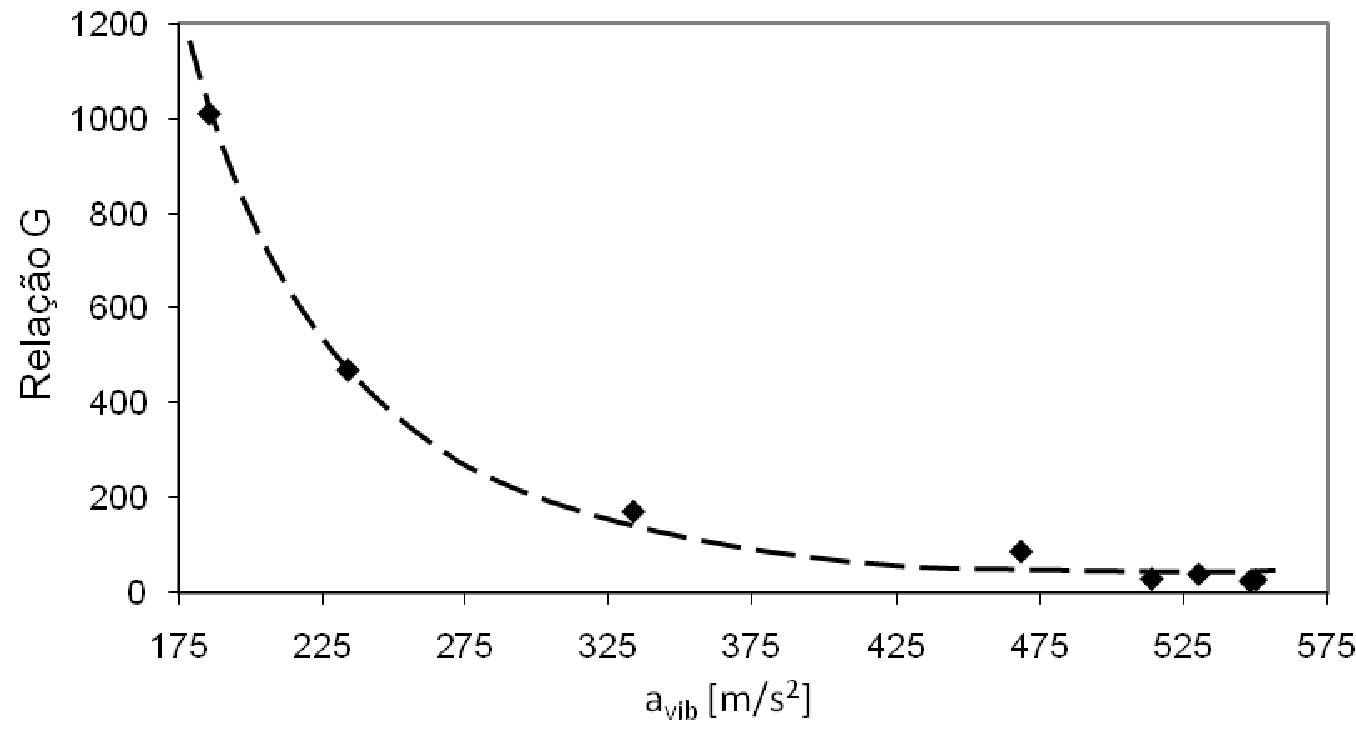

Figura 5.11 - Relação $G$ versus aceleração de vibração $\left(a_{v i b}\right)$.

O gráfico mostra que a relação $G$ tende a diminuir drasticamente com o aumento da magnitude da excitação forçada. Isto indica muito claramente a mudança do mecanismo de desgaste do rebolo, sugerindo que o desgaste da ferramenta ocorre predominantemente pela fratura do ligante quando existe vibração no processo. Este tipo de desgaste do rebolo é o maior responsável pela perda diametral do mesmo e conseqüentemente pela diminuição da relação $G$. 


\subsubsection{Freqüências Excitadas Durante a Retificação}

Foram produzidos dois gráficos diferentes, sendo o primeiro do tipo cascata (ou waterfall) que exibe a aceleração no espectro da freqüência para cada um dos 15 ciclos do ensaio. O gráfico foi preparado para que seja possível observar as regiões do espectro de maior amplitude e as possíveis diferenças entre os 15 ciclos. Já o segundo gráfico mostra a média da aceleração dos 15 ciclos do ensaio no espectro da freqüência. Isto para observar os valores da frequiência durante os testes de retificação. $\mathrm{O}$ espectro da frequiência foi obtido pela transformada de Fourier dos valores de aceleração dos ciclos.

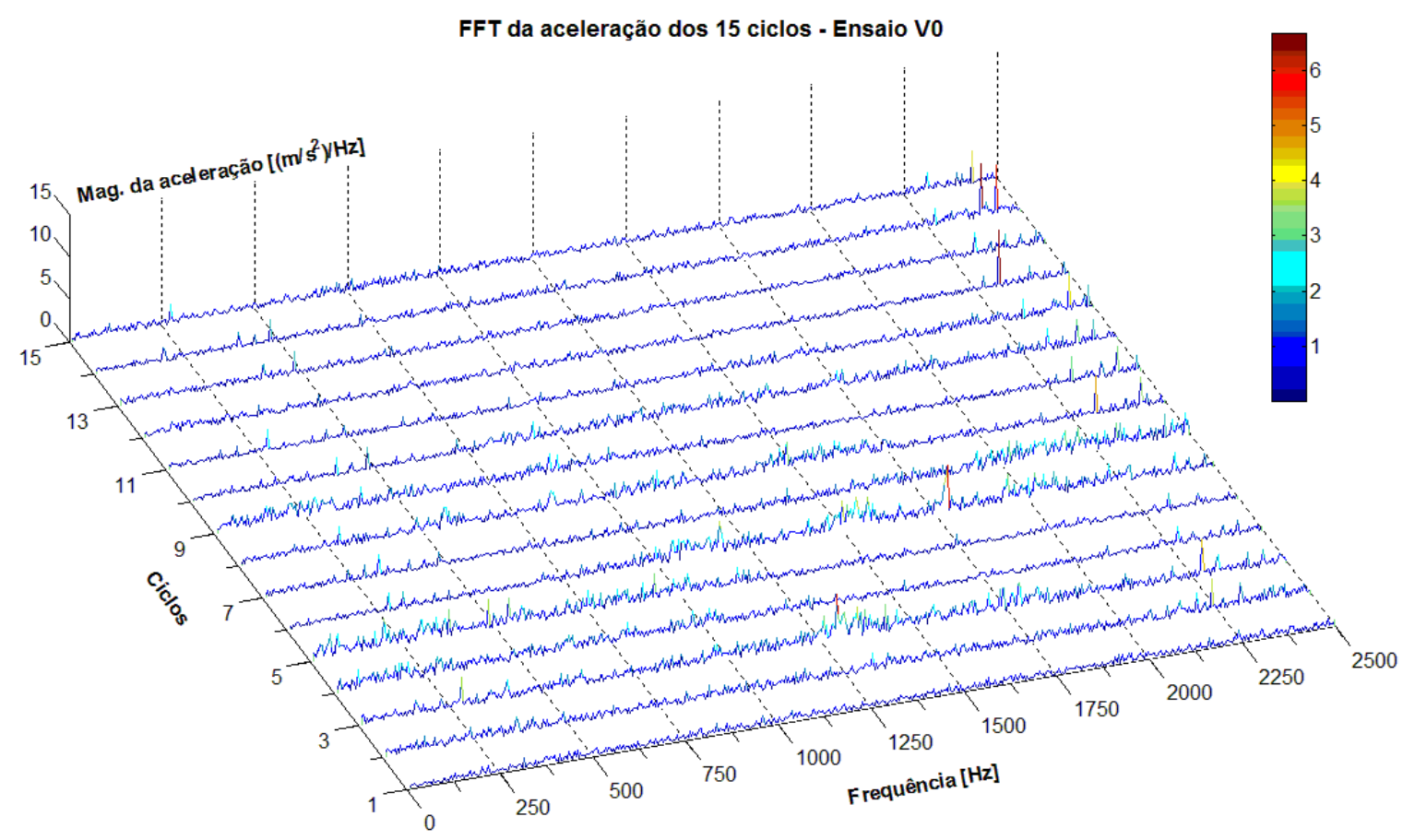

Figura 5.12 - Espectro da freqüência da aceleração para cada ciclo do ensaio V0. 


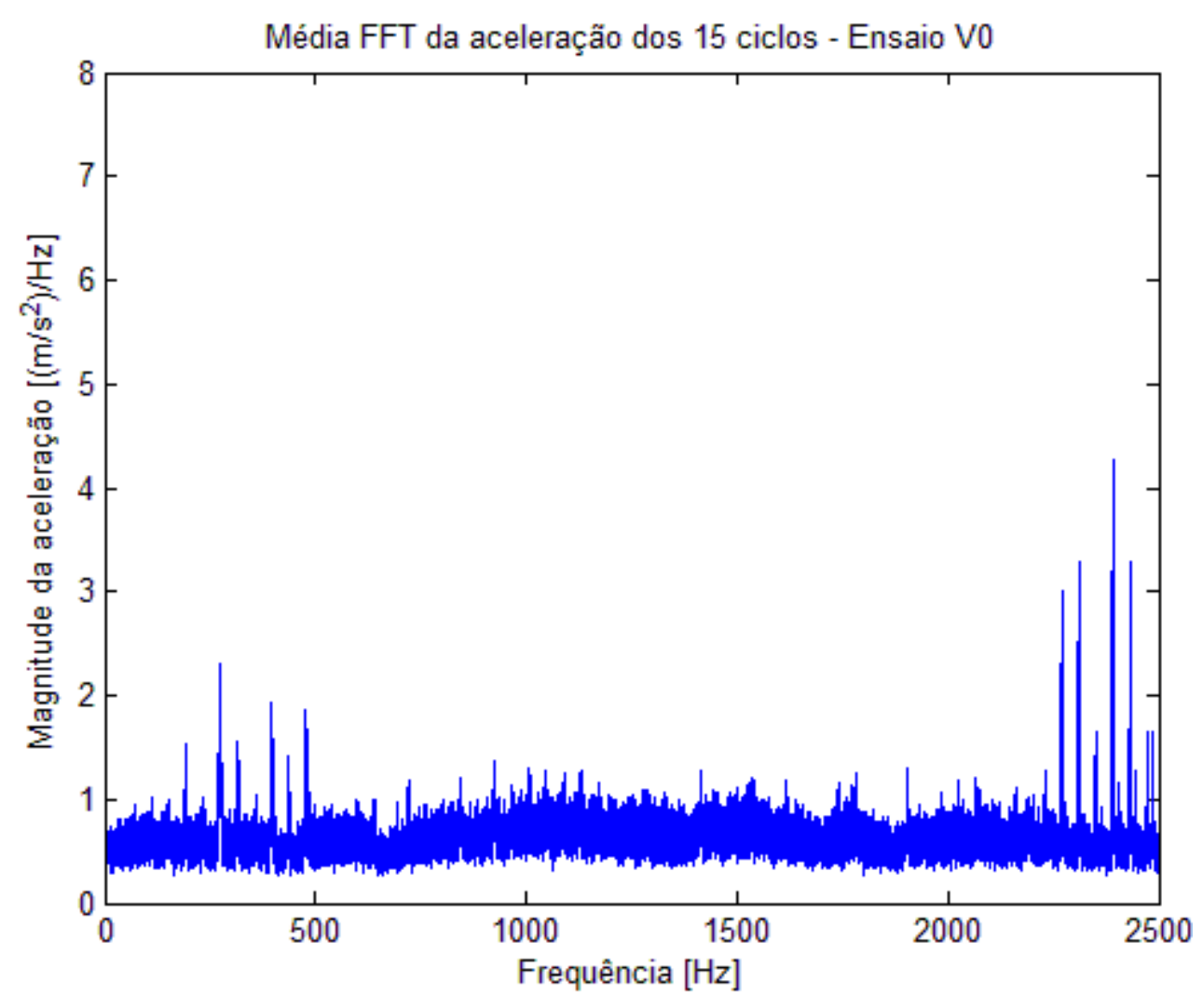

Figura 5.13 - Média do espectro da frequiência da aceleração para o ensaio V0.

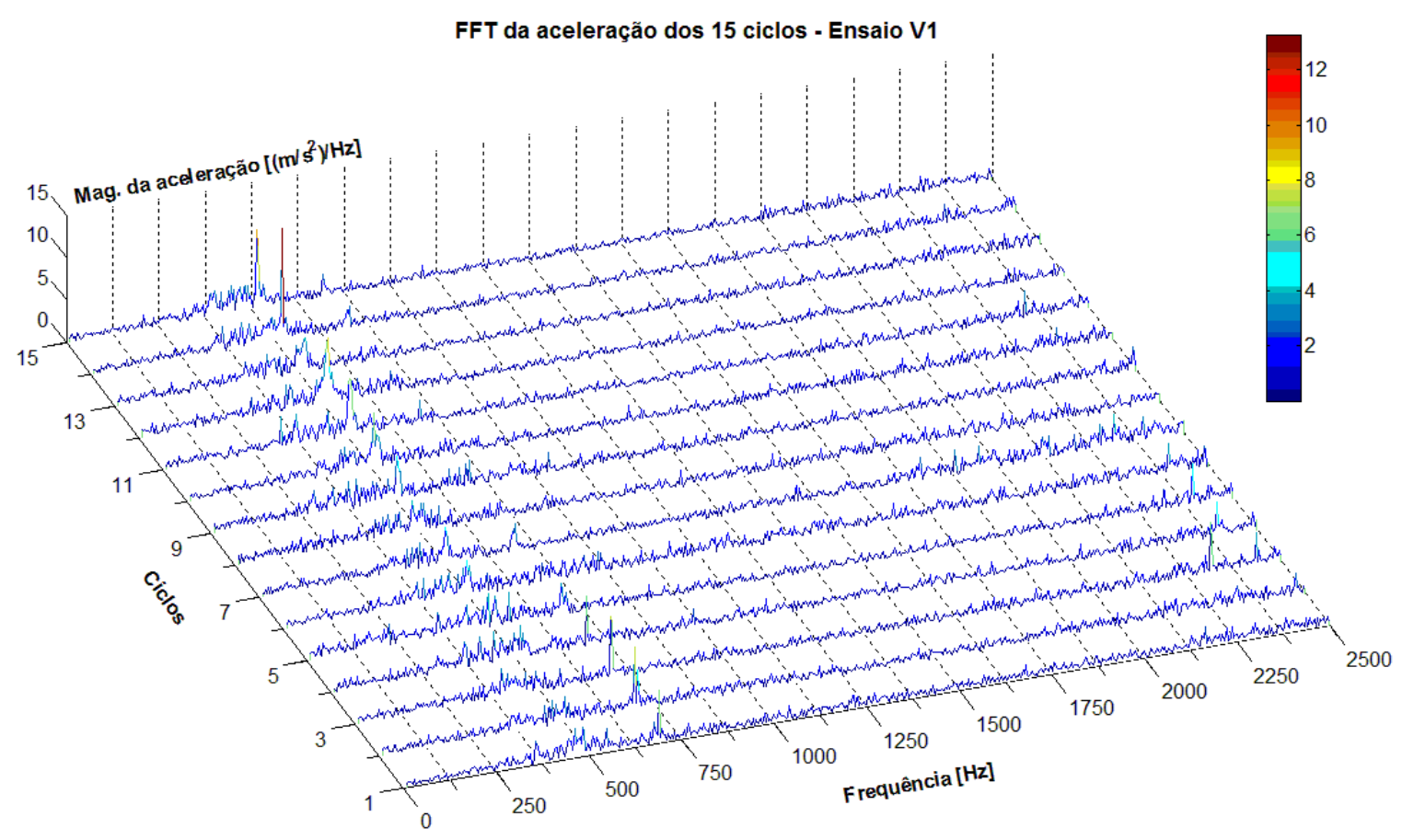

Figura 5.14 - Espectro da frequiência da aceleração para cada ciclo do ensaio V1. 


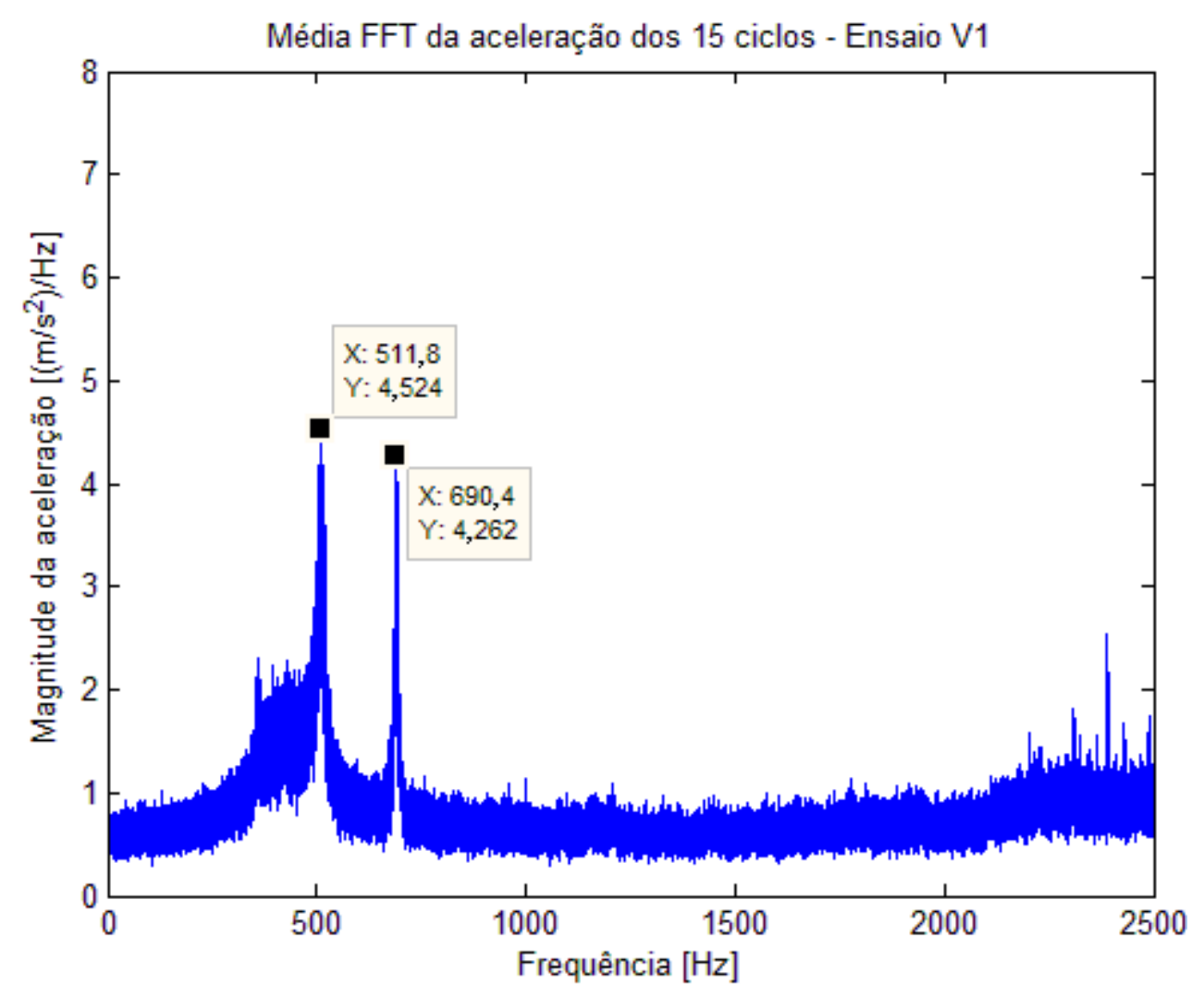

Figura 5.15 - Média do espectro da freqüência da aceleração para o ensaio V1.

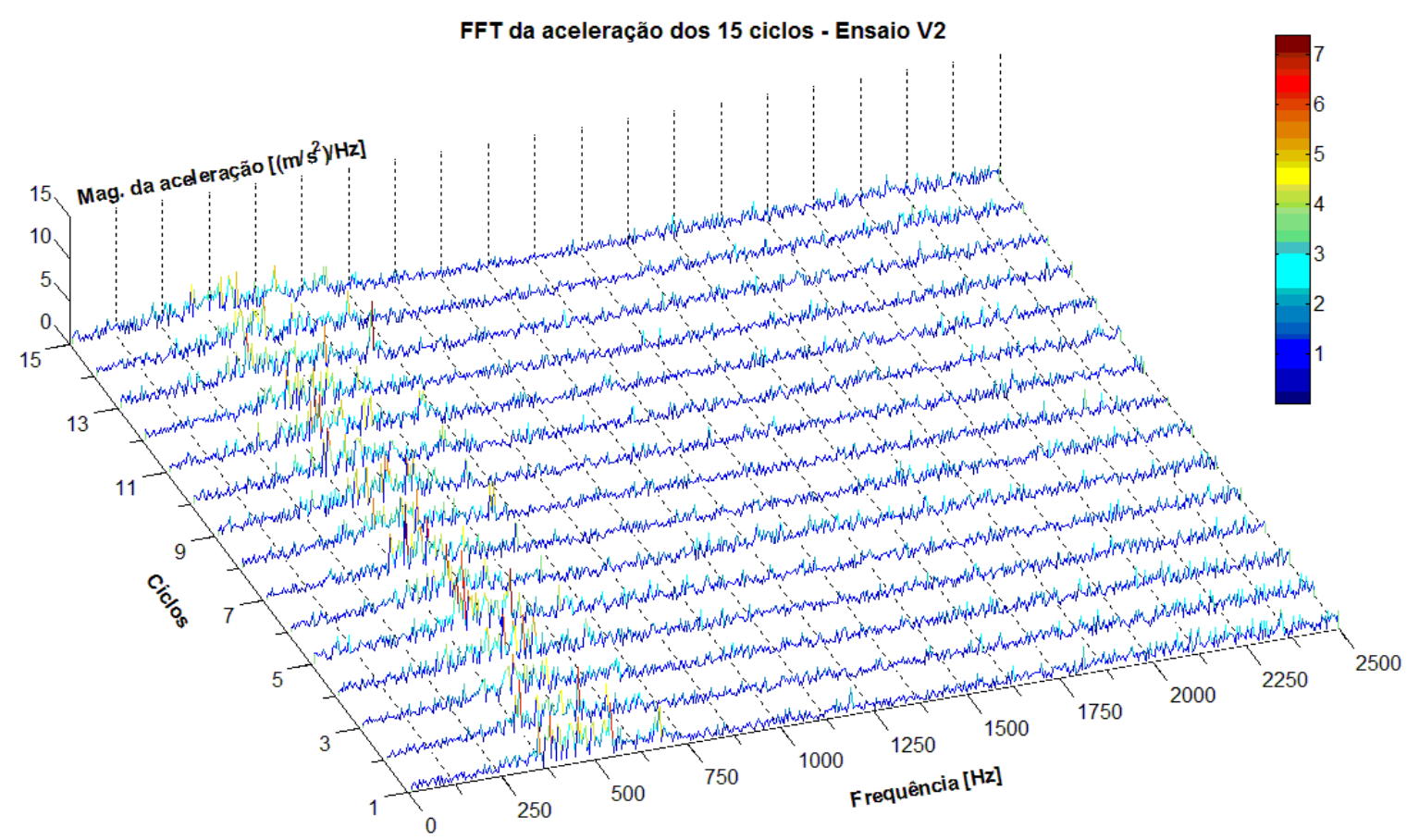

Figura 5.16 - Espectro da freqüência da aceleração para cada ciclo do ensaio V2. 


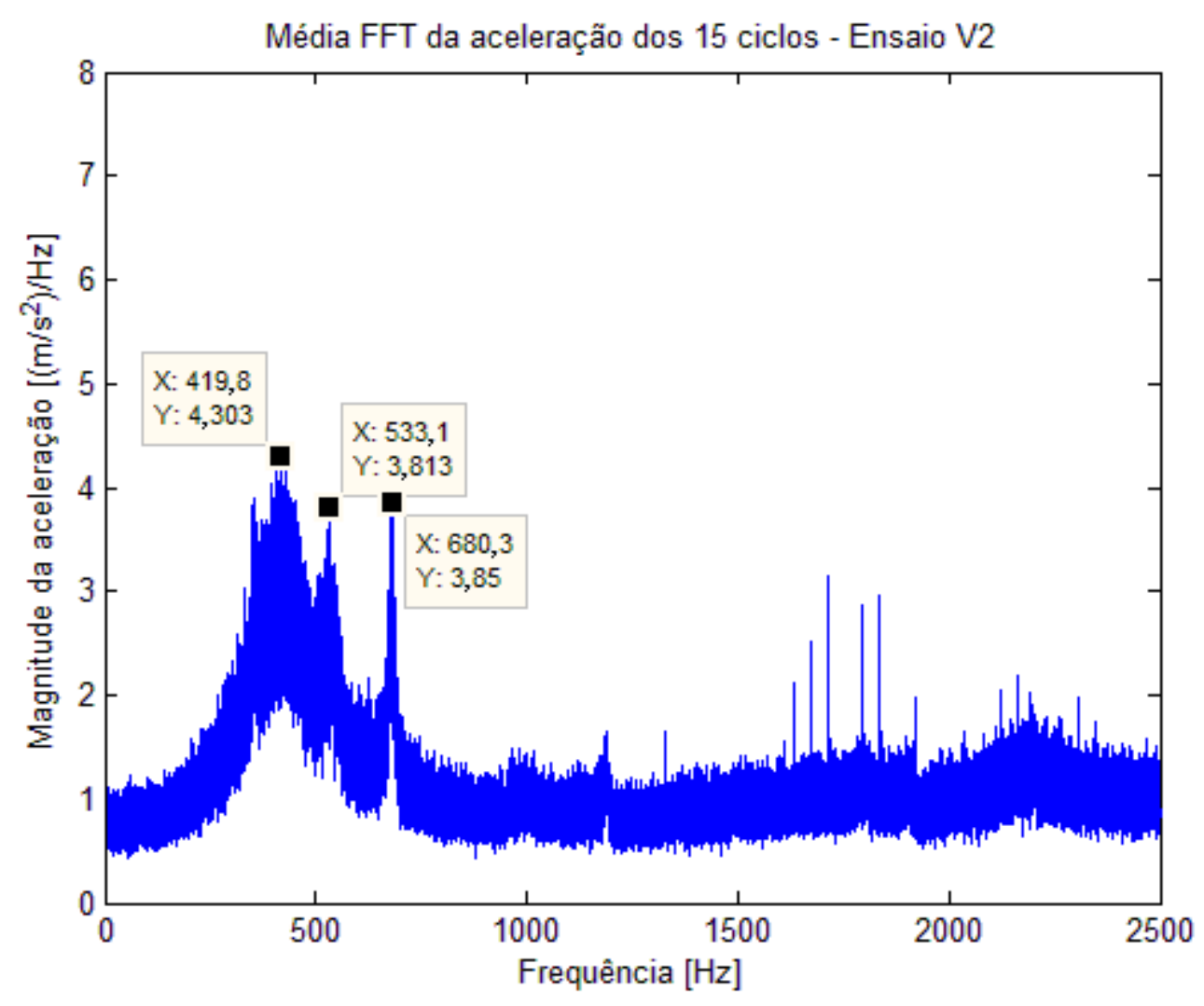

Figura 5.17 - Média do espectro da freqüência da aceleração para o ensaio V2.

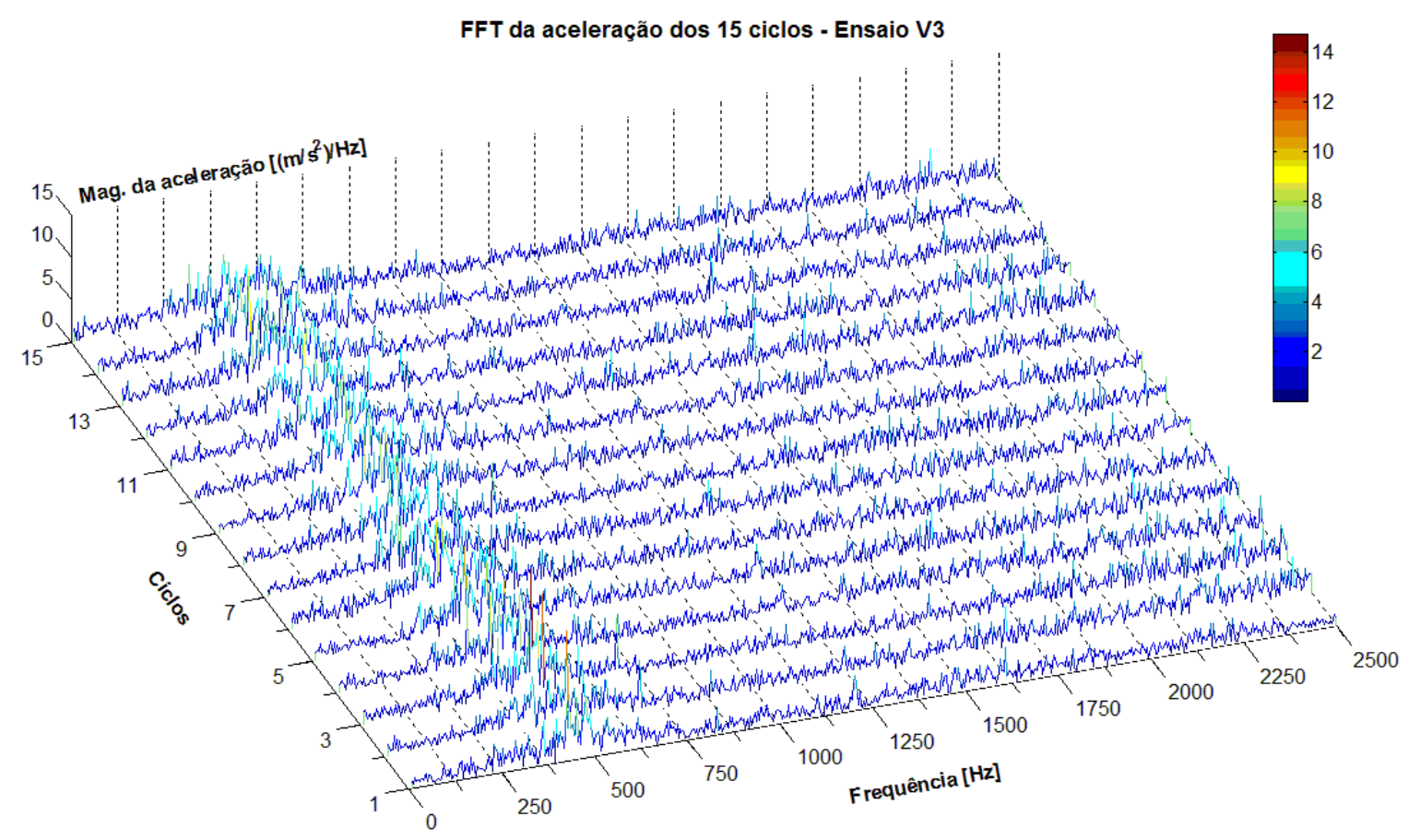

Figura 5.18 - Espectro da freqüência da aceleração para cada ciclo do ensaio V3. 


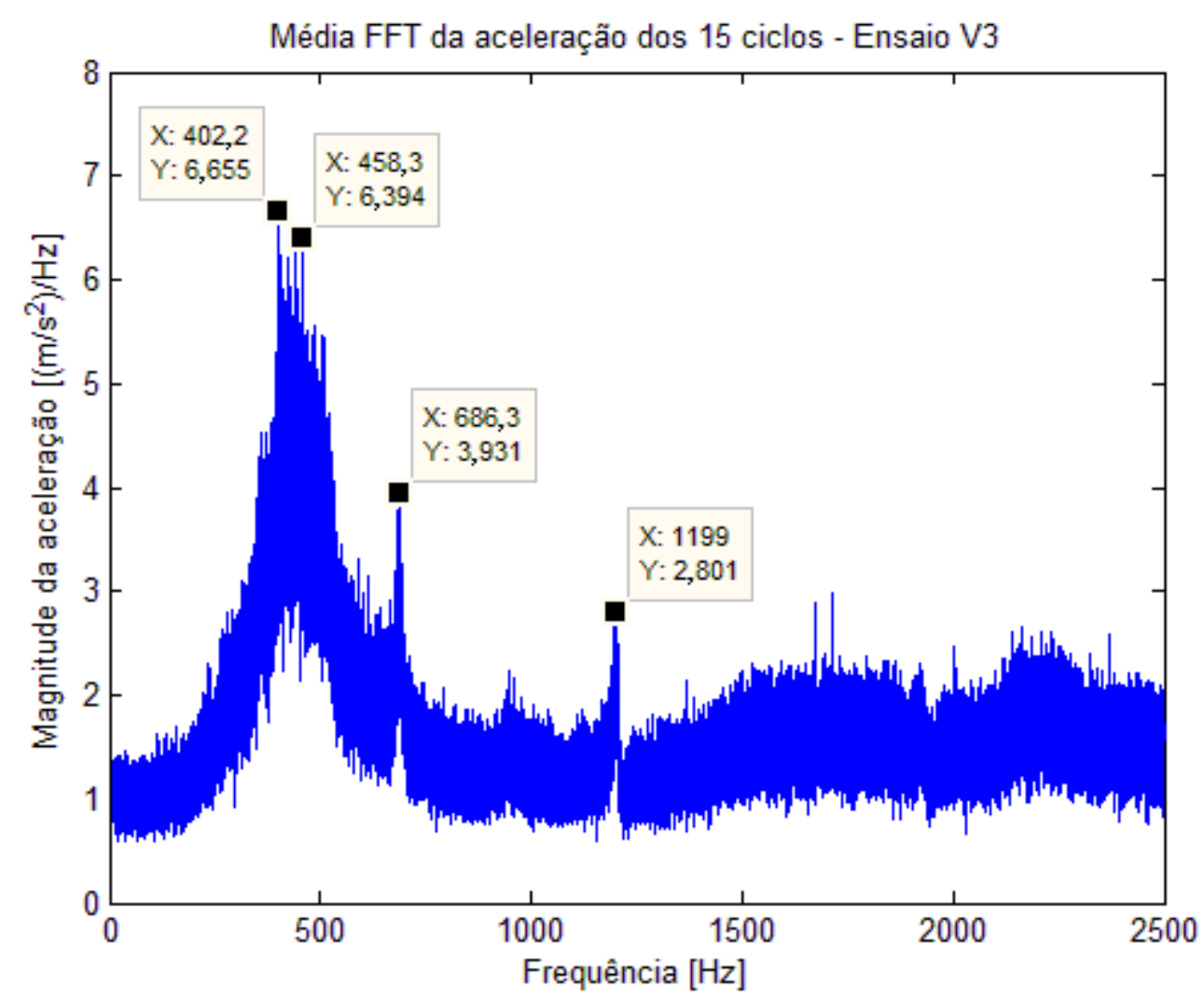

Figura 5.19 - Média do espectro da freqüência da aceleração para o ensaio V3.

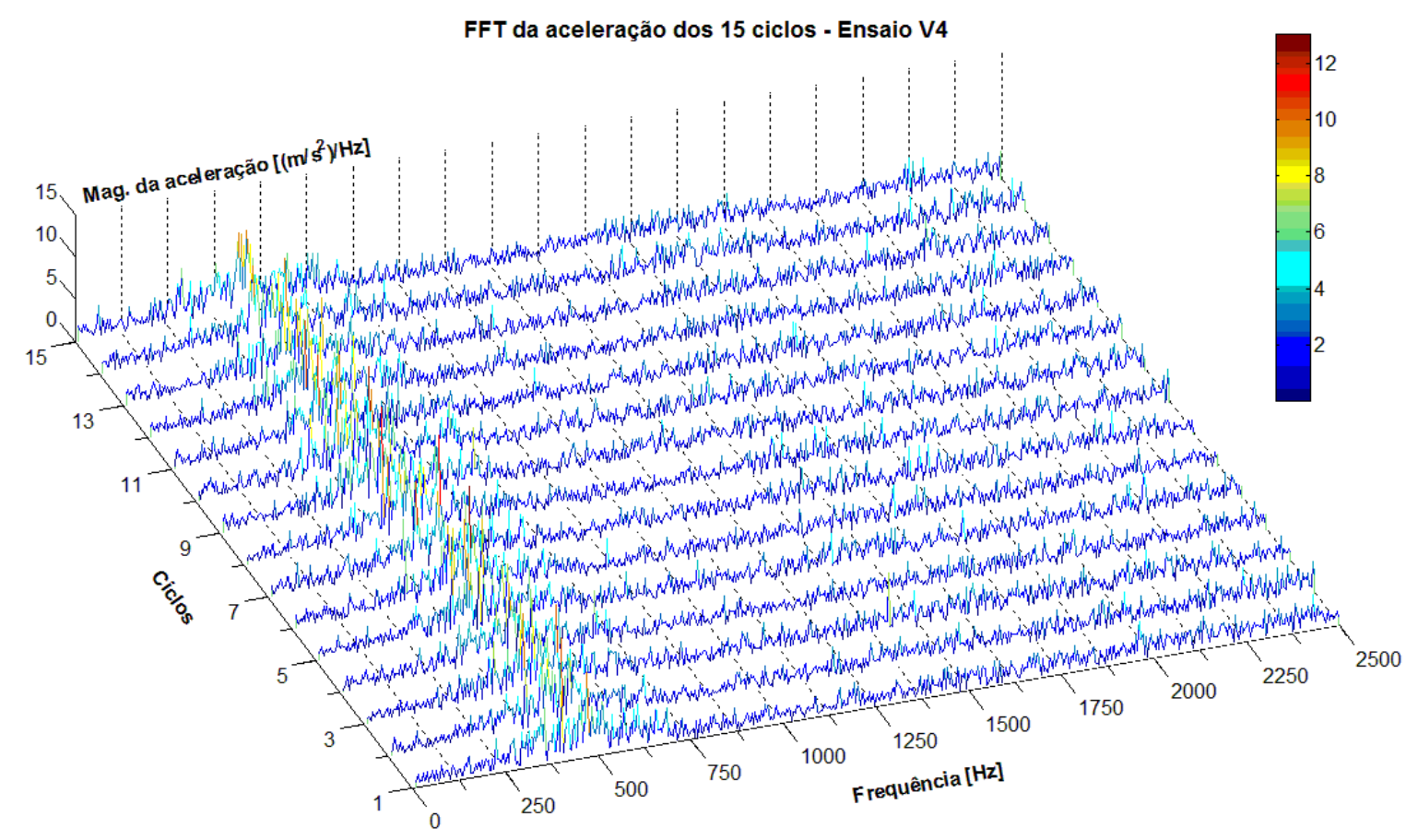

Figura 5.20 - Espectro da freqüência da aceleração para cada ciclo do ensaio V4. 


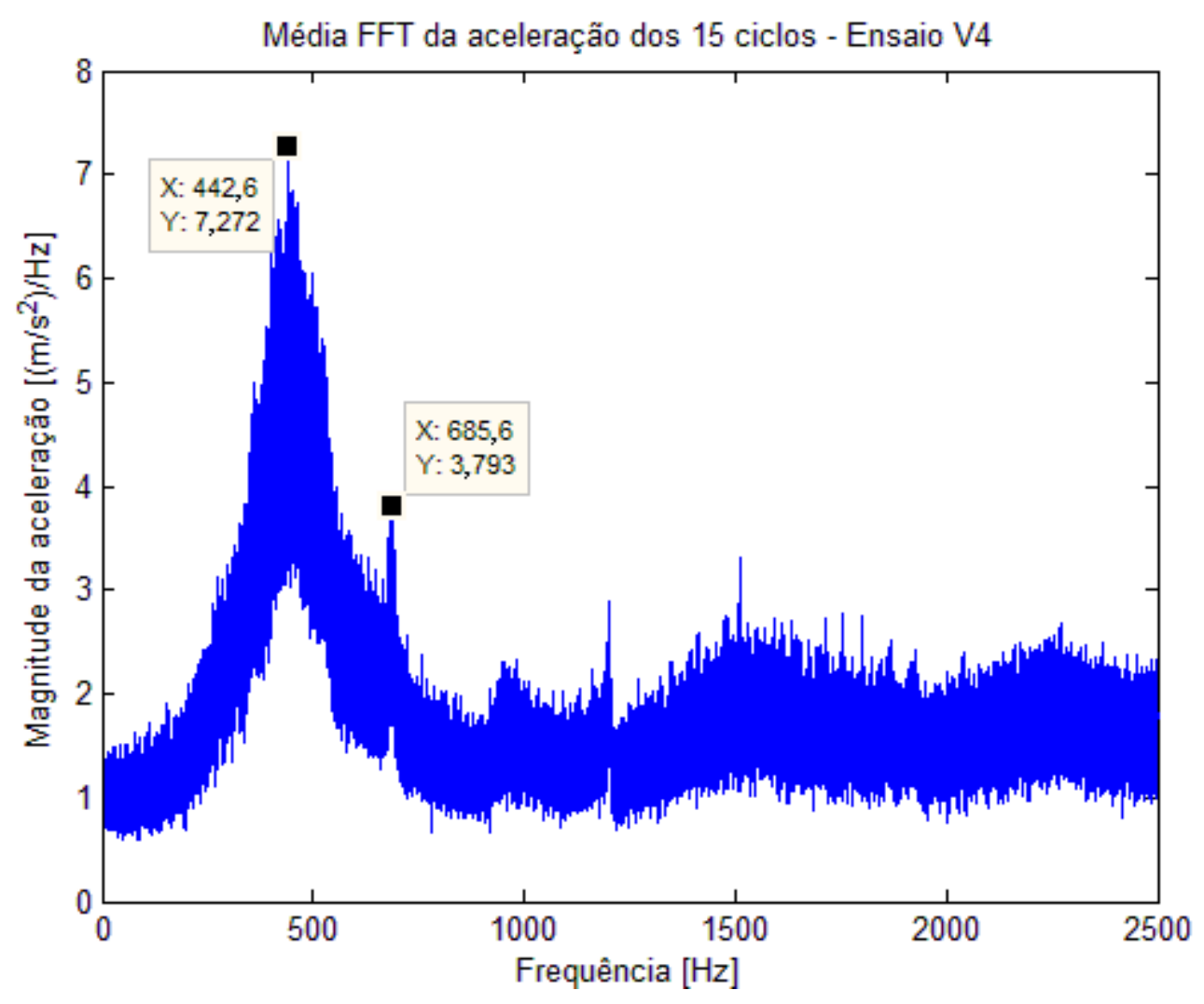

Figura 5.21 - Média do espectro da freqüência da aceleração para o ensaio V4.

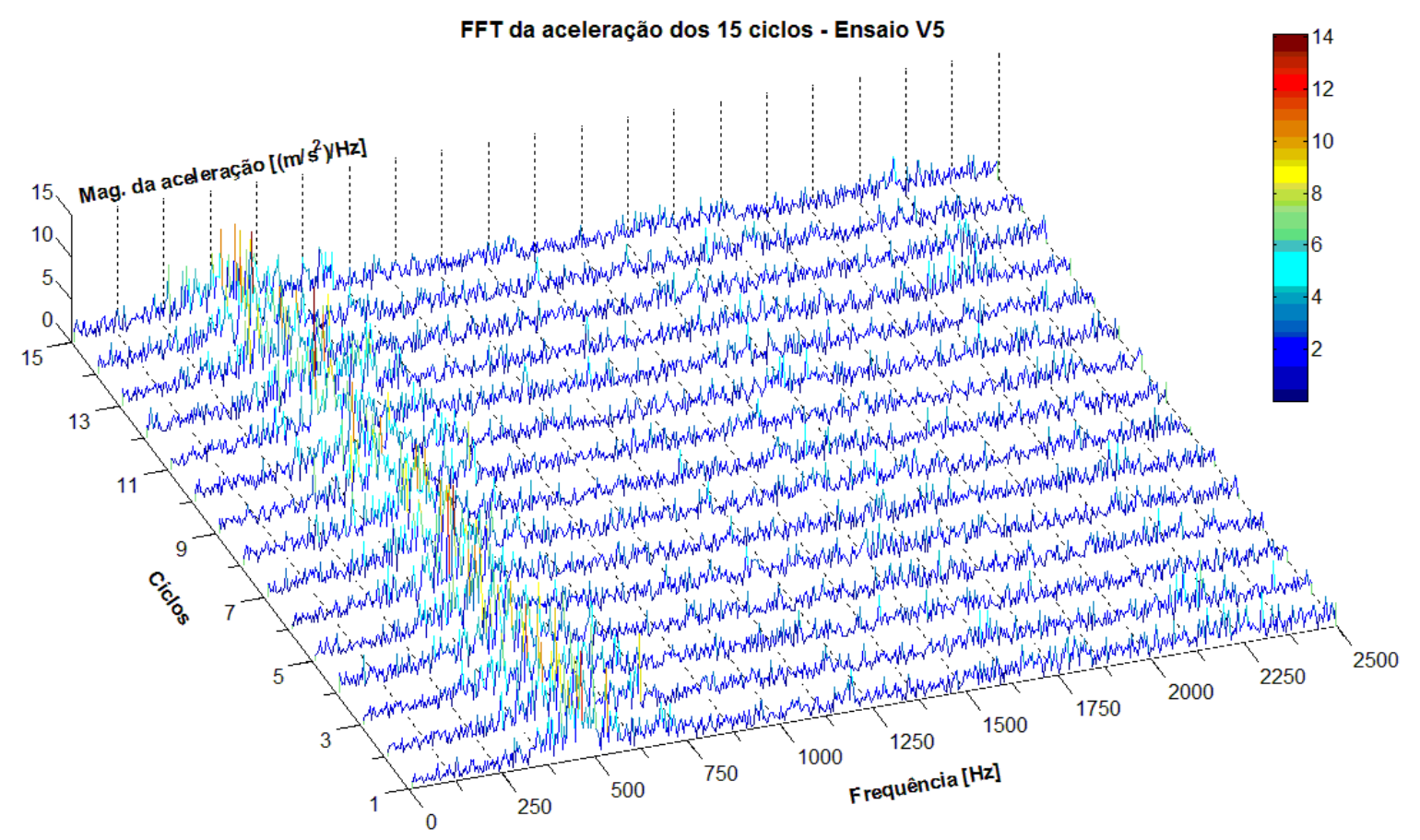

Figura 5.22 - Espectro da freqüência da aceleração para cada ciclo do ensaio V5. 


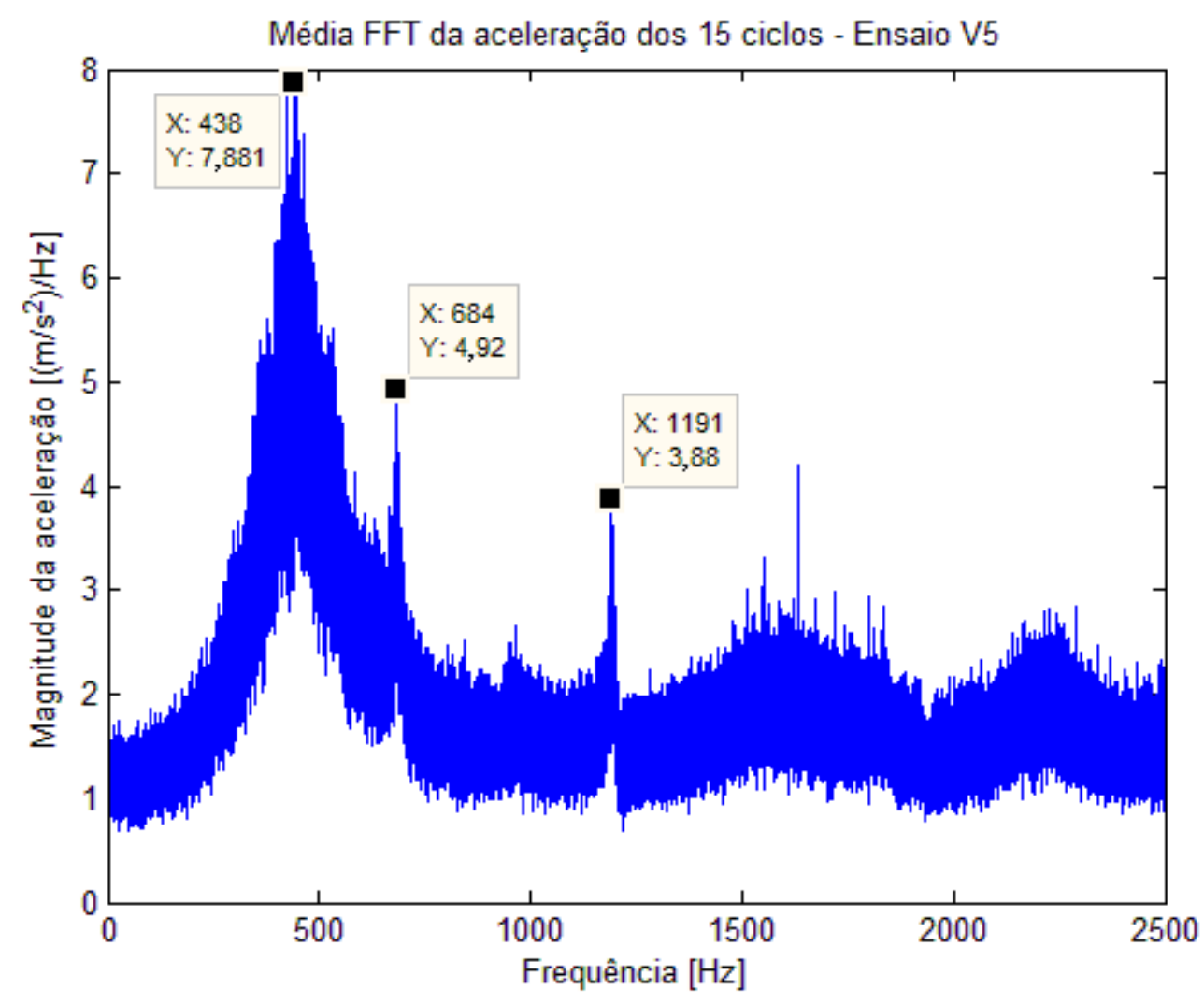

Figura 5.23 - Média do espectro da freqüência da aceleração para o ensaio V5.

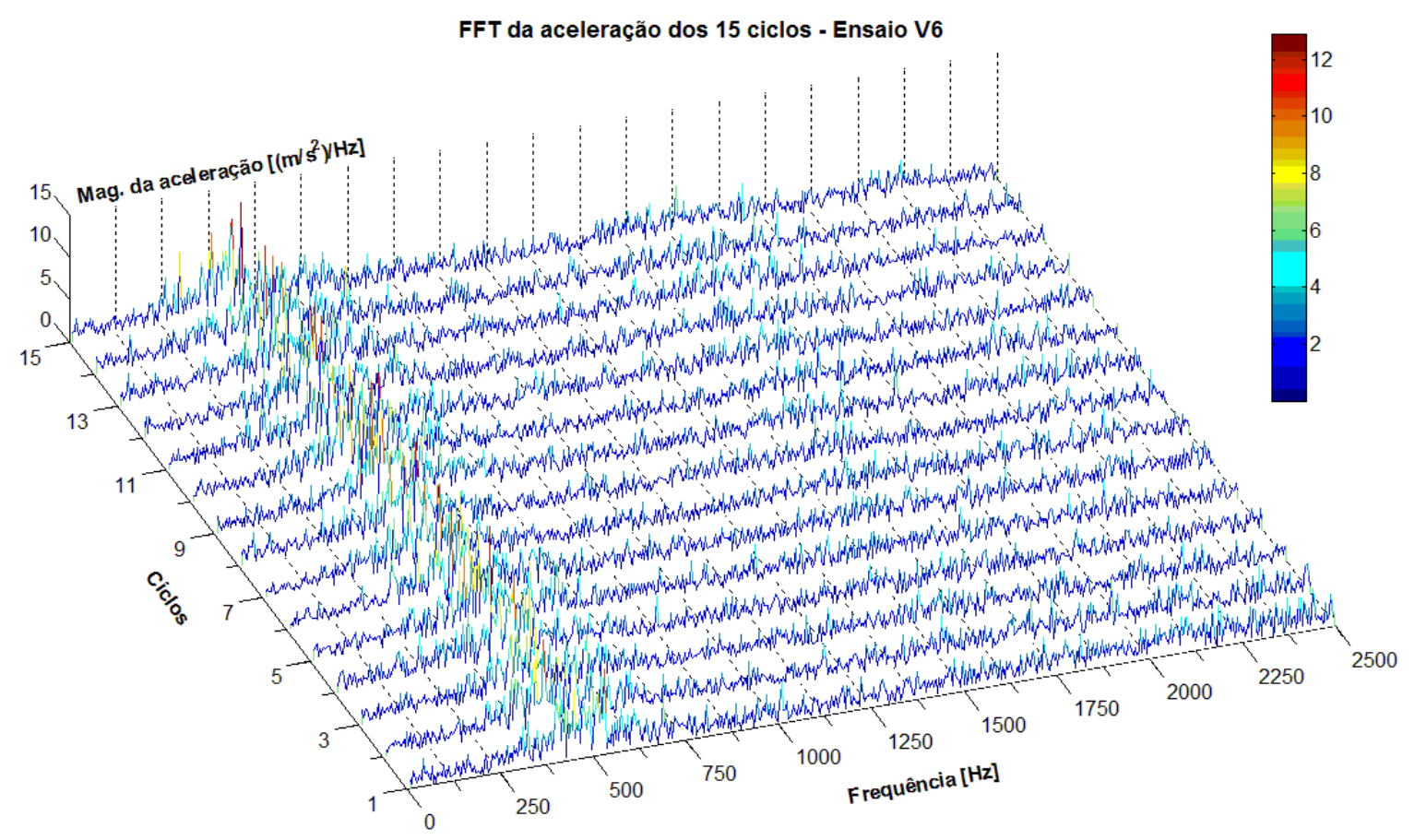

Figura 5.24 - Espectro da freqüência da aceleração para cada ciclo do ensaio V6. 


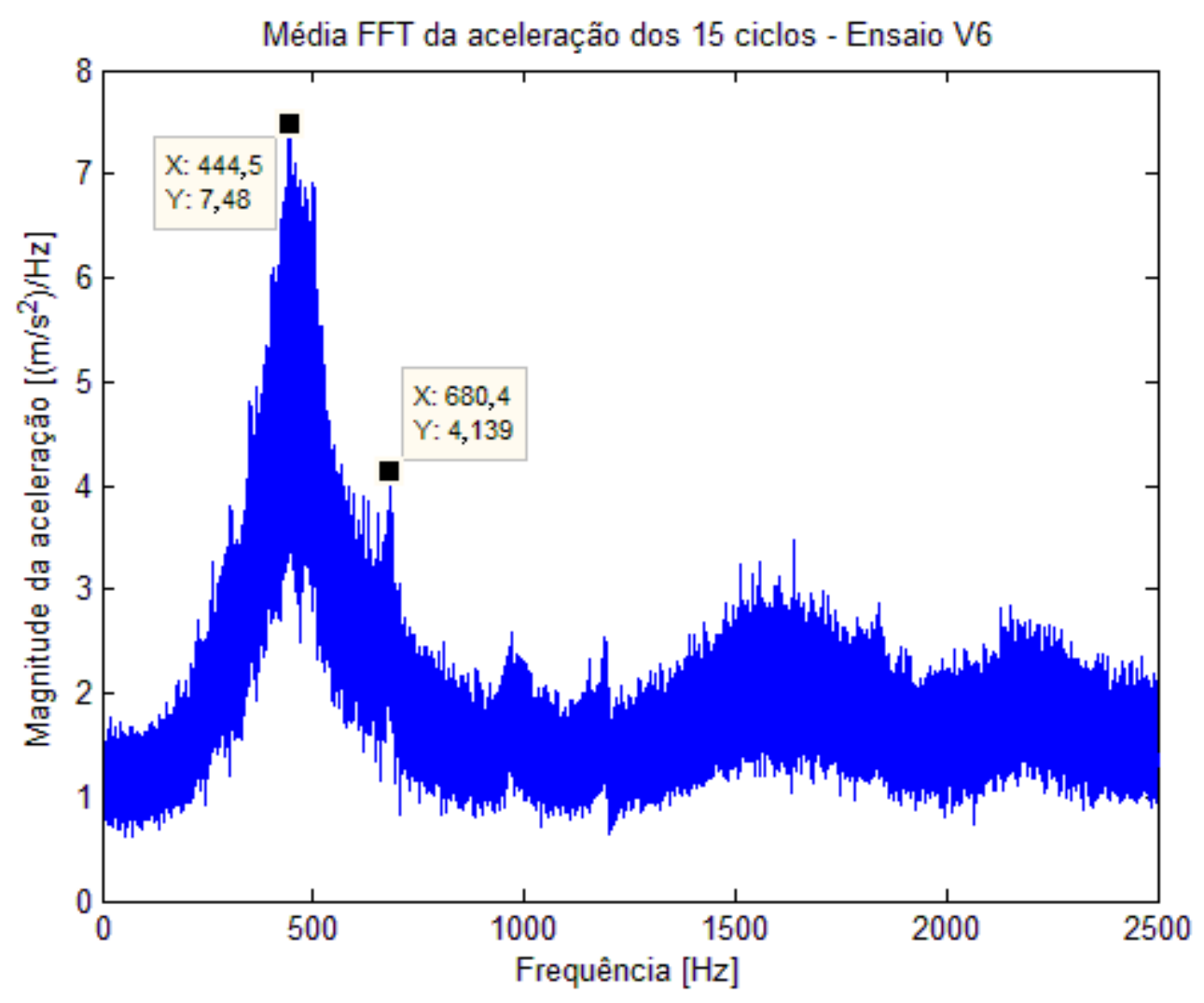

Figura 5.25 - Média do espectro da freqüência da aceleração para o ensaio V6.

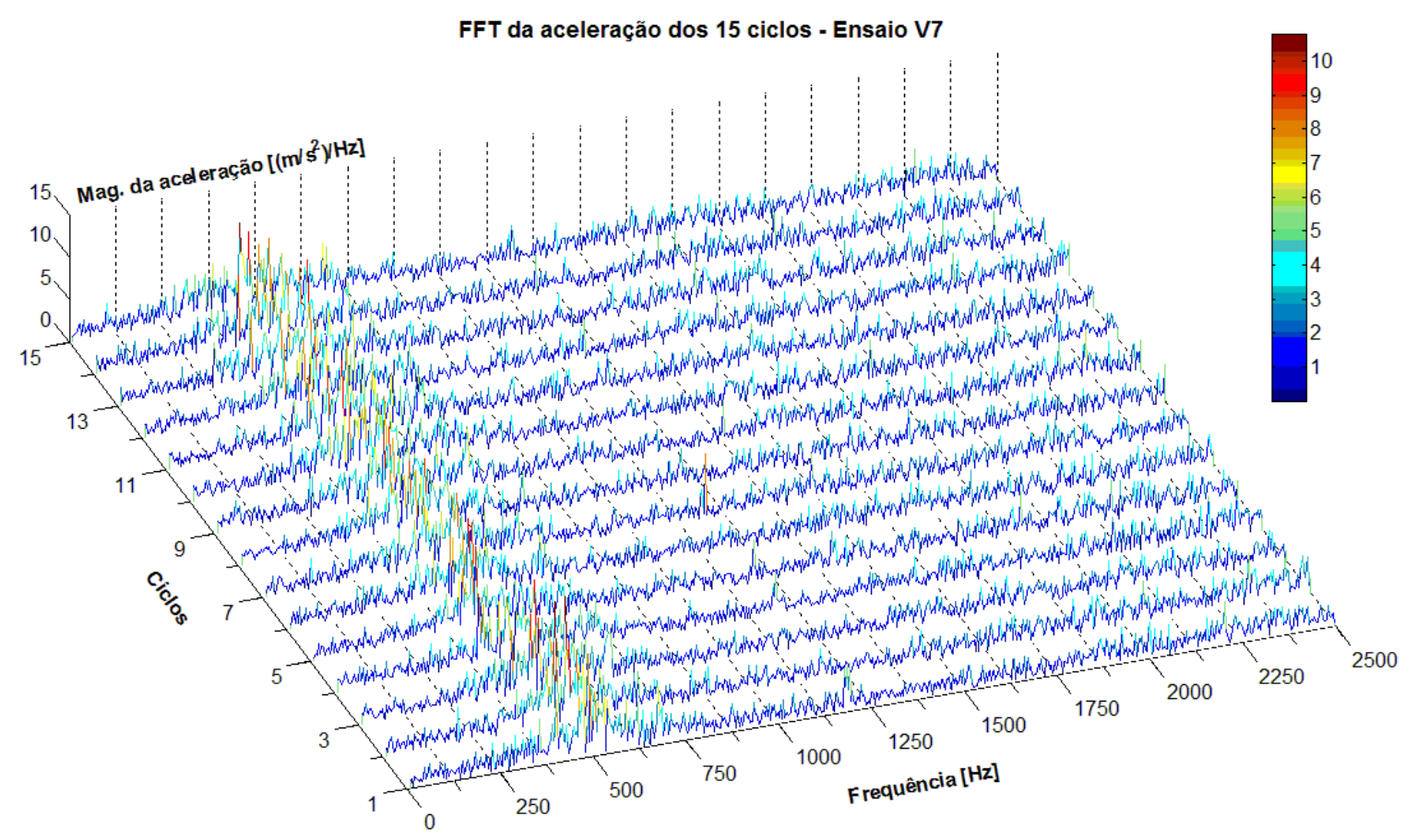

Figura 5.26 - Espectro da freqüência da aceleração para cada ciclo do ensaio V7. 


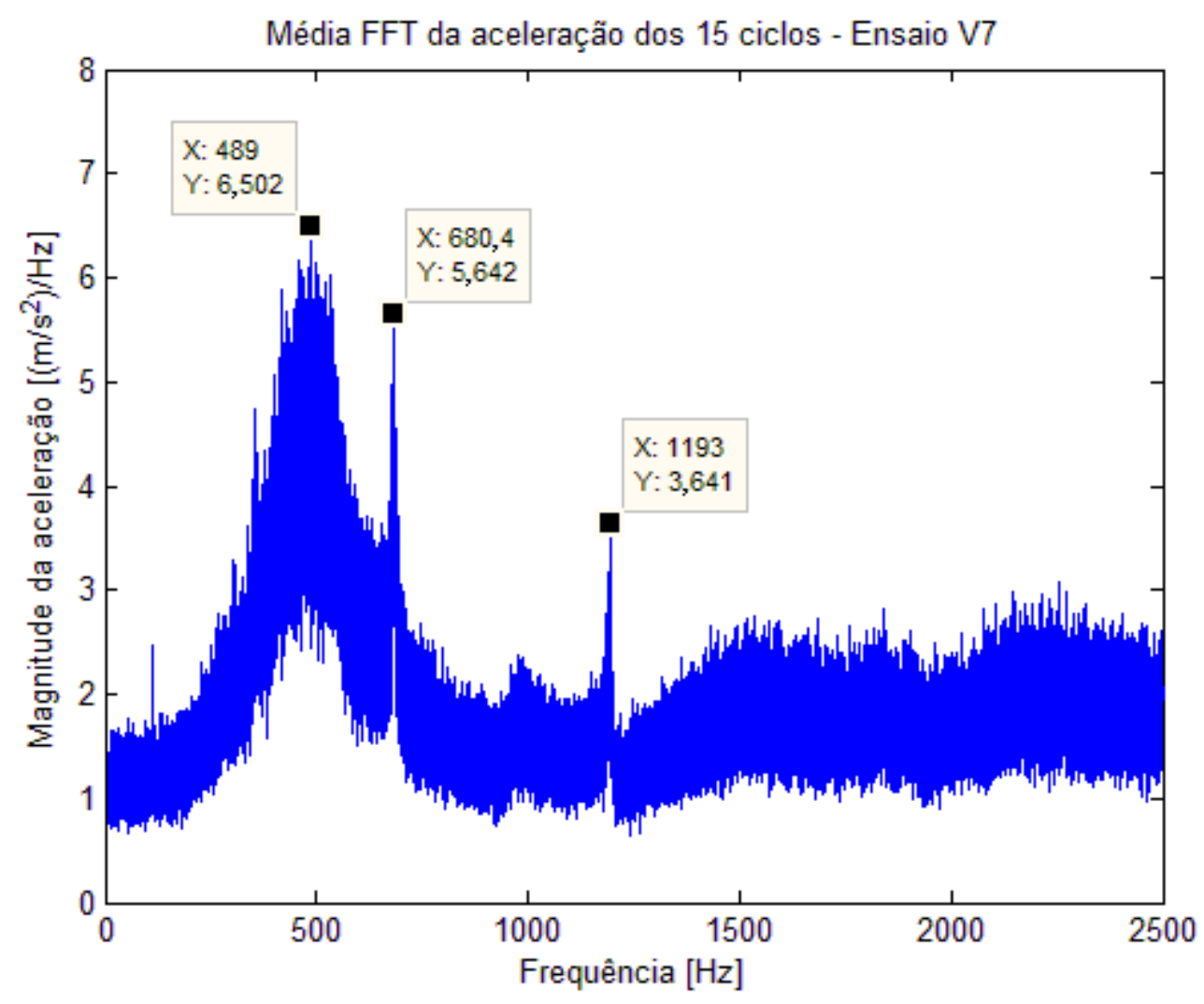

Figura 5.27 - Média do espectro da freqüência da aceleração para o ensaio V7.

As Figuras 5.12 a 5.27 mostram a progressão da amplitude de vibração no espectro da freqüência durante os ensaios. Existem alguns valores de freqüência encontrados que aparecem com certa constância nos ensaios. Apesar de ocorrerem pequenas variações em torno das mesmas, pode-se fixar um valor para cada uma. Desta forma tem-se: $450 \mathrm{~Hz}$ na qual ocorre a maior amplitude de vibração; $520 \mathrm{~Hz}$ que aparece nos ensaios V1 e V2; além das freqüências 680 e $1190 \mathrm{~Hz}$.

De acordo com os gráficos, fica claro que a maior amplitude de excitação ocorre entre as freqüências 450 e $520 \mathrm{~Hz}$. Isto sugere, pelo gráfico da resposta em freqüência da peça (Figura 5.5), que o segundo modo de vibrar da peça é o predominante durante os ensaios de retificação. 
É importante notar que durante a retificação o sistema excitado é composto dos dois subsistemas, ou seja: o subsistema do rebolo e o da peça. Estes dois subsistemas estão em contato e, portanto existe uma rigidez de contato entre eles fazendo com que a resposta em freqüência do sistema excitado durante a retificação seja ligeiramente diferente da resposta encontrada nos subsistemas separadamente.

No entanto, os gráficos mostram um comportamento muito parecido com a resposta em frequiência da peça. Assim, pode-se concluir que o comportamento durante a retificação tende a ser semelhante ao comportamento do subsistema de menor rigidez, neste caso, o subsistema da peça.

Outros valores de freqüência, como 680 e $1190 \mathrm{~Hz}$, podem estar relacionados com outros modos de vibrar do sistema.

Pode-se concluir, por enquanto, que ao se excitar o sistema, a resposta coincide aproximadamente com a freqüência natural da peça e o aumento nos níveis de vibração trazem consigo aumento nos valores de circularidade, rugosidade e desgaste do rebolo.

\subsection{Configuração 3}

A Configuração 3 apresenta os resultados obtidos durante a retificação com alta velocidade de corte. Serão avaliados os resultados de potência de corte, rugosidade, erro de circularidade e desgaste do rebolo. Os valores de aceleração foram integrados para obtenção da velocidade. 


\subsubsection{Potência de Retificação, Rugosidade e Circularidade}

As Figuras 5.28 e 5.29 mostram os resultados da potência de retificação, erro de circularidade e rugosidade de cada teste. $\mathrm{O}$ valor da potência é o valor médio de todos os 15 ciclos de retificação para cada ensaio.

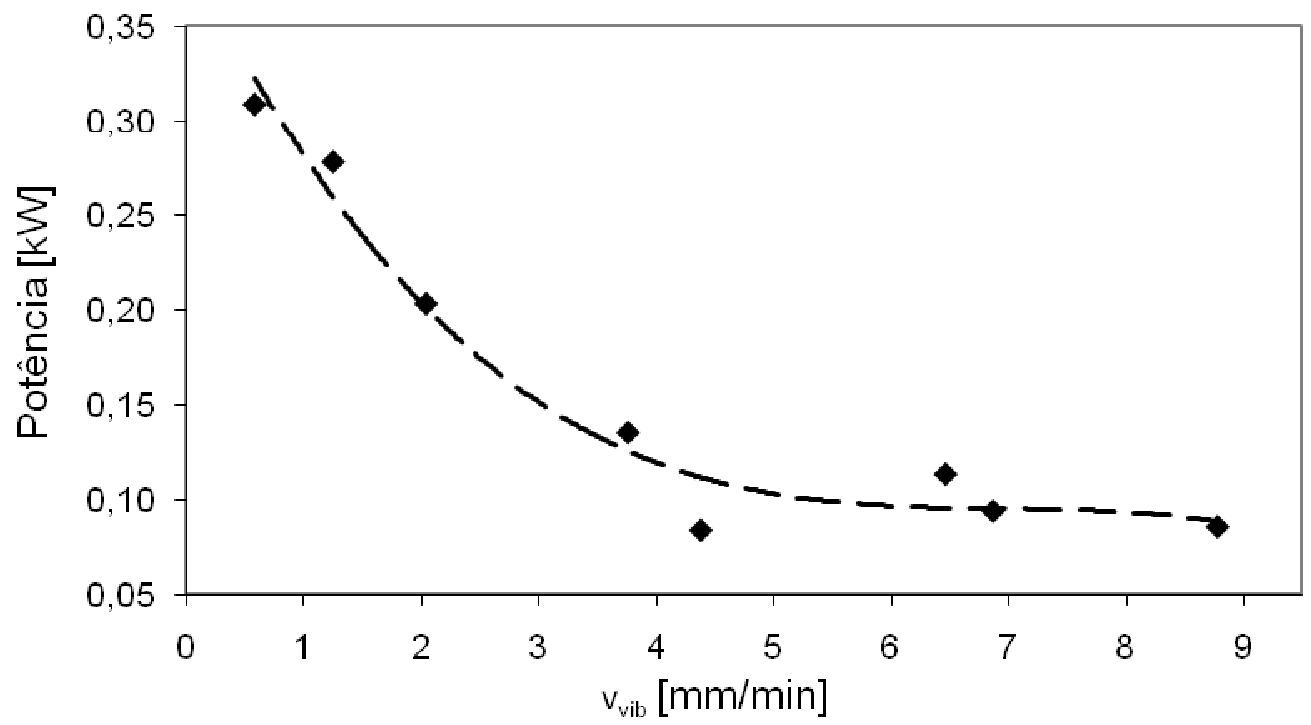

Figura 5.28 - Potência de corte versus velocidade de vibração $\left(v_{v i b}\right)$.

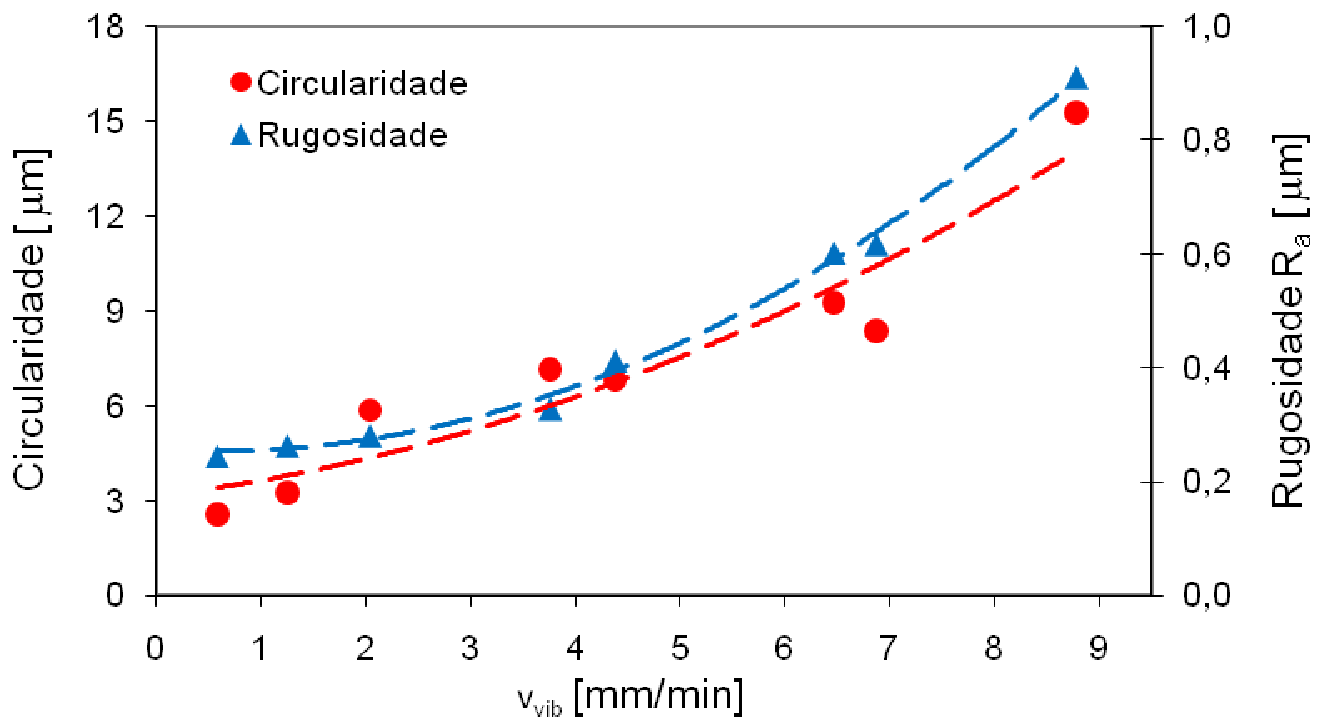

Figura 5.29 - Erro de circularidade e rugosidade versus velocidade de vibração $\left(v_{v i b}\right)$. 
Como esperado, os valores de circularidade e rugosidade aumentam com o aumento da velocidade de vibração. Um comportamento contrário é observado para a potência. Estes resultados indicam que existe uma mudança na cinemática do processo, induzindo uma alta variação nos valores de espessura de cavaco (máximos e mínimos) para maiores níveis de excitação randômica.

Esta variação, no entanto, não ocorre durante a formação do cavaco, mas sim entre a formação dos mesmos, originando, portanto, cavacos de diferentes espessuras. Isto ocorre, pois o tempo decorrido em que um grão abrasivo permanece em contato com a peça, na ordem de micro segundos, é muito menor do que o tempo de variação do sinal de excitação gerado (período da menor frequiência).

Assim, a excitação randômica reduz a distribuição de grãos dinâmica na superfície do rebolo, aumentando os valores de circularidade e rugosidade da peça, além de diminuir a potência de retificação. Este comportamento interessante faz com que o rebolo atue de forma semelhante a uma ferramenta de maiores grãos abrasivos e mais espaçados, o que pode ser interessante para operações de retificação de desbaste.

Evidentemente o aumento da espessura de cavaco em alguns grãos irá influenciar o desgaste do rebolo. Esta influência pode ser observada na Figura 5.30. 


\subsubsection{Desgaste do Rebolo}

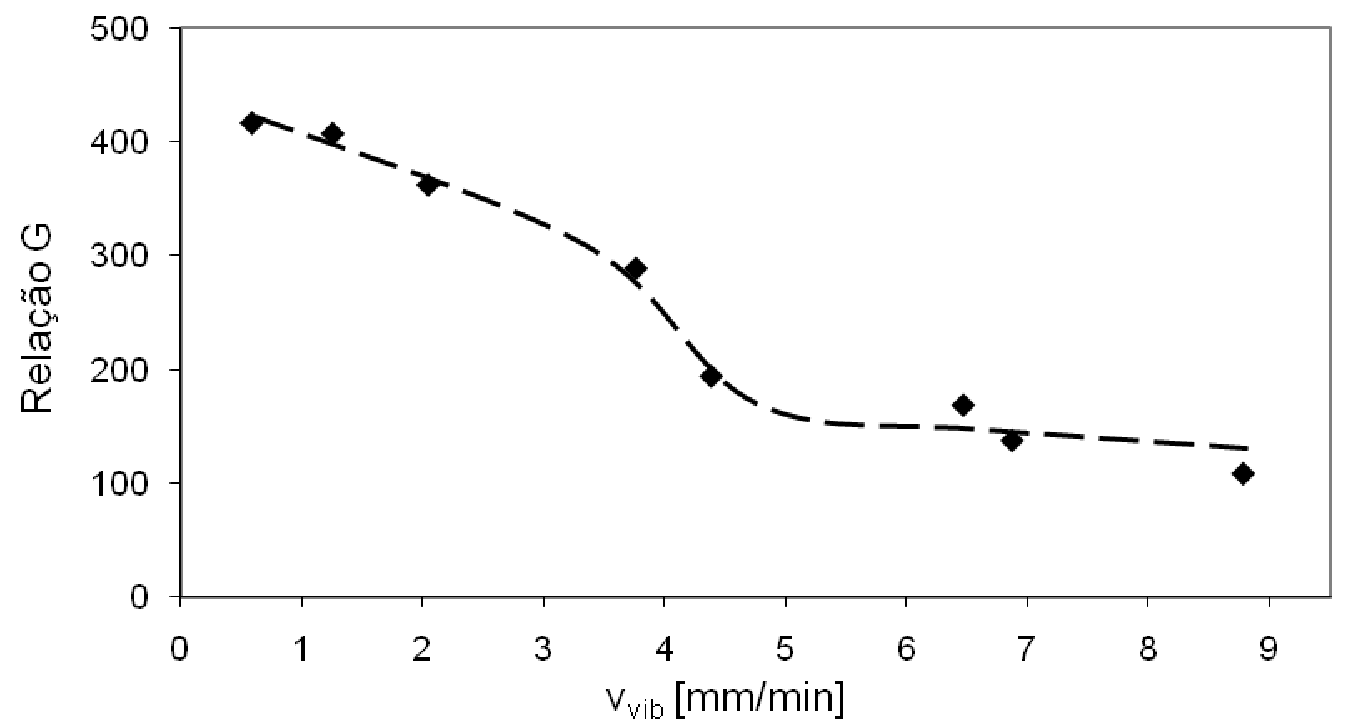

Figura 5.30 - Relação $G$ versus velocidade de vibração $\left(v_{v i b}\right)$.

A curva de tendência da Figura 5.30 possui o mesmo comportamento das curvas presentes nas Figuras 5.4 e 5.11. Os valores de relação $G$ são muito menores nos testes com excitação forçada, pois além do corpo-de-prova possuir uma geometria de menor rigidez, a fixação do mesmo é feita apenas pela placa de três castanhas, diferentemente da montagem biengastada (entre - pontas) da Configuração 1. Conseqüentemente, a rigidez do sistema é bem menor.

Assumindo os valores de velocidade de vibração $\left(v_{v i b}\right)$ como incrementos instantâneos na velocidade de avanço $\left(v_{f}\right)$, pode-se afirmar que existe uma correlação da mesma com a força tangencial por grão $\left(F_{t 1 g}\right)$. Portanto, altas velocidades de vibração presentes no processo de retificação geram altos valores de desgaste do rebolo.

Os resultados de desgaste do rebolo obtidos nos testes anteriores sugerem que o mecanismo predominante de desgaste do rebolo do processo de retificação onde existe 
vibração forçada ou auto-excitada é de natureza mecânica e não por difusão química ou deterioração térmica.

É interessante observar que a redução de potência com aplicação de excitações ao longo do processo pode viabilizar maiores taxas de remoção num regime de desbaste. $\mathrm{O}$ desgaste do rebolo, aumentado em tais condições, poderia ser diminuído com o uso de ligas eletrolíticas. Dessa forma, abre-se a possibilidade de um processo de retificação assistido por vibrações que pode aumentar a capacidade de remoção para uma dada potência instalada.

\subsection{Ensaios Adicionais de Retificação}

Os ensaios adicionais de retificação serão apresentados de forma a mostrar alguns fenômenos observados nos testes anteriores e também apresentar uma tentativa de diminuição das vibrações durante o processo com a utilização de um amortecedor passivo.

\subsubsection{Potência de Retificação Durante a Vibração Forçada e Formação da Vibração Auto-excitada}

Após a análise dos gráficos das Figuras 5.9 e 5.28, decidiu-se por realizar um teste onde a excitação é ligada no meio do ciclo e desligada antes do final da operação. A Figura 5.31 apresenta o mapa acústico do ensaio juntamente com o gráfico de potência de corte. 


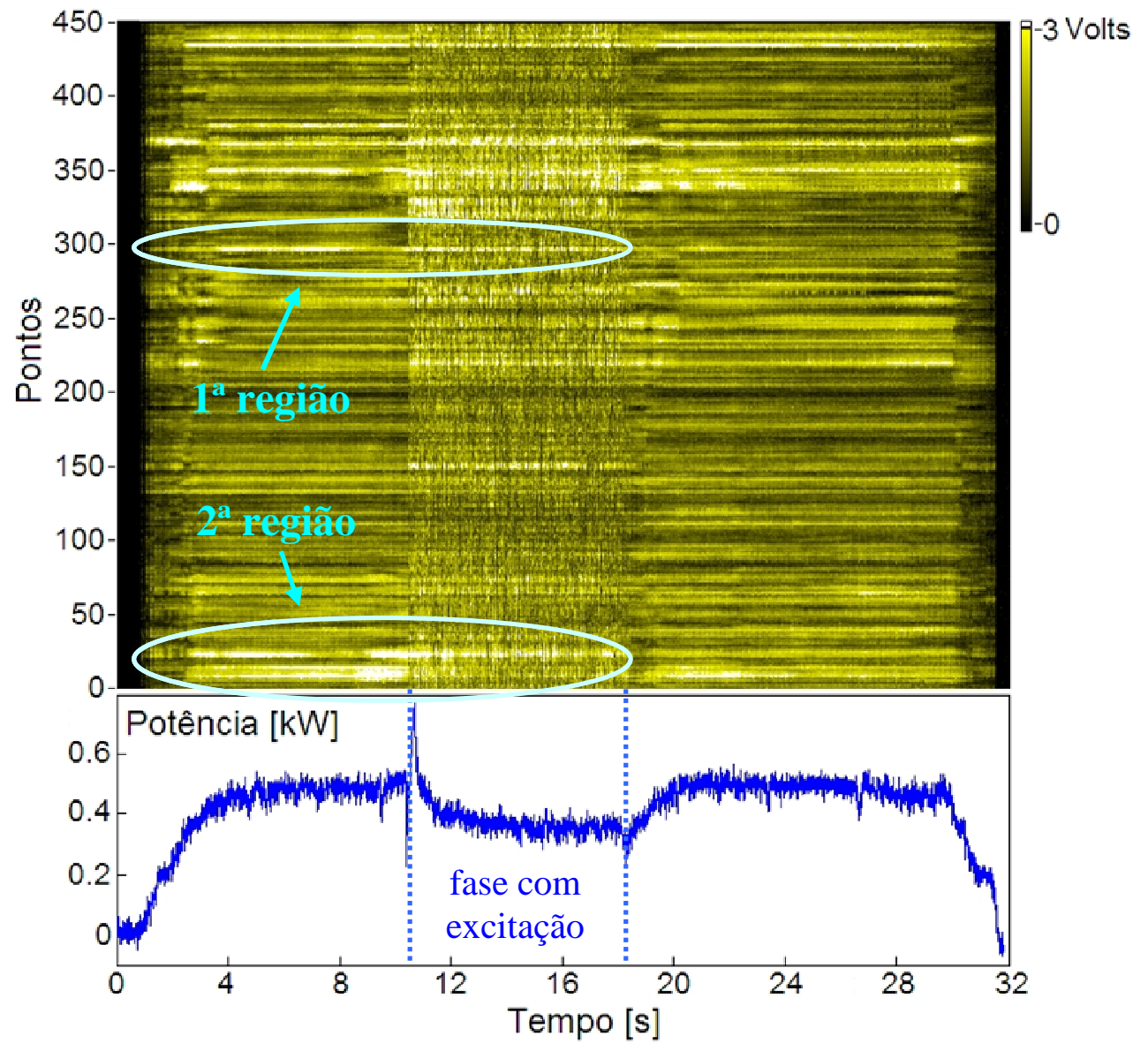

Figura 5.31 - Mapa acústico do efeito da vibração na topografia do rebolo e potência de retificação.

Observa-se na Figura 5.31 a diminuição da potência e a mudança do padrão do mapa acústico com a introdução de vibração no processo. O mapa acústico mostra que a distribuição da energia acústica durante a excitação possui um comportamento mais aleatório quando comparado com o período sem excitação.

Algumas linhas horizontais são observadas no mapa acústico da Figura 5.31. Estas linhas mais claras indicam grande intensidade de emissão acústica, devido às altas interações entre os grãos e a peça. Quando a excitação é ligada, o rebolo inicia a perda de grãos de forma mais intensa. Isto pode ser observado em algumas regiões onde existem linhas claras que se tornam mais escuras (baixa intensidade) após a fase com excitação ( $1^{\mathrm{a}}$ e $2^{\mathrm{a}}$ regiões). 
A potência de corte, como nas Figuras 5.9 e 5.28, diminui durante a excitação mostrando que o mecanismo de desgaste do rebolo nestas condições é essencialmente mecânico e conforme os resultados apresentados de desgaste do rebolo sugerem, este mecanismo é predominantemente o de fratura do ligante. Nesse caso, a aplicação de vibrações ao longo do processo funcionou como uma dressagem do rebolo, pois possibilitou a modificação da camada superficial da ferramenta. Futuras pesquisas devem ser realizadas no sentido de se avaliar a viabilidade de se anular o início da trepidação com a aplicação de vibrações aleatórias ao longo do processo, sempre que necessário.

O outro ensaio realizado mostra o aparecimento da vibração auto-excitada no processo. Neste caso, as condições de corte são as mesmas do ensaio anterior, com exceção da velocidade de corte $\left(v_{c}\right)$, igual a $30 \mathrm{~m} / \mathrm{s}$, e a excitação que ocorreu durante todo o ciclo e foi do tipo senoidal, com frequiência igual à rotação do rebolo (aproximadamente $24,5 \mathrm{~Hz}$ ). Os testes foram repetidos cinco vezes com o mesmo resultado final. A Figura 5.32 exibe o mapa acústico de um destes testes. 


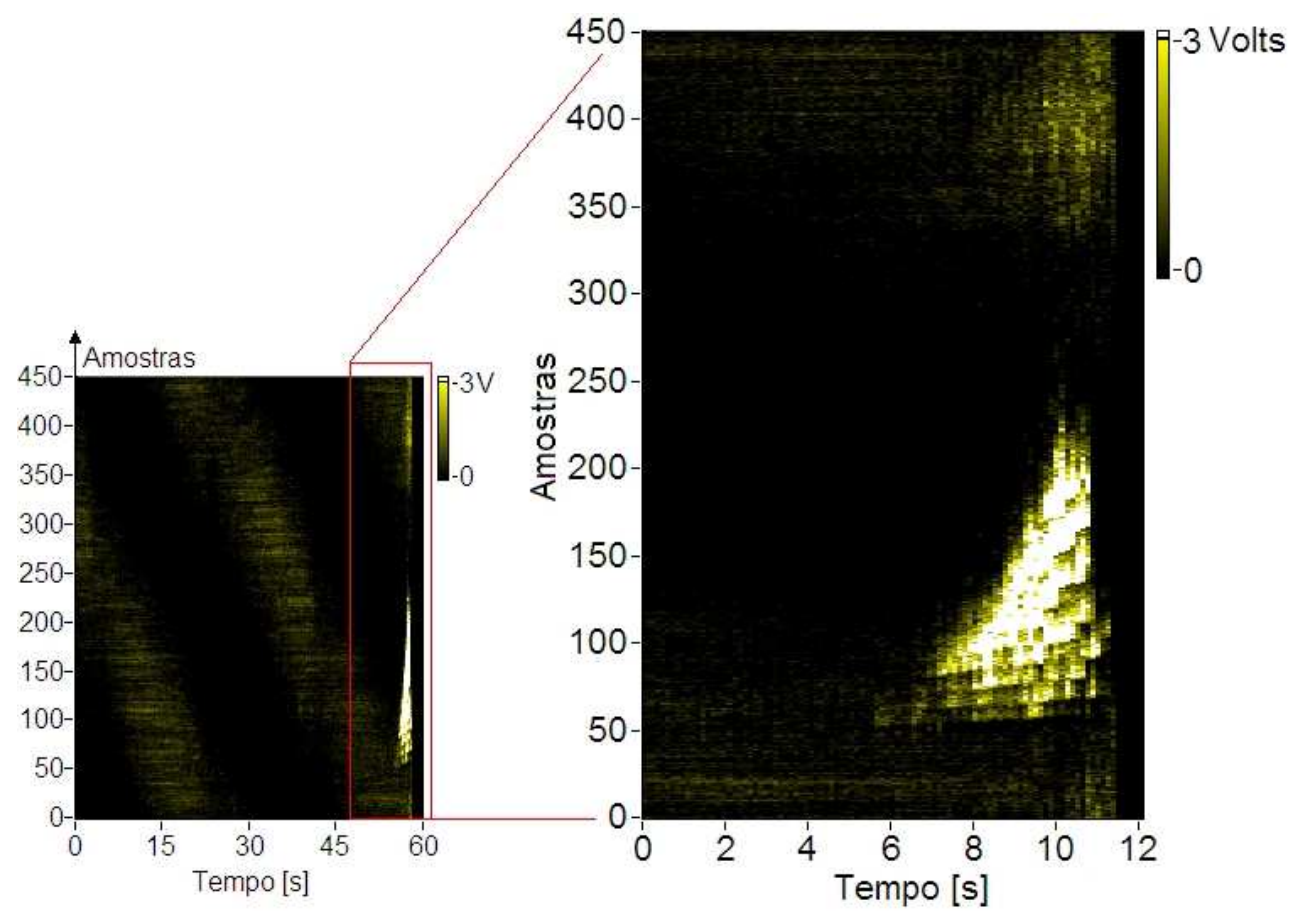

Figura 5.32 - Mapa acústico com a presença de trepidação causada pela vibração senoidal.

Para o tipo de ensaio proposto por este trabalho (retificação de peças DTG de baixa rigidez estrutural), os lóbulos formados na superfície do rebolo de $\mathrm{CBN}$ não apresentaram uma progressão lenta. Ao contrário, se iniciaram em um ponto da sua superfície e rapidamente se propagaram. $\mathrm{O}$ ciclo foi então interrompido para evitar a formação dos lóbulos por toda a circunferência da ferramenta e a sua possível quebra.

A trepidação sempre inicia em uma região com alta intensidade de emissão acústica, provavelmente causada pelo empastamento do rebolo. Além disso, quando iniciada, preenche as áreas escuras do gráfico onde não existia contato da peça com o rebolo, o que significa que vibrações forçadas periódicas podem acelerar a sua formação.

É importante notar que a quantidade de lóbulos na Figura 5.32 é 9 (número obtido da contagem em uma linha vertical - indicando uma revolução do rebolo). Se este número for multiplicado pela rotação em Hertz do rebolo temos que esta vibração ocorre a aproximadamente $220,5 \mathrm{~Hz}$, valor este muito próximo do primeiro modo de vibrar da peça. 


\subsubsection{Influência do Amortecedor Passivo na Retificação de Sede de Válvulas}

As Figuras 5.33 e 5.34 mostram os mapas acústicos da retificação de sede de válvulas realizados com e sem amortecedor passivo.

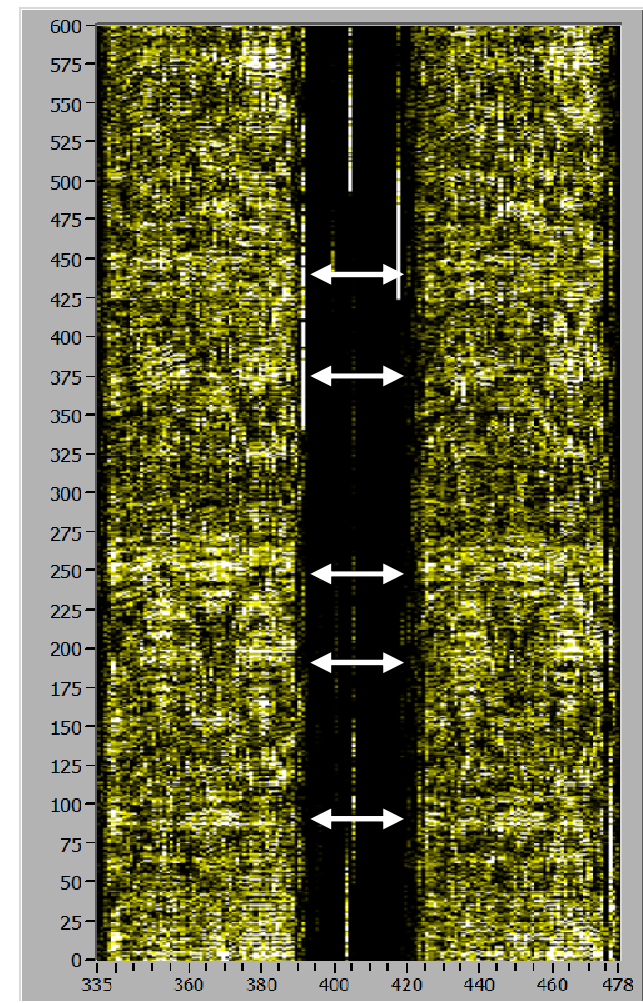

Sem Amortecimento

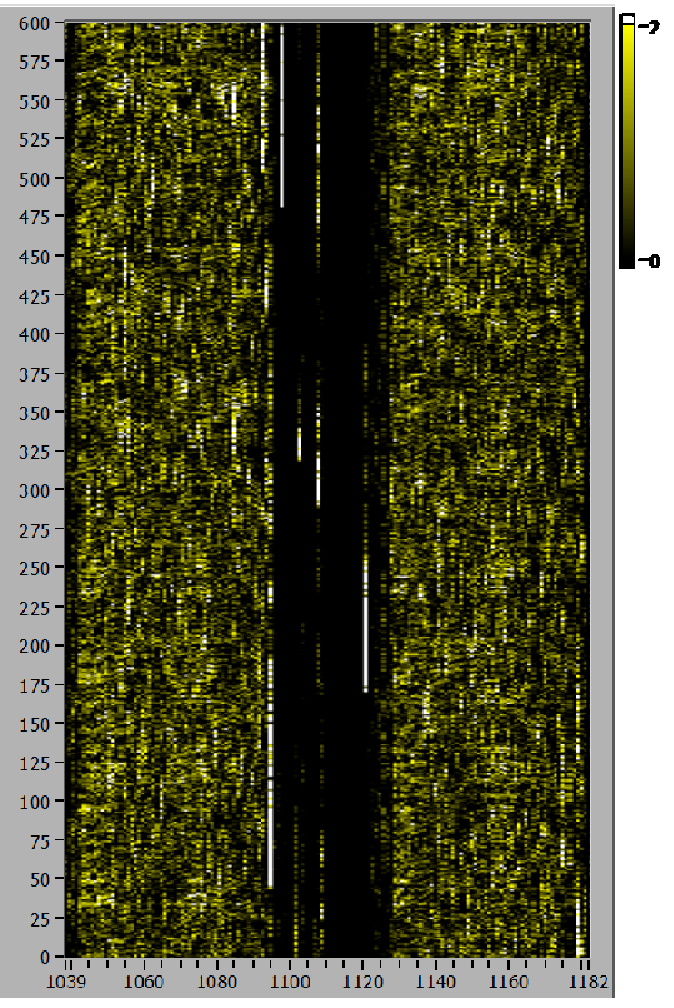

Com Amortecimento

Figura 5.33 - Mapa acústico do processo de retificação de sede de válvulas com e sem o amortecedor passivo. 


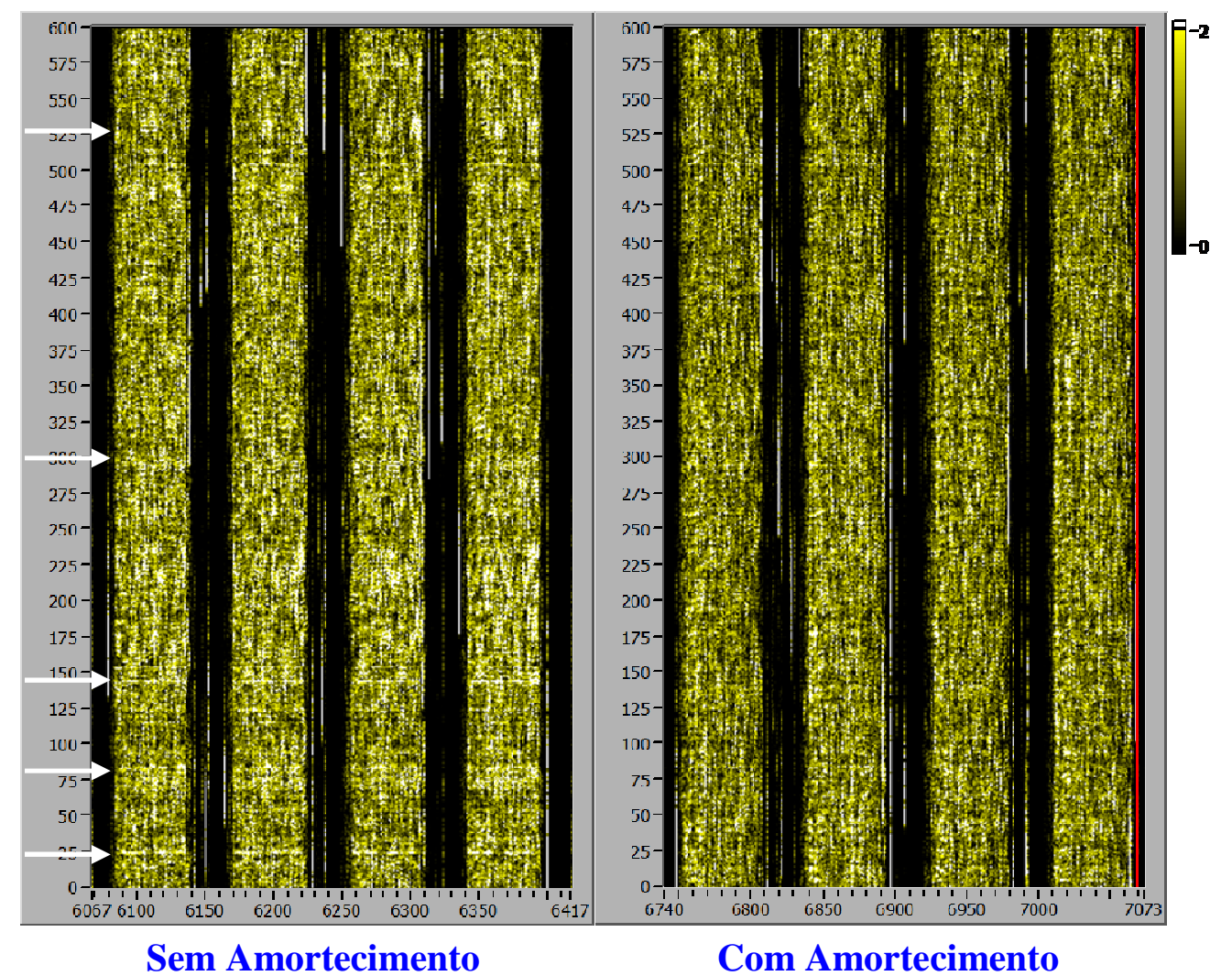

Figura 5.34 - Mapa acústico das últimas quatro válvulas antes da operação de dressagem com e sem a utilização do amortecedor passivo.

Pela análise dos mapas acústicos, pode-se afirmar que a presença do amortecedor na retificação melhora a distribuição da energia acústica do processo. Isto pode ser observado pela presença de linhas horizontais mais claras na retificação sem a utilização do amortecedor. Estas linhas mais claras estão relacionadas com o início ou a presença de vibração no processo.

Na retificação com a utilização do amortecedor passivo, estas linhas desaparecem e o mapa acústico apresenta uma melhor distribuição de energia acústica, isto indica uma interação grão-peça mais uniforme, sem a presença de vibração.

A Figura 5.35 exibe o resultado do erro médio de circularidade das últimas 30 válvulas retificadas antes da operação de dressagem do rebolo. Os testes foram realizados duas vezes para cada condição (com e sem a presença do amortecedor). 


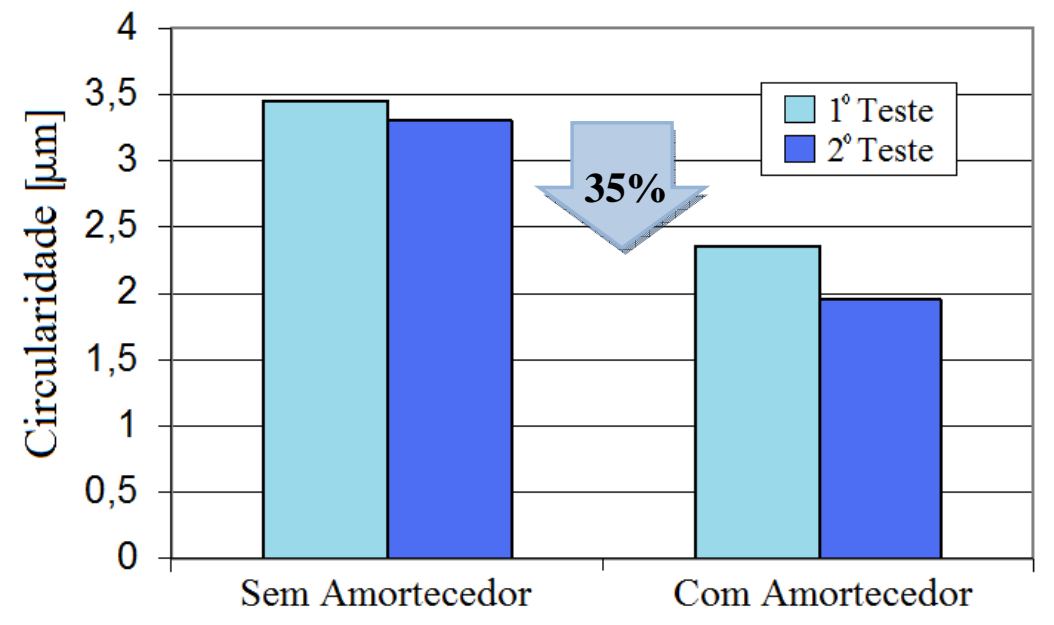

Figura 5.35 - Erro de circularidade das últimas 30 válvulas antes da operação de dressagem com e sem a utilização do amortecedor passivo.

Quando o amortecedor é utilizado, a redução nos valores de circularidade é evidente e pode representar uma melhora em diversos aspectos da operação de retificação, tais como: redução do desgaste do rebolo, aumento do número de peças retificadas entre as operações de dressagem e melhoria da qualidade superficial das peças. A diminuição média dos valores de circularidade foi de $35 \%$.

Apesar dos bons resultados, o mecanismo entrou em desuso após alguns meses devido ao desgaste excessivo do material testado no contato com a sede da válvula e à dificuldade de montagem do mesmo. 


\section{Capítulo 6}

\section{CONCLUSÃO}

Com base nos resultados obtidos desta pesquisa, pode-se concluir que:

- $\quad$ Para os ensaios sem excitação externa o mecanismo de desgaste do rebolo associado com a força de retificação é relevante quando comparado com outros tipos de mecanismos relacionados com a composição do material. Existe um valor limite de força tangencial por grão onde acima do mesmo, a relação $G$ diminui drasticamente.

- $\quad$ Nos ensaios de retificação com vibração forçada, pode-se concluir que existe uma correlação da velocidade de vibração com a força tangencial por grão, já que esta velocidade age como incrementos instantâneos na velocidade de avanço, Portanto, as altas velocidades de vibração na retificação geram altos valores de desgaste do rebolo.

- $\quad$ A excitação randômica reduz a distribuição de grãos dinâmica na superfície do rebolo, aumentando assim, os valores de circularidade e rugosidade da peça, além de diminuir a potência de retificação. A diminuição do valor da potência ocorre devido a uma mudança na cinemática do processo, induzindo uma grande variação nos valores de espessura de cavaco. Este comportamento faz com que o rebolo atue como uma ferramenta de maior grão abrasivo, o que pode ser interessante para operações de retificação de desbaste. 
- Durante a formação da trepidação na retificação de materiais DTG, os lóbulos gerados na superfície do rebolo de CBN não apresentaram uma progressão lenta. Ao contrário, se iniciaram em um ponto da sua superfície e rapidamente se propagaram.

- $\quad$ O mapa acústico foi capaz de identificar a formação da trepidação durante o processo, e também permitiu a identificação da frequiência de vibração pela contagem dos lóbulos.

- $\quad$ O mecanismo apresentado como amortecedor passivo se mostrou efetivo na diminuição das vibrações, melhorando a distribuição da energia acústica do processo e gerando efeitos benéficos à peça retificada. Este mecanismo, no entanto, deve ser aperfeiçoado para facilitar a sua montagem e manutenção. 


\section{CAPÍtulo 7}

\section{SUGESTÕES PARA TRABALHOS FUTUROS}

Com base nos estudos e conclusões apresentadas, algumas sugestões para trabalhos futuros podem ser citadas, tais como:

- A análise de outros tipos de rebolos utilizando a metodologia desenvolvida na obtenção do gráfico da relação $G$ versus força tangencial por grão $\left(F_{t l g}\right)$. A curva obtida pode ser definida como "curva característica de desgaste do rebolo" e esta pode ser utilizada na classificação de diferentes tipos de rebolo;

- $\quad$ Nos ensaios de retificação com vibração forçada, a utilização do sistema shaker-haste-mancal se mostrou eficiente, no entanto, a montagem do acelerômetro no mancal longe da sede da válvula pode modificar ligeiramente os valores medidos de aceleração. Uma alternativa é a utilização de sensores de deslocamento sem contato físico, posicionados para medição da vibração da sede da válvula;

- Utilização de atuadores piezoelétricos na texturização de peças com o intuito de adicionar funções específicas a estes componentes, como o aumento da capacidade de carga em mancais hidrostáticos; e

- Utilização de atuadores piezoelétricos na texturização de rebolos com o objetivo de otimizar o processo de retificação. 


\section{REFERÊNCIAS BIBLIOGRÁFICAS}

ALBIZURI, J,; FERNANDES, M.H.; GARITAONANDIA, I.; SABALZA, X.; URIBEETXEBERRIA, R.; HERNÁNDEZ, J.M., An active system of reduction of vibrations in a centerless grinding machine using piezoelectric actuators. International Journal of Machine Tools and Manufacture, Volume 47, Issue 10, Pages 1607-1614, 2007.

ALFARES, M. e ELSHARKAWY, A., Effect of grinding forces on the vibration of grinding machine system. International Journal of Machine Tools and Manufacture, 40/14:2003-2030, 2000 .

ALTINTAS, Y., Manufacturing Automation: Metal Cutting Mechanics, Machine Tool Vibrations, and Cnc Design. Cambridge University Press, New. York, NY, 2000.

ALTINTAS, Y. e WECK, M., Chatter stability of metal cutting and grinding. Annals of the CIRP, 53/2:619-652, 2004.

ARRILlAGA, J. e WATSON, N.R. Power System Harmonics $\left(2^{\text {nd }}\right.$ edition). John Wiley \& Sons Ltd. 412p, 2003.

BAYLIS, R.J. e STONE, B.J., The build up and decay of vibration during grinding. Annals of the CIRP, 32/1:265-268, 1983.

BAYLIS, R.J. e STONE, B.J., The effect of grinding wheel flexibility on chatter. Annals of the CIRP, 38/1:307-310, 1989.

BIANCHI, E.C., Ação da geometria teórica do cavaco no desgaste de rebolos de CBN com ligante resinóide. Tese (doutorado) - Escola de Engenharia de São Carlos, Universidade de São Paulo, São Carlos, 1992.

BIFANO, T.G. e YI, Y., Acoustic emission as an indicator of material-removal regime in glass micro-machining. Precision Engineering, 4/4:219-227, 1992.

BIFFI, M., Desenvolvimento do processo de retificação com alta velocidade em sede de válvulas de motores à combustão interna usando rebolo de $\mathrm{CBN}$ vitrificado. Dissertação 
(Mestrado em Engenharia Mecânica) - Escola de Engenharia de São Carlos - Universidade de São Paulo, São Carlos, 2003.

BRODTMANN, R.; GAST, T.; THURN, G., An optical instrument for measuring the surface roughness in production control. Annals of the CIRP, 33/1:403-406, 1984.

BUZDUGAN, G.; MIHÃILESCU, E.; RADES, M., Vibration measurement. Kluwer Academic Publishers Group (Netherlands), 1986.

BZYMEK, Z.M.; SONG, G.; HOWES, T.D.; GARRETT, R.E., Design of Flexible Grinding Wheel with Variable Hub Thickness, Trans. Of ASME, Journal of Engineering for Industry, 116/May:260-262, 1994.

CHEN, X.; ROWE, W.B. e CAI, R., Precision grinding using CBN wheels. International Journal of Machine Tools \& Manufacture 42, pp.585-593, 2002.

CHEN, X.; ROWE, W.B.; MILLS, B. e ALLANSON, D.R., Analysis and simulation of the grinding process. Part IV: Effects of wheel wear. International Journal of Machine Tools \& Manufacture 38/1-2:41-49, 1998.

CHIU, N. e MALKIN, S., Computer simulation for cylindrical plunge grinding. Annals of the CIRP, 341/1:383-387, 1993.

DAVID, C. e WARNECKC, G., A correlation between cutting process and dynamics of the machine-tool-system in grinding. Trans. NAMRI/ SME 24:51-56, 1996.

DINIZ, A.E.; CUPINI, N.L.; VILELLA, R.C., Monitoramento do processo de usinagem por emissão acústica. XI Congresso Brasileiro de Engenharia Mecânica, São Paulo, 1991.

DINIZ, A.E.; MARCONDES, F.C.; COPPINI, N.L., Tecnologia da usinagem dos materiais. 3. ed. Artliber, 244 p., 2001.

DORNFELD, D. e CAI, H.G., An investigation of grinding and wheel loading using acoustic emission. ASME, 106:28-33, 1984.

DREW, S.J.; MANNAN, M.A.; ONG, K.L.; STONE, B.J., An investigation of in-process measurement of ground surfaces in the presence of vibration. International Journal of Machine Tools \& Manufacture, 39:1841-1861, 1999.

DREW, S.J.; MANNAN, M.A.; ONG, K.L.; STONE, B.J., The measurement of forces in grinding in the presence of vibration. International Journal of Machine Tools \& Manufacture, 41:509-520, 2001.

EWINS, D.J., Modal Testing: Theory and Practice. Research Studies Press/ John Wiley \& Sons Inc., Inglaterra, 1988.

FELÍCIO, L.C., Modelagem da Dinâmica de Sistemas e Estudo da Resposta. São Carlos, SP: RiMa Editora, v.1, 567 p, 2007. 
FORTH, M., Erkennen und mindern von werkstückwelligkeiten während des außenrundschleifens, Doctoral Thesis, Universität Hannover, 1989.

GOMES, J.J.F., Identificação em processo de mecanismos de desgaste de rebolos. Tese (Doutorado em Engenharia Mecânica) - Escola de Engenharia de São Carlos - Universidade de São Paulo, São Carlos, 2001.

GONZALEZ-BRAMBILA， O.; RUBIO， E.; JAUREGUI， J.; HERRERA-RUIZ， G., Chattering detection in cylindrical grinding processes using the wavelet transform. International Journal of Machine Tools \& Manufacture, 46:1934-1938, 2006.

GOVEKAR, E.; BAUS, A.; GRADIŠEK, J.; KLOCKE, F.; GRABEC, I., A new method for chatter detection in grinding. Annals of the CIRP, 51/1:267-270, 2002.

GRADIŠEK, J.; BAUS, A.; GOVEKAR, E.; KLOCKE, F.; GRABEC, I., Automatic chatter detection in grinding. International Journal of Machine Tools \& Manufacture, 43:1397-1403, 2003.

GRAHAM, W. e VOUTSADOPOULOS, C.M., Fracture wear of grinding wheels. Int. J. Mach. Tool Des. Res., 18/2:95-103, 1978.

HAMDI, H.; DURSAPT, M.; ZAHOUANI, H., Characterization of abrasive grain's behavior and wear mechanisms. Wear, 254:1294-1298, 2003.

HASHIMOTO, F.; KANAI, A.; MIYASHITA, M., Growing mechanism of chatter vibrations in grinding processes and chatter stabilization index of grinding wheel, Annals of the CIRP, 33/1:259-263, 1984.

HASSUI, A.; DINIZ, A.E.; OLIVEIRA, J.F.G.; FELIPE, J.; GOMES, J.J.F., Experimental evaluation on grinding wheel wear through vibration and acoustic emission. Wear, 217:7-14, 1998.

HITCHINER, M.P., Precision grinding systems for production grinding with vitrified CBN. SME Technical paper MR90/507:1-11, 1990.

HITCHINER, M.P., Technological advances in creep feed grinding of superalloys with CBN. In: 3rd International Machining and Grinding Conference SME, Cincinnati, Ohio, October 47, 1999.

HITCHINER, M.P., Advantages in production grinding with $\mathrm{CBN}$ and their influence on machine tool design. Saint Gobain Grinding Conference, São Carlos, São Paulo, em CD, 2001.

HITCHINER, M.P. e WILKS, J., Some Remarks on the chemical wear of diamond and cubic BN during turning and grinding. Wear, 114:327-338, 1987. 
HONG, S.K.; NAKANO, Y.; KATO, H., Improvement of dynamic characteristics of cylindrical grinding machines by means of dynamic dampers. Proc. of the 1st Int. Conf. on New Manufacturing Technology, Chiba, Japan, p.413-418, 1990.

HORIUCHI, O. e KOJIMA, H., A new liquid-injection type automatic balancer for the grinding wheel (in Japanese). JSPE, 52/2:713-718, 1986.

HOSHI, T.; MITSUI, S.; HORIUCHI, O., A method for controlling vibration in plunge-cut cylindrical grinding (in Japanese). JSPE 53/6:940-945, 1987.

HUNDT, W.; LEUENBERGER, D.; REHSTEINER, F., An approach to monitoring of the grinding process. Annals of the CIRP, 43/1:295-298, 1994.

INASAKI, I., Selbsterregte ratterschwingungen beim schleifen, methoden zu ihrer unterdrückung, Werkstatt und Betrieb, 110/8:521-524, 1977.

INASAKI, I; KARPUSCHEWSKI, B.; LEE, H.-S., Grinding chatter - origin and suppression. Annals of the CIRP, 50/2:515-534, 2001.

INASAKI, I. e OKAMURA, K., Monitoring of dressing and grinding processes with acoustic emission signals. Annals of the CIRP, 34/1:277-280, 1985.

INASAKI, I.; TONSHOFF, H.K.; HOWES, T.D., Abrasive machining in the future. Annals of the CIRP, 42/2:723-732. 1993.

ISHIKAWA, T.; KUMAR, K.V., Conditioning of Vitrified Bond Superabrasive Wheels, SME MR910172, 1991.

JACKSON, M.J.; DAVIS, C.J.; HITCHINER M.P.; MILLS, B., High-speed grinding with CBN grinding wheels - applications and future technology. Journal of Materials Processing Technology, 110/1:78-88(11), 2001.

JACKSON, M.J. e MILLS, B., Microscale wear of vitrified abrasive materials. Journal of Materials Science, 39:2131-2143, 2004.

JEMIELNIAK, K., Some aspects of acoustic emission signal processing. CIRP January Meeting, STC Cutting, Paris, pp. 1-8, 1997.

KLOCKE, F.; BRINKSMEIER, E.; EVANS C.; HOWES, T., INASAKI, I., MINKE, E., TÖENSHOFF, H.K., WEBSTER, J.A., STUFF, D., High-speed grinding - fundamentals and state of the art in Europe, Japan, and the USA. Annals of the CIRP, 46/2:715-724, 1997.

KLUFT, W., A monitoração dos processos reduz custos e desperdícios. Revista Máquinas \& Metais, 10:60-80, 1994.

KOHLI, S. P.; GUO, C.; MALKIN, S., Energy partition for grinding with aluminum oxide and CBN abrasive wheels. ASME Journal of Engineering for Industry, 117:160-168, 1995. 
KÖNIG, W e KLOCKE, F., Fertingungsverfahren (Band 2): Schleifen, Honen, Läpen. VDI Verlag Duesseldorf, 1996.

KOPAK, J. e KRAJNIK, P., High-performance grinding - A review. Journal of Materials Processing Technology, 175:278-284, 2006.

LAVINE, A. S.; MALKIN, S.; JEN, T. C., Thermal aspects of grinding with CBN abrasives. Annals of the CIRP, 38/1:557-560, 1989.

LYONS, R.G. Understanding Digital Signal Processing. Boston: Addison Wesley Longman, 1997.

MCFARLAND, D.M.; BAILEY, G.E.; HOWES, T.D., D.M., The design and analysis of a polypropylene hub CBN wheel to suppress grinding chatter. J. Manuf. Sci. Eng., ASME 1211, pp. 28-31, 1999.

MALKIN, S., Current trends in CBN grinding technology. Annals of the CIRP, 34/1:557-560, 1985.

MALKIN, S., Grinding technology: theory and aplications of machining with abrasives. 1.ed. Chichester, Ellis Horwood Limited, 1989.

MANNAN, M.A.; DREW, S.J.; STONE, B.J., Torsional vibration effects in grinding? Annals of the CIRP, 49/1:249-252, 2000.

MANNAN, M.A.; FAN, W.T.; STONE, B.J., The effects of torsional vibration on chatter in grinding. Journal of Materials Processing Technology, 89-90:303-309, 1999.

MARTIN, K. e YEGENOGLU, K., HSG Technologie - Handbuch zur praktischen anwendung, Geuhring Automation GmbH, Stetten a.k.M.-Ffronstetten, Germany, 1992.

MCCONNELL, K.G., Vibration testing: theory and practice. Wiley-Interscience, New York, 606 pp., 1995.

OLIVEIRA, J.F.G.; BIANCHI, E.C.; SOUZA, G.F., O desempenho de rebolos pode ser controlado pela dressagem. Revista Máquina \& Metais, 317:12-25, 1992.

OLIVEIRA, J.F.G.; DORNFELD, D.A., Application of AE contact sensing in reliable grinding monitoring, Annals of the CIRP, 50/1:217-220, 2001.

OLIVEIRA, J.F.G.; SILVA, E.J.; BIFFI, M., New architecture control system for an intelligent high speed grinder. Abrasives Magazine, October, 2002.

OLIVEIRA, J.F.G.; SILVA, E.J.; GUO, C.; HASHIMOTO, K., Industrial Challenges in Grinding. Annals of the CIRP, No Prelo, 2009.

OLIVEIRA, J.F.G.; FRANÇA, T.V.; WANG, J.P. Experimental analysis of wheel/workpiece dynamic interactions in grinding. Annals of the CIRP, 57/1:329-332, 2008. 
ORYŃSKI, F. e PAWŁOWSKI, W., The influence of grinding process on forced vibration damping in headstock of grinding wheel of cylindrical grinder. International Journal of Machine Tools \& Manufacture, 39:229-235, 1999.

ORYŃSKI, F. e PAWŁOWSKI, W., The mathematical description of dynamics of the cylindrical grinder. International Journal of Machine Tools \& Manufacture, 42:773-780, 2002.

ORYŃSKI, F. e PAWŁOWSKI, W., Simulation and experimental research of the grinder's wheelhead dynamics. Journal of Vibration \& Control, 10:915-930, 2004.

RAMESH, K.; LEWIS, W.G.; YUI, A.; HUANG, H., Enhancing truing ratio and dressing performance of high speed vitrified CBN wheels using speed reversal method. Grinding \& Abrasives Magazine, August/September, 2005.

ROWE, W.B.; EBBRELL, S.; MORGAN, M.N., Process Requirements for Cost-Effective Precision Grinding. Annals of the CIRP, 53/1:255-258, 2004.

SEXTON, J.S. e STONE, B.J., The Development of an ultrahard abrasive grinding wheel which suppresses chatter, Annals of the CIRP, 30/1:215-218, 1981.

SILVA, E.J., Análise de estratégias de retificação de virabrequins automotivos forjados utilizando rebolos de CBN vitrificados em altas velocidades. Tese (doutorado) - Escola de Engenharia de São Carlos, Universidade de São Paulo, São Carlos, 2004.

SOARES, D.D. e OLIVEIRA, J.F.G., Diagnóstico de processos de retificação pela análise de sinais. Revista Máquina \& Metais, 436:140-157, 2002.

STETIU, G. e LAL, G.K., Wear of grinding wheels. Wear, 30:229-236, 1974.

SWEENEY, G.; LAMB, E.J.; LIMB, M.E., A rig to investigate both cylindrical and external grinding under steady and vibration conditions and some preliminary results appertaining to vibrational grinding as a production technique. Int. J. Mach. Tool Des. Res., 10:161-178, 1970.

TAKAGI, J. e LIU, M., Fracture characteristics of grain cutting edges of CBN wheel in truing operation. Journal of Materials Processing Technology, 62/4:397-402, 1996.

TAWAKOLI, T., Requirements for high-efficiency deep grinding. Industrial Diamond Review, 50/539:177-182, April, 1990.

TAWAKOLI, T., High efficiency deep grinding. Mechanical Engineering. Pub.l. London. ISBN 085298820 6, 1993.

TELLBÜSCHER, E., Konstruktion von dämpfern und deren einsatz an rundschleifmaschinen, Doctoral Thesis, TH Aachen, 1986.

TÖNSHOFF, H.K.; FRIEMUTH, T.; BECKER, J.C., Process monitoring in grinding. Annals of the CIRP, 51/2:551-571, 2002. 
TÖNSHOFF, H. K. e GRABNER, T., Cylindrical and profile grinding with boron nitride wheels. Proceedings of the 5th International Conference on Production Engineering, Tokyo, p.326-343, 1984.

TÖNSHOFF, H.K. e INASAKI, I., Sensors in manufacturing. Wiley-VCH publisher, 2001.

TSO, P.L., Study on the grinding of Inconel 718. Journal of Materials Processing Technology, 55:421-426, 1995.

VAN VLACK, L.H., Princípios de ciência e tecnologia dos materiais, Tradução de Edson Monteiro, 11ª Edição, Editora Campus, Rio de Janeiro, Brasil, 1984.

VANSEVENAT, I. R. E., An improved mathematical model to predict residual stresses in surface plunge grinding. Annals of the CIRP, 36/1:413-416, 1989.

VIEIRA J.M.; LIBARDI, R.; CANCILIERI, H.A.; LIMA, A., Como o calor pode afetar a integridade superficial das peças. Revista Máquina \& Metais, 397:28-36, 1999.

VIEIRA, J.M. e OLIVEIRA, J.F.G., Monitoring of plunge center-less grinding through acoustic emission. Abrasives Magazine, December/January, 2002.

WANG, J.P., Avaliação do Desempenho de Rebolo de CBN na Retificação de Ligas de Alto Desempenho. Dissertação (Mestrado em Engenharia Mecânica) - Escola de Engenharia de São Carlos - USP, 2008.

WANG, Z.; WILlETT, P.; AGUIAR, P.R.; WEBSTER, J., Neural network detection grinding burn from acoustic emission. International Journal of Machine Tools \& Manufacture, 41:283-309, 2001.

WEBSTER, J., Selection on coolant type and application technique in grinding. Supergrind, p.205-218, 1995.

WEBSTER, J.; MARINESCU, I.; BENNET, R., Acoustic emission for process control and monitoring of surface integrity during grinding. Annals of the CIRP, 43/1:299-304, 1994.

WECK, M. e BRECHER, C., The Essential Difference of the Chatter Phenomena between Processes with Defined and Undefined Cutting Edges. Technical Presentation in CIRP-STC "G,", Paris, 2001.

WECK, M.; HENNES, N.; SCHULZ, A., Dynamic behavior of cylindrical traverse grinding processes. Annals of the CIRP, 50/1:213-216, 2001.

WEINGAERTNER, W.L. e SEVERIANO, A.C., Desenvolvimento de rebolos superabrasivos. Disponível em: 〈http://www.usinagem-brasil.com.br>. Acesso em: março, 2006.

WERNER, G., High-eficiency deep grinding (HEDG) - Eine neue variante des Hochleistungsschleifens verbindet das hochgeschwindigkeits- und tiefschleifen, Deutsches Industrieforum fur technologie, Germany, 1995. 
WERNER, G. e TAWAKOLI, T., High-efficiency deep grinding with CBN. Industrial Diamond Review, 48/526:124-128, 1988.

XUE, L.; NAGHDY, F.; COOK, C., Monitoring of wheel dressing operations for precision grinding. Industrial Technology, IEEE ICIT '02. 2002 IEEE International Conference, 2:12961299, 2002.

YUI, A. e LEE, H., Surface grinding with ultra high speed CBN wheel. Journal of Materials Processing Technology, 62, p.393-396, 1996. 


\section{ANEXO}

\section{PESQUISAS ORIGINADAS DESTE TRABALHO}

Duas frentes de pesquisa se originaram deste trabalho de doutorado, são estas: Texturização de rebolos; e Análise da rugosidade em relação à profundidade de dressagem e à vibração no processo de retificação. Estas pesquisas foram temas de trabalhos de iniciação científica dos alunos Alex Camilli Bottene e Rafael Saia, respectivamente. Os trabalhos, em fase de investigação inicial, foram realizados utilizando uma bancada semelhante à utilizada nesta pesquisa e tiveram participação direta do aluno de doutorado.

A técnica desenvolvida no primeiro trabalho está sendo patenteada (patente nacional) e recebeu o número de registro P.I. 0.804.585-2 junto ao Instituto Nacional da Propriedade Industrial (INPI), tendo o seu pedido publicado na Revista da Propriedade Industrial - RPI N . 1998, página 81, item 2.1 (NOTIFICAÇÃO DE DEPÓSITO DE PEDIDO DE PATENTE).

Serão apresentados os objetivos destes trabalhos assim como alguns resultados dos mesmos.

\section{Texturização de Rebolos}

Este trabalho teve como objetivo produzir texturas controladas na superfície de peças cilíndricas metálicas durante o processo de retificação, utilizando para isto um rebolo de superfície previamente condicionada por um excitador eletrodinâmico responsável por alterar 
a profundidade de dressagem durante o processo de afiação do rebolo. Desta forma, a textura realizada no rebolo por meio do processo de dressagem é transmitida para a peça durante o processo de retificação da mesma.

A bancada de testes (Figura 1) é composta por um atuador (shaker) que movimenta o dressador de ponta única e gera marcas padronizadas em um rebolo de óxido de alumínio, software de comando do atuador e software de monitoramento de operação.

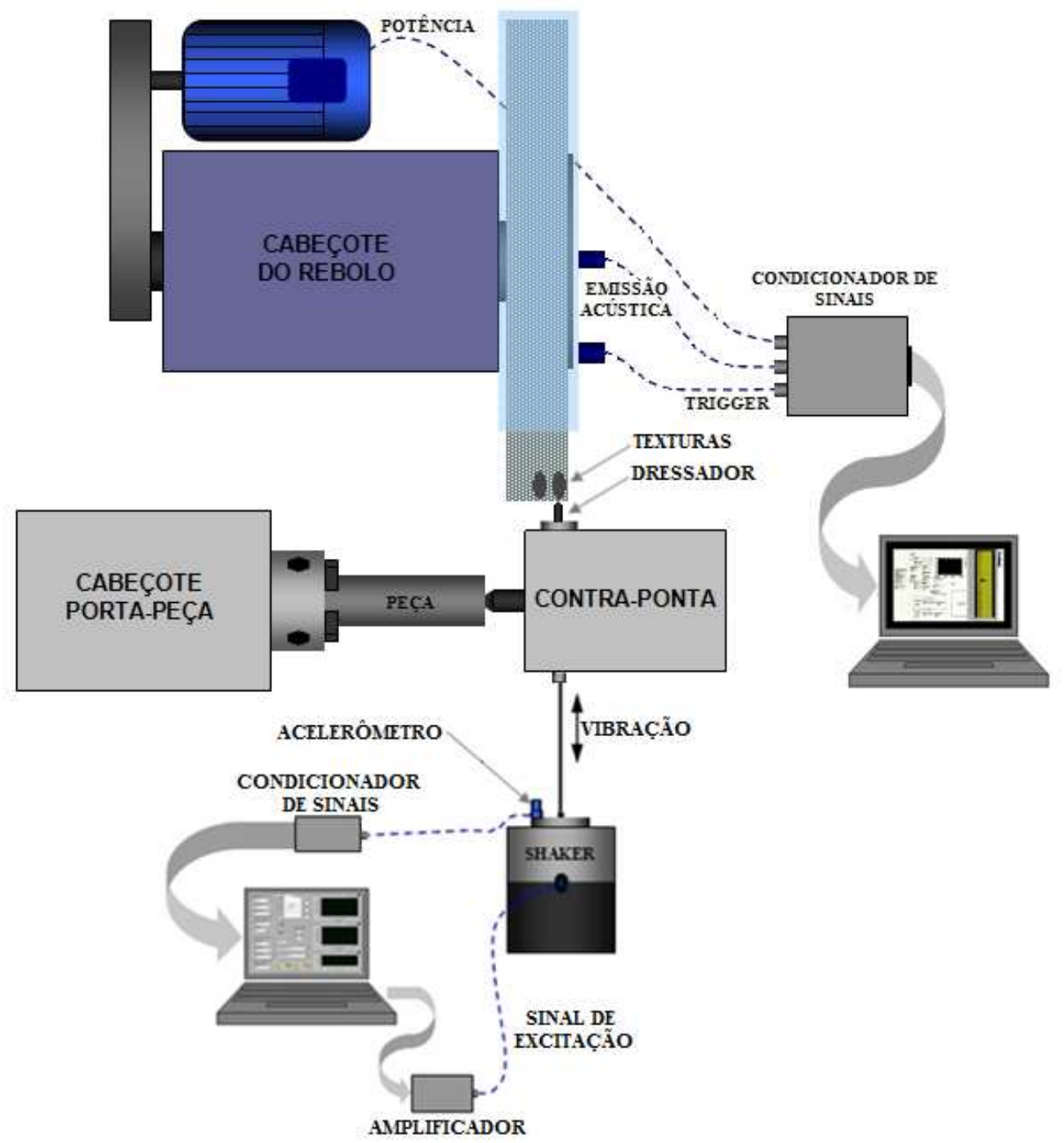

Figura 1 - Bancada de testes utilizada para a texturização de rebolos. 
O software de comando do atuador é responsável pelo envio do sinal (com o padrão de textura selecionado) para o shaker de forma sincronizada com a rotação do rebolo e velocidade longitudinal de dressagem.

Esta técnica permite a criação de variados padrões de texturização, podendo ser utilizada em diversas aplicações de acordo com as especificações do produto final. Dentre alguns exemplos de aplicação, pode-se citar a retificação de canais de lubrificação em mancais e camisas de pistão, ou ainda a texturização de cilindros de laminação para criação de padrões em chapas metálicas. A Figura 2 exibe alguns mapas acústicos dos padrões obtidos na superfície do rebolo durante a dressagem.
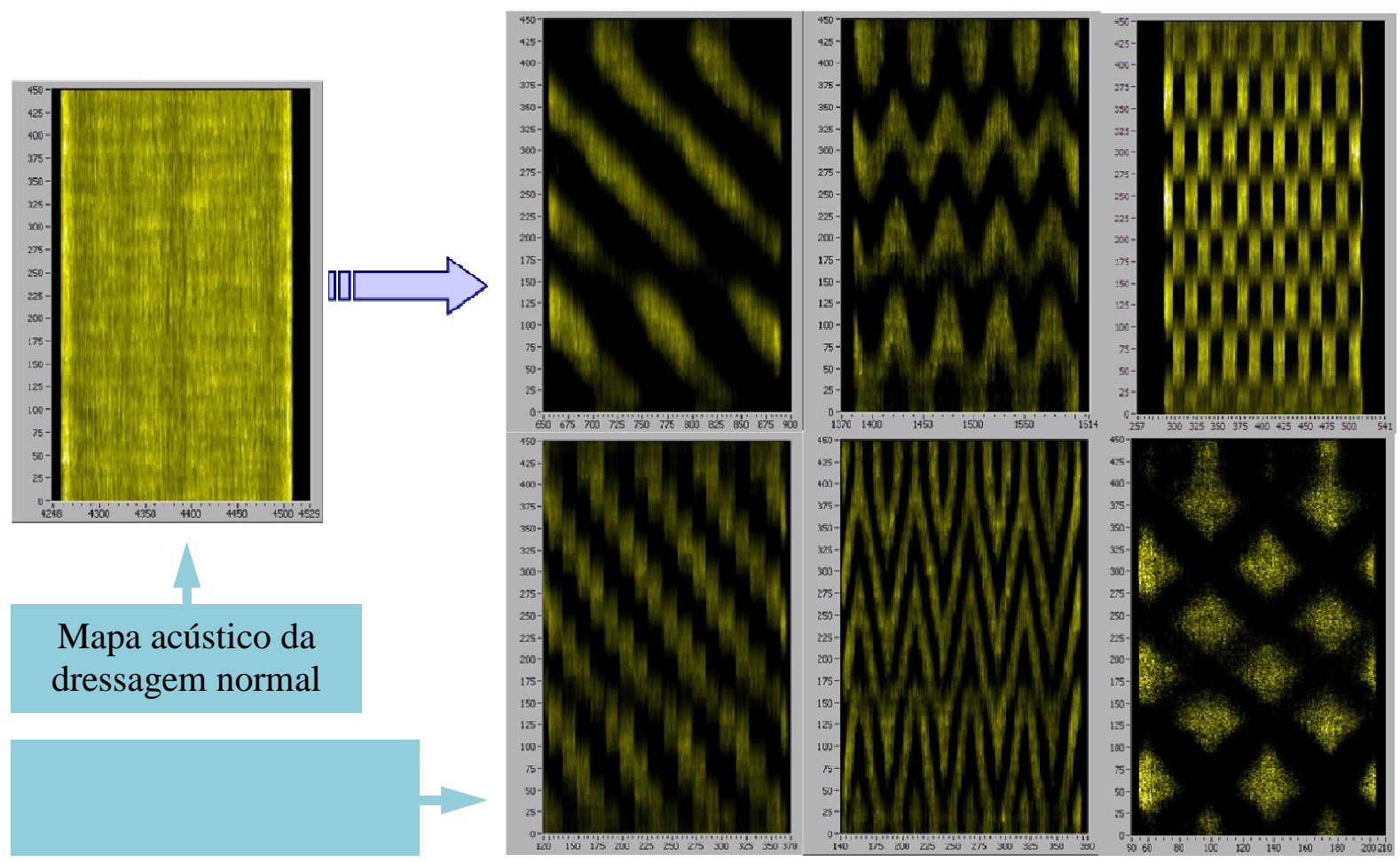

Figura 2 - Mapas acústicos da operação de dressagem com diferentes padrões.

Após a dressagem, e a conseqüente texturização do rebolo, inicia-se o processo de retificação para que o padrão inscrito na circunferência do rebolo seja transmitido para a 
superfície da peça. A Figura 3 exibe algumas peças texturizadas obtidas da operação de retificação.

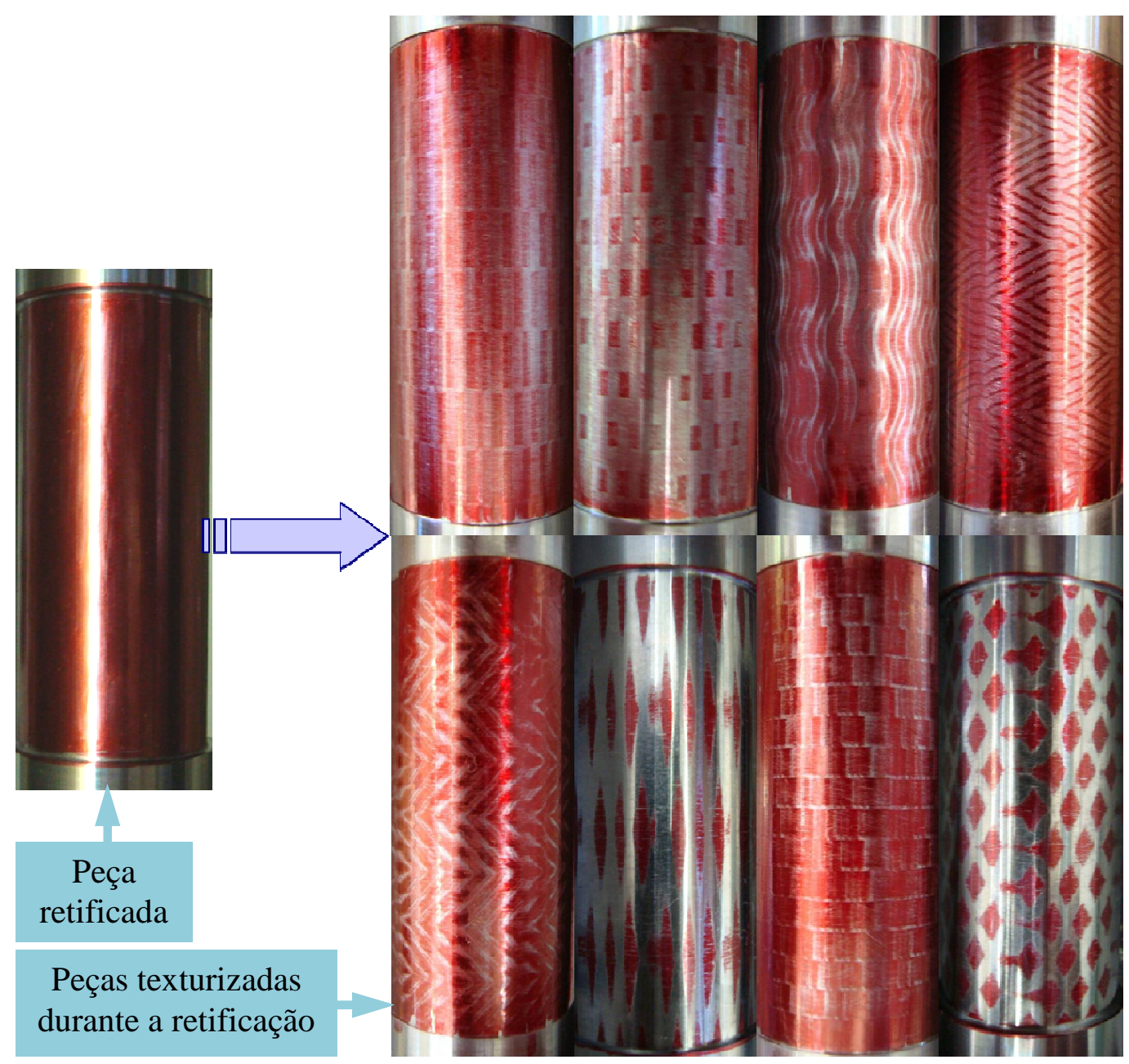

Figura 3 - Fotos das peças texturizadas durante a retificação com diferentes padrões.

Os resultados possibilitaram a validação da metodologia empregada no desenvolvimento desta nova técnica de retificação. O sistema utilizado para texturização do rebolo, composto pelo excitador eletrodinâmico (shaker), permitiu com sucesso a inscrição das texturas pré-determinadas na superfície do rebolo durante a operação de dressagem e a seguida transferência destas para a circunferência da peça no processo de retificação. 
No entanto, a utilização do shaker como atuador gera um processo pouco preciso e de baixa resolução. Desta forma, os próximos passos terão como objetivo a utilização de atuadores piezoelétricos, com a finalidade principal de possibilitar uma ferramenta robusta para aplicações industriais. Além disso, outros estudos de desenvolvimento e aplicação da técnica serão realizados.

\section{Estudo da Dressagem com Vibração Forçada na Rugosidade de Peças Retificadas}

Este projeto de pesquisa tem como foco principal o estudo da influência da vibração randômica durante a dressagem na rugosidade da peça retificada. Para isto, o comportamento da rugosidade de peças retificadas foi analisado em diversas condições de dressagem com e sem excitação randômica forçada.

Outro importante objetivo é a comparação do desempenho dos dois tipos de dressadores: fliese e ponta única. Deseja-se analisar como cada um deles afeta a agressividade do rebolo e como são influenciados pela vibração randômica.

A bancada de testes utilizada neste trabalho é semelhante à da texturização de rebolos exibida na Figura 1. A diferença está no tipo de excitação do sistema composto pelo excitador eletrodinâmico. A excitação utilizada foi do tipo randômica e o software que controla o shaker é o mesmo utilizado na Configuração 2 e 3 desta tese.

Os parâmetros de dressagem e retificação utilizados nesta pesquisa podem ser observados nas Tabelas 1 e 2 . Na dressagem, foram utilizados duas profundidades $\left(a_{d}\right)$ diferentes com os respectivos valores da largura de atuação do dressador $\left(b_{d}\right)$ medidos em um microscópio equipado com câmera fotográfica para o cálculo do grau de recobrimento $\left(U_{d}\right)$. 
Tabela 1 - Parâmetros de dressagem dos ensaios.

\begin{tabular}{|c|c|}
\hline \multicolumn{2}{|c|}{ Parâmetros de Dressagem } \\
\hline Profundidade de dressagem $\left(a_{d}\right)$ & 10 e $30 \mu \mathrm{m}$ \\
\hline Tipo de dressador & Fliese e ponta única \\
\hline Velocidade do rebolo $\left(v_{s}\right)$ & $45 \mathrm{~m} / \mathrm{s}$ \\
\hline Grau de recobrimento $\left(U_{d}\right)$ & 1,3 e 6 \\
\hline
\end{tabular}

Tabela 2 - Parâmetros de retificação dos ensaios.

\begin{tabular}{|c|c|}
\hline \multicolumn{2}{|c|}{ Parâmetros de Retificação } \\
\hline Rebolo de $\mathrm{Al}_{2} \mathrm{O}_{3}$ vitrificado & 38A 80 KVHB \\
\hline Corpos-de-prova & ABNT 4340 (temperado, 48 HRc) \\
\hline Velocidade de avanço $\left(v_{f}\right)$ & $0,6 \mathrm{~mm} / \mathrm{min}$ \\
\hline Velocidade de corte $\left(v_{c}\right)$ & $60 \mathrm{~m} / \mathrm{s}$ \\
\hline Rotação da peça $\left(n_{w}\right)$ & $200 \mathrm{rpm}$ \\
\hline Largura de retificação $(b)$ & $10 \mathrm{~mm}$ \\
\hline Número de ciclos por ensaio & 1 \\
\hline Sobremetal & $0,7 \mathrm{~mm}$ \\
\hline Tempo de centelhamento $($ spark-out $)$ & 3 segundos \\
\hline Fluido de corte & Fluido de corte semi-sintético $(5 \%)$ \\
\hline
\end{tabular}

A medição da rugosidade foi realizada com os mesmo parâmetros e equipamentos descritos no item 4.7 desta tese.

Os gráficos com os resultados obtidos das medições são apresentados nas Figuras 4 e 5. 


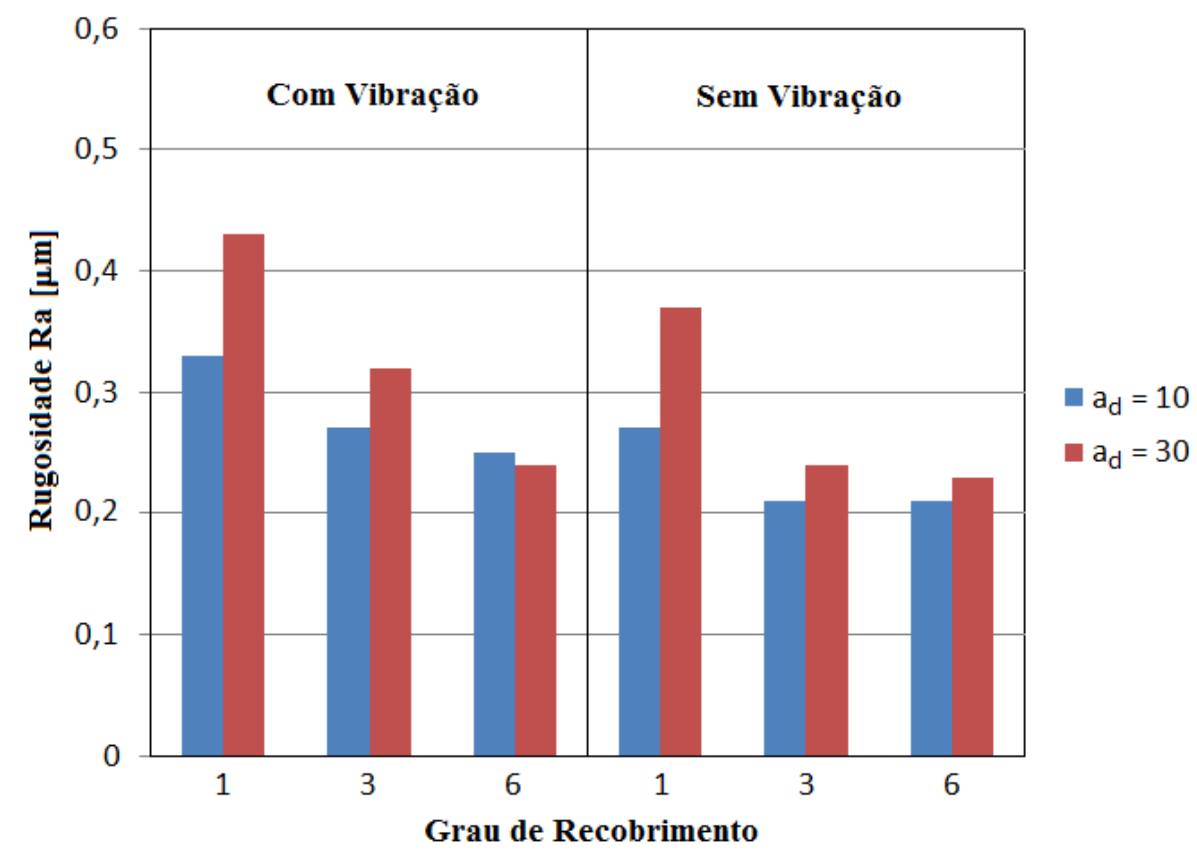

Figura 4 - Resultados dos ensaios realizados com o dressador tipo ponta-única.

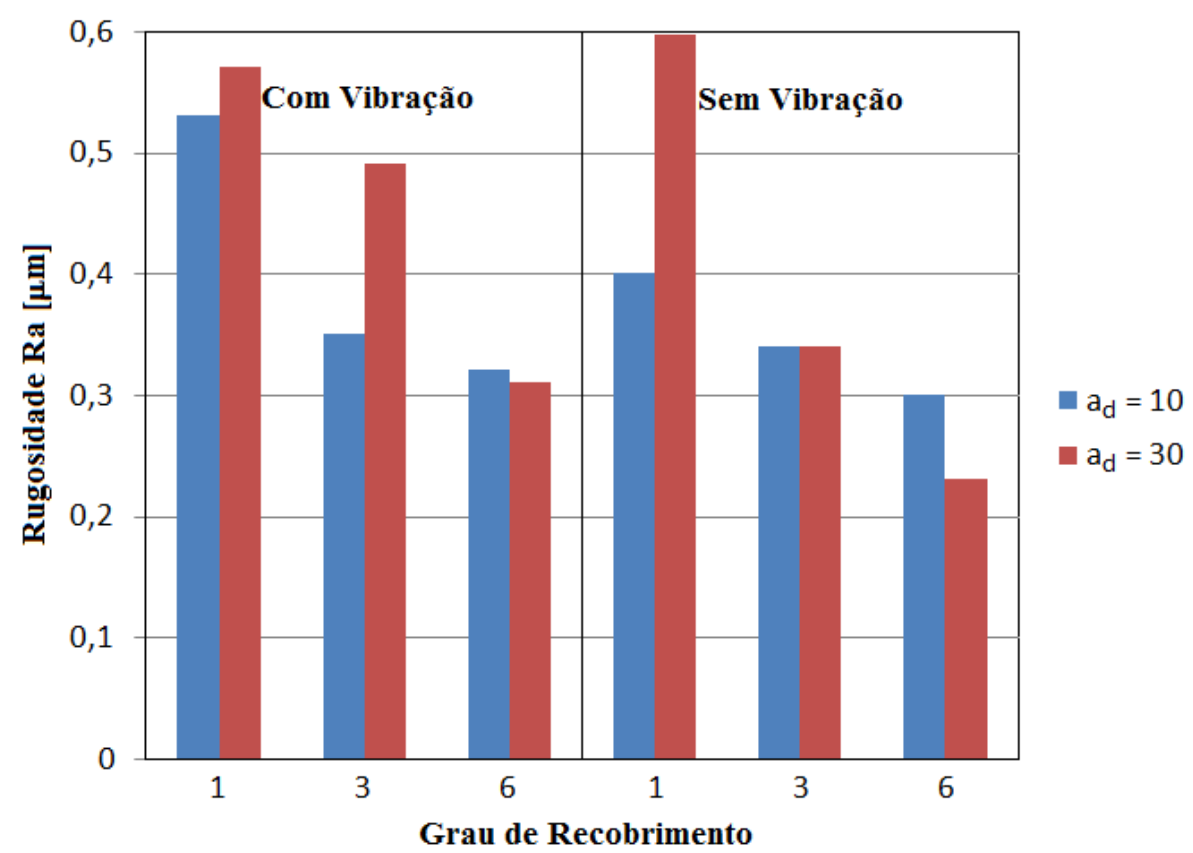

Figura 5 - Resultados dos ensaios realizados com o dressador tipo fliese.

Primeiramente, uma análise geral de todos os gráficos mostra que rugosidades menores são atingidas com valores de grau de recobrimento $\left(U_{d}\right)$ elevados. Além disso, o aumento da profundidade de dressagem $\left(a_{d}\right)$ piora a rugosidade das peças, no entanto este 
comportamento é relevante apenas para valores de $U_{d}$ próximos a 1 . Verifica-se que o dressador do tipo fliese deixou o rebolo mais agressivo nos dois casos (com e sem vibração).

Os valores de rugosidade das peças retificadas após a dressagem com vibração forçada são nitidamente maiores que os valores resultantes da dressagem sem vibração. A amplitude de vibração gerada pelo software, em freqüências variadas, acarreta uma variação da força atuante em cada grão abrasivo.

Desta forma, a profundidade e o passo de dressagem sofrem variações aleatórias durante o processo gerando uma superfície mais agressiva em relação à dressagem sem vibração.

Uma análise geral dos resultados sugere que a dressagem com vibração forçada aumenta a capacidade de corte do rebolo. Esta afirmação é consistente com os resultados da rugosidade, já que quanto mais agressivo é o rebolo maior será a rugosidade das peças retificadas. No teste com o dressador de ponta única, $U_{d}=3$ e $a_{d}=30 \mu \mathrm{m}$, a vibração aumentou a rugosidade em $33 \%$. Já com o uso do dressador do tipo fliese, $U_{d}=3$ e $a_{d}=30$ $\mu \mathrm{m}$, a vibração aumentou a rugosidade em $44 \%$.

O estudo conclui que é possível aumentar a faixa de utilização de rebolos, deixando o processo mais flexível. Por exemplo, quando se deseja aumentar a capacidade de corte do rebolo, sem a necessidade de rugosidades muito baixas, como em operações de desbaste, a presença de vibração durante a dressagem pode ser utilizada como recurso, evitando a troca do rebolo por um mais agressivo.

Outros parâmetros devem ser avaliados para uma melhor análise do efeito da vibração aleatória no processo de dressagem, tais como: a potência de retificação, a emissão acústica (mapa acústico) e o desgaste do rebolo. 